
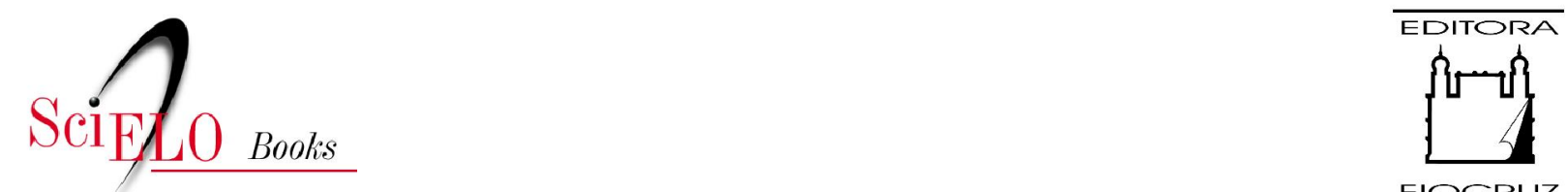

FIOCRUZ

\title{
Avaliação em saúde
}

dos modelos teóricos à prática na avaliação de programas e sistemas de saúde

\author{
Zulmira Maria de Araújo Hartz \\ Ligia Maria Vieira da Silva \\ (orgs.)
}

SciELO Books / SciELO Livros / SciELO Libros

HARTZ, ZMA., and SILVA, LMV. orgs. Avaliação em saúde: dos modelos teóricos à prática na avaliação de programas e sistemas de saúde [online]. Salvador: EDUFBA; Rio de Janeiro: Editora FIOCRUZ, 2005, 275 p. ISBN: 978-85-7541-516-0. Available from: doi: 10.7476/9788575415160. Also available from in ePUB from: http://books.scielo.org/id/xzdnf/epub/hartz-9788575415160.epub.

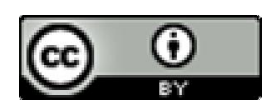

All the contents of this work, except where otherwise noted, is licensed under a Creative Commons Attribution $\underline{4.0 \text { International license. }}$

Todo o conteúdo deste trabalho, exceto quando houver ressalva, é publicado sob a licença Creative Commons Atribição 4.0.

Todo el contenido de esta obra, excepto donde se indique lo contrario, está bajo licencia de la licencia Creative Commons Reconocimento 4.0. 


\section{AVALIAÇÃO}

EM

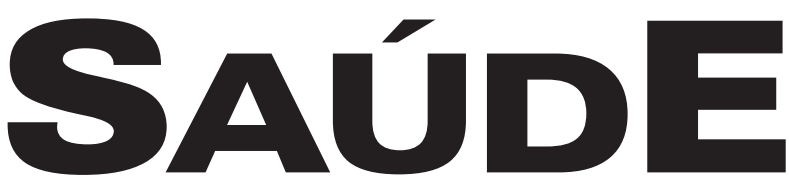

Dos Modelos Teóricos à Prática na Avaliação de Programas e Sistemas de Saúde 


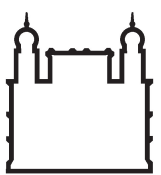

\section{Fundação Oswaldo Cruz}

Presidente

Paulo Gadelha

Vice-Presidente de Ensino, Informação e Comunicação

Maria do Carmo Leal

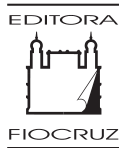

\section{Editora Fiocruz}

Diretora

Maria do Carmo Leal

Editor Executivo

João Carlos Canossa P. Mendes

Editores Científicos

Nísia Trindade Lima

Ricardo Ventura Santos

Conselho Editorial

Ana Lúcia Teles Rabello

Armando de Oliveira Schubach

Carlos E. A. Coimbra Jr.

Gerson Oliveira Penna

Gilberto Hochman

Joseli Lannes Vieira

Lígia Vieira da Silva

Maria Cecília de Souza Minayo

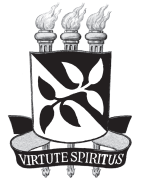

Universidade Federal da Bahia

Reitor

Naomar de Almeida Filho

Vice-reitor

Francisco José Gomes Mesquita

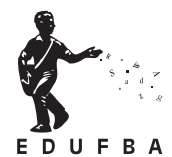

\section{Editora da Universidade}

\section{Federal da Bahia}

Diretora

Flávia M. Garcia Rosa

Conselho Editorial

Titulares

Ângelo Szaniecki Perret Serpa

Caiuby Alves da Costa

Charbel Ninõ El-Hani

Dante Eustachio Lucchesi Ramacciotti José Teixeira Cavalcante Filho

Alberto Brum Novaes

Maria Vidal de Negreiros Camargo

Suplentes

Antônio Fernando Guerreiro de Freitas

Evelina de Carvalho Sá Hoisel

Cleise Furtado Mendes 


\section{AVALIAÇÃo EM}

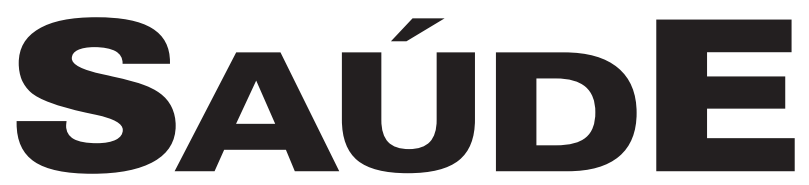

Dos Modelos Teóricos à Prática na Avaliação de Programas e Sistemas de Saúde

\section{ZULMIRA MARIA DE ARAÚJO HARTZ LIGIA MARIA VIEIRA DA SILVA ORGANIZADORAS}

TERCEIRA REIMPRESSÃO

Salvador/Rio de Janeiro Maio 2010 
Todos os direitos desta edição reservados à Fundação Oswaldo Cruz/Editora e à Editora da Universidade Federal da Bahia. Feito o depósito legal.

Nenhuma parte deste livro pode ser reproduzida, sejam quais forem os meios empregados, a não ser com a permissão escrita do autor e das editoras, conforme a Lei n 9610 , de 19 de fevereiro de 1998.

$1^{\text {a }}$ edição: 2005

$1^{\text {a }}$ reimpressão: 2006

$2^{\mathrm{a}}$ reimpressão: 2008

$3^{\mathrm{a}}$ reimpressão: 2010

Capa

Heloisa Diniz e Guilherme Ashton (FIOCRUZ)

Editoração Eletrônica e Arte Final

Gabriela Nascimento (EDUFBA)

Revisão de Textos e Normalização

Tânia de Aragão Bezerra e Magel Castilho de Carvalho (EDUFBA)

Biblioteca Central Reitor Macêdo Costa - UFBA

A945 Avaliação em saúde : dos modelos teóricos à pratica na avaliação de programas e sistemas de saúde / Zulmira Maria de Araújo Hartz, Ligia Maria Vieira-daSilva (organizadoras). - Salvador : EDUFBA ; Rio de Janeiro : Fiocruz, 2005. 275 p. : il.

ISBN 85-232-0352-4

1. Sistema Único de Saúde (Brasil) - Avaliação. 2. Saúde pública - Brasil Avaliação. 3. Política de saúde. 4. Clínica médica - Zona rural - Canadá.

5. Mortalidade infantil - Brasil, Nordeste. 6. Regionalização da medicina - Brasil.

I. Hartz, Zulmira Maria de Araújo. II. Vieira-da-Silva, Ligia Maria.

CDU - 614(81)

CDD - 614.440981

\section{EDITORA FIOCRUZ}

Av. Brasil, 4036, sala 112

Manguinhos

21040-361 Rio de Janeiro RJ

Tels: (21) 3882-9039 / 3882-9041

Fax: (21) 3882-9007

editora@fiocruz.br

www.fiocruz.br

\section{EDUFBA}

Rua Barão de Geremoabo, s/n

Campus de Ondina

40170-290 Salvador BA

Tels: (71) 3283-6159 / 3283-6160

Fax: (71) 3283-6160 / 3283-6164

edufba@ufba.br

www.edufba.ufba.br 


\section{AUTORES}

Zulmira Maria de Araújo Hartz. Médica. Pesquisadora da ENSP-Fiocruz (aposentada), professora-pesquisadora convidada do departamento de medicina social e preventiva e do Grupo de pesquisa interdisciplinar de saúde (GRIS) da Faculdade de medicina da Universidade de Montreal. Doutora pela Universidade de Montreal. Canadá.

Ligia Maria Vieira da Silva. Médica. Professora Adjunta do Instituto de Saúde Coletiva da Universidade Federal da Bahia (ISC/UFBA). Doutora pela Universidade de São Paulo - USP. Pesquisadora IC do CNPq. Brasil.

André-Pierre Contandriopoulos. Professor Titular do Departamento de Administração de Saúde da Universidade de Montreal (DASUM). Pesquisador associado do Centro de Pesquisa em Gestão da Escola Politécnica em Paris e membro da Sociedade Real do Canadá. Pesquisador do Grupo de Pesquisa Interdisciplinar de Saúde (GRIS), Universidade de Montreal. Canadá.

Claude Sicotte. Professor Titular do Departamento de Administração da Saúde. Doutor em Organização dos Serviços de Saúde pela Universidade de Montreal. Pesquisador do Grupo de Pesquisa Interdisciplinar de Saúde (GRIS), Universidade de Montreal. Canadá.

Gerluce Alves Pontes da Silva. Médica sanitarista da Secretaria de Saúde do Estado da Bahia. Mestre em Saúde Coletiva (ISC/UFBA). Brasil.

Hung Nguyen. Possui formação em Econometria e Gestão de Sistemas. Atualmente, trabalha para o Consórcio Regional de Saúde e Serviços Sociais da Montérégie e para o Instituto Nacional de Saúde Pública na integração dos serviços de primeira linha nos níveis local e regional. Pesquisador do Grupo de Pesquisa Interdisciplinar de Saúde (GRIS), Universidade de Montreal. Canadá.

Jean Louis Denis. Professor Titular no Departamento de Administração da Saúde. Doutor em Organização dos Serviços de Saúde pela Universidade de Montreal. Pesquisador do Grupo de Pesquisa Interdisciplinar de Saúde (GRIS), Universidade de Montreal. Canadá.

Luis Eugênio Portela Fernandes de Souza. Médico. Professor do Instituto de Saúde Coletiva da Universidade Federal da Bahia (ISC/UFBA). Doutor pela Universidade de Montreal. Canadá. 
Maria Guadalupe Medina. Médica. Mestre em Saúde Comunitária. Pesquisadora do Instituto de Saúde Coletiva da Universidade Federal da Bahia (ISC/UFBA). Brasil.

Nassera Touati. Diplomada em Engenharia. Doutorado em Administração na Escola Superior das Minas de Paris. Pesquisadora do Grupo de Pesquisa Interdisciplinar de Saúde (GRIS), Universidade de Montreal. Canadá.

Paulo Germano de Frias. Médico com mestrado em Pediatria. Professor e pesquisador do Núcleo de Avaliação do Instituto Materno-Infantil de Pernambuco (IMIP). Brasil.

Pedro Israel Cabral de Lira. Doutor em Medicina. Professor da Universidade Federal de Pernambuco. Brasil.

Rosana Aquino. Médica. Mestre em saúde comunitária. Pesquisadora do Instituto de Saúde Coletiva da Universidade Federal da Bahia (ISC/UFBA). Brasil.

Rosario Rodriguez. Pesquisadora do Grupo de Pesquisa Interdisciplinar de Saúde (GRIS), Universidade de Montreal. Canadá.

Sônia Cristina Lima Chaves. Odontóloga. Professora Adjunta da Faculdade de Odontologia / UFBA. Doutora em Saúde Coletiva (ISC/UFBA). Brasil.

Vitória Solange Coelho Ferreira. Enfermeira sanitarista. Professora da Universidade Estadual de Santa Cruz (UESC). Mestre em Saúde Coletiva (ISC/UFBA). Brasil. 


\section{SUMÁRIO}

\section{Prefácio}

Avaliaçāo em Saúde: uma prática em construção no Brasil Jairnilson Silva Paim

Apresentação

Avaliando a Implantação das Intervençōes em Saúde:

NOVAS CONTRIBUIÇÕES

Zulmira Maria de Araújo Hartz e Ligia Maria Vieira da Silva

1. Concettos, Abordagens e Estratégias para a Avalaação em Saúde

Ligia Maria Vieira da Silva

2. Uso de Modelos Té́ricos na Avalaaçāo em Saúde:

ASPECTOS CONCEITUAIS E OPERACIONAIS

Maria Guadalupe Medina, Gerluce Alves Pontes Silva, Rosana Aquino, Zulmira Maria de Araújo Hartz

3. Conferência de Consenso sobre a Imagem-Objetivo da

Descentralizaçāo da Atenção à Saúde no Brasil

Luís Eugênio Portela Fernandes de Souza, Ligia Maria Vieira da Silva, Zulmira Maria de Araújo Hartz

4. INTERSETORIALIDADE em Saúde: UM ESTUdo de caso

Vitória Solange Coelho Ferreira, Ligia Maria Vieira da Silva

5. Avaliação da Implantação de um Projeto para Redução da

MORTALIDADE INFANTIL

Paulo Germano de Frias, Pedro Israel Cabral de Lira, Zulmira Maria de Araújo Hartz

6. Metodologia para Análise da Implantação de Processos

Relacionados à Descentralização da Atenção à Saúde no Brasil Ligia Maria Vieira da Silva, Zulmira M. Araújo Hartz, Sônia Cristina Lima Chaves, Gerluce Alves Pontes da Silva

7. Uma ExperiênCia de Integração dos Atendimentos Médicos

em UMA Zona RuRal: os desafios da ImPLANTAÇĀo

Nassera Touati, André-Pierre Contandriopoulos, Jean Louis Denis, Rosario Rodriguez, Claude Sicotte, Hung Nguyen 


\section{AVALIAÇÃO EM SAÚDE: UMA PRÁTICA EM CONSTRUÇÃO NO BRASIL}

Diversas iniciativas voltadas para a avaliação em saúde no Brasil vêm sendo desenvolvidas, de forma progressiva, nas últimas três décadas. Inicialmente, foram realizadas pesquisas acadêmicas com a intenção de avaliar serviços ou estabelecimentos de saúde. Posteriormente, as próprias políticas racionalizadoras que valorizavam o planejamento de saúde, mediante a formulação dos programas de extensão de cobertura (PECs) e dos programas especiais, traziam nos seus documentos tópicos que sugeriam uma preocupação com a avaliação. Estes apresentavam proposições relativas a um elenco de indicadores e a montagem de sistemas de informação, sugerindo uma intenção de imprimir racionalidade nas intervenções em saúde.

As Ações Integradas de Saúde (AIS) e os Sistemas Unificados e Descentralizados de Saúde (SUDS), enquanto políticas democratizantes, também valorizaram o planejamento e a avaliação através da programação e orçamentação integrada (POI) e dos primeiros planos estaduais e municipais de saúde na década de oitenta. Nos anos noventa, ainda que as conferências e os conselhos de saúde constituíssem espaços potenciais para a expansão e institucionalização da avaliação, as fragilidades dessas instâncias de controle social e o esvaziamento da planificação pela onda neoliberal retardaram a consolidação da avaliação em saúde no Sistema Único de Saúde (SUS). Mesmo assim, distintos estudos sobre a produção científica e tecnológica da área de Planificação e Gestão em Saúde (P\&G) já apontavam para o crescimento de investigações sobre avaliação em saúde.

Na presente década, pode-se afirmar que o interesse pela avaliação em saúde não se restringe ao âmbito acadêmico. O próprio Ministério da Saúde (MS) tem encomendado um conjunto de estudos nessa perspectiva, não só por exigência de financiadores externos, mas devido a uma crescente consciência de responsabilização entre seus técnicos e dirigentes. Trata-se de um 
contexto muito favorável para o lançamento do livro Avaliação em Saúde: dos modelos teóricos à prática na avaliação de Programas e Sistemas de Saúde, organizado pelas professoras Zulmira Maria de Araújo Hartz e Ligia Maria Vieira da Silva e contando com a participação de mais de uma dezena de destacados colaboradores nacionais e internacionais.

Além do desenvolvimento da área sugerido pelo título, o leitor seguramente perceberá duas grandes contribuições dos seus autores. A primeira decorre da abrangência dos seus objetos, ou seja, não se restringe à avaliação de ações, serviços e estabelecimentos de saúde, ousando avançar para a avaliação de programas, sistemas e políticas de saúde. A segunda corresponde ao questionamento da avaliação de "caixa preta", ou seja, a que ignora o contexto e os passos intermediários no alcance de produtos e resultados. Nesse sentido, apresenta abordagens criativas para a sua superação.

Cada capítulo deste livro fornece indicações preciosas para pesquisadores, gestores, técnicos e cidadãos interessados em avaliações que não desperdicem o senso comum mas que, também, não sejam reféns de autoenganos, falsas consciências, equívocos desnecessários e ideologias. Ainda que os valores e crenças estejam presentes nas práticas sociais, inclusive na prática científica, o exercício permanente da crítica, do diálogo e da discussão, de um lado, e a explicitação de categorias, conceitos, teorias, modelos teóricos, métodos e técnicas de investigação, de outro, representam caminhos produtivos para que a avaliação em saúde não desconheça o senso comum, mas procure superá-lo.

O campo da Saúde Coletiva no Brasil tem dado o seu testemunho de que a construção do saber e a constituição dos sujeitos epistêmico e avaliador podem ser realizadas por vias alternativas e mediante práxis contra-hegemônica. Este livro, lançado oportunamente pela Editora Fiocruz, em co-edição com a Editora da Universidade Federal da Bahia (EDUFBA), ratifica essa trajetória do campo, propiciando caminhos criativos para a avaliação em saúde a partir da produção teórica, metodológica, tecnológica e de experiências concretas.

Salvador, maio de 2005.

Jairnilson Silva Paim

Médico. Professor Titular em Política de Saúde do Instituto de Saúde

Coletiva da Universidade Federal da Bahia. Pesquisador 1A do CNPq. 


\section{Apresentação}

\section{AVALIANDO A IMPLANTAC̣ÃO DAS INTERVENÇÕES EM SAÚDE: NOVAS CONTRIBUIÇÕES}

Vários fatores de ordem teórica e prática podem influenciar a reprodutibilidade operacional ou a transferência, do nacional ao local, de uma intervenção de saúde.

A análise de implantação ou implementação tem exatamente como foco da avaliação a relação entre a intervenção (políticas, programas, serviços, ações) e seu contexto de inserção na produção dos efeitos, o que se torna particularmente importante quando a intervenção é complexa, com múltiplos componentes e contingencial. A compreensão das diversas injunções de natureza técnica, ética ou política, relacionadas ao sucesso ou resistência organizacional se tornam indispensáveis de serem mensuradas e analisadas no momento de se explicar "o porquê e o como» da efetividade dessas ações e se constituem no eixo dos estudos de caso aqui apresentados.

Neste livro, concebemos como público-alvo todos os profissionais de saúde que, no campo das práticas ou da pesquisa, se questionam sobre a integridade, a qualidade e a integração das intervenções no sistema único de saúde (SUS), interessados que estão em demonstrar a credibilidade dos resultados de sua implantação e dos seus efeitos sobre a saúde da população. O que nos orientou na sua organização foi uma tentativa de facilitar respostas para um conjunto de indagações que compartilhamos com os autores dos diversos capítulos no ensino da avaliação de programas e sistemas locais de saúde, em projetos de formação acadêmica ou profissional. Ele se coloca assim enquanto ferramenta didática para o leitor que pretenda compreender e participar de uma análise de implantação em suas diversas etapas, integrando adequadamente a contribuição dos processos e resultados das ações focalizadas com a agenda política nas quais estão 
inseridas. Este conjunto de experiências tenta, portanto, responder a uma ou mais das seguintes questões gerais:

Como elaborar modelos e medidas para avaliar a implantação ou implementação das intervenções de saúde?

Qual a contribuição dos diferentes componentes ou atividades para a produção dos resultados dessas ações?

Como explicar a interação do meio de implantação e os efeitos observados?

Em um formato mais específico, os diversos capítulos, abaixo sumarizados, sugerem pistas de resposta para as seguintes indagações:

a) Qual o modelo teórico ou lógico supostamente mais adequado às diferentes intervenções focalizadas?

b) Que abordagens parecem ser mais apropriadas para construir os instrumentos metodológicos (escolha de critérios, indicadores e medidas de maior relevância)?

c) Como atribuir pesos e padrões para estimar o grau de implantação?

d) Como verificar as relações entre os diversos níveis de análise: a implantação das ações, o contexto e os efeitos observados?

e) Que formatos adotar para a apresentação dos resultados dos estudos?

No primeiro capítulo, o «estado da arte» da avaliação é revisado com o objetivo de estabelecer um diálogo entre diferentes marcos conceituais, tipologias e estratégias para a avaliação em saúde, bem como situar os demais capítulos em relação ao elenco de possibilidades dessa temática.

O segundo capítulo trabalha com diretrizes teórico-metodológicas para elaboração dos modelos das intervenções no âmbito das pesquisas avaliativas, cuja operacionalização se apóia na utilização das técnicas de consenso, objeto do terceiro capítulo.

O capítulo 4, embora se constituindo ainda em resultados de um «estudo de caso piloto», utilizando a matriz preliminar do modelo submetido ao consenso, relatado no capítulo anterior, abrange o conjunto de componentes da análise de implantação, aplicada a avaliação da gestão descentralizada, em um sistema local de saúde. 
Os capítulos 5 e 6 , ambos relacionados às ações de controle para redução da mortalidade infantil na região Nordeste, abordam os componentes 1 e 2 da análise de implantação, tendo como eixo as seguintes questões gerais, respectivamente:

Qual é a influência do contexto político-organizacional na implantação de um programa intersetorial em um estudo de caso no estado da Bahia?

Como as variações no grau de implantação influenciam os efeitos observados em dois estudos de caso no estado de Pernambuco?

0 capítulo 7, tradução do relato de uma experiência canadense, convergindo e reforçando a importância dos aspectos metodológicos previamente abordados, conclui nosso livro enfocando uma questão de importância fundamental: a universalidade de alguns problemas e alternativas, próprios à avaliação da integração das práticas em organizações assistenciais, que certamente contribuirão para se avaliar o êxito da implantação da política nacional de regionalização na perspectiva do SUS.

Fruto de uma experiência ao mesmo tempo didática e de investigação, centrada em uma íntima interação com os serviços de saúde, este livro é, portanto, o produto da interseção entre diversos temas e disciplinas matéria-prima do campo da avaliação em saúde, que esperamos possa ser continuamente aprimorada na prática avaliativa de nossos leitores.

As organizadoras 


\section{CONCEITOS, ABORDAGENS E ESTRATÉGIAS PARA A AVALIAÇÃO EM SAÚDE}

Ligia Maria Vieira da Silva

\section{REVISITANDO O CAMPO DA AVALIAC̣ÃO}

A avaliação pode ser considerada como um componente das práticas presente em diversos âmbitos e campos do espaço social. As suas diversas possibilidades de expressão, nesses diferentes campos, tem gerado uma polissemia conceitual e metodológica que torna obrigatório, tanto para o gestor quanto para o pesquisador, uma explicitação das suas opções teóricas e técnicas (GRÉMY, 1983; VIEIRA-DA-SILVA e FORMIGLI, 1994; CONTANDRIOPOULOS e outros, 2000).

Entre as diversas definições existentes sobre o significado da avaliação, aquelas referentes a avaliação de programas sociais têm conseguido maior consenso. Uma delas relaciona a avaliação ao processo de determinação do esforço, mérito ou valor de algo ou do produto desse processo (SCRIVEN, 1991). Patton, ao desenvolver uma abordagem da avaliação denominada de "avaliação focada para a utilização" inclui na sua definição: a) a maneira de fazer a avaliação que corresponderia à coleta sistemática de informações sobre as atividades, características e resultados dos programas; b) o propósito da avaliação, ou seja, fazer julgamentos sobre os programas e/ou para subsidiar o processo de tomada de decisões sobre futuras programações (PATTON, 1997). Já Rossi e Freeman, que editam um dos mais conhecidos livros sobre avaliação, a consideram como sinônimo de pesquisa avaliativa e a definem como a aplicação sistemática dos procedimentos oriundos da investigação em ciências sociais para analisar programas de intervenção (ROSSI; FREEMAN, 2004). 
Na mesma perspectiva de delimitar o campo da avaliação ao julgamento de programas sociais, Contandriopoulos formulou uma das definições mais simples e abrangentes. Segundo esse autor, a avaliação pode ser considerada como um julgamento sobre uma intervenção ou sobre qualquer dos seus componentes com o objetivo de auxiliar na tomada de decisões (CONTANDRIOPOULOS e outros, 1997). O problema com esse conceito é que a definição de intervenção feita pelo autor limita o escopo da avaliação ${ }^{1}$ à dimensão instrumental da ação.

O conceito de campo, enquanto rede de relações entre agentes e instituições, no sentido que Ihe é dado por Bourdieu (1979; BOURDIEU e WACQUANT, 1992), pode contribuir para uma concepção da avaliação muito mais abrangente do que aquela restrita à dimensão racional da ação, ou aquela que situa a avaliação em relação ao uso instrumental dos resultados (PATTON, 2001). Nessa perspectiva, a definição de avaliação proposta por Contandriopoulos será aqui ajustada ao escopo maior do campo da avaliação substituindo o conceito de "intervenção" por aquele de "práticas sociais"2 - em relação às quais, as práticas de saúde podem ser consideradas como um caso particular. Isto porque, a avaliação toma por objeto desde as práticas do cotidiano até aquelas relacionadas com o trabalho, nos seus diversos âmbitos, o que envolve as intervenções sociais planejadas. O significado do que seria o "julgamento" também pode variar desde a formulação de um juízo de valor dicotômico qualitativo ou quantitativo (cuidado à saúde, bom ou ruim, cobertura vacinal igual ou superior a $70 \%$ ou inferior a 70\%) até uma análise que envolva o significado do fenômeno.

A ampliação da definição de Contandriopoulos se justifica por referência à consolidação da avaliação enquanto campo. Este se revela não apenas na ampliação da produção científica específica, mas sobretudo pela rede de agentes (pesquisadores, avaliadores e gestores) e associações profissionais envolvidos (CHELIMSKY, 1997; MCDAID, 2003), pelo seu reconhecimento enquanto disciplina e profissão (CHELIMSKY e SHADISH, 1997; SMITH, 2001) bem como pela diversificação das áreas temáticas que são objeto de avaliação sistemática (SCRIVEN, 2001).

Cabe aqui uma distinção entre monitoramento e avaliação pontual. 0 monitoramento corresponderia ao acompanhamento sistemático sobre algumas das características dos serviços enquanto que a avaliação pontual refere-se ao julgamento sobre os mesmos em um determinado ponto do tempo. 
Dessa forma, em algumas circunstâncias, o monitoramento pode produzir informações para a realização de uma avaliação mas não corresponder necessariamente a implementação da mesma. Ou seja, quando a atividade de monitoramento se resume ao registro contínuo de variáveis ao longo do tempo se superpõe à montagem de um sistema de informação. A transformação de dados em informação bem como a sua utilização para a avaliação, requer a formulação de uma pergunta específica que orientaria a análise e os possíveis sentidos a serem atribuídos aos achados empíricos. A otimização dos sistemas de informação para fins de avaliação bem como a indicação adequada acerca da necessidade ou não da realização de avaliações pontuais ou de investigações avaliativas requer certo grau de institucionalização da avaliação (HARTZ, 1999).

\section{O ESPECTRO DA AVALIAC̣ÃO}

Para fins didáticos, pode-se imaginar essa diversidade de possibilidades de expressão como faixas ou pontos de um espectro, cujo extremo esquerdo pode ser representado pelas avaliações presentes na vida cotidiana e o outro extremo pela investigação avaliativa ${ }^{3}$ (Figura 1). A avaliação das práticas cotidianas corresponderia a um julgamento que se faz a partir do recurso a noções oriundas do "senso comum", a técnicas não sistemáticas de observação e à análise e formulação de juízos de valor dicotômicos e simplificados. Por exemplo, ao final de um dia de trabalho uma equipe de saúde reúne-se para "fazer um balanço" das atividades daquele dia referentes ao funcionamento de um serviço de controle de hipertensão arterial. Consideram que o balanço é "positivo" pois a demanda foi "grande" e o atendimento foi "bom" deixando os usuários "satisfeitos". Esse balanço corresponde a um julgamento das práticas rotineiras do trabalho daquela equipe a partir da percepção dos seus componentes acerca do que seria um desempenho "positivo" no trabalho, uma "grande" demanda, um "bom" atendimento e uma adequada "satisfação" dos usuários.

Já a pesquisa avaliativa corresponderia ao julgamento que é feito sobre as práticas sociais a partir da formulação de uma pergunta não respondida ainda na literatura especializada, sobre as características dessas práticas, em geral, ou em um contexto particular, através do recurso a metodologias científicas. As práticas que têm sido mais freqüentemente objeto de avaliação 
são aquelas resultantes da ação social planejada tais como políticas, programas e serviços de saúde.

Entre esses dois extremos opostos do espectro da avaliação estaria uma multiplicidade de possibilidades de avaliação para a gestão ou avaliação administrativa em saúde. A realização de um inquérito populacional para avaliar a cobertura vacinal em um município determinado pode, por exemplo, ser uma avaliação administrativa que estaria próxima a pesquisa avaliativa por recorrer a metodologia científica. Contudo, pode ser considerada como pesquisa avaliativa se vier a preencher uma lacuna no conhecimento sobre a situação do controle de determinado problema de saúde como a poliomielite, plausível de ser atribuída a essa ação (VIEIRA-DA-SILVA e outros, 1997).

Esse espectro da avaliação tem sido reconhecido por alguns autores, tanto em relação ao objeto da avaliação quanto ao método e abordagem. Alguns deles referem-se a avaliação presente no "mundo não acadêmico" e na vida privada, nesta incluindo outros setores das práticas sociais como degustação de vinho e astrologia (PATTON, 1997; SCRIVEN, 2001) ou avaliação "pessoal" (SCRIVEN, 1991).

Quanto ao objeto, alguns autores, apesar de reconhecerem a diversidade do campo da avaliação enfocam principalmente os métodos e técnicas relacionados a avaliação de programas sociais (SCRIVEN, 1991; ROSSI; FREEMAN, 2004; PATTON, 1997). Existe uma preocupação em estabelecer diferenças entre o que seria pesquisa e o que seria avaliação normativa ou administrativa, havendo inclusive variações acerca daquilo que se considera como pesquisa (CONTANDRIOPOULOS; CHAMPAGNE e outros, 1997; SCRIVEN, 2001). Alguns autores tratam exclusivamente da pesquisa avaliativa, embora reconheçam que a avaliação é uma arte que envolve outras habilidades além da metodologia científica (ROSSI; FREEMAN, 2004).

Patton, refere-se a enorme diversidade existente ao interior do campo da avaliação e adverte que as tentativas de reduzir essa complexidade a algumas categorias corre o risco de excessiva simplificação. Entretanto, para fins práticos, esse autor discute três objetivos primários para avaliação de programas: a) para fazer julgamentos; b) para facilitar o seu desenvolvimento c) para contribuir com o conhecimento (PATTON, 1997).

Outra dicotomia, freqüente entre os autores de língua inglesa, aparece como a oposição entre avaliação somativa (summative) e formativa (formative). A avaliação somativa de um programa é aquela conduzida após o término do 
programa e tem por objetivos prestar contas a uma audiência externa (órgão financiador) ou gestor. Esse tipo de avaliação distingue-se da denominada avaliação formativa que é freqüentemente conduzida durante a implementação de um programa e que tem por objetivo apoiar o desenvolvimento do mesmo (SCRIVEN, 1991). Em ambos os casos, a definição do "foco da avaliação" requer o diálogo entre os especialistas em avaliação e os clientes (STECHER; DAVIS, 1987).

Mesmo no interior de subáreas temáticas e/ou movimentos do campo da avaliação esse espectro é sempre referido. O consenso de Gothenburg sobre avaliação de impactos em saúde considerou três possibilidades metodológicas: a) estimativa rápida de impacto (rapid health impact appraisal); b) análise do impacto em saúde (health impact analysis) e c) revisão de impactos em saúde (health impact review) (WHO, 1999).

\section{A TEORIA E A DIVERSIDADE DAS ABORDAGENS}

As primeiras décadas de constituição do campo da avaliação foram marcadas por grandes estudos com ênfase no desenho e no método (SUCHMAN, 1967). Posteriormente, com a limitação do poder explicativo dessas investigações, ao lado do seu custo e complexidade, alternativas metodológicas foram buscadas nas meta-análises, nos estudos qualitativos (COOK; REICHARDT, 1986 (1982); PATTON, 1987) e naqueles orientados pela teoria do programa (CHEN, 1990).

A teoria de que se fala não são as grandes teorias sociais, e sim aquelas referentes ao programa, seu contexto e interações (HOUSE, 2001). Chen define teoria como um conjunto de pressupostos, princípios e ou proposições que explicam ou guiam a ação social. Em outras palavras, a teoria do programa deveria especificar tudo que deve ser feito para alcançar os objetivos desejados, quais os impactos que podem ser antecipados e como isso se produz. Esse autor ainda distingue as teorias causais ou descritivas que teriam como objetivo explicar as relações entre a intervenção, a implementação e os resultados daquelas normativas ou prescritivas que estariam voltadas para definir a imagem-objetivo, ou seja, como devem ser as intervenções, o processo de implementação do programa e os resultados. A teoria necessária para realizar uma avaliação envolveria, na sua opinião, tanto a dimensão causal quanto aquela normativa (CHEN, 1990). 
A ênfase na teoria como estratégia metodológica privilegiada para a avaliação de programas remete à elaboração de modelos lógicos ou teóri$\cos ^{4}$ como componente necessário desse processo (MERCER; GOEL, 1994; CONTANDRIOPOULOS; CHAMPAGNE e outros, 2000).

$\mathrm{O}$ que se quer chamar a atenção aqui, em relação à teoria, diz respeito a sua relação com a polissemia conceitual e diversidade de abordagens existentes para a avaliação na bibliografia especializada sobre o tema. É constatação recorrente que cada autor que escreve sobre o tema propõe uma nova matriz (framework) ou modifica aquelas preexistentes com variações, ou acrescenta novos atributos dos programas a serem avaliados ou define de forma diferente termos antigos (VIEIRA-DA-SILVA e FORMIGLI, 1994; CONTANDRIOPOULOS; CHAMPAGNE e outros, 1997). Desde 1981 que Scriven edita o "Thesaurus" da avaliação, numa referência ao dicionário equivalente da língua inglesa (SCRIVEN, 1991). As diversas matrizes existentes para a avaliação do "desempenho de sistemas de saúde" (KNOWLES e outros, 1997; WHO, 2000; CANADA, 2001; HURST; HUGHES, 2001) são mais um exemplo dessa diversidade e do pequeno grau de consenso existente no campo da avaliação.

Essa diversidade reflete, por um lado, o estágio incipiente de desenvolvimento da avaliação enquanto disciplina científica e a natureza e abrangência do campo da avaliação que comporta uma multiplicidade de possibilidades de recorte do real. Em outras palavras, tendo em vista que as opções técnicas são também opções teóricas (BOURDIEU, 1989), a multiplicidade de formas de definir as abordagens, dimensões e atributos para a avaliação refletem, em alguma medida, as escolhas teóricas dos autores que são tantas quanto os possíveis "pontos de vista" que correspondem a posições que os autores ocupam no espaço social e campos a que pertencem, sua formação intelectual e trajetória social.

\section{ABORDAGENS, NÍVEIS, DIMENSÕES, CRITÉRIOS E INDICADORES PARA A AVALIAC̣ÃO}

Como não há método separado da prática de pesquisa (BOURDIEU e outros, 1999), também para a avaliação isso é verdadeiro. Cada avaliação é um caso particular que requer criatividade por parte do investigador/avaliador na formulação da melhor estratégia, na seleção da abordagem na 
definição de níveis e atributos, bem como na seleção de critérios, indicadores e padrões. Principalmente na hipótese de tratar-se de uma avaliação voltada para a gestão dos serviços, há que incorporar os agentes do programa (stake-holders) em muitas das definições do foco da avaliação (GUBA; LINCOLN, 1989; PATTON, 1997; FETTERMAN, 1997). A sistematização que se segue pretende auxiliar o avaliador a tomar conhecimento do leque de possibilidades para facilitar o processo de delimitação do objeto e de formulação do projeto de avaliação.

\section{ABORDAGENS}

Numa primeira aproximação com o objeto a ser avaliado, poderíamos recorrer à classificação das abordagens possíveis feita por (DONABEDIAN, 1988), que é utilizada e revisitada quase quarenta anos depois (HANDLER e outros, 2001). Com base no enfoque sistêmico e principalmente preocupado em avaliar a qualidade do cuidado médico, Donabedian sistematizou diversas propostas de abordagem na tríade: estrutura-processo-resultados. A estrutura diria respeito aos recursos materiais, humanos e organizacionais, o processo a tudo aquilo que medeia a relação profissional-usuário e os resultados estariam relacionados tanto com o produto das ações (consultas, exames, visitas) quanto com a modificação no estado de saúde de indivíduos e da população. Embora ela tenha utilidade prática na primeira aproximação com o objeto da avaliação, a abrangência dessa classificação e a redução que ela opera do real têm sido apontadas como suas principais limitações (VIEIRA-DA-SILVA; FORMIGLI, 1994).

\section{NÍVEIS E OBJETO DA AVALIAC̣ÃO}

Para prosseguir na delimitação do objeto a ser avaliado é necessário definir quais os níveis da realidade que se quer estudar. O campo da saúde é formado por instituições públicas e privadas que desenvolvem ações de promoção, prevenção e cura voltadas para a população e que podem ser abordadas, entre outras possibilidades, a partir dos seguintes níveis (Figura 2) ${ }^{5}$ :

a) Ações - diz respeito às ações de promoção, prevenção e cura desenvolvidas pelos agentes individualmente; 
b) Serviços - corresponde a um grau de maior complexidade de organização das ações onde diversos agentes se articulam para desenvolver atividades, coordenadas ou não, voltadas para um grupo etário ou problema de saúde. Como exemplo pode-se citar um serviço para o atendimento pediátrico ou um serviço de saúde ocupacional;

c) Estabelecimentos - correspondem a unidades sanitárias de diferentes níveis de complexidade tais como centros de saúde, hospitais, policlínicas.

c) Sistema ${ }^{6}$ - seria o nível mais complexo de organização das práticas que envolveria todos os outros e sua coordenação. Pode corresponder a um sistema municipal, estadual ou nacional.

A avaliação de políticas, programas e projetos pode recortar todos os níveis do sistema de saúde. As políticas de saúde podem ser consideradas como a ação ou omissão do Estado enquanto resposta social, diante dos problemas de saúde e seus determinantes, bem como da produção, distribuição e regulação de bens e serviços e ambientes que afetam a saúde dos indivíduos e da coletividade (PAIM, 2002; PAIM, 20037 ). Dessa forma, a avaliação de políticas pode incluir, tanto análises sobre a natureza do Estado e do poder político envolvidos na sua formulação quanto estudos sobre os programas ${ }^{8}$ relacionados com a sua operacionalização. Por fim, embora a avaliação de políticas freqüentemente envolva a avaliação de programas, a distinção entre essas duas dimensões das práticas pode ser necessária para fins analíticos (VIEIRA-DA-SILVA, 1999) ${ }^{9}$.

\section{ATRIBUTOS OU CARACTERÍSTICAS}

A seleção das características ou atributos das práticas, serviços, programas, estabelecimentos ou do sistema de saúde a serem avaliadas contribui para o aprofundamento no processo de definição do foco da avaliação. Aqui é onde existe a maior diversidade terminológica e polissemia conceitual. As opções ora apresentadas representam uma atualização de proposição anterior (VIEIRA-DA-SILVA; FORMIGLI, 1994) onde buscou-se incorporar conceitos com certo grau de consenso na literatura revisada que guardassem coerência entre si e com um modelo teórico (Figura 3). 
Em resposta ou não a necessidades de saúde, os indivíduos desenvolvem necessidades de serviços de saúde (PAIM, 1982). Essas necessidades podem ser objeto de graus distintos de controle, a saber, controle de causas, de riscos ou de danos que dependem do estágio de desenvolvimento da história de um agravo à saúde e das características do modelo assistencial (PAIM, 1999). Para cada um desses níveis de controle existem diversas possibilidades de intervenção (Quadro 1) cujas características ou atributos têm sido consideradas como relevantes para a avaliação, podendo ser agrupados de acordo com as seguintes características, entre outras possibilidades (Figura 3):

a) Relacionados com a disponibilidade e distribuição social dos recursos:

- Cobertura,

- Acessibilidade,

· Eqüidade.

b) Relacionados com o efeito das ações:

- Eficácia,

- Efetividade,

- Impacto.

c) Relacionados com os custos e produtividade das ações:

. Eficiência.

d) Relacionados com a a adequação das ações ao conhecimento técnico e científico vigente:

. Qualidade técnico-científica.

e) Relacionados com a adequação das ações aos objetivos e problemas de saúde:

- Direcionalidade e consistência (análise estratégica).

f) Relacionados com o processo de implantação das ações:

- avaliação do grau de implantação e (ou) avaliação de processo,

- análise de implantação - estudos que investigam as relações entre o grau de implantação, o contexto e os efeitos das ações. 
g) Características relacionais entre os agentes das ações:

- usuário x profissional (percepção dos usuários sobre as práticas, satisfação dos usuários, aceitabilidade, acolhimento, respeito a privacidade e outros direitos cidadãos),

- profissional x profissional (relações de trabalho e no trabalho),

- gestor x profissonal (relações sindicais e de gestão).

A primeira preocupação do gestor em relação a uma intervenção sanitária está relacionada com a magnitude da oferta das ações e serviços. Em que medida os recursos existentes são suficientes para atender às necessidades da população-alvo? Essa pergunta pode ser respondida através da avaliação de cobertura que é aquela que mede a proporção da população que se beneficia do programa ou intervenção (ROSSI; FREEMAN, 2004). A cobertura pode ser pensada em relação a intervenções de diversos tipos, desde aquelas voltadas para a promoção da saúde ou para o controle de causas até aquelas vinculadas ao cuidado propriamente dito, ou seja, ao controle de danos (Quadro 1). A cobertura pode ser considerada como potencial quando o que se mede são os recursos materiais ou humanos disponíveis para a realização de determinada ação. Nesse caso, ela é superponível ao conceito de "oferta de serviços". Já a cobertura real ou utilização de serviços corresponde a proporção da população que efetivamente se beneficiou de determinada intervenção, que de fato usou os serviços (SOBERÓN, 1988). A cobertura pode ser calculada tendo por referência um sistema estruturado para o atendimento à demanda espontânea ou ser pensada em relação à oferta organizada ${ }^{10}$ de ações programáticas (Figura 3).

A acessibilidade, embora seja um conceito relacionado com o de cobertura, não é equivalente. Ela tem sido definida como uma relação entre os recursos de poder dos usuários e os obstáculos colocados pelos serviços de saúde (FRENK, 1992). Os recursos de poder podem ser de natureza econômica, social e cultural. Já os obstáculos podem ser geográficos (distância, transporte), organizacionais (existência de filas, tempo de espera injustificável, natureza do acolhimento) e econômicos.

O acesso pode ser confundido com a utilização de serviços quando só se quer analisar a obtenção do cuidado pelo indivíduo que dele necessita. Quando existem dificuldades importantes para essa utilização, o conceito de acessibilidade relacionado aos obstáculos existentes à obtenção dos servi- 
ços, por parte dos usuários, passa a ter grande valor, como é o caso do Brasil. Segundo a Pesquisa Nacional por Amostra de Domicílios (PNAD) realizada em 1998, 5 milhões de pessoas referiram ter necessitado, mas não procuraram um serviço de saúde, alegando principalmente falta de recursos financeiros (obstáculo econômico). Estimativas desse mesmo estudo indicam que 755.521 pessoas que procuraram atendimento não foram atendidas por motivos diversos: ou não conseguiram vaga ou senha (obstáculos organizacionais ou de oferta), ou não havia serviço especializado (oferta), ou não havia médico atendendo ou esperaram muito e desistiram (obstáculos organizacionais). Além disso, o acesso a consultas médicas aumenta expressivamente com a renda (recursos de poder econômicos) (BRASIL-IBGE, 2000). Esses dados revelam o sofrimento dos usuários muitas vezes obrigados a aguardar em longas filas nas portas dos serviços de saúde. Por outro lado, o tempo de espera para o acesso a procedimentos especializados pode interferir com o próprio efeito do cuidado se o mesmo não é feito tempestivamente.

Já o conceito de equidade ${ }^{11}$ aqui será usado no sentido que lhe é dado por Perelman, ou seja, como um instrumento da justiça para resolver as contradições entre as diversas fórmulas da justiça formal ou abstrata (PERELMAN, 1996). O que equivale a dizer que devemos tratar desigualmente desiguais e priorizar para a intervenção sanitária grupos sociais com maiores necessidades de saúde. A eqüidade recorta e relaciona-se com quase todos os demais atributos. Pode-se pensar em equidade no acesso, no acolhimento, na qualidade e na efetividade. A oferta organizada de ações voltadas para enfrentar determinado problema de saúde pode ampliar a acessibilidade da população aos diversos níveis do cuidado e, dessa forma, ampliar a cobertura real das referidas ações.

A segunda e importante característica das práticas de saúde diz respeito aos possíveis efeitos que as mesmas possam ter sobre o estado de saúde dos indivíduos, grupos ou populações. A distinção entre eficácia como efeito de uma intervenção em situação experimental e efetividade como o efeito da mesma em sistemas operacionais vem se mantendo ao longo dos anos (DONABEDIAN, 1990; MAYNARD; MCDAID, 2003). Já o conceito de impacto tem sido usado frequentemente com o mesmo sentido dado a efetividade, ou seja, relacionado ao efeito de intervenções em sistemas reais e não em situações experimentais da pesquisa. Contudo, o conceito de impacto tem sido também usado para designar o efeito de uma intervenção 
em relação a grandes grupos populacionais ou em grandes intervalos de tempo. Exemplificando, seria necessário que determinada tecnologia fosse eficaz em ensaios experimentais para que, ao ser utilizada em sistemas operacionais possa ser efetiva, e, se associada a uma cobertura elevada, durante determinado período, tenha a possibilidade de causar impacto sobre o nível de saúde de uma população com redução de morbidade. Uma vacina que obtém elevada eficácia em ensaios experimentais pode ter baixa efetividade ao ser administrada em usuários de um Centro de Saúde devido a problemas da rede de frio, por exemplo. Já para o controle de viroses para as quais exista uma vacina eficaz, é necessário que os serviços atinjam elevadas coberturas vacinais em todo o país, ou seja, sejam efetivos, para então se falar em impacto da medida.

A eficiência tanto tem sido usada como medida da produtividade do sistema como da sua relação com os custos (HARTZ; POUVOURVILLE, 1998). A incorporação de avaliações econômicas na definição das prioridades relacionadas com a saúde das populações tem sido feita para fazer face aos crescentes custos da atenção médico-hospitalar e também para garantir a equidade de ações de promoção à saúde e reformas na organização dos sistemas de saúde (MCDAID, 2003).

A qualidade técnico-científica do cuidado no sentido que Ihe foi dado por Vuori (1982), corresponde à adequação das ações ao conhecimento técnico e científico vigente. Ou seja, em que medida as tecnologias que estão sendo usadas são aquelas consideradas como mais indicadas e eficazes pela comunidade científica?

No caso das ações conduzidas a partir de algum grau de planejamento a análise estratégica ${ }^{12}$ (CAMPOAMOR, 1990; CONTANDRIOPOULOS; CHAMPAGNE e outros, 1997) auxilia a responder a pergunta acerca da consistência e direcionalidade do plano (MATUS, 1993). Ou seja, em que medida as atividades propostas são pertinentes, tendo em vista os objetivos do programa e os problemas diagnosticados?

Já as análises de implantação são muito relevantes para a avaliação de programas de saúde porque permitem ao investigador estudar os processos relacionados à operacionalização dos mesmos. As avaliações de efetividade, conduzidas, muitas vezes a partir de estratégias do tipo "caixa preta ${ }^{13}$ ", chegam a resultados bastante diferenciados com problemas de generalização de resultados (DENIS; CHAMPAGNE, 1997; HOUSE, 2001). Abrir a "caixa pre- 
ta" não apenas tem elucidado problemas na operacionalização dos programas como tem sido útil para a formulação de recomendações voltadas para o aperfeiçoamento dos mesmos (HULSCHER e outros, 2003). Os processos, a maneira pela qual os programas são implementados, podem ser tão importantes quanto os resultados. Em algumas circunstâncias, o processo de implantação de programas de reorganização da atenção à saúde pode envolver a participação dos diversos profissionais, promover a integração entre os mesmos e os gestores de tal forma, que o próprio desenvolvimento das relações interpessoais pode passar a ser um resultado relevante (PATTON, 2002)14.

Por último, o bloco dos atributos denominados como "relacionais", que podem ou não fazer parte das análises de implantação, cria toda uma nova perspectiva para a avaliação em saúde. Corresponde a valorizar as características do acolhimento, a garantia dos direitos individuais à privacidade e as características das relações no trabalho como componentes da qualidade da atenção e promoção da saúde.

As intervenções de saúde variam conforme o modelo assistencial ou modelos assistenciais dominantes em diferentes contextos. As características acima relacionadas podem ser pensadas tanto para a atenção à demanda espontânea quanto para a oferta organizada voltada para o controle de riscos e causas (PAIM, 1999).

\section{ESTRATÉGIAS E DESENHOS}

As estratégias de pesquisa para a avaliação correspondem às possíveis maneiras de mobilizar recursos teóricos e técnicos visando responder à pergunta de investigação de forma a evitar viéses e também responder a hipóteses rivais. O conceito de desenho será usado para designar aquelas estratégias mais estruturadas, relacionadas principalmente com a investigação em epidemiologia (ALMEIDA-FILHO e ROUQUAYROL, 1999).

Os desenhos possíveis para a pesquisa avaliativa têm sido propostos a partir de uma comparação com o desenho experimental ou de intervenção, tido como tipo ideal, capaz de responder aos principais desafios à validade interna (CAMPBELL; STANLEY, 1966). Esses autores discutem 12 fatores que ameaçam a validade da pesquisa em cerca de 16 diferentes desenhos. Teoricamente, o desenho experimental seria capaz de dar conta da maioria desses possíveis vieses tais como: história, maturação, familiaridade ao teste, 
instrumentação, regressão à média, seleção, mortalidade experimental entre outros (CAMPBELL; STANLEY, 1966). Os desenhos experimentais correspondem aos "ensaios clínicos" ou estudos de intervenção na epidemiologia (Quadro 2).

A critica às limitações do desenho experimental para avaliação de programas dizem respeito a problemas éticos e operacionais (SMITH, 1980). A escolha aleatória de participantes para um estudo geralmente encontra resistências com recusas frequentes tanto devido ao caráter arbitrário dessa designação quanto devido as diferenças na natureza e atratividade das intervenções. Por outro lado, os estudos experimentais são caros e demandam longo tempo. Do ponto de vista ético, não se admite observar um grupo de pessoas com um problema sem aportar nenhuma solução para o mesmo (SMITH, 1980). Particularmente, no que diz respeito às avaliações em saúde, os desenhos observacionais são preferidos em detrimento dos experimentais, tendo em vista principalmente questões éticas, bem como a complexidade das intervenções de saúde coletiva e sua relação com o contexto (ALMEIDA-FILHO; ROUQUAYROL, 1999).

Como uma alternativa às limitações da ênfase no método e nos desenhos do tipo caixa preta, experimentais, têm sido propostas estratégias complementares buscando explicar variações nos resultados a partir das variações na implantação e no contexto (DENIS; CHAMPAGNE, 1997; HARTZ, 1997; CONTANDRIOPOULOS e outros, 2003; FRIAS; HARTZ, 2003; VIEIRA-DA-SILVA e outros, 2003), com ênfase na teoria (CHEN, 1990) e com recurso a técnicas não estruturadas ou qualitativas (COOK; REICHARDT, 1986; PATTON, 1987; GUBA; LINCOLN, 1989; FETTERMAN, 1997).

$O$ debate quantitativo $x$ qualitativo é considerado como superado por alguns autores, tendo em vista que limites e possibilidades são hoje reconhecidos tanto em relação ao uso de técnicas quantitativas quanto para aquelas qualitativas (COOK, 1997; HOUSE, 2001). Alguns, porém, ainda consideram como atual o debate argumentando que se tratam de divergências filosóficas (SMITH, 2001). Em outras disciplinas do campo científico, essa é considerada como uma falsa questão (BOURDIEU, 1989). O que é considerado, por esse último autor, como relevante para o processo de investigação, é a construção do objeto e a mobilização de todas as técnicas possíveis para analisá-lo (BOURDIEU,1998).

No caso particular da avaliação, existem muitos objetos pré-construídos dado seu caráter predominantemente instrumental, principalmente nas 
avaliações formativas e voltadas para a gestão. Contudo, na pesquisa avaliativa, há necessidade e existe um grande espaço de possibilidades de construção do objeto, principalmente nas análises de implantação.

Menos com a intenção de apresentar um "livro de receitas" e mais com o objetivo de sistematizar possibilidades, para orientar escolhas práticas, pode-se classificar as estratégias possíveis em estruturadas ou "pronto para usar" (prêt-à-porter) ${ }^{15}$ e semi estruturadas ${ }^{16}$ ou "sob medida" (sur mesure) (HARTZ, 1999). Entre as estratégias estruturadas podem ser incluídos os clássicos desenhos experimentais, os quase-experimentais e mesmo alguns considerados como não experimentais (CAMPBELL; STANLEY, 1966). Os desenhos epidemiológicos que têm sido usados para avaliação em saúde podem ser considerados como estruturados e apresentam uma equivalência com aqueles propostos por Campbell e Stanley (Quadro 2).

Já os pouco estruturados geralmente são estudos de caso $^{17}$ que, a depender dos níveis de análise e da profundidade, podem mobilizar diversas técnicas de coleta de dados qualitativos como: observação etnográfica, grupos focais, entrevistas em profundidade, histórias de vida e análise documental (COOK; REICHARDT, 1986 (1982); YIN, 1994) (PATTON, 1987; GUBA; LINCOLN, 1989).

A escolha da estratégia relaciona-se com o processo anterior de delimitação do foco e de construção do objeto da avaliação. Avaliar a dimensão relacional das práticas requer a realização de estudos de caso e o uso de técnicas qualitativas (HADAD e outros, 2002). Da mesma forma nas análises de implantação a resposta à pergunta acerca das relações entre o grau de implantação e os contextos políticos e organizacionais requer a realização de análises históricas, entrevistas em profundidade e a elaboração de modelos teóricos causais (DENIS; CHAMPAGNE, 1997; HARTZ e outros, 1997, 2003; PATTON, 2002). Esses dois tipos de avaliação são muito úteis para o gestor no que diz respeito a geração de informações voltadas para as retificações necessárias nos programas em curso (HULSCHER; LAURANT e outros, 2003).

A avaliação de cobertura e de utilização de serviços impõe a quantificação e o uso de desenhos estruturados como o inquérito (VIEIRADA-SILVA e outros, 1995; TRAVASSOS e outros, 2002). Para as avaliações de eficácia de tecnologias os desenhos indicados ainda são os experimentais ou quase-experimentais observacionais do tipo estudos ecológicos, casocontrole e coortes (BARRETO e outros, 2002). 
Já em relação a avaliação da efetividade de programas há uma tendência crescente ao uso de síntese de pesquisas como uma estratégia prioritária para responder a perguntas sobre o efeito de tecnologias ou programas em sistemas operacionais (COOK, 1997). Por outro lado, diante da complexidade da avaliação da efetividade de programas em contextos diferenciados, propõe-se o uso articulado entre diversas investigações com desenhos tradicionais ou não, tendo em vista a limitação dos desenhos quando considerados de forma isolada (PAWSON; TILLEY, 2001). A ampliação da base de evidências assim conseguida, ao lado da utilização da teoria e de desenhos sintéticos pode permitir a realização de inferências causais com maior segurança (CHEN, 1990). Por fim os estudos considerados como de desenvolvimento de novas tecnologias para interveção ou avaliação requerem uma ênfase no pólo teórico e síntese de conhecimento (CONTANDRIOPOULOS e outros, 1994).

\section{CONSIDERAÇÕES FINAIS}

O campo da avaliação expandiu-se consideravelmente no final do século XX tanto em produção científica quanto no que diz respeito a sua institucionalização. As suas principais características são a diversidade conceitual e terminológica, a pluralidade metodológica e a multiplicidade de questões consideradas como pertinentes. Persiste uma importante lacuna relacionada com a incorporação do conhecimento produzido no plano da investigação pelos profissionais de saúde e pelos gestores.

Há um crescente consenso que as diferenças nas abordagens e estratégias metodológicas para a avaliação dependem dos objetos e circunstâncias (ROGERS, 2001). O julgamento adequado sobre o valor de uma intervenção requer muitas vezes a mobilização de diferentes estratégias metodológicas, visita ao conhecimento anteriormente produzido e desenvolvimento teóricoconceitual (PAWSON; TILLEY, 2001). Em síntese, a avaliação pode produzir informação tanto para a melhoria das intervenções em saúde como para o julgamento acerca da sua cobertura, acesso, eqüidade, qualidade técnica, efetividade, eficiência e percepção dos usuários a seu respeito. Com essa finalidade pode e deve mobilizar as estratégias e técnicas necessárias da epidemiologia e das ciências humanas, sem preconceitos e sem interdições. 


\section{Quadro 1}

Possíveis relações entre abordagens, características selecionadas das práticas e níveis de controle

\begin{tabular}{|c|c|c|c|}
\hline $\begin{array}{l}\text { Abordagens } \\
\text { Características } \\
\text { das práticas }\end{array}$ & Estruturas & Processos & $\begin{array}{l}\begin{array}{r}\text { Resultados } \\
\text { (Efetividade } \\
\text { /impacto) }\end{array} \\
\text { Níveis } \\
\text { de controle } \\
\text { Controle de causas }\end{array}$ \\
\hline Cobertura & $\begin{array}{l}\text { Cobertura potencial } \\
\text { de uma ação } \\
\text { educativa relacionada } \\
\text { com a promoção da } \\
\text { saúde } \\
\text { (ex: proporção de } \\
\text { panfletos disponíveis em } \\
\text { relação a população-alvo } \\
\text { relacionados com os } \\
\text { benefícios de fazer } \\
\text { exercícios físicos) }\end{array}$ & $\begin{array}{l}\text { Cobertura real dessa } \\
\text { mesma ação } \\
\text { educativa relacionada } \\
\text { com a promoção da } \\
\text { saúde } \\
\text { (ex: proporção de } \\
\text { panfletos efetivamente } \\
\text { distribuídos em relação à } \\
\text { população-alvo) }\end{array}$ & Promoção da saúde \\
\hline Cobertura & $\begin{array}{l}\text { Cobertura potencial } \\
\text { de ações relacionadas } \\
\text { ao controle da } \\
\text { qualidade da água }\end{array}$ & $\begin{array}{l}\text { Cobertura real dessas } \\
\text { mesmas ações. } \\
\text { Organização } \\
\text { adequada do } \\
\text { acolhimento em } \\
\text { Centros de Saúde }\end{array}$ & $\begin{array}{l}\text { Controle de riscos } \\
\text { Eliminação de } \\
\text { agentes } \\
\text { potencialmente } \\
\text { causadores de } \\
\text { doenças de } \\
\text { transmissão hídrica }\end{array}$ \\
\hline Acessibilidade & $\begin{array}{l}\text { Distribuição } \\
\text { geográfica adequada } \\
\text { dos Centros de } \\
\text { Saúde. } \\
\text { Equipamentos } \\
\text { necessários à } \\
\text { realização de exames } \\
\text { complementares }\end{array}$ & $\begin{array}{l}\text { Cuidado adequado } \\
\text { ao diagnóstico }\end{array}$ & $\begin{array}{l}\text { Controle de danos } \\
\text { Pessoas com agravos } \\
\text { à saúde que tenham } \\
\text { tido acesso ao } \\
\text { cuidado adequado } \\
\text { podem curar-se do } \\
\text { agravo }\end{array}$ \\
\hline Qualidade técnica & & & $\begin{array}{l}\text { Controle de danos } \\
\text { Cura }\end{array}$ \\
\hline
\end{tabular}




\section{Quadro 2}

Tipo de Estratégia/Desenho

\begin{tabular}{|c|c|c|c|}
\hline & Experimental & Quase Experimental & Não Experimental \\
\hline \multirow[t]{3}{*}{ Estruturados } & $\begin{array}{l}\text { Pré-Teste Pós-teste } \\
\text { Com controle } \\
01 \text { X } 02 \\
03 \text { X } 04 \\
\text { Campbell(1963) }\end{array}$ & $\begin{array}{l}\text { Séries Temporais } \\
\ldots \mathrm{O}_{1} \mathrm{O}_{2} \mathrm{O}_{3} \times \mathrm{O}_{4} \mathrm{O}_{5} \mathrm{O}_{6}\end{array}$ & $\begin{array}{l}\text { Um grupo Pós-teste } \\
\qquad \text { X } 01 \\
\text { Pré-Teste Pós-teste } \\
01 \text { X } 02 \\
\text { Campbell(1963) }\end{array}$ \\
\hline & $\begin{array}{l}\text { Intervenção } \\
\text { Lilienfeld (1976) }\end{array}$ & $\begin{array}{l}\text { Séries Temporais } \\
\text { Caso-Controle } \\
\text { Coortes } \\
\text { Lilienfeld (1976) }\end{array}$ & $\begin{array}{l}\text { Estudos transversais } \\
\text { Lilienfeld (1976) }\end{array}$ \\
\hline & $\begin{array}{l}\text { Intervenção } \\
\text { Almeida Filho; } \\
\text { Rouquayrol } \\
\text { (1999) }\end{array}$ & $\begin{array}{l}\text { Observacional } \\
\text { Agregados } \\
\text { Individual } \\
\text { Longitudinal } \\
\\
\text { Almeida-Filho; } \\
\text { Rouquayrol } \\
\text { (1999) }\end{array}$ & $\begin{array}{l}\text { Estudos transversais } \\
\text { Almeida-Filho; } \\
\text { Rouquayrol } \\
\text { (1999) }\end{array}$ \\
\hline Semi-estruturados & $\begin{array}{l}\text { Estudos de caso } \\
\text { com análise histórica }\end{array}$ & $\begin{array}{l}\text { Estudo comparado de } \\
\text { casos múltiplos } \\
\text { Estudos centrados na } \\
\text { teoria e desenhos } \\
\text { sintéticos } \\
\text { (CHEN, 1990) }\end{array}$ & $\begin{array}{l}\text { Estudos de caso } \\
\text { (YIN,1994) } \\
\text { Pesquisa de } \\
\text { desenvolvimento } \\
\text { (CONTANDRIOPOULOS, } \\
\text { 1994) }\end{array}$ \\
\hline
\end{tabular}


Figura 1

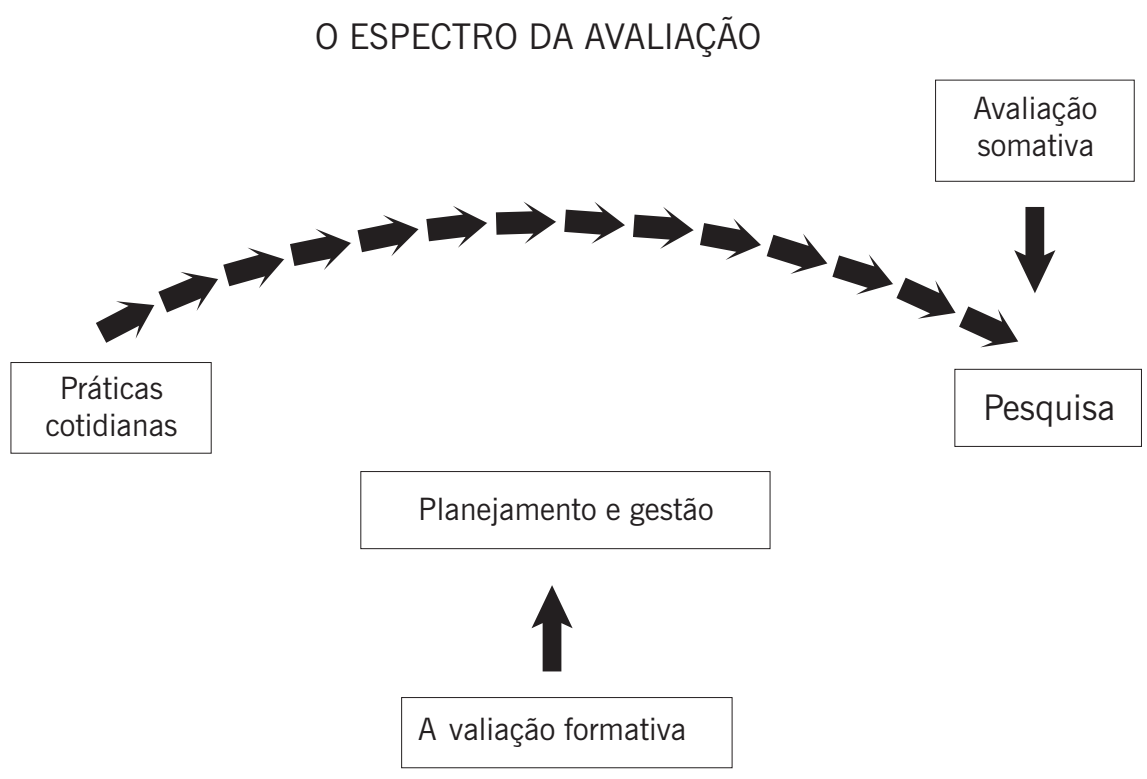

Figura 2

NÍVEIS E OBJETOS DA AVALIAÇÃO

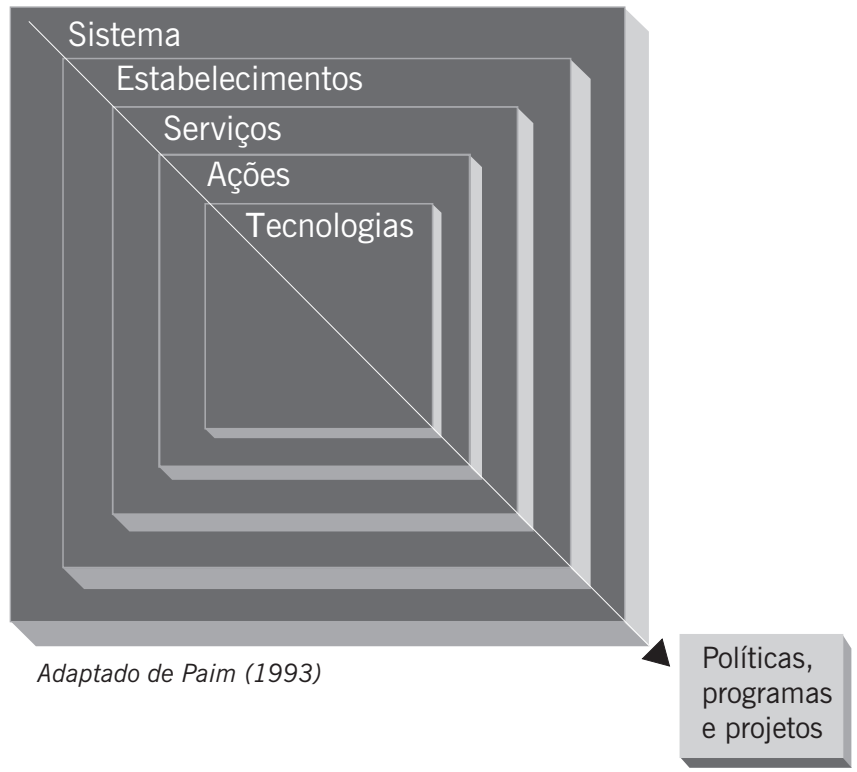




\section{Figura 3}

Atributos ou Características para Avaliação em Saúde

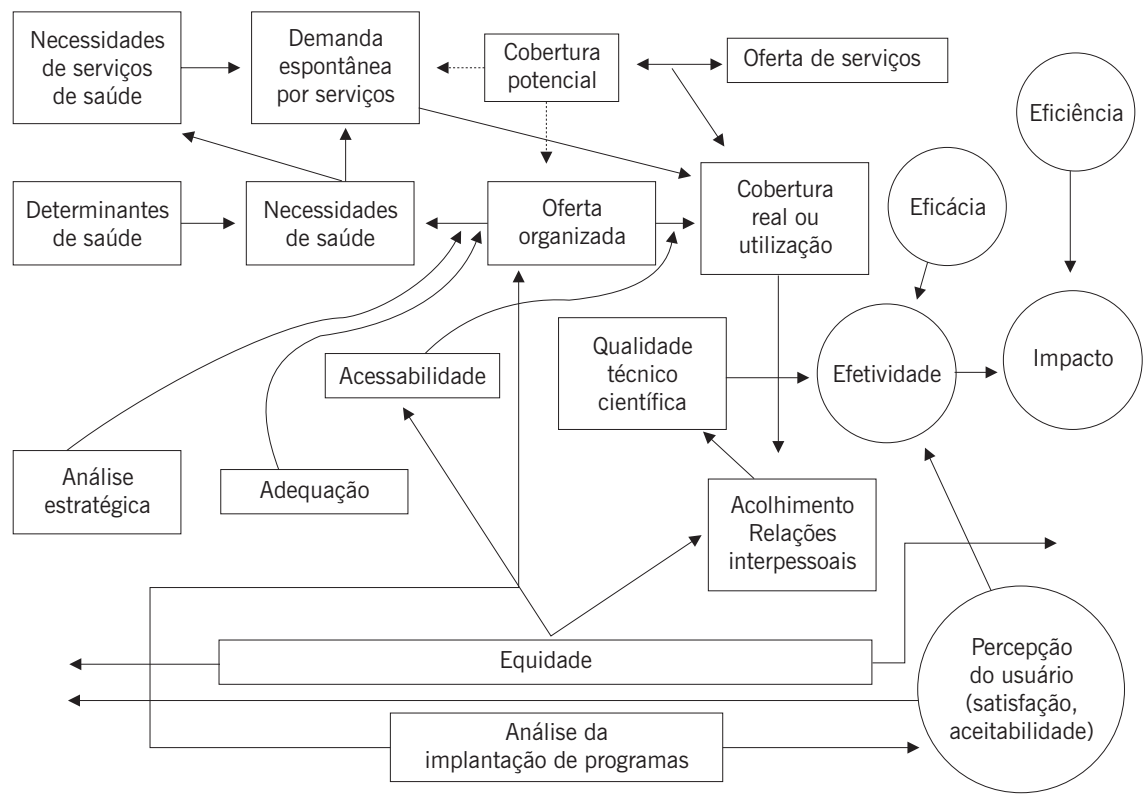

\section{NOTAS}

${ }^{1}$ Para Contandriopoulos, uma intervenção é um conjunto de meios (físicos, humanos, financeiros e simbólicos) organizados em um contexto específico, em um dado momento, para produzir bens ou serviços para modificar uma situação problemática (CONTANDRIOPOULOS, 1997).

${ }^{2} \mathrm{O}$ conceito de práticas sociais usado aqui é aquele desenvolvido por Bourdieu, segundo o qual, as práticas sociais são a relação entre uma situação e um habitus. Para melhor compreensão dos conceitos de campo e habitus sugere-se a leitura dos livros La Distinction (1979) e Le sens pratique (1980) deste autor.

3 Embora o termo "avaliativo" seja um anglicismo o seu uso vem sendo progressivamente incorporado aos textos acadêmicos sobre a avaliação. A expressão que consta do Dicionário Aurélio, "avaliatório", é menos utilizada embora também correta.

${ }^{4}$ Uma análise mais detalhada sobre modelos lógicos e teóricos é objeto do capítulo 2 do presente livro.

${ }^{5}$ Tipologia adaptada de (PAIM, 1993).

${ }^{6}$ Ver discussão detalhada sobre a avaliação de sistemas em (VIEIRA-DA-SILVA, 1999). 
${ }^{7}$ Paim, J. S. Políticas de saúde no Brasil. Epidemiologia e Saúde. Rouquayrol; AlmeidaFilho. Rio de Janeiro: MEDSI, 2003 (no prelo).

${ }^{8}$ Os programas correspondem a um grau de organização das práticas onde há definição de objetivos, atividades e recursos para resolução de problemas definidos de saúde. 0 programa pode ou não estar sendo desenvolvido ao interior de um serviço, estabelecimento ou sistema de saúde.

${ }^{9}$ Diversas outras possibilidades de delimitação de níveis existem. Nos capítulos 4, 5 e 6 do presente livro o leitor verá diferentes níveis selecionados para a realização de investigações avaliativas.

${ }^{10}$ Os conceitos de demanda espontânea e oferta organizada são aqueles utilizados por Paim (1999).

11 Uma análise detalhada do significado do conceito de equidade é feita no ensaio "Vieira-da-Silva; Almeida-Filho, 2000. Distinção, diferença, desigualdade, iniquidade e a saúde: uma análise semântica. VI Congresso da ABRASCO. Salvador, Bahia."

${ }^{12}$ A "análise estratégica" para Contandriopoulos e Campoamar tem um sentido distinto daquele que é usado pela OPS no documento "Formulacion de Políticas de Salud" (CPPS/ OPS, 1975). Neste último documento, a definição de estratégias relaciona-se com a análise da viabilidade política para a implementação do plano enquanto que a análise das relações entre objetivos e proposições é denominada análise de coerência (CPPS/ OPS, 1975).

${ }^{13}$ A expressão "caixa preta" tem sido usada por diversos autores numa referência aos desenhos que só investigam os resultados das intervenções não se preocupando com os processos e contextos.

${ }^{14}$ Diversos exemplos de análise de implantação de programas são descritos no presente livro. No capítulo 7, Contandriopoulos e colaboradores descrevem uma experiência canadense de integração de serviços de saúde que foi objeto de uma investigação sobre a sua implantação. Já os capitulos 5, 4 e 6 referem-se a investigações realizadas no Brasil sobre a implantação de programas e políticas de abrangência diversa tais como: a assistência farmacêutica (FRIAS; HARTZ), a intersetorialidade (COELHO; VIEIRA-DASILVA) e a descentralização da gestão do SUS (VIEIRA-DA-SILVA; HARTZ e outros).

${ }^{15} \mathrm{~A}$ analogia entre os desenhos estruturados da pesquisa e a costura do tipo "pronta entrega" (pret-à-porter) por um lado e os estudos semi-estruturados e a costura feita "sob medida" (sur mesure) por outro foi feita por Hartz em debate sobre a institucionalização da avaliação (HARTZ, 1999).

${ }^{16}$ A expressão "semi-estruturadas" aqui não tem o sentido de pouco rigor e sim refere-se à flexibilidade possível nessas estratégias de investigação.

${ }^{17}$ Os estudos de caso podem ser únicos ou múltiplos, com uma ou diversas unidades ou níveis de análise (YIN, 1994).

\section{REFERÊNCIAS}

ALMEIDA-FILHO, N.; ROUQUAYROL, M.Z. Desenhos de Pesquisa em Epidemiologia. Epidemiologia e Saúde. Almeida-Filho, N. e Rouquayrol, M.Z. São Paulo; Belo Horizonte, Editora Médica e Científica Ltda. MEDSI. 1999. 
BARRETO, M.; RODRIGUES, L.; CUNHA, S.; PEREIRA, S.; HIJJAR, M.; ICHIHARA, M.; DE BRITO, S.C.; I.,D. "Design of the Brazilian BCG-REVAC trial against tuberculosis: a large, simple randomized community trial to evaluate the impact on tuberculosis of BCG revaccination at school age." Control Clin Trials v. 23, n. 5, p. 540-553, 2002.

BOURDIEU, P. La distinction. Critique social du jugement. Paris: Minuit, 1979.

BOURDIEU, P. O poder simbólico. Rio de Janeiro, Lisboa: DIFEL, Bertrand Brasil, 1989.

BOURDIEU, P.; CHAMBOREDON, J.C.; PASSERON, J.C. A profissão do sociólogo: preliminares epistemológicas. Petrópolis: Vozes, 1999.

BOURDIEU, P.; WACQUANT, L.J.D. Réponses. Pour une anthropologie réflexive. Paris: Seuil, 1992.

BRASIL-IBGE. Pesquisa Nacional por amostra de domicílios. Acesso e utilização de serviços de saúde:1998. Rio de Janeiro: IBGE: 96. 2000.

CAMPBELL, D.T.; STANLEY, J.C. Experimental and quasi-experimental designs for research. Chicago: Rand Mc Nally College Publishing Company (Reprinted from Handbook of Research on Teaching, American Educational Research Association, 1963), 1966.

CAMPOAMOR, N.R. Evaluación de los sistemas locales de salud. Los sistemas locales de salud. J. M. Paganini and R. C. Mir. Washington, D.C.: Organizacion Panamericana de La Salud, 1990. p. 463-467.

CANADA. Health Care in Canada. Ottawa: Canadian Institute for Health Information, 2001.

CHELIMSKY, E. The coming transformations in evaluation. Evaluation for the 21st century: a handbook. C.E.S.W. (eds.). Thousand Oaks-London-New Delhi: Sage Publications, 1997. p. 1-26.

CHELIMSKY, E.; Shadish, W. R. Preface. Evaluation for the 21st century: a handbook. S. Publications. Thousand Oaks-London-New Delhi: Sage Publications: xi-xiii, 1997. CHEN, H. Theory - driven evaluations. Newbury Park: Sage Publications, 1990. CONTANDRIOPOULOS, A.; CHAMPAGNE, F.; DENIS, J.; AVARGUES, M. "L'evaluation dans le domaine de la santé: concepts et méthodes." Revue Epidemiologie et Santé Publique, n. 48, p. 517-539, 2000.

CONTANDRIOPOULOS, A.; CHAMPAGNE, F.; DENIS, J.; PINEAULT, R. Avaliação na área de saúde: conceitos e métodos. Avaliação em saúde: dos modelos conceituais à prática na análise da implantação de programas. Rio de Janeiro: FIOCRUZ/Hartz, ZA, 1997. p. 29-48.

CONTANDRIOPOULOS, A.P.; CHAMPAGNE, F.; POTVIN, L.; DENIS, J.L; BOYLE, P. Saber preparar uma pesquisa. São Paulo/Rio de Janeiro: Hucitec/Abrasco, 1994. p. 35-55 / 79-86.

COOK, T. Lessons learned in evaluation over the past 25 years. Evaluation for the 21st century: a handbook. C.E.S.W. (eds.). Thousand Oaks: Sage Publications, 1997. p. 30-52. 
COOK, T.D.; Reichardt, C.S. Métodos cualitativos y cuantitativos en investigación evaluativa. Madrid: Ediciones Morata. (1986; 1982)

DENIS, J.; CHAMPAGNE, F. Análise da implantação de programas. Avaliação em saúde: dos modelos conceituais à prática na análise da implantação de programas. Rio de Janeiro: FIOCRUZ/Hartz, ZA. (ed.). 1997. p. 49-88.

DONABEDIAN, A. The definition of quality: a conceptual exploration. Explorations in quality assessment and monitoring. v. 1: the definition of quality and approaches to its assessment. A. Donabedian. Ann Arbor, Michigan: Health Administration Press, 1988. p. 3-31.

DONABEDIAN, A. "The seven pillars of quality." Arch. Pathol Lab Med, 114, p. 1115-1118, 1990.

FETTERMAN, D.M. Empowerment evaluation and accreditation in higher education. Thousands Oaks,London, New Delhi: Sage Publications, 1997.

FRENK, J.M. El concepto y la medición de accesibilidad. Investigaciones sobre servicios de salud: una antología. K. L. OPAS (White, editor principal). Washington, D.C.:OPS, 1992. p. 929-943.

GRÉMY, F. "Evaluation of medical action and of action in public health." Effective Health Care, v. 1, n. 1, p. 11-23, 1983.

GUBA, E.; Lincoln, Y. Fourth generation evaluation. Chapter 1: the coming of age of evaluation. Newbury Park: Sage Publications, 1989. p. 21-49.

HABERMAS, J. Teoria de la acción comunicativa I. Madri: Taurus, 1987.

HADAD, S.; FRANCA, E.; UCHOA, E. "Preventable infant mortality and quality of health care: maternal perception of the child's illness and treatment." Cad Saude Publica, v. 18, n. 6, p. 1519-1527, 2002.

HANDLER, A.; ISSEL, M.; TURNOCK, B. "A conceptual framework to measure performance of the public health system." American Journal of Public Health, v. 91, n. 8, p. 1235-1239, 2001.

HARTZ, Z.A. "Institucionalizing the evaluation of health programs and policies in France: cuisine internationales over fast food and sur mesure over ready-made." Cadernos de Saúde Pública, 1999, p. 229-260.

HARTZ, Z.A.; Champagne, F.; CONTANDRIOPOULOS, A.P.; C, L.M.d. Avaliação do Programa Materno-infantil : análise de implantação em sistemas locais de saúde no Nordeste do Brasil. Avaliação em saúde: dos modelos conceituais à prática na análise da implantação de programas. H.Z. (ed.). Rio de Janeiro: FIOCRUZ, 1997.

HARTZ, Z.A.; POUVOURVILLE, G. "Avaliação dos programas de saúde: a eficiência em questão." Ciência e Saúde Coletiva, v. 3, n. 1, p. 68-82, 1998.

HOUSE, E.R. "Unfinished Business: causes and values." American Journal of Evaluation, v. 22, n. 3, p. 309-315, 2001.

HULSCHER, M.E.J.L.; LAURANT, M.G.H.; GRAL, R.P.T.M. "Process evaluation on quality improvement interventions." Qual Saf Health Care, n. 12, p. 40-46, 2003. 
HURST, J.; HUGHES, M.J. Performance Measurement and Performance Management in OECD Health Systems, OECD, 2001.

KNOWLES, J.C.; LEIGHTON, C.; STINSON, W. Measuring results of Health Sector Reforma for System Performance: a Handbook of Indicators. Bethesda, Maryland, ABT Associates Inc. Development Associates Inc. Harvard School of Public Health, 1997.

MATUS, C. Política , Planejamento e Governo. Brasília: IPEA, 1993.

MAYNARD, A.; MCDAID, D. "Evaluating health interventions: exploiting the potential." Health Policy, n. 63, p. 215-226, 2003.

MCDAID, D. "Evaluating health interventions in the 21st century: old and new challenges." Health Policy, n. 63, p. 117-120, 2003.

MERCER, S.L.; GOEL, V. "Program evaluation in the absence of goals: a comprehensive approach to the evaluation of a population-based breast cancer screening program." The Canadian Journal of Program Evaluation, v. 9, n. 1, p. 97-112, 1994.

ORGANIZACIÓN PANAMERICANA DE LA SALUD/Centro Panamericano de Planificación de la Salud. Formulación de Políticas de Salud. Santiago, 1975. 77 p.

PAIM, J.S. As ambiguidades da noção de necessidades de saúde. Introdução à crítica ao planejamento de saúde. Salvador: Universidade Federal da Bahia-Departamento de Medicina Preventiva, 1982.

PAIM, J.S. A reorganização das práticas em distritos sanitários. In: MENDES, E.V. Distrito sanitário. O processo social de mudança das práticas sanitárias do Sistema Único de Saúde. São Paulo/Rio de Janeiro: HUCITEC/ABRASCO, 1993.

PAIM, J.S. A reforma sanitária e os modelos assistenciais. In: ROUQUAYROL; ALMEIDAFILHO. Epidemiologia e saúde. Rio de Janeiro: MEDSI, 1999. p. 473-488.

PAIM, J.S. Saúde, política e reforma sanitária. Salvador: CEPS-ISC, 2002.

PAIM, J.S. Políticas de saúde no Brasil. In: ROUQUAYROL; ALMEIDA-FILHO. Epidemiologia e saúde. Rio de Janeiro: MEDSI, 2003, p. 600. (no prelo).

PATTON, M.Q. How to use qualitative methods in evaluation. Newbury Park LondonNew Delhi: SAGE publications, 1987.

PATTON, M.Q. Utilization-focused evaluation. The new century text. Thousands Oaks- London- New Delhi: SAGE Publications, 1997.

PATTON, M.Q. "Evaluation, knowledge management, best practices, and high quality lessons learned." American Journal of Evaluation, v. 22, n. 3, p. 329-336, 2001.

PATTON, M.Q. Qualitative research and evaluation methods. Thousands Oaks London- New Delhi: SAGE Publications, 2002.

PAWSON, R.; TILLEY, N. "Realistic evaluation bloodlines." American Journal of Evaluation, v. 22, n. 3, p. 317-324, 2001.

PERELMAN, C. Ética e direito. Tradução: Maria Ermantina Galvão G. Pereira. São Paulo: Martins Fontes, 1996.

ROGERS, P.J. "The whole world is evaluating half-full glasses." American Journal of Evaluation, v. 22, n. 3, p. 431-435, 2001. 
ROSSI, P.H.; FREEMAN, H.E. Evaluation, a systematic approach. Beverly Hills: Sage Publications, 2004.

SCRIVEN, M. Evaluation thesaurus. Thousands Oaks London- New Delhi: SAGE Publications, 1991.

SCRIVEN, M. "Evaluation: future tense." American Journal of Evaluation, v. 22, n. 3, p. 301-307, 2001.

SMITH, M.F. "Evaluation: preview of the future." American Journal of Evaluation, v. 22, n. 3, p. 281-300, 2001.

SMITH, N. "The feasibility and desirability of experimental methods in evaluation." Evaluation and Program Plannin, n. 3, p. 251-256, 1980.

SOBERÓN, G. "La extensión de cobertura de los servicios de salud." Gaceta Médica de Méxiico, v. 124, n. 5-6, p. 163-166, 1988.

STECHER, B.M.; DAVIS, W.A. How to focus an evaluation. Newbury Park, London, New Delhi: Sage Publications, 1987.

SUCHMAN, E.A. Evaluative Research-Principles and Practice in Public Service and Social Action Programs. New York: Russel SAGE Foundation, 1967.

TRAVASSOS, C.; VIACAVA, F.; PINHEIRO, R.; BRITO, A. "Utilization of health care services in Brazil: gender, family characteristics and social status." Revista Panamericana de Salud Publica, v. 11, n. 5-6, p. 365-73, 2002.

VIEIRA-DA-SILVA, L.M. "Avaliação do processo de descentralização das ações de saúde." Ciência e Saúde Coletiva, v. 4, n. 2, p. 331-339, 1999a.

VIEIRA-DA-SILVA, L.M. "The field of evaluation and the sur mesure strategy." Cadernos de Saúde Pública, v. 15, n. 2, p. 247-248, 1999b.

VIEIRA-DA-SILVA, L.M.; FORMIGLI, V.; CERQUEIRA, M.; KRUCHEVSKY, L. "Coberturas vacinais superestimadas? Novas evidências a partir do inquérito de Pau da Lima." Revista Panamericana de Salud Pública, v. 1, p. 444-450, 1997.

VIEIRA-DA-SILVA, L.M.; FORMIGLI, V.L.A. "Avaliação em saúde: limites e perspectivas." Cadernos de Saúde Pública, v. 10, n. 1, p. 80-91, 1994.

VIEIRA-DA-SILVA, L.M.; FORMIGLI, V.L.A.; CERQUEIRA, M.P.; KRUCHEVSKY, L.; TEIXEIRA, M.M.A.; BARBOSA, A.S.M.; CONCEIÇÃO, P.S.A.; KHOURI, M.A.; NASCIMENTO, C.L. "O processo de distritalização e a utilização de serviços de saúde avaliação do caso de Pau da Lima." Cadernos de Saúde Pública, v. 11, n. 1, p. 72 - 84, 1995.

VUORI, H.V. Quality Assurance of Health Services. Concepts and Methodology. Copenhagen, WHO, Regional Office for Europe, 1982.

WHO. Health Impact Assessment: main concepts and suggested approach. Gothenburg consensus paper. Gothenburg, WHO- European Centre for Health PolicyECHP, 1999.

WHO. World Health Report. Geneva, World Health Organization, 2000.

YIN, R. K. Case study research. Design and methods. Beverly Hills, California: Sage Publications, 1994. 


\title{
USO DE MODELOS TEÓRICOS NA AVALIAC̣ÃO EM SAÚDE: ASPECTOS CONCEITUAIS E OPERACIONAIS
}

\author{
Maria Guadalupe Medina \\ Gerluce Alves Pontes Silva \\ Rosana Aquino \\ Zulmira Maria de Araújo Hartz
}

\section{INTRODUÇÃO}

O questionamento sobre o papel desempenhado pela teoria no campo da avaliação de programas de saúde põe, a nosso ver, a necessidade de uma reflexão mais abrangente sobre o próprio papel que ela desempenha na produção do conhecimento científico, estabelecendo um diálogo entre a Epistemologia e o campo da avaliação de serviços de saúde. Caberia indagar como este campo se apropria dos termos teoria, modelo, modelo teórico e modelo lógico e discutir qual o lugar do saber científico, do senso comum e do saber prático na construção dos modelos utilizados.

A ciência é um modo particular de se produzir crenças que se diferencia dos demais por colocar como suposto a noção do real, isto é, "algo permanente e externo sobre o qual nosso pensamento não pode incidir, que pode afetar os homens por igual, de modo que a conclusão que se obtém referente a ele é a mesma para todos. Há, portanto, coisas reais, cujos caracteres são inteiramente independentes das nossas opiniões sobre elas" e que, além disso, afetam os nossos sentidos de acordo com leis regulares; isto significa que além da precedência de uma realidade objetiva, há que afirmá-la como racional, e sendo racional, passível de teste realizado com respeito a determinadas regras, válidas para todos os indivíduos (SAMAJA, 
1996) ${ }^{1}$. Durkheim (1984) afirma que devemos tomar os fatos sociais como coisas, separando os fenômenos em si mesmos das representações sociais que os sujeitos fazem a seu respeito.

O conhecimento científico, produto da investigação científica, resulta de um permanente ir e vir entre teoria e empiria, de uma constante tensão entre o normativo - o universal, o endógeno, os sistemas formais - e o constatativo - o observável. De uma permanente mediação da experiência pela teoria e da teoria pela experiência (SAMAJA, 1996). Até mesmo as opções técnicas mais empíricas são inseparáveis das opções teóricas de construção do objeto e, somente em função de um corpo de hipóteses derivado de um conjunto de pressuposições teóricas, um dado empírico pode funcionar como prova ou evidência (BOURDIEU, 1989).

Duas questões merecem ser assinaladas neste momento. Primeiro, que essa mediação se faz como necessária porque o real, o "mundo dos fatos" não é passível de apropriação em sua totalidade, tal como se manifesta. Como corolário, o objeto da investigação científica é e não é o real, ou seja, é o real, mas não tal e qual ele se apresenta; é o real recortado, reduzido ou transformado por algo que informa sobre o real, por um arcabouço conceitual, por um sistema de idéias, por um construto sobre esse mesmo real. "Temos um mundo de certezas do qual sempre partimos, inclusive para dar sentido ao nosso assombro filosófico e nossos interrogantes científicos" (SAMAJA, 1996).

A produção do conhecimento científico opera a partir de rupturas com o senso comum num processo de investigação que requer o exercício do rompimento das adesões mais profundas e mais inconscientes do sujeito, onde o pesquisador busca substituir as suas impressões particulares sobre um determinado objeto por um corpo de conhecimentos tão independente quanto possível de sua relação primitivamente estabelecida com o mundo social. Isto não significa a negação pelo pesquisador de sua própria experiência prática, da qual, inclusive, ele extrai um conjunto de saberes, mas sim, de tomar esta experiência como uma informação, no sentido de que ela deve ser compreendida, completada, retificada e reinterpretada. 0 pesquisador deve apreender seu ponto de vista enquanto um ponto de vista, ao mesmo tempo desconfiando e tomando em consideração sua experiência (BACHELARD, 1996; BOURDIEU, 1989; PINTO, 1996).

A objetividade dos objetos científicos é indissociável do ato de objetivação: objetivar o objeto e o observador objetivando seu objeto, exer- 
citando a vigilância epistemológica do processo de investigação científica em diversos níveis (BACHELARD, 1996).

O objeto da ciência é, portanto um objeto construído que mescla componentes empíricos e componentes teóricos que é, por suposto, inteligível, passível de investigação, o que pressupõe a possibilidade de descrição de seus componentes e a possibilidade de sua re-elaboração segundo alguma racionalidade (SAMAJA, 1996).

Podemos dizer que o objeto da investigação científica é um construto da realidade passível de modelagem. Modelizar significa representar o objeto, seus movimentos e suas relações tendo por referência uma construção teórica: a teoria do objeto-modelo.

Segundo Bunge (1974), o passo inicial para a conquista conceitual da realidade é, paradoxalmente, a idealização. "É o nascimento do objetomodelo ou modelo conceitual de uma coisa ou de um fato". O objeto-modelo representa os traços-chave ou essenciais de um objeto completo. Não se trata aqui, ainda, de representar um sistema de idéias (teoria) particular. 0 conceito de modelo aqui tomado, nesta etapa, é a de representação esquemática de um objeto completo e não de modelo enquanto sistema hipotético-dedutivo particular, ou seja, de uma teoria relativa àquela idealização.

Como representação esquemática de uma idealização, o objeto-modelo deve ser, ao menos em parte, convencional, e necessariamente reproduzirá as características comuns a classes de fatos ou de coisas, perdendose, com isso, a individualidade de um fato ou de uma coisa, mas, permitindo, por outro lado, a representatividade de toda uma classe de coisas ou de fatos (BUNGE, 1974).

Despido de uma teoria que o suporte, o objeto-modelo, por si só, não auxilia muito o processo de investigação científica. Assim, ao primeiro movimento - da intuição - há que se agregar uma segunda condição ou qualidade: a razão. Há que dotar o objeto de certas propriedades passíveis de serem tratadas pela teoria. Há que enxertá-lo de uma teoria suscetível de ser confrontada com os fatos. De acordo com Bunge (1974), este é o segundo passo a ser dado no processo de conquista conceitual da realidade: a construção da teoria do objeto-modelo ou, em outros termos, a elaboração do modelo teórico. 
Modelo teórico é, pois, um "sistema hipotético-dedutivo que concerne a um objeto-modelo, que é, por sua vez, uma representação conceitual esquemática de uma coisa ou situação real ou suposta como tal" (BUNGE, 1974).

Os objetos-modelo, portanto, fazem parte das teorias científicas e os modelos teóricos encerram objetos-modelo. Vale ressaltar que, ainda que seja possível, ou mesmo desejável que se represente os modelos teóricos através de diagramas, ou de símbolos, é imperiosa a descrição das idéias, dos enunciados que compõem a teoria específica, pois "os componentes das teorias são idéias e não imagens" (BUNGE, 1974).

Assim, o modelo teórico é uma teoria específica de um objeto suposto real, constituída por uma teoria geral enriquecida de um objeto-modelo. Para esse autor, esse movimento de enriquecimento da teoria geral com um objetomodelo significa o estreitamento do domínio de ação da teoria geral e a possibilidade de torná-la verificável. Neste sentido, nenhuma teoria geral é verificável, exceto através da mediação de teorias específicas que a têm de suporte e que estreitam o seu domínio. Isto não significa, contudo, que a não comprovação de fatos relacionados a uma teoria específica invalide a teoria geral, uma vez que isto pode implicar tão-somente a necessidade de complexificação da teoria específica ou a modificação do objeto-modelo (BUNGE, 1974).

Na mesma linha, Almeida Filho (2000) refere que na produção do conhecimento científico, os objetos de conhecimento seriam operados como objetos-modelos, isto é, figuras capazes de instrumentalizar o pensamento sobre as coisas, sobre os processos, fenômenos ou eventos e que a conquista conceitual da realidade teria início pela integração do objeto-modelo em uma teoria, um conjunto de proposições relativas às propriedades de tal objeto que não seriam sensorialmente abordáveis, particularmente seus determinantes.

No campo da avaliação, a idéia que operacionaliza o objeto-modelo é a expressão "modelo lógico" (logic model ou logical framework), consensualmente aceita pela maioria dos avaliadores (RUSH; OGBORNE, 1991; MCLAUGHLIN; JORDAN, 1999; ROWAN, 2000; COOKSY e outros, 2001; MILLAR, 2001; UNRAU, 2001; RENGER; TITCOMB, 2002) . Objeto deste capítulo, a reflexão sobre o desenho dos modelos teóricos e/ou lógicos se dará abordando o papel que a teoria desempenha no processo da avaliação em saúde, as diretrizes para construção de modelos em avaliação e a discussão acerca da matriz de medidas. 


\section{DESENHANDO O MODELO TEÓRICO/LÓGICO}

\section{A TEORIA NO CAMPO DA AVALIAÇÃO}

No campo da avaliação, o debate em torno do papel da teoria e a utilização de modelos teóricos tem assumido contornos muito particulares. As origens da avaliação centrada na teoria (theory-driven evaluation) remontam aos anos $70 \mathrm{com}$ a proposta do PCM (Project Cycle Management) pelo Banco Mundial, posteriormente incorporada como logical framework pelos avaliadores da USAID, nos programa de ajuda ao desenvolvimento, e institucionalizada pelo setor público canadense nos anos 80 (HARTZ, 1999a; HARTZ, 1999b; CRACKNELL, 2000). A partir da década de 80, passa a haver um movimento de mudança de uma avaliação metodologicamente orientada para uma avaliação orientada pela teoria. A não utilização da teoria na avaliação de programas resultou em uma avaliação do tipo insumos/ produtos (black box evaluations), não sensível aos contextos políticos e organizacionais, e que relegava temas como as relações entre a intervenção ofertada e a intervenção planejada, entre os objetivos oficias e os objetivos operativos, ou entre efeitos esperados e não esperados (CHEN, 1990).

Para Contandriopoulos e outros (2000), uma teoria se expressaria pelos enunciados das relações que existem entre conceitos, que podem ser amplamente gerais e formalizados, ou ter um alcance menor, os denominados modelos teóricos, que seriam uma solução teórica para a questão de uma dada pesquisa.

Chen (1990) define teoria como um conjunto inter-relacionado de pressupostos, princípios, e/ou proposições para explicar ou guiar as ações sociais. $\mathrm{O}$ autor considera que para muitos cientistas sociais a teoria estaria relacionada só com o propósito de descrever e explicar um dado fenômeno, um tipo de "teoria descritiva", enquanto que o tipo de teoria que seria avaliativa em forma seria do tipo "teoria prescritiva", pois explicita o que deve ser feito ou como tornar algo melhor ${ }^{2}$. Ao discutir a natureza da teoria dos programas (intervenções) indica que ela tem preocupações tanto descritivas como prescritivas, ou científicas e práticas.

Tal fato implicaria, segundo Chen (1990), que a teoria de um programa teria duas partes, a primeira, a teoria prescritiva, com referência a estrutura que o programa deveria ter (tratamento, produtos e processo de 
implementação), e a segunda, a teoria descritiva, com referência aos mecanismos causais que relacionam o tratamento utilizado no programa, o processo de implementação e os produtos.

Para aquele autor, a construção da teoria do programa é um atividade carregada de valor, (idéias ou sentidos do que "deve ser") que precisa incorporar tanto os saberes científicos como os saberes práticos dos grupos implicados na avaliação (stakeholders).

Alguns autores trabalham com os conceitos de macroteoria e microteoria do Programa. A microteoria, baseada em normas, descreveria os aspectos estruturais e operacionais do Programa, produzindo informações sobre as sua partes; a macroteoria detalharia os aspectos organizacionais e sóciopolíticos que favoreceriam ou inibiriam os efeitos do programa. A microteoria estabelece, então, uma relação entre os recursos disponíveis, atividades e resultados enquanto que a macroteoria se preocupa com os aspectos relacionados ao contexto de implantação do Programa (HARTZ, 1997).

Os pressupostos implícitos são ainda referidos como as teorias das políticas, apesar de que mais freqüentemente os termos empregados são teoria do programa ou lógica do programa, sendo apontadas diferenças importantes entre estes dois termos (LEEUW, 2003). A lógica do programa especificaria os insumos (inputs), componentes do programa, os resultados a curto e longo prazo, e os vínculos entre eles, raramente assinalando os mecanismos responsáveis por essa vinculação. Por outro lado, uma teoria do programa seria uma teoria explícita ou modelo de como o programa causa os efeitos pensados ou observados.

O modelo lógico é entendido enquanto um esquema visual que apresenta como um programa deve ser implementado e que resultados são esperados (ROWAN, 2000). O processo para a construção da representação visual permite que a racionalidade implícita dos programas, percebidas pelos gerentes e demais grupos implicados, seja explicitada através da busca da opinião de especialistas e inclusão de informações de pesquisas (RENGER; TITCOMB, 2002), levando-se a uma maior possibilidade de construção de acordos em relação aos componentes do programa e aos resultados da avaliação.

Apresentar e discutir o modelo lógico de um programa é o que permite definir exatamente o que deve ser medido e qual a parcela de contribuição do programa nos resultados observados. Explicitar o modelo lógico implica em 
descortinar quais os limites ou debilidades de seus pressupostos, possibilitando identificar onde melhores evidências devem ser buscadas (MAYNE, 2000).

No entender de Rowan (2000) uma questão que merece ser discutida é se o modelo lógico poderia representar a teoria de mudança do programa (program's theory of change). Para esse autor, o modelo lógico estaria mais relacionado com a teoria de implementação do programa e não com a teoria do programa, que trataria dos mecanismos que fazem com que a implementação do programa alcance os resultados propostos/esperados.

Concepção diferenciada a essa proposição pode ser encontrada na literatura, em que se observa a correspondência entre os termos modelo lógico e microteoria do programa, e dos aspectos relacionados aos determinantes de sua implementação, à macroteoria, onde se faz a análise do contexto (HARTZ, 1997). Há ainda o emprego dos termos modelo lógico, modelo teórico e teórico-lógico como equivalentes (HARTZ, 1999a).

A construção do modelo teórico ou teórico-lógico do programa, explicitando sua racionalidade subjacente, inclui, portanto, especificações sobre o problema ou comportamento visado, a população alvo, as condições do contexto, o conteúdo do programa e os atributos necessários e suficientes para produzirem isolada ou integradamente os efeitos esperados.

O modelo teórico de um programa deve explicitar como o programa idealmente funciona (HARTZ, 1999), que argumentações teóricas dão suporte à hipótese apresentada e que hipóteses alternativas (rivais) serão afastadas. É necessário mostrar consciência da complexidade da situação e compreensão de outros fatores que jogam papel importante na produção dos resultados (esperados e não esperados), indicando as evidências que serão buscadas para demonstrar que o programa em questão promoveu uma significante contribuição para os mesmos (MAYNE, 2000).

Finalmente, é importante salientar que a elaboração de um modelo teórico/lógico deve ser convincente, apresentando plausibilidade das associações estabelecidas. Isto significa, necessariamente, que sua construção não despreza o acúmulo produzido pelas experiências e conhecimentos prévios e que as possibilidades colocadas pelo processo de investigação, orientadas pela teoria, podem contribuir significativamente para a redução das incertezas sobre o impacto atribuível ao programa, bem como uma razoável estimativa desse impacto. 
Métodos para a reconstrução das teorias de programas e políticas são apresentados com o intuito de contribuir para torná-las mais explícitas e transparentes e evitar erros no planejamento de programas e no resultado de avaliações (LEEUW, 2003).

Independente da terminologia assumida pelo pesquisador, o importante a assinalar é que, em se tratando da avaliação de programas, é fundamental a explicitação clara dos pressupostos que orientam a sua formulação. Vantagens de tal explicitação incluem uma maior precisão do desenho do programa, um melhor manejo na definição de responsabilidades, um melhor planejamento dos estudos avaliativos.

\section{DIRETRIZES PARA A CONSTRUÇÃO DE MODELOS EM AVALIAÇÃO}

O desenho do modelo lógico de um programa é o primeiro passo no planejamento de uma avaliação, sendo muitos os caminhos que podem ser utilizados na sua construção (ROWAN, 2000; MERCER; GOEL, 1994; RUSH; OGBORNE, 1991; MCLAUGLIN; JORDAN, 1999; RENGER; TITCOMB, 2002).

Construir o desenho lógico de um programa significa esquadrinhá-lo em termos da constituição de seus componentes e da sua forma de operacionalização, discriminando todas as etapas necessárias à transformação de seus objetivos em metas, abstraindo-se aqui suas determinações contextuais.

Ao desenvolver a construção do modelo lógico em relação ao Ontario Breast Cancer Screening Program, Mercer e Goel (1994) se deparam com um conjunto de dificuldades, das quais destacamos algumas, que nos fazem pensar sobre os limites e possibilidades do desenho de modelos lógicos em avaliação de programas de saúde. A primeira dificuldade relacionava-se à natureza complexa e multifacetada do Programa. Assim, o conjunto de componentes, além de ser diverso, alguns interdependentes, operavam sob lógicas distintas e, muitas vezes, contraditórias; a segunda dificuldade referia-se à própria ausência de consenso entre objetivos, metas e resultados esperados do Programa por parte da própria equipe que o concebeu; a terceira, dizia respeito à natureza descentralizada do Programa, o que significava que sua operacionalização era construída de forma distinta em função das características locais em que ele se implantava.

Este artigo é ilustrativo porque o autor identifica obstáculos a elaboração de um modelo lógico, levantando problemas muito próprios à realidade 
dos sistemas de saúde que os pesquisadores em avaliação costumam lidar. Os programas, que são um dos objetos possíveis da avaliação, geralmente partem de uma política governamental de larga ou de pequena escala que, às vezes, nem apresentam diretrizes e estratégias claramente definidas, e são permeados por contradições e lacunas, pois em geral são implementados antes da conclusão do desenho e da criação de consenso entre os grupos implicados sobre os objetivos e prioridades (MERCER; GOEL, 1994).

Em tese, um programa deve ter objetivos atividades e recursos definidos. Entretanto, na realidade concreta dos serviços de saúde, muitas vezes esses elementos são contraditórios, e tais contradições podem ser evidenciadas através da realização de uma análise estratégica, abordada em outro capítulo deste livro.

Diante das dificuldades apontadas, tem sido destacado que a participação dos grupos envolvidos no programa é fundamental na elaboração do modelo lógico, o que associado à busca da opinião de especialistas e revisão de literatura pode transformar esta fase inicial da avaliação em uma tarefa árdua, contudo, indispensável (RENGER; TITCOMB, 2002).

No entender de McLaughlin e Jordan (1999) pode-se falar em um processo do modelo lógico, tendo como produtos finais o diagrama do modelo lógico, com a essência do programa, um texto descrevendo o diagrama e o plano de medidas. No decorrer do processo alguns estágios deveriam ser vencidos: realizar coleta de informações sobre o programa a partir de várias fontes (documentos, entrevistas, revisão de literatura); definir claramente o problema objeto da intervenção e seu contexto; identificar os elementos do modelo lógico; desenhar o modelo lógico; e finalmente, avaliar continuamente, junto aos grupos envolvidos, se o modelo produzido representa a lógica do programa.

Segundo Rossi e colaboradores (1999), o modelo lógico deve apresentar três componentes fundamentais: primeiro, o plano da organização do Programa; segundo, o plano da utilização do Programa - estes dois primeiros componentes conformam a teoria de processo do Programa - e, terceiro, a teoria de impacto do Programa.

Em um modelo lógico de um programa devem constar:

a) os componentes - essenciais e secundários - do Programa;

b) os serviços relacionados e as práticas requeridas para execução dos seus componentes; 
c) os resultados esperados, suas metas e efeitos na situação de saúde da população e organização dos serviços.

Vários caminhos para o desenvolvimento dos modelos estão presentes na literatura, com diversos níveis de especificidade, complexidade e tipos de representação visual, como já mencionado (RUSH; OGBORNE, 1991; MERCER; GOEL, 1994; WONG-RIEGER; DAVID,1995; MCLAUGHLIN; JORDAN, 1999; ROWAN, 2000; RENGER; TITCOMB, 2002). Em geral, classificam-se as propostas em dois grandes grupos, um que parte dos efeitos que se espera que a intervenção tenha, isto é, a solução do problema selecionado, e a partir daí se desenha o programa e suas atividades, e o outro que é desencadeado pela seleção dos componentes do programa e se considera a rota até os objetivos e efeitos esperados. Há ainda a possibilidade da "abordagem mista", mencionada na elaboração do modelo lógico do projeto Nova Scotia Primary Care Project (ROWAN, 2000).

A seguir, no intuito de melhor explicitar diversas possibilidades de construção de modelos na avaliação de programas, são apresentados exemplos de esquemas de apresentação de modelos teóricos ou lógicos, que facilitam a compreensão de experiências práticas de sua utilização. Ressalta-se que as ilustrações abaixo nem sempre apresentam os fatores contextuais relacionados à implementação dos programas, contempladas em outros capítulos desta publicação.

\section{Figura 1}

Elementos de um modelo lógico

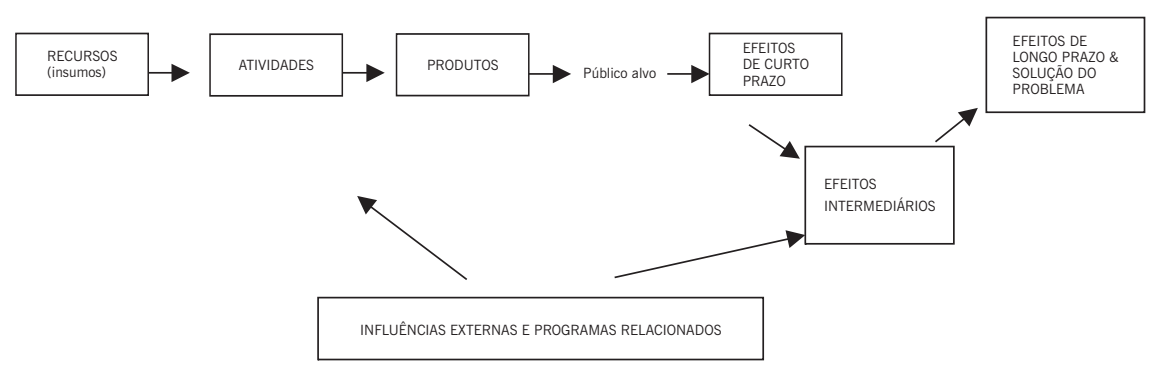

Fonte: Jordan; Mclaughlin (1999). 
Figura 2

Esquema básico de modelo lógico com objetivos de implementação e de resultados demarcados

COMPONENTES PRINCIPAIS

(atividades/recursos)<smiles>C1CCCC1</smiles>

OBJETIVOS DE IMPLEMENTAÇÃO (ex: fornecer, dar )<smiles>C1=CC2CCCCC2C1</smiles>

PRODUTOS

(ex: indicadores dos serviços prestados e características dos clientes)<smiles>C1CCCC1</smiles>

OBJETIVOS A CURTO PRAZO

(ex: elevar, reduzir, maximizar, evitar)<smiles>C1CCC2CCCC2C1</smiles>

OBJETIVOS A LONGO PRAZO

(ex: prevenir)

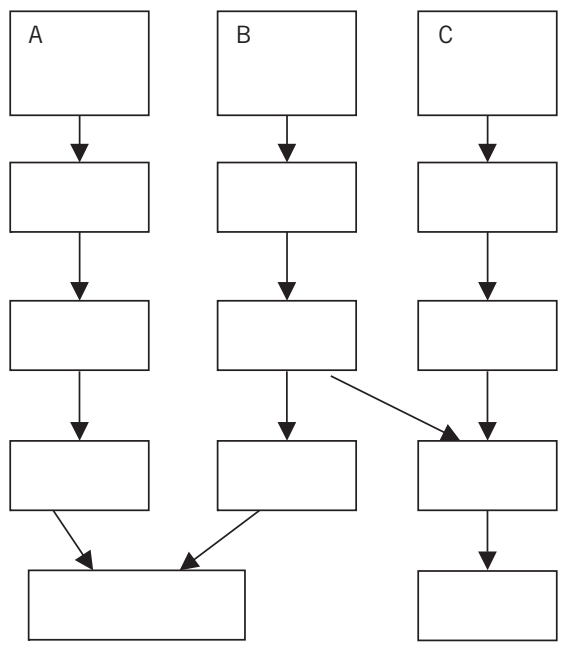

Fonte: Rush; Ogborne (1991).

\section{Figura 3}

Esquema de modelo lógico para programas de conscientização na área da saúde

$\begin{array}{llll}\text { ATIVIDADES } & \text { PRODUTOS DOS } & \text { RESULTADOS } & \text { RESULTADOS } \\ \text { DO PROGRAMA } & \text { SERVIÇOS OFERTADOS } & \text { IMEDIATOS } & \text { FINAIS } \\ & \text { (Tipos, clientes) } & \begin{array}{l}\text { (atitudes, sentimentos, } \\ \text { (comportamentos) }\end{array} & \text { motivações) }\end{array}$

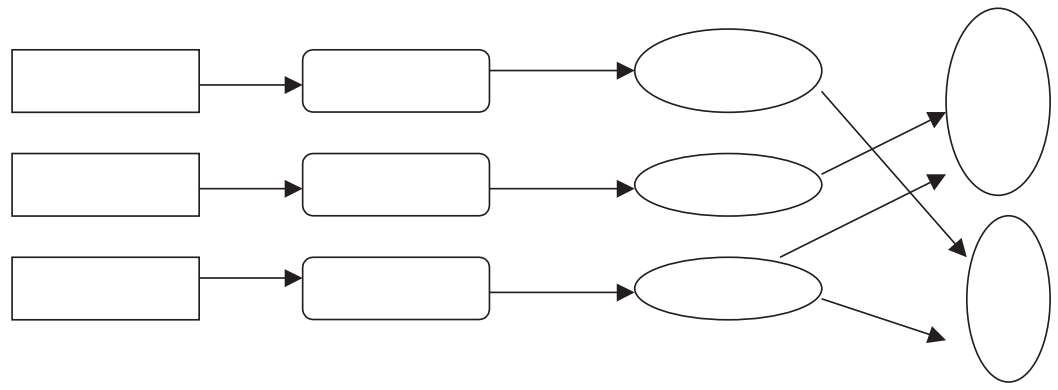

Fonte: Wong-Rieger; David (1995). 


\section{Figura 4}

Modelo lógico de um Programa de controle de Câncer de Mama

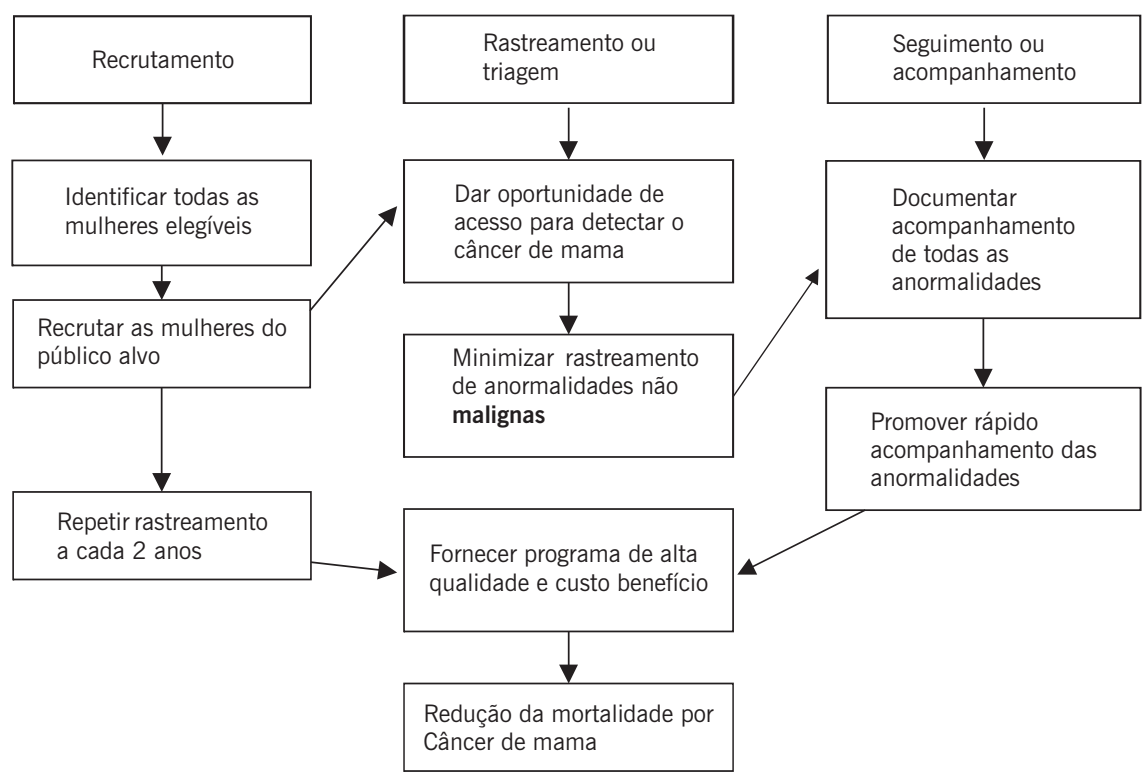

Fonte: Mercer; Goel (1994) ${ }^{3}$ adaptado por Hartz (2000).

Após a elaboração do modelo lógico é importante verificar se o mesmo atingiu o objetivo de representar a lógica do programa, e para tanto são sugeridas as seguintes questões ao final do processo (MCLAUGHIN; JORDAN, 1999):

1) O nível de detalhe foi suficiente para criar entendimento dos elementos e de suas relações?

2) Está a lógica do programa completa? Foram todos os elementos relacionados?

3) A lógica do programa é teoricamente boa? Todos os elementos foram colocados juntos seguindo uma lógica? Existem outros caminhos plausíveis de se alcançar os resultados esperados do programa?

4) Todos os fatores relevantes do contexto foram identificados e suas potenciais influências descritas? 
A Unidade de Comunicação em Saúde da Universidade de Toronto recomenda ainda que se utilize como critério de avaliaçao da qualidade do modelo sua leveza (número de elementos por página ou slide) e clareza na apresentação gráfica (HCU/CHP, 2001).

\section{MATRIZ DE MEDIDAS DO MODELO TEÓRICO/LÓGICO: UM DESAFIO A SER VENCIDO}

As razões que orientam a utilização de medidas que permitam avaliar a perfomance de um programa relacionam-se à responsabilidade da equipe gestora em prestar contas sobre o alcance dos objetivos propostos, bem como à necessidade de implementar melhorias na sua qualidade (MCLAUGHIN; JORDAN, 1999).

As estratégias de mensuração devem contemplar não apenas o monitoramento das características essenciais do programa, mas, especialmente, as relações de causa-efeito presumidas no modelo lógico, incluindo os supostos fatores contextuais que interagem na sua implantação. Tratase, portanto, de testar a hipótese do programa, e ainda que os resultados tenham sido alcançados, cabe indagar que características do programa contribuíram para o alcance dos efeitos esperados e não esperados. Mayne (2000) ressalta que nenhum fator, isoladamente, "causa" um efeito observado. Ao invés disso, este é sempre o resultado de um número de fatores que contribuem para o mesmo.

O primeiro passo na avaliação de desempenho de um programa é determinar se o que foi planejado - as atividades enunciadas no modelo lógico realmente ocorreu. Para tanto é necessário que as atividades apresentem um nível de detalhamento compatível com as necessidades de mensuração.

Em segundo lugar, é necessário avaliar os produtos e o impacto do programa, verificando se os resultados, de fato, estão relacionados às ações desenvolvidas ou em que medida podem ser explicadas por hipótese causais rivais.

A implementação da avaliação de um programa requer o desenho de uma matriz que apresente os critérios/indicadores e parâmetros que serão utilizados, bem como as respectivas fontes de informação a serem consideradas.

Segundo Donabedian (1986), um critério pode ser definido como um componente ou aspecto da estrutura de um serviço/sistema ${ }^{4}$ de saúde, ou 
de um processo ou resultado de um cuidado que dá suporte à qualidade da atenção prestada. Já o parâmetro é uma especificação quantitativa precisa do nível de um critério que conferirá qualidade em um grau determinado. Como exemplo, a concentração de profissionais por leito em uma unidade de terapia intensiva seria um critério de qualidade desse serviço enquanto que uma razão maior ou igual a dois profissionais por leito seria um parâmetro especificado do critério de qualidade desse serviço.

No contexto da avaliação de programas e serviços de saúde, indicadores de saúde, além de representarem medidas do impacto dos serviços sobre a saúde de populações, precisam considerar a mensuração da adequação, da infra-estrutura dos serviços e da efetividade dos processos. Indicadores isolados não são capazes de prover um quadro conclusivo acerca do desempenho dos serviços de saúde, sendo necessária a definição de conjuntos de indicadores relevantes para conduzir uma determinada avaliação. Adicionalmente, a avaliação de indicadores quantitativos não deve ser conduzida de forma isolada nem deve encerrar-se em si mesma, mas sim constituir-se em ferramenta que permita a formação de opinião e a tomada de decisões (NHCP, 2002).

Para eleição de critérios/indicadores de avaliação devem ser adotados critérios bem definidos. Tradicionalmente, os seguintes critérios de seleção têm sido recomendados: simplicidade (facilidade de cálculo); validade (em função da característica que se deseja medir); disponibilidade (utilização de dados disponíveis); robustez (pouco sensível às deficiências dos dados necessários a sua construção); sinteticidade (refletir o efeito do maior número possível de fatores); discriminatoriedade (alto poder discriminatório espaço e tempo) e cobertura (referir-se, se necessário, a cada país/território e não somente determinada área/grupo). (JORDAN FILHO, 1974).

Donabedian (1986) ressalta como características avaliativas importantes dos critérios de qualidade a validade (que pode ser científica ou consensual e que confere legitimidade ao processo avaliativo), a relevância, a disponibilidade e qualidade do registro, a adaptabilidade à avaliação (ou seja, sua susceptibilidade à modificação ao longo do tempo), sua capacidade de ser mais ou menos estrito e sua eficiência em rastrear o problema.

Os atributos necessários aos indicadores na avaliação de programas, definidos pelos critérios de seleção, buscam garantir que estes expressem 
medidas que considerem a abrangência multidimensional do fenômeno saúde-doença e das intervenções em saúde como processos complexos, variáveis e multifacetados. Neste sentido, outras experiências têm ampliado o escopo destes critérios definindo como relevantes que os indicadores de avaliação de serviços devam (NHCP, 2002):

1. Representar aspectos importantes da saúde pública ou do desempenho do sistema de saúde;

2. Ser mensurável (válido e confiável) na população geral e em diversas populações (população indígena, sexo, urbano/rural, estrato sócioeconômico);

3. Ser compreensível para as pessoas que necessitam agir;

4. Galvanizar ação de indivíduos, grupos organizados e organizações públicas e privadas em nível nacional, estadual ou local;

5. Ser relevante para a política e a prática dos serviços, no sentido em que avaliam ações que podem levar a melhoria da situação de saúde, alterando o curso do indicador;

6. Refletir resultados de ações quando medidos no tempo;

7. Ser coletado e analisado de forma oportuna exeqüível, quanto ao custo-benefício;

8. Ser coerente com processos nacionais de definição de dados.

Um passo fundamental para a avaliação dos indicadores é o estabelecimento de padrões de desempenho, que definem o que se pretende alcançar com a execução da ação, devendo ser definidos desde o início da avaliação, de forma a permitir determinar se a atividade foi executada com sucesso ou se foi eficaz (PAG APS, 1997).

Freqüentemente, os padrões de desempenho podem ser quantificados. Para algumas ações e serviços, existem parâmetros técnico-científicos que podem ser utilizados como padrões. Um exemplo clássico é a cobertura vacinal, cujo padrão deve corresponder com a cobertura a ser atingida para interrupção da cadeia de transmissão da doença. Em outras situações em que não existem parâmetros técnico-científicos, o estabelecimento de padrões pode ser feito através da análise da série histórica dos indicadores, pela adoção do valor dos indicadores para outras populações ou para o 
estado ou país ou através de mecanismos de consenso, definindo patamares a serem alcançados.

Assim, os parâmetros para o processo de avaliação nem sempre estão objetivamente estabelecidos. Do mesmo modo, a forma de medi-los pode variar. Muitas vezes, é necessário que o grupo que conduz o processo de avaliação construa consensos, não só em relação aos parâmetros mais apropriados, como quanto ao método mais adequado de aferir o que se quer avaliar.

Donabedian (1986) chama a atenção para as diferentes possibilidades de construção de consenso, quais sejam, o comitê tradicional no qual um dos membros é o coordenador, o método Delphi, onde os membros que definem os critérios e parâmetros não chegam a se encontrar e todo processo de consulta é realizado por via eletrônica ou por telefone, e o método do grupo nominal, que prevê uma primeira etapa de consulta individual prévia, uma segunda etapa de debate entre os participantes e, finalmente, uma terceira etapa de consulta individual em que cada participante tem a possibilidade de rever seu ponto de vista inicial.

Os processos de construção de consenso não só ampliam a possibilidade de validade dos critérios/indicadores como conferem maior legitimidade aos processos avaliativos.

Toma-se como exemplo da experiência nacional da Oficina do Pacto da Atenção Básica que reuniu em 2001, técnicos do Ministério da Saúde, das Secretárias Estaduais de Saúde e gestores municipais para selecionar os indicadores para avaliação da atenção básica no Brasil, a partir de um conjunto de critérios previamente acordados. Iniciativas desta natureza, além de evidenciar que estes não são processos meramente técnicos, estão em consonância com referências internacionais que têm privilegiado o desenvolvimento de metodologias de constituição de consensos entre gestores, financiadores, avaliadores e técnicos acerca do conjunto de indicadores mais relevantes para medição do impacto de serviços de saúde (KNOWLES e outros, 1997).

Finalmente, há que se destacar os aspectos relacionados à própria construção dos indicadores. Embora o termo "dados" possa sugerir que os elementos de informação em que se apóia a análise científica são dados ou prontos, eles são sempre o produto de uma atividade de construção teórica. O investigador não recebe os dados passivamente, pois a análise e construção dos dados e indicadores também caracterizam a "fase" de coleta de dados" (MERLLIÉ, 1996). 
Merllié (1996) exemplifica, a partir de investigações conduzidas no campo das ciências sociais, alguns aspectos relevantes quanto à utilização de dados quantitativos:

- A necessidade de questionamento sobre as condições práticas da elaboração dos dados, atentando que suas inexatidões não são equivalentes em todos os lugares e em todas as épocas e que as causas da diferença entre o fenômeno e sua inscrição estatística não tem efeito constante entre os grupos sociais e as diferentes instituições responsáveis pela coleta de dados etc.;

- A relevância do cuidado e do rigor ao comparar indicadores que são construídos a partir de diferentes conceitos e critérios gerais e a partir de diversas fontes;

. A possibilidade de variabilidade dos resultados interna a uma mesma pesquisa, ressaltando a importância do que aparentemente não passa de "simples detalhes": a periodicidade da coleta (mensal/anual), a redação das perguntas, o papel da mera repetição da passagem do entrevistador na mudança das respostas dos entrevistados em estudos de acompanhamento etc;

. O paradoxo da utilização de categorias com grande uso em pesquisas e nas instituições, que tem como vantagem a possibilidade de comparação e como inconvenientes a possibilidade do vocabulário comum dissimular diferenças na construção da noção e a tendência das pesquisas negligenciarem a explicitação dos procedimentos metodológicos;

- As conseqüências da utilização de dados de diversas fontes combinados para cálculo de indicadores, devido as diferentes condições em que são efetuadas as classificações;

- Os cuidados com a construção dos instrumentos de medição e com as condições técnicas de sua aplicação, assim como com as formas de codificação e classificação.

Assim constitui etapa fundamental da avaliação a análise da qualidade dos dados que geraram os indicadores de saúde, especialmente quando fontes secundárias são utilizadas, embora a produção de dados primários também deva ser objeto de reflexão crítica rigorosa. 
Especialmente quanto às fontes secundárias, vale ressaltar que a mensuração é dificultada pelos limites da informação em saúde, tanto a natureza das informações disponíveis, restritas, em sua maioria a doenças, agravos e procedimentos, e quanto à qualidade dos dados aos quais se pode ter acesso, nacional e localmente, considerando as marcantes heterogeneidades regionais e locais dos sistemas de informação e dos sistemas estaduais e municipais de saúde. Somam-se a estas questões, em que pese a crescente descentralização dos sistemas de informação, os limites quanto a compatibilização de conceitos e critérios dos diferentes sistemas, o que dificulta o estabelecimento de associações entre as diversas variáveis relacionadas ao estado de saúde e entre estas, condições de vida e produção de serviços de saúde.

\section{CONCLUSÃO}

No campo da saúde, cada vez é mais reforçada a necessidade de uma permanente avaliação das intervenções realizadas. Em que pese os limites e dificuldades que enfrentam os projetos de avaliação em saúde, como nos alerta Barreto (1998), o crescimento exponencial da produção de novas tecnologias voltadas para o cuidado, que passam a ser usadas, nem sempre tendo a sua eficácia comprovada e, muitas vezes, gerando efeitos indesejáveis e altos custos, impõe o desenvolvimento e aprimoramento de metodologias de investigação dos serviços de saúde.

São vários os desafios conceituais e metodológicos presentes para a realização de uma avaliação, e o debate em torno de questões fundamentais, a exemplo do papel que a teoria desempenha no processo da avaliação em saúde, está longe de ser esgotado.

Alguns deles merecem ser pontuados pelas implicações que apresentam para qualquer processo de avaliação em saúde.

Um primeiro desafio é o objeto da avaliação em saúde - as ações e práticas de saúde - que têm natureza social e histórica, o que não pode ser negligenciado por quem pretende avaliá-las (VIEIRA-DA-SILVA; FORMIGLI, 1994). Se é fato que, pela sua natureza, o objeto da avaliação se modifica em função do tempo e do contexto, também o é que o próprio processo de pesquisa, na avaliação, transforma o objeto avaliado. Conforme assinala Samaja (1993), o objeto de investigação não é apenas o real recortado, 
mas, é um objeto que se transforma no e pelo processo de pesquisa. E mais, se transforma não em relação àqueles aspectos periféricos ao processo de investigação, mas, possivelmente, naquilo que faz parte da sua essência, que é tomado e problematizado no processo de avaliação.

Em se tratando, especificamente, da avaliação de programas, agregase uma dificuldade adicional, relacionada à natureza complexa, multifacetada e abrangente que assumem (HARTZ, 1995; MERCER; GOEL, 1994; CONTANDRIOPOULOS; CHAMPAGNE e outros, 1997; HARTZ, 1997; HARTZ, 1999a). Programas abrigam, freqüentemente, um conjunto de componentes e práticas que operam, muitas vezes, com lógicas distintas e, até mesmo, contraditórias. Nem sempre há consenso entre objetivos, metas e resultados por parte da equipe que os concebem e sua operacionalização apresenta, como possibilidade, uma grande variabilidade na implementação local (MERCER; GOEL, 1994).

Um segundo desafio a se considerar é a dimensão subjetiva do processo de avaliação (SERAPIONE, 1999). Considerando que esta diz respeito a um julgamento sobre uma dada intervenção (CONTANDRIOPOULOS; CHAMPAGNE e outros, 1997), deve-se ter em mente que qualquer juízo de valor está orientado por uma visão de mundo. Há, portanto, uma dimensão subjetiva do processo de avaliação que não pode ser desprezada e que conforma tanto o recorte do objeto e dos objetivos, quanto o modelo teórico que serve de parâmetro de referência, quando se estabelecem comparações no processo avaliativo.

Usuários dos serviços, representantes da população, profissionais de saúde e gestores dos serviços têm objetivos e percepções distintas em relação aos serviços de saúde e, geralmente, dão prioridade a aspectos diferentes quando avaliam a qualidade das ações de saúde. Não só para democratizar as avaliações que pretendem influenciar processos de tomada de decisão nos serviços, considerar diversos atores envolvidos amplia o poder da avaliação de desvendar distintos aspectos de uma mesma intervenção e de seus efeitos (SERAPIONE, 1999).

Um terceiro desafio refere-se à validade dos estudos. Avaliar intervenções, enquanto ações de natureza transformadora, exige suficiente flexibilidade de modelos e métodos utilizados pelo avaliador, de forma a permitir lidar com inovações identificando seus efeitos esperados e inesperados. Além disso, incluir diversas visões promovendo a integração de diferentes 
pontos de vista no processo de avaliação, se, por um lado, favorece a superação de visões unilaterais dos problemas enfrentados (SERAPIONE, 1999) e facilita a incorporação dos resultados nas decisões a serem adotadas, por outro, intensifica o caráter subjetivo dos processos de avaliação.

O processo saúde-doença, objeto das intervenções que se deseja avaliar, possui múltiplas determinações causais, sendo a ação dos serviços de saúde apenas um dos fatores atuando sobre o estado de saúde de indivíduos e populações em contextos sócio-econômicos, políticos e culturais extremamente complexos. Mesmo nos modelos teóricos mais simplificados, para a maioria dos problemas de saúde, abordam-se sempre vários fatores etiológicos ou de risco, que atuam isoladamente ou em interação (ALMEIDAFILHO; ROUQUAYROL, 2002).

A necessidade de contextualização dos efeitos (condicionalidade da efetividade) e as restrições dos chamados métodos quantitativos têm promovido, no campo da avaliação de programas, o desenho de novas estratégias metodológicas como avaliações multicêntricas e estudos de caso múltiplos com níveis de análise imbricados (Hartz 1999), onde se combinam abordagens quantitativas e qualitativas e se lança mão de alternativas, como a triangulação, com vistas a aumentar a validade do estudo na aproximação com um objeto de natureza tão complexa.

De fato, a questão da validade é uma preocupação central na realização de qualquer pesquisa. Enquanto o aprimoramento das alternativas metodológicas na pesquisa avaliativa contribui para o aumento da validade interna da pesquisa, a principal vantagem de uma avaliação orientada pela teoria (theory-driven evaluation) é poder contribuir para a "reprodutibilidade ou validade externa das intervenções governamentais em larga escala" (HARTZ, 1999). Particularmente nos estudos de caso, a capacidade de uma pesquisa fornecer resultados generalizáveis a outras populações, contextos ou períodos, está diretamente relacionada à robustez e capacidade de explicação da teoria no seu confronto com a realidade empírica (YIN, 1993; CONTANDRIOPOULOS e outros, 1994).

Finalmente, é necessário trazer para o campo da Epistemologia uma profunda reflexão do como se faz a produção do conhecimento de "objetos mutantes" e de como se estabelecem relações entre teoria e empiria num campo em que a subjetividade e a praxis do investigador é constitutiva do próprio objeto, na medida em que ele é um agente transformador da prática 
avaliada no momento mesmo em que a avalia. É preciso reconhecer as dificuldades epistemológicas no campo da avaliação para não resolver o problema da forma menos criativa: negar a importância do papel da teoria neste campo. Para isso, epistemólogos, avaliadores e gestores das intervenções avaliadas precisam continuamente se debruçar sobre problemas concretos de investigação para pensar que especificidades relacionadas ao campo da avaliação em saúde, dada a complexidade de seu objeto e sua natureza de prática social transformadora, devem ser consideradas na elaboração de modelos lógicos e no desenho de estratégias de investigação, de sorte que a Epistemologia possa contribuir de forma mais efetiva para enriquecer o debate sobre a importância da teoria no campo da avaliação em saúde.

\section{NOTAS}

${ }^{1} \mathrm{O}$ debate em torno da objetividade do conhecimento é bem anterior, opondo, na filosofia, o realismo e o idealismo. A possibilidade de apropriação dessa realidade por meio da razão marca um debate filosófico destacando-se como expoentes, na modernidade, Descartes (racionalismo cartesiano), Kant (revolução copernicana que põe o sujeito no centro do processo de conhecimento), Hegel (a razão histórica) e Marx (materialismo histórico).

${ }^{2}$ O que Chen denomina "teoria" é considerado por Rossi, no prefácio do livro, como um conhecimento substantivo do que vai ser avaliado (CHEN, 1990).

${ }^{3}$ Adaptado por Hartz (2001). Notas do Curso "Avaliação de sistemas e serviços de saúde". ISC/UFBA.

${ }^{4}$ Donabedian se refere a sistema, entretanto todos os exemplos apresentados no artigo são baseados em serviços, daí termos optado por incluir serviço na definição, uma vez que sistema tem para nós uma conotação específica.

\section{REFERÊNCIAS}

ALMEIDA-FILHO, N. A ciência da saúde. São Paulo: HUCITEC, 2000.

ALMEIDA-FILHO, N.; ROUQUAYROL, M.Z. Introdução à epidemiologia. 3ed. Rio de Janeiro: MEDSI, 2002. 293 p.

BACHELARD, G. A formação do espírito cientifico: contribuição para uma psicanálise do conhecimento. Rio de Janeiro: Contraponto, 1996. 316p.

BARRETO, M.L. Por uma epidemiologia da saúde coletiva. Revista Brasileira de Epidemiologia, v. 1, n. 2, p. 104-122, 1998.

BOURDIEU, P. Introdução a uma sociologia reflexiva. In: BOURDIEU, P. O poder simbólico. Cap. 2, Lisboa / Rio de Janeiro: DIFEL / BERTRAN BRASIL, 1998. p18-58. 
BUNGE, M. Os conceitos de modelo. Modelos na ciência teórica. In: BUNGE, M. Teoria e realidade. São Paulo: Perspectiva, 1974. p. 11-40.

CHEN, H. T. Theory - Driven evaluations. Newbury Park: Sage Publications. 1990. CONTANDRIOPOULOS, A.P.F.; CHAMPAGNE e outros. L' évaluation dans le domaine de la santé: concepts et méthodes. Révue d'Epidemiologie et Santé Publique, v. 48, p. 517-539, 2000.

CONTANDRIOPOULOS, A.P.F.; CHAMPAGNE, e outros. Avaliação na área de saúde: conceitos e métodos. In: HARTZ. Z.M.A. Avaliação em saúde: dos modelos conceituais à prática na análise da implantação de programas. Rio de Janeiro: FIOCRUZ, 1997. p. 29-48.

CONTANDRIOPOULOS, A.P.C.F; POTVIN, L; DENIS, J. L.; BOYLE, P. Saber preparar uma pesquisa. São Paulo/Rio de Janeiro: Hucitec/Abrasco, 1994. p. 43-55, 79-86. COOKSY, L.J.G.; PAIGE; KELLY; ADAM, P. The program logic model as an integrative framework for a multimethod evaluation. Evaluation and Program Planning, 2001, v. 24, p. 119-128.

CRACKNELL, B.E. Evaluating development aid. London: Sage Publications, 2000, $384 \mathrm{p}$.

DONABEDIAN, AMD. Criteria and standards for quality assesment and monitoring. QRB, v. 12, n. 3, p. 99-108, 1986.

DURKHEIM, E. As regras do método sociológico. Lisboa: Presença. 1984. 165 p. JORDAN FILHO, L. e outros. Revisão analítica dos indicadores de saúde. Revista Brasileira de Estatística, v. 35, p. 22-26, 1974.

HARTZ, Z.d.A. Uso de traçadores para avaliação de qualidade da assistência à criança: o controle da doença diarréica e das infecções respiratórias agudas em dois centros de saúde. Revista do IMIP, v. 9, n. 2, p. 35-50, 1995.

HARTZ, Z.d.A. Avaliação em saúde: dos modelos conceituais à prática na análise da implantação de programas. Rio de Janeiro: FIOCRUZ, 1997.

HARTZ, Z.d.A. Avaliação dos programas de saúde: perspectivas teórico-metodológicas e políticas institucionais. Ciência e Saúde Coletiva, v. 4, n. 2, p. 341-354, 1999a.

HARTZ, Z.d.A. Institucionalizing the evaluation of health programs and policies in France: cuisine internationales over fast food and sur mesure over ready-made. Cadernos de Saúde Pública, v. 15, n. 2, p. 229-260, 1999b.

HCU/CHP (Health Comunication Unit Center for Health Promotion, University of Toronto). 2001. Logic Models. http://www.utoronto.ca/chp/hcu

KNOWLES, J.C.; LEIGHTON, C.; STINSON, W. Measuring result of health sector reform for system performance: a handbook of indicators. Special Initiatives Report n. 1. Behesada, MD: Partnerships for Health Reform, Abt Associates Inc. 1997.

LEEUW, F.L. Reconstructing program theories: methods available and problems to be solved. The American Journal of Evaluation, v. 24, n. 1, p. 5-20, 2003.

MAYNE, J. Addressing atribuition through contribution analysis: using performance measures sensibly. Canadian Journal of Program Evaluation, v. 16, n. 1, p. 124, 2000. 
MCLAUGHLIN, J.A.; JORDAN, G.B. Logic Models: a tool for telling your program's performance story. Evaluation and Program Planning, v. 22, p. 65-72, 1999.

MERCER, S.L.; GOEL, V. Program evaluation in the absence of goals: a comprehensive approach to the evaluation of a population-based breast cancer screening program. The Canadian Journal of Program Evaluation, v. 9, n. 1, p. 97-112, 1994.

MERLLIÉ, D.A Construção estatística. In: CHAMPAGNE, P.; LENOIR, R, MERLLIÉ e PINTO, L. Iniciação à prática sociológica. Petropólis: Vozes, 1996.

MILLAR, A. Logic models: a system tool for performance management. Evaluation and Program Planning, v. 24, n. 1, p. 73-81, 2001.

NATIONAL HEALTH PERFORMANCE COMMITTEE - NHCP. National Report on Health Sector Performance Indicators 2001. Queensland Health, Brisbane, 2002.

PAG APS. Programa Avançado de Gerenciamento em Atenção Primária à Saúde. Avaliando a qualidade do serviço. Guia do usuário. Juiz de Fora, 1997.

PINTO, L. Experiência vivida e exigência científica de objetividade. In: CHAMPAGNE, P.; LENOIR, R.; MERLLIÉ; PINTO, L. Iniciação à prática sociológica. Petropólis: Vozes, 1996.

RENGER, R.; TITCOMB, A. A Three-Step Approach to Teaching Logic Models. American Journal of Evaluation, v. 23, n. 4, p. 493-503, 2002.

ROSSI, P.H.; FREEMAN, H.E.; LIPSEY, M.W. Evaluation: a systematic approach. Thousand Oaks: SAGE Publications, 1999.

ROWAN, M.S. Logic models in primary care reform: navigating the evaluation. Canadian Journal of Program Evaluation, v. 15, n. 2, p. 81-92, 2000.

RUSH, B.; OGBORNE, A. Program logic models: expanding their role and structure for program planning and evaluation. The Canadian Journal of Program Evaluation, v. 6, p. 95-106, 1991.

SAMAJA, J. Epistemología y metodología. Elementos para una teoría de la investigación científica. Buenos Aires: EUDEBA, 1996. 414 p.

SERAPIONI, M. Avaliação da qualidade em saúde: a contribuição da sociologia da saúde para a superação da polarização entre a visão dos usuários e a perspectiva dos profissionais de saúde. Saúde em Debate. Rio de Janeiro, v. 23, n. 53, p. 8192, 1999.

UNRAU, Y. A. Using client exit interviews to illuminate outcomes in program logic models: a case example. Evaluation and Program Planning, v. 24, p. 353-361, 2001.

VIEIRA-DA-SILVA, L.M.; FORMIGLI, V.L.A. Avaliação em saúde: limites e perspectivas. Cadernos de Saúde Pública, v. 10, n. 1, p. 80-91, 1994.

WONG-RIEGER, D.; DAVID, L. Using program logic models to plan and evaluate education and prevention programs. evaluationmethods sourcebook II. A. J. Love. Ottawa, Ontario, Canadian Evaluation Society, 1995, p. 120-137.

YIN, R.K. Case study designs for evaluating high-risk youth programs: the program dictates the design. Applications of case study research, 1993. p. 77-93. 


\section{CONFERÊNCIA DE CONSENSO SOBRE A IMAGEM-OBJETIVO DA DESCENTRALIZAÇÃO DA ATENÇÃO À SAÚDE NO BRASIL'}

Luís Eugênio Portela Fernandes de Souza

Ligia Maria Vieira da Silva Zulmira Maria de Araújo Hartz

\section{INTRODUÇÃO}

A descentralização das ações e dos serviços de saúde tem sido parte integrante das políticas brasileiras de saúde desde o início da década de 80 com as estratégias das Ações Integradas de Saúde (AIS) e dos Sistemas Unificados e Descentralizados de Saúde (SUDS). É, contudo, após a promulgação da Constituição de 1988 que a descentralização se institucionaliza enquanto política, passando a ser uma das principais diretrizes setoriais. Na década de 90, o processo de descentralização se acelera, a partir da edição das Normas Operacionais Básicas, em particular as NOB-01/93 e 01/96, e se associa a propósitos de redefinição do modelo assistencial.

Diversos estudos investigam os efeitos da descentralização sobre as práticas gerenciais e assistenciais e mesmo sobre o estado de saúde da população (ALMEIDA, 1988; MENDES, 1992; HEIMANN, 1998). As investigações avaliativas, no entanto, se ressentem da falta de uma imagemobjetivo bem estabelecida, com a qual se possa avaliar o grau de implantação e os efeitos da descentralização. Trata-se de um problema metodológico importante, cuja superação pode contribuir para o desenvolvimento do debate político e da investigação científica em torno da reorganização setorial.

Afinal, aonde se quer chegar com a descentralização da saúde? Em que consiste o chamado "novo modelo assistencial"? Alguns podem consi- 
derar a simples ampliação da cobertura assistencial, outros, a existência da referência aos serviços de alta e média complexidade, já outros, a existência de ações programáticas voltadas para problemas prioritários, a humanização do cuidado, o trabalho em equipe, a integralidade ou a existência de ações intersetoriais. São diversas as combinações de dimensões do sistema de saúde que poderiam compor uma imagem-objetivo ${ }^{2}$ da descentralização. Na prática, os autores têm adotado, freqüentemente, de modo implícito, imagens-objetivo específicas para seus estudos. Essa variação nas percepções, se, por um lado, reflete a diversidade de projetos políticos no campo da saúde no Brasil, por outro, pode implicar a impossibilidade de comparar estudos, reduzindo a chance de consolidação da produção científica sobre o tema da descentralização da saúde.

É clara, então, a necessidade de se superar esse obstáculo metodológico, formulando-se uma imagem-objetivo que sirva de referência para as diversas pesquisas sobre a descentralização da saúde. Não se trata, todavia, de uma tarefa simples.

Em primeiro lugar, a produção científica sobre o tema é grande e apresenta divergências significativas na sua interpretação. Em segundo lugar, a definição de uma imagem-objetivo implica necessariamente em julgamentos de valor. Por último, não é possível dissociar a dimensão política da dimensão técnica no momento de se selecionar critérios para avaliar a descentralização.

A composição dessa imagem-objetivo, portanto, pressupõe a adoção de metodologias capazes de dar conta simultaneamente dos aspectos éticos, políticos e técnicos do problema. E mais: exige que as metodologias permitam o estabelecimento de um consenso mínimo entre os especialistas no assunto.

Por tudo isso, a definição de uma imagem-objetivo para a descentralização da saúde requer a utilização de uma técnica de obtenção de consenso. De fato, ao tomar em conta a produção científica, as opiniões dos especialistas e os projetos presentes na cena política, uma estratégia de busca de consenso permite a consideração dos aspectos técnicos da questão sob análise sem negligenciar os elementos de ordem ética e política.

Estratégias para obtenção de consenso entre especialistas vêm sendo largamente conduzidas em diversos campos do saber, e, em particular, no campo da saúde, para a definição de critérios, padrões e indicadores para avaliação da qualidade do cuidado (DONABEDIAN, 1988; BROWN e outros, 2001). 
De forma semelhante, o projeto de investigar os efeitos das políticas de descentralização sobre a organização dos serviços de saúde no país pode se beneficiar da utilização de estratégias de obtenção de consenso no que diz respeito à imagem-objetivo e, conseqüentemente, às dimensões, critérios e indicadores para a avaliação da descentralização.

Neste capítulo, descreve-se o processo e apresentam-se os resultados de uma consulta a um comitê de especialistas sobre uma proposta de imagem-objetivo da gestão descentralizada da saúde. A consulta visou, exatamente, a definir os pontos consensuais da proposta. Esta experiência foi conduzida como um componente do projeto de investigação "Avaliação da descentralização da atenção à saúde na Bahia" (VIEIRA-DA-SILVA e outros, 2002).

Inicialmente, faz-se uma breve discussão sobre os tipos de técnicas de obtenção de consenso comumente utilizadas. Em segundo lugar, descreve-se a técnica especificamente adotada no caso do projeto de investigação. A seguir, apresentam-se os resultados obtidos, ou seja, expõe-se a proposta de imagem-objetivo decorrente da discussão entre os especialistas. Finalmente, tecem-se as considerações finais. Não se tem a pretensão de se apresentar uma imagem-objetivo definitiva, mesmo porque os consensos são sempre provisórios, mas espera-se que a iniciativa estimule a discussão.

\section{AS DIVERSAS TÉCNICAS DE CONSENSO}

Diferentes técnicas vêm sendo utilizadas para se obter o consenso entre especialistas (DONABEDIAN, 1988; FAVARO; FERRIS, 1991; ANAES, 1999, PINEAULT; DAVELUY, 1986). Entre elas, destacam-se o comitê tradicional, o método Delfos, o grupo nominal e o júri simulado.

O comitê tradicional é a técnica que envolve a discussão aberta sobre um tema determinado entre especialistas selecionados. A sua maior vantagem é a possibilidade de trocas de idéias e de confronto entre opiniões divergentes. Um consenso nascido de um debate rico tende a ser bastante sólido. Por outro lado, o comitê tradicional tem a desvantagem de permitir a influência do "argumento de autoridade". De modo semelhante, os participantes mais "aguerridos" podem fazer prevalecer a sua opinião mais pela ênfase na defesa da sua posição do que pela qualidade intrínseca dos seus argumentos. Ademais, a obtenção do consenso pode ser dificultada por 
conta das diferenças de valores ideológicos, culturais e éticos entre os especialistas ou da existência de problemas de relacionamento interpessoal.

O método Delfos, por sua vez, utiliza questionários, que são respondidos individualmente por especialistas selecionados. As respostas obtidas são tratadas estatisticamente, através do cálculo de medidas de tendência central e/ou de dispersão, e os resultados são repassados aos participantes. Realiza-se, então, uma segunda rodada de questionários. Os respondentes podem manter ou modificar suas respostas anteriores. Procede-se a um segundo tratamento estatístico. Caso não se tenha alcançado um grau de consenso considerado satisfatório, novas rodadas de questionários e análises estatísticas podem ocorrer. Esse método apresenta a grande vantagem de dar tempo para que os especialistas reflitam tranqüilamente. Ademais, elimina a possibilidade de ocorrência de "argumentos de autoridade" e de problemas de relacionamento interpessoal. A sua grande desvantagem é não permitir a discussão e a interação entre os componentes, o que, eventualmente, pode empobrecer o resultado final. Outra dificuldade atém-se à duração do processo, que pode levar meses.

O grupo nominal foi originalmente proposto por Delbecq, Van de Ven e Gustafson (FAVARO; FERRIS, 1991; PINEAULT; DAVELUY, 1986). Trata-se, em essência, de um processo estruturado de troca de informações. A um grupo reunido, põe-se uma questão específica. Os especialistas, individualmente e por escrito, respondem à questão. Os cartões com as respostas são recolhidos e o coordenador as apresenta ao grupo, preservando o anonimato dos respondentes. Ocorre, então, uma breve discussão, apenas para esclarecimentos ou justificativas das respostas apresentadas. A seguir, os participantes listam, individualmente, as respostas que Ihes parecem mais adequadas. As diversas listas são consultadas, verificando-se as respostas mais votadas, que passam a constituir o consenso do grupo. 0 grupo nominal tem a vantagem de permitir que todos os participantes exprimam sua opinião, sem os constrangimentos dos grupos interativos. Além disso, permite que se produza um grande número de idéias. A sua limitação reside no fato de não permitir que mais de uma questão seja abordada a cada vez. Há também o risco de não se conseguir aprofundar as idéias.

Uma técnica de consenso diferente das anteriores foi proposta pela Agence nationale d'accréditation et d'évaluation en santé (ANAES, 1999), da França. Denominada, em francês, "conférence de consensus", optamos 
por nomeá-la como "júri simulado" para não confundi-la com a nossa proposição de conferência de consenso, apresentada adiante. A denominação "júri simulado" parece adequada, dado que a discussão é organizada sob a forma de um tribunal de justiça, com um juiz, advogados de acusação e defesa e jurados. Em julgamento, encontra-se uma questão científica polêmica. Os trabalhos se desenvolvem sob a coordenação do juiz. Os advogados de acusação apresentam os argumentos contra a validade da questão subjudice e os de defesa argumentam a favor. Ao final dos debates, os jurados deliberam, definindo o que vai ser aceito como consenso. É importante ressaltar que os advogados devem reunir, previamente, todas as informações científicas disponíveis sobre a questão. A maior vantagem dessa técnica é permitir que a discussão seja bastante aprofundada, com a apresentação das evidências disponíveis e de diferentes pontos de vista. Suas desvantagens estão relacionadas à logística sofisticada que sua realização exige e, principalmente, à possibilidade de incitar mais ao jogo de ganhar o debate do que à busca do consenso.

Enfim, todas as técnicas apresentam vantagens e desvantagens. A técnica ideal seria aquela que, ao mesmo tempo, estimulasse a busca de um consenso genuíno, permitisse uma ampla discussão entre os especialistas, preservasse 0 anonimato dos participantes e fosse de fácil realização. Provavelmente, nenhuma técnica poderá, na prática, reunir todas essas características. Contudo, é possível se pensar em alternativas, que permitam as aproximações possíveis.

\section{A CONFERÊNCIA DE CONSENSO}

Foi buscando conciliar a possibilidade de discussão aberta e a preservação do anonimato, dentro de uma logística viável, que se propôs uma técnica mista, aqui denominada de conferência de consenso, para a construção da imagem-objetivo da descentralização da saúde, dentro do já referido projeto de investigação sobre a implantação e os efeitos da descentralização da atenção à saúde na Bahia.

A conferência de consenso proposta foi organizada em três etapas: (1) o preenchimento individual de uma matriz por parte dos especialistas convidados, (2) a discussão aberta entre os participantes e (3) uma nova resposta individual às questões postas na matriz. A primeira e a terceira etapas 
foram realizadas de modo a assegurar o anonimato dos respondentes, enquanto a etapa intermediária permitiu o debate. A seguir, são detalhados os procedimentos adotados.

\section{DESENHO DA PROPOSTA INICIAL}

Com base em uma ampla revisão da literatura especializada e no modelo lógico que orientava a pesquisa avaliativa, foi elaborada uma matriz, contendo dimensões, subdimensões e critérios para avaliação da descentralização (Anexo 1).

Essa proposta inicial de imagem-objetivo da descentralização, antes de ser enviada aos especialistas convidados, foi submetida a uma apreciação preliminar, através de uma versão simplificada - uma única rodada da técnica do grupo nominal, em uma turma de 18 técnicos do Ministério da Saúde, alunos de um programa de mestrado profissionalizante em gestão da saúde. Verificou-se que o instrumento era de fácil compreensão e preenchimento. Além disso, e mais importante, todas as dimensões e subdimensões e todos os critérios constantes da matriz foram considerados pertinentes, em se tratando de uma avaliação da descentralização a partir de uma perspectiva nacional. Se analisado sob a perspectiva do nível local, o instrumento precisaria ser complementado.

Identificou-se ainda a necessidade de modificação do sistema de pontuação adotado. A pontuação, baseada inicialmente em percentagens, passou a se basear em um sistema de escala de zero a dez pontos. A modificação visou a tornar independentes as avaliações de cada critério, dando, assim, maior grau de liberdade de escolha aos respondentes.

\section{SELEÇÃO DO GRUPO DE ESPECIALISTAS}

O grupo de especialistas foi formado por gestores e técnicos da saúde, de um lado, e pesquisadores, de outro. A escolha dos gestores e técnicos foi feita a partir de consultas à Secretaria de Políticas de Saúde do Ministério da Saúde e à Associação Brasileira de Pós-Graduação em Saúde Coletiva. Foram convidados profissionais responsáveis pela formulação de políticas nacionais de saúde e pela gestão de sistemas municipais, onde existiam indícios de mudanças importantes nas práticas de saúde. Já os investiga- 
dores foram selecionados a partir de sua produção intelectual específica relacionada à temática dos modelos assistenciais. 0 grupo ficou composto de 15 pessoas, número adequado à realização de uma discussão aprofundada em um tempo viável. Vale ressaltar que os convites aos especialistas não tiveram caráter institucional. Ao contrário, foram estritamente pessoais.

\section{AS ETAPAS DA CONFERÊNCIA}

Na primeira etapa, os participantes da conferência receberam, por correio eletrônico, a proposta inicial de imagem-objetivo, organizada sob a forma de uma matriz. Os especialistas foram solicitados a manifestar individualmente a sua concordância ou discordância com a proposta. Cada participante ponderou, atribuindo de um a dez pontos, a importância relativa de cada uma das dimensões e subdimensões da descentralização e de cada um dos critérios de avaliação. Puderam também sugerir a exclusão ou a modificação de dimensões, subdimensões e critérios ou propor a inclusão de novos. Dos quinze formulários expedidos, dez retornaram preenchidos.

De posse das respostas, a equipe coordenadora da pesquisa consolidou as informações, segundo respondente, preservando o anonimato (anexo 2).

Na segunda etapa, realizou-se uma reunião presencial com o grupo de especialistas. Dessa reunião, participaram dez pessoas, sete das quais haviam respondido anteriormente ao instrumento enviado. Inicialmente, foi apresentada a tabela que consolidava as respostas. A seguir, foi aberto 0 debate, organizado em quatro tópicos relacionados às dimensões política, gerencial, assistencial e de efetividade das práticas. Durante um dia inteiro, os participantes tiveram a oportunidade de expressar suas opiniões e seus argumentos. Não se tentou definir, nesse momento, o consenso. 0 encontro serviu, exclusivamente, ao enriquecimento da discussão. Ao final da discussão, dispunha-se de uma nova matriz de imagem-objetivo, que incorporava as sugestões dos participantes. Como na discussão haviam se expressado, em vários pontos, visões divergentes, essa matriz trazia elementos discordantes e até contraditórios.

Na terceira e última etapa da conferência, os especialistas, que estiveram presentes à reunião, foram solicitados a se manifestar mais uma vez de 
maneira individual e anônima, preenchendo a nova matriz. Nesse momento, poderiam manter suas primeiras respostas ou modificá-las a partir da consideração dos resultados da rodada de preenchimento da primeira matriz e da discussão ocorrida durante o encontro.

Recolhidas as respostas contidas nesta segunda matriz, a equipe de pesquisa realizou um novo tratamento estatístico. Identificaram-se, então, os pontos de maior acordo e os de maior desacordo. Verificou-se que houve unanimidade apenas em relação às dimensões da descentralização. Ou seja, houve acordo irrestrito em se analisar a descentralização a partir das quatro dimensões: política, gerencial, assistencial e de efetividade das práticas sanitárias. Por outro lado, foram muitas as sugestões de inclusão de novas subdimensões e, especialmente, de novos critérios para se avaliar a descentralização. A seguir, foi apresentada a proposta de imagem-objetivo resultante da conferência.

\section{A PROPOSTA DE IMAGEM-OBJETIVO DA DESCENTRALIZAÇÃO}

Como mencionado, a matriz preenchida na última etapa da conferência continha todas as dimensões, subdimensões e todos os critérios oriundos tanto da proposta inicial, quanto das sugestões dos especialistas.

Desta matriz, cada um dos critérios de avaliação, de todas as dimensões e subdimensões da descentralização, recebeu uma nota, de zero a dez, representando a opinião do especialista sobre a sua importância. Uma nota dez significava que o critério era da mais alta importância para se avaliar a descentralização. Uma nota zero, por outro lado, significava que o critério deveria ser excluído. Caso todos os critérios de uma determinada subdimensão recebessem notas zero, a subdimensão seria excluída. De modo análogo, se todas as subdimensões de uma certa dimensão fossem excluídas, a dimensão também o seria.

Para todos os critérios, foram calculados a média aritmética e o desvio-padrão. Quanto maior a média, maior a importância do critério. 0 desvio-padrão, por sua vez, permitiu a estimativa do grau de consenso. Quanto menor o desvio-padrão, maior o grau de consenso, independentemente da importância conferida do critério.

A equipe coordenadora da conferência estabeleceu os seguintes pontos de corte: 
1. Todo critério com média igual ou superior a sete foi considerado como importante. Abaixo disso, seria pouco importante, não devendo fazer parte da imagem-objetivo da descentralização da saúde;

2. Todo critério com desvio-padrão inferior a três foi considerado consensual. Caso fosse também importante, o critério deveria ser incluído na imagem-objetivo;

3. Os critérios com média igual ou superior a sete e desvio-padrão igual ou superior a três, apesar de importantes, não deveriam compor a imagem-objetivo, pois não seriam consensuais.

A combinação dessas duas medidas permitiria, teoricamente, a identificação de quatro tipos de critérios: (1) critérios de avaliação da descentralização que são, consensualmente, importantes; (2) critérios, consensualmente, pouco importantes; (3) critérios importantes, em que prevaleceu a discordância entre os especialistas; e (4) critérios, pouco importantes, em que prevaleceu o dissenso. Na prática, entretanto, nenhum critério foi considerado, de modo consensual, pouco importante.

Os três quadros a seguir apresentam os resultados encontrados. 0 quadro 1 traz os critérios importantes e consensuais, que vêm a constituir a imagem-objetivo da descentralização. 0 quadro 2 mostra os critérios importantes, mas que não obtiveram consenso. E o quadro 3 exibe os critérios considerados pouco importantes, mas que também não alcançaram um grau suficiente de consenso.

Ao analisar estes quadros, o que primeiro chama a atenção é o grande número de critérios propostos: 93, no total. Esta profusão de critérios para se avaliar a descentralização é, por si só, indicativa da complexidade do problema e da diversidade de perspectivas passíveis de adoção.

Mais importante, no entanto, é o fato de ter sido possível se selecionar 53 critérios, a partir dos requisitos de importância (média igual ou superior a sete) e consenso (desvio-padrão menor que três), para compor uma imagem-objetivo da descentralização da saúde. Cria-se, dessa forma, a possibilidade que estudos e debates se concentrem em aspectos considerados relevantes por muitos especialistas. Tal concentração pode favorecer a produção de conhecimento sobre a reorganização setorial da saúde e a sua utilização na elaboração de políticas. 
Outro aspecto que merece referência atém-se ao aproveitamento dos critérios constantes da primeira proposta de imagem-objetivo, concebida pelo grupo de pesquisadores. Dos 30 critérios inicias, 24 foram mantidos entre os 53 da proposta final.

Durante a etapa presencial da conferência, o debate foi bastante rico e relativamente polêmico. Uma primeira discussão deu-se em torno da necessidade de se qualificar a descentralização a ser avaliada. Trata-se de definir a imagem-objetivo da descentralização ou do sistema local de saúde? A descentralização é um meio ou um fim? É possível se avaliar a descentralização, examinando-se apenas o desempenho do nível municipal?

Dessa discussão, concluiu-se que é preciso contemplar a questão da articulação regional e nacional, das relações entre as três esferas de governo, ainda que o recorte da avaliação seja o município, entendido como a ponta do sistema, onde se materializa o resultado da descentralização, expresso na mudança ou na manutenção do atual modelo assistencial.

Contudo, argumentou-se que não há motivos para se fixar, prioritariamente, no âmbito das relações intergovernamentais. A descentralização pode ser definida, mais genericamente, como a aproximação do poder de decisão ao local de execução das práticas de saúde. Nesse sentido, a imagem-objetivo em discussão não se refere aos objetivos finalísticos ou doutrinários do SUS, que já estão contemplados em lei. O desafio é construir um instrumento que, estabelecendo critérios de maneira consensual, permita a realização de avaliações mais objetivas do processo de reorganização do setor da saúde.

Foi importante ficar acordado que se trata de um instrumento de pesquisa. Os consensos políticos mais gerais se constroem em outros fóruns. Ademais, o instrumento em discussão é uma proposta de imagem-objetivo e não uma relação de indicadores concretos de avaliação. Entretanto, se não contém indicadores, o instrumento contempla critérios que servirão para balizar a avaliação da gestão descentralizada, utilizando-se de uma gradação que vai da descentralização incipiente a avançada, passando pela intermediária.

Sendo uma imagem-objetivo, é possível construir um único instrumento aplicável a diferentes tipos de municípios, independentemente, por exemplo, do tipo de gestão descentralizada, se plena do sistema ou da atenção básica, ou do porte do município. Poderia-se, inclusive, pensar em indicadores opcionais, que mediriam um mesmo critério, mas que seriam aplicados de acordo com as características dos municípios pesquisados. 
Notou-se ainda que existem, freqüentemente, zonas de sobreposição entre os critérios e mesmo entre as subdimensões. Ademais, os critérios de uma mesma subdimensão não constituem, necessariamente, uma mesma categoria taxonômica. Contudo, não pareceu aos especialistas que isso comprometesse a qualidade do instrumento em discussão. A inexistência de hierarquização entre os critérios, garantida pela adoção de um sistema de pontuação em escala de zero a dez, tornou possível a existência de zonas de sobreposição ou de categorias diferentes, sem que se gerassem incoerências ou contradições.

\section{OS PONTOS DE CONSENSO E DE DISSENSO}

\section{CONSENSO E DISSENSO NA DIMENSÃO POLÍTICA}

Analisando os resultados da discussão de cada dimensão, especificamente, observa-se que, na dimensão política, quanto às subdimensões "competências e relações entre os três níveis de governo", "projeto de governo" e "capacidade de governo", todos os critérios são importantes e consensuais.

A subdimensão "competências e relações entre os três níveis de governo" surgiu da compreensão de que, para se avaliar um município, deve-se considerar sua inserção no sistema de saúde regional, estadual e, mesmo, nacional. Uma cidade que organiza, satisfatoriamente, seu sistema municipal, mas que "fecha as fronteiras" aos cidadãos de outros municípios não tem o mesmo nível de desempenho de outras cidades que estão integradas em um sistema regional, estadual e nacional.

A questão dos serviços de alta complexidade traz exemplos claros da importância da integração entre as três esferas de governo. Se não há sentido em imaginar que todos os serviços devam estar disponíveis em todas as localidades, é correto pensar que os cidadãos de todos os municípios devam ter acesso a toda a gama de ações e serviços de saúde. Nesse sentido, importa menos saber que esfera de governo é diretamente responsável pela oferta do serviço e mais se a integralidade da atenção e o acesso aos serviços estão garantidos.

Dentro da subdimensão "projeto de governo", houve um debate sobre as diferenças entre programa eleitoral, plano de governo e compromisso político. A inclusão da saúde como prioridade no programa eleitoral não parece 
ser um critério importante para se avaliar o projeto de governo. Mais relevante do que o enunciado em programas de campanha e mesmo em planos de governo é o efetivamente executado. Por isso, deve-se avaliar o projeto de governo na maior concretude possível: nos orçamentos e nas ações do governo. De todo modo, o essencial é o compromisso político com a saúde, que deve estar claro a ponto de ser percebido pela maioria da população.

Nessa mesma subdimensão, debateu-se a questão das iniciativas intersetoriais, consideradas, por todos, como um critério importante para se avaliar a descentralização. Salientou-se, todavia, a necessidade de se especificar o tipo de iniciativa intersetorial que se pretende considerar. É importante que as iniciativas analisadas estejam relacionadas de modo inequívoco com a saúde. Além disso, é preciso ter em conta o financiamento das ações intersetoriais. Se representarem uma redução do gasto setorial, com a inclusão, por exemplo, do saneamento no orçamento da saúde, tais ações falam contra a gestão descentralizada.

Discutiu-se ainda a questão do financiamento em geral. Houve polêmica: alguns participantes consideram o cumprimento da Emenda Constitucional no 29 um critério fundamental para a avaliação da gestão descentralizada. Para outros, a proporção de gastos com a saúde no orçamento não é um bom critério, pois é muito influenciado pelo porte dos municípios. Em grandes municípios, uma proporção menor pode representar um investimento significativo, enquanto em cidades menores, mesmo uma proporção elevada pode não representar muito. Ao final, como já visto, o critério do financiamento segundo a EC-29 foi mantido.

Embora não tenha sido proposta, formalmente, sua inclusão entre os critérios, foi sugerido, durante o debate, que a eqüidade na repartição dos recursos fosse contemplada no item relativo ao financiamento.

Vale registrar que o financiamento está presente em dois momentos no instrumento proposto: como critério da subdimensão "projeto de governo" e como elemento para medir a prioridade dada à saúde.

Em relação à subdimensão "capacidade de governo", também ocorreu um rico debate. Os especialistas consideram que a capacidade de governar é fundamental, em particular, por seu caráter cultural e político de conquista de adesões ao projeto de governo. Por isso mesmo, o cargo de gestor da saúde - secretário municipal, secretário estadual, ministro - é eminentemente político. De modo coerente com essa concepção, os participantes da 
conferência enfatizaram os critérios relativos à capacidade de construção de um projeto comum e de articulação política. Foi sugerida ainda a inclusão de um critério concernente à capacidade dialógica e de síntese de interesses.

Por outro lado, houve questionamentos sobre alguns dos critérios de avaliação dessa subdimensão. Um dos critérios problematizados foi o da política de recursos humanos. A questão é: serve ao propósito de avaliação da capacidade de governo saber se a política de pessoal é adequada? Não se trata de um critério mais apropriado à dimensão gerencial?

Outro critério problematizado foi a capacidade de liderança do gestor. Alguns participantes criticaram não o critério em si, mas o fato de estar colocado na subdimensão da capacidade de governo e não na da governabilidade. Argumentou-se que, se a capacidade de liderança é que vai permitir ao gestor ampliar sua liberdade de ação na arena política, ela é um elemento da governabilidade do sistema.

Na dimensão política, a subdimensão "governabilidade" foi a mais discutida. Ao contrário das demais, nessa subdimensão predominou o dissenso. Dos 14 critérios propostos para se avaliar a governabilidade, apenas três foram consensuais. Além disso, foi grande o número de critérios pouco importantes: exatamente sete, a metade do total.

Um critério muito debatido, dentro dessa subdimensão, foi a autonomia financeira da Secretaria Municipal de Saúde. Alguns participantes salientaram a diferença de significado da autonomia entre municípios de grande e de pequeno porte.

Chamou-se a atenção para a possível confusão entre a autonomia em si e certos instrumentos gerenciais, como a Comissão Permanente de Licitações (CPL). Uma secretaria pode ter autonomia, sem ter uma CPL. Para alguns membros da conferência, incluir entre os critérios a existência da CPL é um equívoco, pois a imagem-objetivo da descentralização deve se concentrar em macro-categorias, descartando aspectos demasiadamente específicos. Para outros participantes, ao contrário, é fundamental manter a referência à $\mathrm{CPL}$, dado que dificuldades no processo de compras podem ser politicamente comprometedoras.

Vale registrar ainda que se sugeriu a transferência do critério da CPL para a subdimensão "capacidade de governo". A sugestão, no entanto, não foi formalizada por nenhum participante, com a sua inclusão na matriz. 
Correlato à autonomia financeira, o critério da existência de um fundo especial de despesa foi sugerido. A maioria dos participantes, no entanto, o considerou pouco importante. Na verdade, foi o menos importante de todos os critérios propostos para avaliar a governabilidade.

Dessa discussão, resultou que a autonomia financeira da SMS, com Comissão de Licitação, foi considerada importante e obteve um grau elevado de consenso, integrando a imagem-objetivo da descentralização.

A capacidade de iniciativa política do gestor municipal também mereceu discussão. Um participante da conferência chegou a questionar o significado preciso da expressão "iniciativa política". Entretanto, um consenso se estabeleceu rapidamente sobre a importância da articulação não somente com os gestores federal e estadual, mas também com outros gestores municipais. Lembrou-se que a integralidade da atenção à saúde não pode ser garantida sem essa articulação. Esse critério foi o mais importante e o mais consensual, dentro da subdimensão da governabilidade.

A discussão sobre a capacidade de iniciativa política levou ao surgimento de critérios alternativos ao proposto originalmente, com diferenças relativas ao aspecto enfatizado. Assim, um participante sugeriu o critério da capacidade do gestor de argumentar e convencer parceiros estaduais e federais. Outro propôs algo como a existência de relações políticas civilizadas entre o prefeito e o governador ou entre as esferas políticas. Um terceiro sugeriu que se avaliasse a capacidade de desconcentrar poder das três esferas de governo. Todos esses três critérios foram considerados importantes por muitos especialistas, mas não obtiveram um grau suficiente de consenso para integrar a imagem-objetivo.

A capacidade do gestor de produzir fatos técnicos, políticos e sociais que ampliem seus graus de liberdade - um critério surgido durante o debate - foi o terceiro e último critério importante e consensual da subdimensão da governabilidade.

O critério relativo à base de apoio no parlamento suscitou polêmica. Alguns vêem um perigo em se estar avaliando positivamente um apoio parlamentar, conquistado a partir de "conchavos" e práticas clientelistas. Outros acreditam que, por ser essencial a sustentação parlamentar, a ocorrência de práticas condenáveis não justifica a exclusão do critério.

Todos que expressaram opinião a respeito concordam com a necessidade de se ponderar separadamente o apoio no parlamento e o apoio na 
sociedade civil. O parlamento e o movimento social têm dinâmicas próprias. Além disso, deve-se lembrar que a relação do gestor da saúde com o parlamento e com a sociedade civil envolve a pressão de "lobbies" e grupos de interesse particulares.

Sugeriu-se ainda a inclusão de um critério relativo ao apoio na comunidade, por se considerar que, no nível local, há uma proximidade dos serviços com a população, que torna a dimensão comunitária significativa para a avaliação e distinta do apoio na sociedade civil organizada.

Um outro ponto levantado referiu-se à importância e à dificuldade de se levar em conta os interesses da parcela desorganizada da população.

Ao final, contudo, não houve acordo suficiente para incluir qualquer um dos critérios relativos ao apoio parlamentar, social ou comunitário - de forma separada ou conjunta - na imagem-objetivo consensual.

Ainda na subdimensão "governabilidade", foi proposta a inclusão de um critério referente à articulação do gestor com a mídia, dada a importância dos meios de comunicação para a disputa de projetos políticos. No entanto, esse critério não obteve a pontuação necessária, em termos de importância, para ser incluído na imagem-objetivo.

Em suma, na dimensão política, o consenso sobre a imagem-objetivo da descentralização da atenção à saúde se construiu com base em quatro subdimensões e treze critérios. Houve um amplo consenso sobre a importância da coordenação e complementaridade entre as ações das três esferas de governo. A subdimensão do projeto de governo, com seus três critérios saúde como prioridade de governo, existência de iniciativas intersetoriais e financiamento segundo a EC-29 - também foi considerada, consensualmente, importante. Os participantes da conferência se puseram de acordo ainda sobre a importância da capacidade de governo para se avaliar a descentralização, mesmo com os questionamentos sobre os critérios relativos à capacidade de liderança do gestor e à política de recursos humanos. A governabilidade, do mesmo modo, foi mantida, por consenso, como uma subdimensão fundamental da imagem-objetivo da descentralização. Quanto aos critérios para se avaliar a governabilidade, no entanto, prevaleceu o dissenso. Como vimos, de 14 critérios sugeridos, apenas três foram considerados, consensualmente, importantes: a autonomia financeira da SMS, a capacidade de iniciativa do gestor municipal junto a outros gestores e a capacidade do gestor de produzir fatos que ampliem seu grau de liberdade. 


\section{CONSENSO E DISSENSO NA DIMENSÃO GERENCIAL}

Na dimensão gerencial, os critérios podem ser classificados em três blocos.

O primeiro bloco, formado pelos critérios que compõem as subdimensões "planejamento e avaliação", "capacidade regulatória da secretaria municipal de saúde", "relação público-privado", "relações da SMS com os profissionais de saúde", é bastante consensual. Além disso, todos os critérios são importantes, com uma única exceção: as organizações sociais.

Ao contrário, o segundo bloco apresenta, essencialmente, pontos divergentes. Este bloco está composto por duas subdimensões. A "estrutura organizacional da secretaria municipal de saúde" só tem um critério, que não é consensual. Como não possui nenhum critério consensual, esta subdimensão não veio a compor a imagem-objetivo da descentralização. 0 "controle social" também é polêmico. Dos onze critérios propostos, apenas três são consensuais e apenas cinco são importantes.

O terceiro bloco reúne duas subdimensões, cujos critérios dividem-se em consensuais e não-consensuais. A "dinâmica gerencial", por exemplo, tem dois critérios consensuais e dois divergentes, sendo que três são importantes. A "organização de serviços", por sua vez, é uma subdimensão de critérios relativamente polêmicos: dos treze, oito são consensuais e cinco divergentes. Quanto ao grau de importância, nove critérios obtiveram médias acima de sete, sendo considerados importantes.

Durante a etapa presencial da conferência de consenso, a dimensão gerencial da descentralização foi bem discutida. Um bom indicador da diversidade de pontos de vista ou de abordagens possíveis foi o número de novos critérios sugeridos: foram 32, que se somaram aos nove critérios iniciais.

Na discussão, chamou-se a atenção para o papel de instância duplamente mediadora da dimensão gerencial. Em um sentido, a gestão faz a mediação entre as dimensões política e assistencial. Em outras palavras, é uma tarefa própria à gestão traduzir as diretrizes políticas em serviços de saúde prestados à população. Em outro sentido, a dimensão gerencial é mediadora temporal entre diretrizes políticas que se sucedem, por exemplo, com as mudanças de governos. Vale acrescentar que a função mediadora não elimina um certo grau de autonomia próprio à dimensão gerencial. Basta lembrar os obstáculos que uma máquina burocrática pode opor à implementação de qualquer política. 
Essa posição intermediária foi talvez responsável por algumas polêmicas durante o debate. Houve muitos questionamentos sobre a melhor localização das subdimensões e dos critérios. O controle social, por exemplo, pertence à dimensão gerencial ou à política? A cobertura e a acessibilidade são critérios da dimensão gerencial ou da assistencial? Em que pesem os questionamentos, não houve proposições formalizadas de transferência de nenhuma subdimensão ou de nenhum critério da dimensão gerencial para uma outra.

Criticou-se também o que seria uma excessiva generalidade dos critérios propostos ou um grau insuficiente de precisão na identificação das competências gerenciais do gestor municipal da saúde. Talvez, por isso, tantos novos critérios tenham sido sugeridos.

Um bom exemplo dessa busca por critérios mais específicos ou precisos se encontra na subdimensão "planejamento e avaliação", que recebeu sugestões como "planejamento por problemas" ou "uso rotineiro da avaliação".

A discussão dessa subdimensão trouxe um ponto interessante, relativo à institucionalização das práticas de planejamento e de avaliação. Alguns especialistas destacaram ser mais importante a incorporação dessas práticas na gestão cotidiana dos serviços do que o seu caráter inovador. Insistiram muito também na necessidade de se valorizar de modo igual o planejamento e a avaliação.

A relação público-privado suscitou bastante discussão. Vários conferencistas manifestaram preferência por uma formulação mais genérica, que abordasse a capacidade regulatória da secretaria municipal da saúde, e não apenas a relação com o setor privado. Considerou-se a idéia de regulação muito interessante, por envolver a noção de articulação permanente entre as atividades de planejamento, controle, supervisão, avaliação e auditoria.

A regulação não se limita ao controle do setor privado conveniado. Na visão dos especialistas, deve incluir o setor privado não-conveniado, como os planos de saúde, e o próprio setor público. Nesse aspecto, é importante analisar a capacidade de contratualização do gestor da saúde: não só poder fazer contratos, mas saber fixar metas e acompanhar o desempenho do serviço contratado.

Uma polêmica se estabeleceu sobre a capacidade do Estado de exercer a regulação. Alguns avaliam que o Estado tem que possuir certa capacidade de oferta de serviços próprios, sob pena de ficar refém do setor 
privado e não conseguir cumprir a função de regulador. Para outros, o Estado pode ser regulador, sem ser produtor direto de serviços. Delegar a produção ao setor privado ou, especialmente, a entes públicos não-estatais, como as organizações sociais, pode favorecer o exercício da atividade regulatória. O essencial é que o Estado garanta a eficácia social do sistema de saúde.

Ainda na subdimensão da relação público-privado, chamou-se a atenção para o fato de que os critérios não podem se limitar à questão da gestão pública dos serviços de alta e média complexidade, único critério proposto inicialmente. Aliás, esse problema não se refere, exclusiva ou preferencialmente, à relação público-privado. Ao interior do próprio setor público, a questão se põe de como equilibrar a relação entre a alta e média complexidade e a atenção básica. As decisões acerca do financiamento são extremamente complexas: a ampliação - necessária, recomendável - da atenção básica gera, por sua vez, maior demanda por procedimentos de alta e média complexidade. Em uma situação de escassez, qual a melhor distribuição de recursos? Qual o ponto de equilíbrio?

Uma ampla discussão se travou sobre a organização administrativa da secretaria municipal de saúde, dando origem a duas novas subdimensões e cinco novos critérios. A descentralização da gestão da saúde exige, muitas vezes, que se criem, nos municípios, novas estruturas organizacionais. Certos participantes crêem que um bom critério para avaliar essa subdimensão seria a verificação do grau com que essas estruturas facilitam a gestão participativa. Outros acreditam que, para se avaliar a gestão, não é importante verificar se há participação dos servidores. Por outro lado, todos estão de acordo sobre a importância de se buscar o envolvimento dos profissionais de saúde nas questões gerenciais.

A segunda nova subdimensão, que foi chamada de dinâmica da gerência, também envolveu o tema da participação dos trabalhadores, destacando-se, todavia, o papel do gerente como coordenador de grupo e a existência de redes de negociação em torno de um projeto comum.

Um aspecto particular, mas muito valorizado, foi a questão de um componente ético na dimensão gerencial. Argumentou-se que as escolhas no cotidiano da gestão são pautadas por valores que precisam ser discutidos e socializados. Sugeriu-se ainda incluir um critério específico sobre transparência da gestão. Como visto anteriormente, algumas dessas sugestões foram consensuais e passaram a compor a imagem-objetivo da descentralização, mas outras, não. 
A subdimensão "organização dos serviços" também foi objeto de muito debate. Alguns conferencistas estimaram que essa subdimensão estaria mais bem posicionada na dimensão assistencial. Outros criticaram o que acharam um excessivo fracionamento dos critérios. Outros ainda sentiram falta de critérios específicos quanto às políticas de insumos, como medicamentos e vacinas, ou quanto à qualidade e continuidade do cuidado, ou ainda quanto às vigilâncias epidemiológica e sanitária. Lembrou-se igualmente a necessidade de se contemplar a capacitação de pessoal. Cogitou-se também incluir um critério particular sobre o Programa de Saúde da Família, mas a ampla maioria foi contrária, argumentando que o ponto fundamental - as concepções que embasam o Programa - já estava contemplado.

O tema da acessibilidade recebeu uma atenção especial. Salientou-se a importância desse critério, tendo em vista a existência de dinâmicas de exclusão, de barreiras criadas pelo próprio sistema de saúde. Nesse sentido, importa verificar o modo como se dá o ingresso do usuário no serviço, para identificar possíveis obstáculos.

Relacionado ao tema da acessibilidade, discutiu-se muito a adscrição de clientela. Se, por um lado, é essencial para o planejamento na lógica da demanda, por outro, pode representar uma barreira, se feita burocraticamente, sem levar em conta o deslocamento real das pessoas no território. Uma adscrição restrita às unidades básicas de saúde será, certamente, problemática. No entanto, se as unidades básicas são, efetivamente, portas de entrada de um sistema integrado, a adscrição será, provavelmente, facilitadora do acesso.

Acrescentou-se que, sem a adscrição, os sistemas de referência e contra-referência limitam-se a ser mecanismos meramente formais de encaminhamento de pacientes e não instrumentos da garantia do acesso aos serviços que cada caso requerer.

A última subdimensão da dimensão gerencial trata do controle social. Muitos conferencistas opinaram que o controle social deveria integrar a dimensão política, e não a gerencial, da imagem-objetivo da descentralização. Ademais, muitos acharam insuficiente apenas um critério, como proposto inicialmente, para se avaliar o controle social. Além de verificar se Conselho Municipal de Saúde (CMS) é atuante, deveria se analisar a lógica do seu funcionamento: que funções exerce, que interesses representa. É preciso averiguar se o CMS tem capacidade de decisão política, define as priorida- 
des de saúde da administração municipal, desenha estratégias, acompanha os trabalhos da Secretaria de Saúde. Com isso, o critério de atuante se tornaria mais concreto.

Diversos outros critérios foram sugeridos, com o objetivo de qualificar a avaliação do controle social: existência de conselhos locais de saúde, transformação dos centros de saúde em unidades gestoras e orçamentárias, existência de corregedoria e de auditoria interna e publicidade dos resultados das ações da Secretaria Municipal de Saúde. Ao final, contudo, apenas três critérios foram consensuais: CMS atuante, prioridades definidas pelo CMS e existência de auditoria interna.

Em suma, na dimensão gerencial, o consenso sobre a imagem-objetivo da descentralização se estabeleceu em sete subdimensões e 23 critérios. Houve grande acordo sobre a importância das ações de planejamento e avaliação, da capacidade regulatória da Secretaria Municipal de Saúde (SMS), incluindo a relação público-privado, da relação da SMS com seus profissionais e da ética na gestão. Ainda que envoltas em alguma polêmica, as subdimensões da organização dos serviços e do controle social obtiveram, ao final, graus elevados de importância e consenso. Contribuiu para isso, provavelmente, o surgimento de vários novos critérios, durante a etapa presencial da conferência. Por fim, vale ressaltar que um único item não foi considerado importante pela maioria dos especialistas: a existência de organizações sociais.

\section{CONSENSO E DISSENSO NAS DIMENSÕES ASSISTENCIAL E DA EFETIVIDADE DAS PRÁTICAS}

A dimensão assistencial e a dimensão da efetividade das práticas foram discutidas conjuntamente, durante a etapa presencial da conferência, apesar de estarem separadas na proposta inicial de imagem-objetivo da descentralização. Na verdade, a opção pela discussão conjunta se justifica, considerando-se que, do ponto de vista teórico, as duas dimensões podem ser integradas em uma única - práticas assistenciais de saúde - com duas subdimensões: a organização e a efetividade.

Um amplo consenso se estabeleceu sobre a centralidade dessas dimensões para se avaliar a descentralização da atenção à saúde. Nelas, é que se pode averiguar se o sistema está funcionando ou não. 
É fácil reconhecer que o Sistema Único de Saúde, desde sua criação, fez progressos nos quesitos de participação social e de descentralização da gestão, mas na questão do cuidado, da assistência real, do conteúdo mesmo das práticas de saúde, os avanços não são evidentes.

Quando se discutem os modelos assistenciais, fala-se, com freqüência, de vínculo e adscrição, acesso e acolhimento, cuidado e atenção, mas quais os significados concretos ou operacionais desses conceitos? Os especialistas concordam que a melhoria da assistência à saúde e da situação de saúde não será resultado de nenhuma estratégia política ou gerencial isolada, mas dependerá de um conjunto bem articulado de estratégias, que desencadeie uma nova dinâmica assistencial. No limite, é preciso retomar o conceito de seguridade social, definindo, simultaneamente, o lugar próprio e as interfaces da prestação de serviços de saúde dentro de uma rede de proteção social.

Entretanto, nem tudo foi consenso. Alguns conferencistas questionaram o critério referente à ênfase na promoção da saúde. Para eles, a integralidade pressupõe um equilíbrio entre as ações de promoção, prevenção, cura e reabilitação, e não a ênfase em algum desses tipos de ação. Além disso, recomendou-se cuidado ao se avaliar a promoção da saúde, pois envolve requisitos que estão fora do setor saúde.

Afirmou-se, sem divergências, que a integralidade exige o uso racional dos serviços, pois se há insuficiências na oferta, há também excessos de utilização. O risco de medicalização é, nesse sentido, claro. A utilização de protocolos, em particular, é bem vista como estratégia de racionalização do uso dos serviços e de garantia da qualidade da atenção.

Destacou-se também que a integralidade tem distintas dimensões, separáveis apenas para fins de análise teórica. Uma dimensão remete aos níveis de atenção (promoção, proteção, cura, reabilitação), como mencionado acima. Outra dimensão, que pode ser caracterizada como tecnológica, torna-se evidente quando se fala em serviços de baixa, média ou alta complexidade. Finalmente, pode se pensar em uma dimensão da integralidade da atenção que remete ao respeito à integridade biopsicossocial da pessoa atendida.

A proposição de duas subdimensões - integralidade das ações e abordagem integral - dentro da dimensão assistencial, buscou, exatamente, dar conta das distintas acepções da noção de integralidade. 
$\mathrm{Na}$ acepção da abordagem integral, enfatizou-se a importância de se buscar avaliar a existência de vínculos efetivos entre os profissionais de saúde e os usuários e de compromissos entre os serviços e a população. A criação desses vínculos e o estabelecimento desses compromissos exigem, claramente, uma reorganização do processo de trabalho em saúde.

Comentou-se que a equipe multiprofissional é, provavelmente, o meio mais adequado para se alcançar a integralidade. Ressaltou-se, todavia, a necessidade de um funcionamento muito bem articulado da equipe, para evitar o risco da fragmentação do cuidado entre um aglomerado de profissionais. A equipe precisaria compartilhar uma concepção integral da pessoa humana e, por isso, talvez valesse a pena incluir um critério que permitisse avaliar a existência dessa concepção. O desenvolvimento de uma concepção holística pode ser favorecido se as equipes podem definir o seu "projeto assistencial", contando com o apoio de gerências descentralizadas.

A questão da visita domiciliar também foi lembrada. Um participante salientou o peso simbólico que tem, para as pessoas, a ida de um profissional de saúde ao seu domicílio. Significa o reconhecimento do usuário como ser humano. É, portanto, um critério importante para se avaliar a abordagem integral.

Houve certa polêmica quanto aos critérios relativos a áreas específicas da assistência. Alguns membros da conferência posicionaram-se contra a referência particular às ações de saúde bucal ou de saúde mental. Outros consideraram importante haver critérios próprios a essas áreas, dado que constituem práticas diferenciadas que permitem qualificar o sistema de serviços de saúde de um modo que outros critérios não conseguem. Nessa linha, chegou-se a sugerir a inclusão de um critério relativo à área de serviço social.

Outra área específica mencionada foi a assistência farmacêutica. Salientou-se que avaliar a disponibilidade de medicamentos e a promoção do uso racional é insuficiente. Deveria se buscar outros critérios que permitissem se avaliar a organização da assistência farmacêutica como um todo.

Sobre a dimensão da efetividade das práticas, durante a discussão, levantaram-se algumas preocupações com a questão da redução das taxas de mortalidade infantil e materna. Registrou-se que uma coisa é reduzir as taxas de patamares elevados para níveis médios e outra é reduzir taxas dos níveis intermediários para níveis baixos. Nesse sentido, o critério deveria 
ser matizado e não ter o mesmo peso, independentemente das taxas de mortalidade dos municípios analisados.

Destacou-se também a importância de se avaliar com mais profundidade a percepção da população. Procurar verificar não somente as pesquisas sobre o grau de satisfação, mas também as formas de uso e a capacidade de resposta da unidade, ou seja, se a população se sente obrigada a retornar ou a peregrinar por várias unidades até ter seu problema resolvido.

Criticou-se, por fim, a ausência de critérios específicos para se avaliar a eqüidade do sistema de saúde, ou, mais pragmaticamente, a eqüidade na utilização dos serviços de saúde. Talvez a alternativa seja verificar essa dimensão através do acesso e da cobertura. Buscar avaliar se há acesso e cobertura iguais para igual necessidade, independentemente de classe social, nível de renda, nível educacional, gênero ou etnia.

Em suma, na dimensão assistencial, o consenso sobre a imagemobjetivo da descentralização foi desenvolvido com base em duas subdimensões e dez critérios. A subdimensão "integralidade das ações" possui critérios consensuais referidos à ênfase nas ações de promoção, à integração das ações promocionais, preventivas, recuperadoras e reabilitadoras e à disponibilidade de medicamentos. A subdimensão "abordagem integral", por sua vez, tem sete critérios consensuais e importantes, que incluem, entre outros, o acolhimento e a atenção domiciliar. Vale ressaltar que apenas dois dos 18 critérios da dimensão assistencial, debatidos durante a conferência, foram considerados pouco importantes.

$\mathrm{Na}$ dimensão de efetividade das práticas, estabeleceu-se o consenso em torno de três subdimensões e nove critérios. A subdimensão "impacto sobre a saúde" ficou com dois critérios amplamente consensuais, relativos à mortalidade infantil e materna. As subdimensões relativas à percepção dos usuários e dos servidores também alcançaram níveis elevados de importância e consenso, com critérios que contemplam tanto as pesquisas de opinião, quanto a capacidade de resposta da equipe local.

\section{CONSIDERAC̣ÕES FINAIS}

A imagem-objetivo da descentralização da saúde, resultante de uma conferência de consenso, envolvendo dez especialistas, comporta 53 critérios de avaliação, agrupados em 16 subdimensões, que, por sua vez, se agrupam em quatro dimensões. 
A dimensão da efetividade das práticas e a dimensão assistencial foram aquelas consideradas como de maior importância, tendo obtido graus mais elevados de consenso. A dimensão gerencial obteve também níveis elevados de importância e de consenso, embora menores que os das dimensões assistencial e de efetividade das práticas. Por último, a dimensão política foi a que conteve, relativamente, mais divergências. Contudo, os pontos consensuais superaram em muito os pontos de dissenso.

Dentre as subdimensões, a capacidade regulatória da SMS e a competência e relações entre os três níveis de governo foram as de maior importância e as de maior grau de consenso. No pólo contrário, a governabilidade e as estruturas organizacionais foram as subdimensões de maior dissenso e de menor importância relativa.

Dentre os critérios, isoladamente, a acessibilidade destacou-se como o mais importante e o mais consensual. O critério "secretaria com capacidade regulatória" veio em segundo lugar. No lado oposto, os critérios de existência de um fundo especial de despesa e de existência de organizações sociais foram os de menor importância e de maior divergência.

É possível agora se retomar a questão posta na introdução: onde se quer chegar com a descentralização da saúde?

Segundo o consenso dos especialistas, a descentralização deve ter impacto sobre o estado de saúde, em particular, reduzindo a mortalidade infantil e a mortalidade materna. Deve buscar a satisfação dos usuários, sobretudo aumentando a resolutividade dos serviços de saúde. Deve buscar a satisfação dos servidores, inclusive através de uma gestão participativa.

As pessoas devem ser bem acolhidas, por equipes multiprofissionais, que definem seus projetos assistenciais de modo a reorganizar o processo de trabalho, com vistas a oferecer uma abordagem integral à pessoa atendida. As ações de saúde devem ser bem integradas, das promocionais até as reabilitadoras. A garantia de acesso ao conjunto dos serviços, incluindo a assistência farmacêutica, é essencial.

A Secretaria Municipal de Saúde deve usar, rotineiramente, as ferramentas do planejamento e da avaliação e precisa ter alta capacidade regulatória, tanto sobre o setor privado, quanto sobre o setor público. A oferta de serviços deve se adequar ao perfil epidemiológico da população e estar organizada em rede hierarquizada. As ações de vigilância epidemiológica e sanitária devem ser integradas. As unidades de saúde devem ser acreditadas. 
A gerência precisa explicitar os valores éticos que guiam suas escolhas. 0 Conselho Municipal de Saúde precisa ser atuante, definindo prioridades e acompanhando as ações da auditoria interna.

Os três níveis de governo - municipal, estadual e federal - precisam trabalhar de modo coordenado e complementar. A saúde deve ser amplamente reconhecida como prioridade de governo, as iniciativas setoriais têm que estar presentes e o financiamento deve respeitar a Emenda Constitucional $n^{\circ} 29$. 0 gestor precisa ter capacidade de liderar e de formar um projeto comum, além de contar com técnicos qualificados. Finalmente, o gestor deve ser capaz de produzir fatos que ampliem seus graus de liberdade de ação.

Se tudo isso for alcançado, pode-se concluir que a descentralização cumpriu plenamente sua missão de estratégia de reorganização da atenção à saúde.

Evidentemente, a imagem-objetivo construída através da conferência não é, nem poderia ser, definitiva. Representa apenas um certo grau de consenso provisório. Contudo, constitui-se em um instrumento útil para a realização de investigações e para a discussão de políticas de saúde.

Os pesquisadores podem encontrar nela um apoio para a realização de suas investigações avaliativas. Poderão utilizar diferentes combinações das dimensões e dos critérios disponíveis, a depender do seu referencial teórico, tendo consciência do grau de consenso e relevância a eles atribuídos por especialistas na temática. Além disso, caso seja utilizada em várias pesquisas, a imagem-objetivo consensuada poderá facilitar a comparação de resultados e ampliar o grau de conhecimento acerca dos processos de reorganização setorial.

Os gestores e formuladores de políticas de saúde, por sua vez, passam a contar com mais um instrumento que Ihes diz em que aspectos concentrar sua atenção. Concretamente, a imagem-objetivo elaborada indica que assegurar a coordenação e complementaridade entre as três esferas de governo e ampliar a capacidade regulatória das Secretarias Municipais de Saúde são dois grandes desafios a enfrentar. 


\section{NOTAS}

${ }^{1}$ Trabalho realizado com o apoio financeiro do Ministério da Saúde. A conferência de consenso de que trata o presente artigo foi convocada pela Secretaria de Política do Ministério da Saúde, pela Associação Brasileira de Pós-Graduação em Saúde Coletiva (ABRASCO) e pelo ISC/UFBA.

${ }^{2}$ Por imagem-objetivo, entende-se não um simples conjunto ou uma soma de objetivos, mas um modelo, inserido em um tempo futuro, cuja construção eliminou os problemas de coerência entre os distintos objetivos, harmonizando-os e ordenando-os (ver BOISIER, 1976, apud COHEN e FRANCO, 1994. p. 86).

\section{REFERÊNCIAS}

ALMEIDA, C. Os atalhos da mudança da saúde no Brasil. Rio de Janeiro: OPAS, 1988. $134 \mathrm{p}$.

ANAES - AGENCE NATIONALE D'ACCRÉDITATION ET D'ÉVALUATION EN SANTÉ. Les conférences de consensus. Base méthodologique pour leur réalisation en France. Paris: ANAES, 1999.

BROWN, A.D.; GOLDACRE, M.J.; HICKS, N.; ROURKE, J.T.; MCMURTRY, R.Y.; BROWN, J.D.; ANDERSON, G.M. Hospitalization for ambulatory care-sensitive conditions: a method for comparative access and quality studies using routinely collected statistics. Canadian Journal of Public Health v. 92, n. 2 p. 155-159. 2001.

COHEN, E.; FRANCO, R. Avaliação de projetos sociais. Petrópolis: Vozes, 1994.

DONABEDIAN, A. Explorations in quality assessment and monitoring. v. II. Ann Arbor, Michigan: Health Administration Press, 1988.

FAVARO, P.; FERRIS, L. Program evaluation with limited fiscal and human resources, 1991.

FLEURY-TEIXEIRA, S. Descentralização dos serviços de saúde: dimensões analíticas. In: IX CONFERÊNCIA NACIONAL DE SAÚDE. Cadernos da nona: descentralizando e democratizando o conhecimento. Brasília: Grupo Técnico da Comissão Organizadora, 1992. 27-37 p.

HEIMANN, L. e outros. A descentralização do sistema de Saúde no Brasil: uma proposta de investigação sobre o impacto de políticas. São Paulo: Instituto de Saúde. Secretaria de Saúde do Estado de São Paulo, 1998.

MENDES, E.V. A descentralização como processo social. In: KALIL, M.E. (org.) Saúde mental e cidadania no contexto dos sistemas locais de saúde. Anais. São Paulo: Hucitec, 1992. p. 65-74.

MULLER NETO, J. Política de saúde no Brasil: a descentralização e seus atores. In: IX CONFERÊNCIA NACIONAL DE SAÚDE. Cadernos da nona: descentralizando e democratizando o conhecimento. Brasília: Grupo técnico da Comissão Organizadora, 1992. p. 43-59. 
PINEAULT, R.; DAVELUY, C. La planification de la santé. Concepts, méthodes, stratégies. Montreal: Agende d'ARC Inc., 1986.

VIEIRA-DA-SILVA, L.; HARTZ, Z.; PAIM, J.; CHAVES, S.; SILVA. G.A.; LOPES, R.; PACHECO, F. Avaliação da descentralização da atenção à saúde na Bahia. Relatório Final de Pesquisa. Salvador: Instituto de Saúde Coletiva, 2002. 


\section{ANEXOS}

\section{Quadro 1}

Imagem-objetivo consensual da descentralização da saúde.

\section{DIMENSÃO POLÍTICA}

1. Competências e relações entre os três níveis de governo

\subsection{Coordenação e complementaridade}

2. Projeto de governo

2.1. Saúde como prioridade de governo

2.2. Existência de iniciativas intersetoriais

2.3. Financiamento de acordo com a Emenda Constitucional $n^{\circ} 29$

3. Capacidade de governo

3.1.Gestor com capacidade de liderança

3.2. Quadros técnicos capacitados em número suficiente

3.3. Política de recursos humanos adequada

3.4. Capacidade dialógica e de síntese de interesses

3.5. Capacidade de formar projeto comum

3.6. Capacidade de articulação política municipal

4. Governabilidade

4.1. Autonomia da Secretaria Municipal de Saúde

4.2. Capacidade de iniciativa junto a outros gestores (estadual/federal/municipal)

4.3. Capacidade do gestor de produzir fatos que ampliem seus graus de liberdade

\section{DIMENSÃO GERENCIAL}

5. Planejamento e avaliação

5.1. Planejamento estratégico

5.2. Avaliação sistemática

5.3. Planejamento por problemas e participativo

5.4. Uso rotineiro da avaliação da qualidade da atenção

5.5. Qualidade do registro e das informações

5.6. Disseminação/discussão dos resultados da avaliação

6. Capacidade regulatória da SMS

6.1. Secretaria com capacidade regulatória

7. Relação público-privado

7.1. Ações de alta e média complexidade geridas pelo setor público

7.2. Controle do setor privado sem relação com o Sistema Único de Saúde

8. Relação da Secretaria Municipal de Saúde com seus profissionais

8.1. Profissionais mobilizados e co-responsáveis

9. Organização dos serviços

9.1. Oferta adequada ao perfil epidemiológico

9.2. Garantia de acesso aos serviços

9.3. Integração dos serviços em rede hierarquizada

9.4. Vigilâncias epidemiológica e sanitária integradas 
9.5. Capacitação de servidores e educação permanente

9.6. Serviços, hospitais e hemocentros acreditados

9.7. Existência de uma política de insumos

9.8. Programação pactuada e integrada

10. Dinâmica da gerência

10.1. Ética na gestão

10.2. Gerência descentralizada

11. Controle social

11.1. Conselho Municipal de Saúde atuante

11.2. Prioridades definidas pelo Conselho Municipal de Saúde

11.3. Existência de auditoria interna

\section{DIMENSÃO ASSISTENCIAL}

12. Integralidade das ações

12.1. Ênfase na promoção da saúde

12.2. Integração de ações preventivas-curativas

12.3. Disponibilidade de medicamentos

13. Abordagem integral

13.1. Utilização de protocolos

13.2. Acolhimento

13.3. Equipes multiprofissionais

13.4. Atenção domiciliar

13.5. Supervisão do trabalho em equipe pelas gerências descentralizadas

13.6. Organização do serviço como processo cotidiano de trabalho

13.7. Equipes de saúde definem "projeto assistencial"

\section{DIMENSÃO DA EFETIVIDADE DAS PRÁTICAS}

14. Impacto sobre a saúde

14.1. Redução da mortalidade infantil

14.2. Redução da mortalidade materna

15. Percepção da população

15.1. Satisfação dos usuários

15.2. Pesquisas de opinião

15.3. Formas de uso pela clientela (repetitivo, peregrinação em diversas unidades de saúde)

15.4. Acolhimento das demandas

15.5. Percepção sobre a capacidade de resposta da equipe profissional

16. Percepção dos servidores

16.1. Satisfação dos servidores com seu trabalho 


\section{Quadro 2}

Critérios importantes, excluídos da imagem-objetivo da descentralização por não serem consensuais

\section{DIMENSÃO POLÍTICA}

Governabilidade

Ampla base de apoio comunitária

Gestor capacitado a argumentar e convencer parceiros estaduais e federais

Relações políticas civilizadas entre as esferas de governo

Capacidade das três esferas de desconcentrar poder

\section{DIMENSÃO GERENCIAL}

Organização dos serviços

Cobertura ampliada

Dinâmica da gerência

Existência de redes de negociação em torno de um projeto comum

Controle social

Capacidade de acompanhamento dos projetos pelo Conselho Municipal de Saúde

Publicidade dos resultados das ações da Secretaria Municipal de Saúde

\section{DIMENSÃO ASSISTENCIAL}

Integralidade das ações

Ações integrais em saúde mental

Ações em outras esferas de cuidado como alimentação, lazer, cultura

Abordagem integral

Acompanhamento da qualidade do cuidado

Realização de fóruns de consenso

Adoção de metodologias de avaliação do processo de trabalho

\section{DIMENSÃO DA EFETIVIDADE DAS PRÁTICAS}

Impacto sobre a saúde

Danos e riscos priorizados

Percepção da população

Vínculos estabelecidos entre usuário e serviço

Respostas efetivamente dadas no local 


\section{Quadro 3}

Critérios excluídos na imagem-objetivo da descentralização por serem pouco importantes e nãoconsensuais

DIMENSÃO POLÍTICA

Governabilidade

Ampla base de apoio no parlamento e na sociedade civil

Capacidade de iniciativa juntos aos níveis estadual e federal

Ampla base de apoio no parlamento

Ampla base de apoio na sociedade civil

Existência de um fundo especial de despesa

Articulação respeitosa com a mídia

Existência de um plano de assessorias

Realização de treinamentos

\section{DIMENSÃO GERENCIAL}

Relação público-privado

Organizações sociais

Estruturas organizacionais da Secretaria Municipal de Saúde

Estruturas horizontalizadas que facilitem a gestão participativa

Organização dos serviços

Redes ambulatorial e hospitalar com fluxos monitorados

Fluxo de pacientes entre municípios monitorado

Programa de certificação profissional implantado

Existência de uma política de investimentos/inversões

Dinâmica da gerência

Gerente como coordenador de grupo

Controle social

Conselho Municipal de Saúde com capacidade de decisão política

Capacidade deliberativa do Conselho Municipal de Saúde

Existência de Conselhos Locais de Saúde

Unidades gestoras e orçamentárias no âmbito dos distritos e unidades de saúde

Engajamento dos profissionais no projeto institucional

Existência de corregedoria

\section{DIMENSÃO ASSISTENCIAL}

Integralidade das ações

Ações integrais de saúde bucal

Abordagem integral

Ações de reabilitação 


\section{ANEXO 1}

Imagem-objetivo da Descentralização da Saúde:

Dimensões, Sub-dimensões e Critérios de Avaliação

\begin{tabular}{|c|c|c|c|}
\hline \multicolumn{4}{|c|}{ Dimensão Política } \\
\hline Sub-dimensões & Critérios de Avaliação & $\begin{array}{l}\text { Pontos Atribuídos } \\
\text { aos Critérios } \\
\text { Escala de zero (sem } \\
\text { importância ou exclusão) } \\
\text { a dez (importância } \\
\text { máxima) }\end{array}$ & $\begin{array}{l}\text { Comentários ou } \\
\text { Observações } \\
\text { (caso prefira excluir o } \\
\text { critério, justifique sua } \\
\text { opinião) }\end{array}$ \\
\hline Projeto de governo & $\begin{array}{l}\text { Prioridade para a } \\
\text { Saúde explicitada no } \\
\text { Plano de Governo } \\
\text { Iniciativas } \\
\text { intersetoriais como } \\
\text { prática regular na } \\
\text { gestão governamental } \\
\text { Financiamento da } \\
\text { Saúde programado e } \\
\text { executado de acordo } \\
\text { com a EC-29 }\end{array}$ & & \\
\hline $\begin{array}{l}\text { Capacidade de } \\
\text { governo }\end{array}$ & $\begin{array}{l}\text { Direção da Saúde } \\
\text { exercida por liderança } \\
\text { política, portadora de } \\
\text { capacidade técnica e } \\
\text { de um projeto de } \\
\text { sistema local de alta } \\
\text { qualidade } \\
\text { Quadros técnicos da } \\
\text { Saúde qualificados e } \\
\text { em número suficiente } \\
\text { Política de recursos } \\
\text { humanos adequada, } \\
\text { com Plano de Cargos } \\
\text { e Salários, admissão } \\
\text { através de concurso } \\
\text { público e incentivo à } \\
\text { capacitação ligado à } \\
\text { remuneração }\end{array}$ & & \\
\hline Governabilidade & $\begin{array}{l}\text { Ampla base de apoio } \\
\text { político no } \\
\text { parlamento municipal } \\
\text { e na sociedade civil } \\
\text { organizada }\end{array}$ & & \\
\hline
\end{tabular}




\begin{tabular}{|l|l|l|l|}
\hline \multicolumn{3}{|c|}{ Dimensão Política } \\
\hline Sub-dimensões & Critérios de Avaliação & $\begin{array}{l}\text { Pontos Atribuídos } \\
\text { aos Critérios } \\
\text { Escala de zero (sem } \\
\text { importância ou exclusão) } \\
\text { a dez (importância } \\
\text { máxima) }\end{array}$ & $\begin{array}{l}\text { Comentários ou } \\
\text { Observações } \\
\text { (caso prefira excluir o } \\
\text { critério, justifique sua } \\
\text { opinião) }\end{array}$ \\
\hline Governabilidade & $\begin{array}{l}\text { Secretaria da Saúde } \\
\text { com autonomia para } \\
\text { utilização dos } \\
\text { recursos municipais, } \\
\text { com Comissão de } \\
\text { licitação e com } \\
\text { contador responsável }\end{array}$ & \\
& $\begin{array}{l}\text { Gestor municipal com } \\
\text { capacidade de } \\
\text { iniciativa política } \\
\text { junto aos níveis } \\
\text { estadual e } \\
\text { federal }\end{array}$ & \\
\hline \multirow{5}{*}{ OBS. ${ }^{1}$} & & \\
\hline
\end{tabular}

${ }^{1}$ Outras sub-dimensões e/ou critérios julgados importantes podem ser inseridos e também pontuados nas planilhas. 


\begin{tabular}{|c|c|c|c|}
\hline \multicolumn{4}{|c|}{ Dimensão Gerencial } \\
\hline Sub-dimensões & Critérios de Avaliação & $\begin{array}{l}\text { Pontos Atribuídos } \\
\text { aos Critérios } \\
\text { Escala de zero (sem } \\
\text { importância ou exclusão) } \\
\text { a dez (importância } \\
\text { máxima) }\end{array}$ & $\begin{array}{l}\text { Comentários ou } \\
\text { Observações } \\
\text { (caso prefira excluir o } \\
\text { critério, justifique sua } \\
\text { opinião) }\end{array}$ \\
\hline $\begin{array}{l}\text { Planejamento e } \\
\text { Avaliação }\end{array}$ & $\begin{array}{l}\text { Práticas regulares de } \\
\text { planejamento de } \\
\text { saúde com um } \\
\text { enfoque estratégico } \\
\text { Avaliação realizada } \\
\text { sistematicamente para } \\
\text { subsidiar o processo } \\
\text { de tomada de decisões }\end{array}$ & & \\
\hline $\begin{array}{l}\text { Relação público- } \\
\text { privado }\end{array}$ & $\begin{array}{l}\text { Conjunto das ações de } \\
\text { alta e média } \\
\text { complexidade geridas } \\
\text { pelo setor público, } \\
\text { com a realização de } \\
\text { parte significativa } \\
\text { dessas ações por } \\
\text { serviços públicos }\end{array}$ & & \\
\hline $\begin{array}{l}\text { Relação da SMS com } \\
\text { profissionais }\end{array}$ & $\begin{array}{l}\text { Projeto da SMS } \\
\text { mobiliza os } \\
\text { profissionais da saúde, } \\
\text { que se sentem co- } \\
\text { responsáveis pelo } \\
\text { projeto político da SMS }\end{array}$ & & \\
\hline $\begin{array}{l}\text { Organização dos } \\
\text { serviços }\end{array}$ & $\begin{array}{l}\text { Oferta de serviços } \\
\text { adequada ao perfil } \\
\text { sócio-epidemiológico } \\
\text { do município } \\
\text { Acessibilidade } \\
\text { garantida à atenção } \\
\text { básica, aos serviços } \\
\text { de urgência/ } \\
\text { emergência, à } \\
\text { hospitalização e aos } \\
\text { serviços de alta e } \\
\text { média complexidade } \\
\text { Cobertura } \\
\text { efetivamente } \\
\text { ampliada, com a } \\
\text { utilização dos serviços } \\
\text { do SUS por, no } \\
\text { mínimo, } 75 \% \text { da } \\
\text { população }\end{array}$ & & \\
\hline
\end{tabular}




\begin{tabular}{|l|l|l|l|}
\hline \multicolumn{3}{|c|}{ Dimensão Gerencial } \\
\hline Sub-dimensões & Critérios de Avaliação & $\begin{array}{l}\text { Pontos Atribuídos } \\
\text { aos Critérios } \\
\text { Escala de zero (sem } \\
\text { importância ou exclusão) } \\
\text { a dez (importância } \\
\text { máxima) }\end{array}$ & $\begin{array}{l}\text { Comentários ou } \\
\text { Observações } \\
\text { (caso prefira excluir o } \\
\text { critério, justifique sua } \\
\text { opinião) }\end{array}$ \\
\hline $\begin{array}{l}\text { Organização dos } \\
\text { serviços }\end{array}$ & $\begin{array}{l}\text { Integração de rede de } \\
\text { serviços regionalizada } \\
\text { e hierarquizada }\end{array}$ & & \\
\hline Controle social & $\begin{array}{l}\text { Existência de CMS } \\
\text { atuante e realização } \\
\text { de Conferência } \\
\text { Municipal de Saúde }\end{array}$ & & \\
\hline OBS. ${ }^{1}$ & & & \\
\hline
\end{tabular}

${ }^{1}$ Outras sub-dimensões e/ou critérios julgados importantes podem ser inseridos e também pontuados nas planilhas. 


\begin{tabular}{|c|c|c|c|}
\hline \multicolumn{4}{|c|}{ Dimensão Assistencial } \\
\hline Sub-dimensões & Critérios de Avaliação & $\begin{array}{l}\text { Pontos Atribuídos } \\
\text { aos Critérios } \\
\text { Escala de zero (sem } \\
\text { importância ou exclusão) } \\
\text { a dez (importância } \\
\text { máxima) }\end{array}$ & $\begin{array}{l}\text { Comentários ou } \\
\text { Observações } \\
\text { (caso prefira excluir o } \\
\text { critério, justifique sua } \\
\text { opinião) }\end{array}$ \\
\hline $\begin{array}{l}\text { Integralidade das } \\
\text { ações }\end{array}$ & $\begin{array}{l}\text { Ênfase nas ações de } \\
\text { promoção da saúde, } \\
\text { com utilização de } \\
\text { tecnologias de } \\
\text { comunicação social } \\
\text { Existência de } \\
\text { integração das ações } \\
\text { promocionais, } \\
\text { preventivas, de } \\
\text { recuperação e de } \\
\text { reabilitação para os } \\
\text { agravos priorizados } \\
\text { Disponibilidade de } \\
\text { medicamentos e } \\
\text { promoção do seu uso } \\
\text { racional } \\
\text { Desenvolvimento de } \\
\text { ações integrais em } \\
\text { saúde bucal de acordo } \\
\text { com o perfil } \\
\text { epidemiológico. }\end{array}$ & & \\
\hline $\begin{array}{l}\text { Abordagem integral } \\
\text { (cuidado completo e } \\
\text { contínuo) }\end{array}$ & $\begin{array}{l}\text { Utilização sistemática } \\
\text { de protocolos de } \\
\text { atenção para os } \\
\text { agravos priorizados } \\
\text { Adoção de estratégias } \\
\text { explícitas de } \\
\text { acolhimento do } \\
\text { usuário (triagem por } \\
\text { profissional de saúde, } \\
\text { flexibilidade na rotina } \\
\text { dos serviços, padrão } \\
\text { razoável de conforto } \\
\text { nas instalações físicas) } \\
\text { Realização regular de } \\
\text { atividades de saúde } \\
\text { por equipes } \\
\text { multiprofissionais }\end{array}$ & & \\
\hline OBS. ${ }^{1}$ & & & \\
\hline
\end{tabular}

${ }^{1}$ Outras sub-dimensões e/ou critérios julgados importantes podem ser inseridos e também pontuados nas planilhas. 


\begin{tabular}{|l|l|l|l|}
\hline \multicolumn{3}{|c|}{ Dimensão da Efetividade das Práticas } \\
\hline Sub-dimensões & Critérios de Avaliação & $\begin{array}{l}\text { Pontos Atribuídos } \\
\text { aos Critérios } \\
\text { Escala de zero (sem } \\
\text { importância ou exclusão) } \\
\text { a dez (importância } \\
\text { máxima) }\end{array}$ & $\begin{array}{l}\text { Comentários ou } \\
\text { Observações } \\
\text { (caso prefira excluir o } \\
\text { critério, justifique sua } \\
\text { opinião) }\end{array}$ \\
\hline $\begin{array}{l}\text { Impactos sobre o } \\
\text { estado de saúde }\end{array}$ & $\begin{array}{l}\text { Redução da } \\
\text { mortalidade infantil } \\
\text { Redução da } \\
\text { mortalidade materna }\end{array}$ & $\begin{array}{l}\text { Redução dos danos e } \\
\text { riscos priorizados no } \\
\text { plano de saúde }\end{array}$ & \\
\hline $\begin{array}{l}\text { Percepção da } \\
\text { população }\end{array}$ & $\begin{array}{l}\text { Satisfação dos } \\
\text { usuários em relação } \\
\text { ao acolhimento, à } \\
\text { atenção básica, à } \\
\text { atenção especializada } \\
\text { e às ações } \\
\text { promocionais e } \\
\text { preventivas }\end{array}$ & $\begin{array}{l}\text { Resultados de } \\
\text { pesquisas de opinião }\end{array}$ & \\
\hline OBS. ${ }^{1}$ & & \\
\hline
\end{tabular}

${ }^{1}$ Outras sub-dimensões e/ou critérios julgados importantes podem ser inseridos e também pontuados nas planilhas. 


\section{ANEXO 2}

\section{Imagem-objetivo da Descentralização da Saúde}

\begin{tabular}{l}
\hline Média Desv-pad \\
\hline
\end{tabular}

DIMENSÃO POLÍTICA

$7,1 \quad 2,57$

1. Competências e relações entre os três níveis

$9,1 \quad 1,36$

1.1. Coordenação e complementaridade

$9,1 \quad 1,36$

\section{Projeto de governo}

$8,4 \quad 1,71$

2.1. Prioridade de Governo

$7,9 \quad 2,13$

2.2. Iniciativas intersetoriais

2.3. Financiamento de acordo com a EC-29

$8,2 \quad 1,87$

$9,2 \quad 1,14$

\section{Capacidade de governo}

3.1. Liderança

3.2. Quadros técnicos

$8,0 \quad 1,85$

$7,4 \quad 2,72$

3.3. Política de RRHH

$8,7 \quad 0,82$

3.4. Capacidade dialógica e de síntese de interesses

$7,0 \quad 2,83$

3.5. Capacidade de formar projeto comum

$7,8 \quad 2,2$

3.6. Articulação municipal

$8,4 \quad 1,35$

$8,6 \quad 1,19$

4. Governabilidade

4.1. Ampla base de apoio no parlamento e na sociedade civil

$6,2 \quad 3,21$

4.2. Autonomia da SMS

$6,0 \quad 3,68$

4.3. Capacidade de iniciativa juntos aos níveis estadual e federal

$7,7 \quad 1,89$

4.4. Ampla base de apoio no parlamento

$6,5 \quad 3,69$

$4,4 \quad 3,95$

4.5. Ampla base de apoio na sociedade civil

$6,3 \quad 3,53$

4.6. Ampla base de apoio comunitária

$7,1 \quad 3,02$

4.7. Capacidade de iniciativa junto ao estadual/federal e aos outros municípios

$8,1 \quad 1,45$

$7,0 \quad 2,98$

4.8. Gestor produzindo fatos que ampliem seus graus de liberdade

4.9. Gestor capacitado a convencer parceiros estaduais e federais

$7,1 \quad 3,03$

4.10. Existência de um fundo especial de despesa

$4,0 \quad 4,36$

4.11. Articulacão respeitosa com a mídia

$6,8 \quad 3,19$

4.12. Relacões políticas entre as esferas de governo

$7,4 \quad 3,2$

4.13. Capacidade das três esferas de desconcentrar poder

7,3

3,12

4.14. Plano de assessorias

2,7

3,45

4.15. Treinamento

$5,1 \quad 3,53$




\title{
INTERSETORIALIDADE EM SAÚDE: UM ESTUDO DE CASO
}

\author{
Vitória Solange Coelho Ferreira \\ Lígia Maria Vieira da Silva
}

\section{INTRODUÇÃO}

A intersetorialidade em saúde tem sido definida como uma coordenação entre setores (OMS, 1984) ou como uma intervenção coordenada de instituições em ações destinadas a abordar um problema vinculado à saúde (SUARÉZ, 1992) ou ainda como a articulação entre saberes e experiências no planejamento, realização e avaliação de ações para alcançar efeitos sinérgicos em situações complexas (JUNQUEIRA; INOJOSA, 1997). Atualmente, é considerada um componente central das políticas de saúde voltadas para a mudança do modelo assistencial (PAIM, 1994; MENDES,1996).

A proposição da intersetorialidade em saúde aparece nos principais planos e programas de organismos internacionais, como a OMS, desde 1961, no Plano Decenal de Saúde Pública da Aliança para o Progresso. A partir de então, recomendações relacionadas com a sua adoção têm sido feitas em diversos documentos e eventos oficiais, valendo destacar a III Reunião Especial de Ministros de Saúde das Américas em 1972, a reunião de Alma-Ata em 1978, o Encontro sobre Ações Intersetoriais em Saúde, em 1986, a Carta de Ottawa, em 1986; a Declaração de Adelaide, em 1988; a Conferência de Sundsvall, em 1991 e de Santa Fé de Bogotá, em 1992, a Declaração de Jacarta sobre Promoção da Saúde no Século XXI, em 1997 e a Conferência Internacional sobre Ações Intersetoriais para Saúde, em 1997.

Nesses eventos, tem sido assinalado de diferentes maneiras que a promoção da saúde também é responsabilidade de setores governamentais 
tais como a agricultura, comércio, educação, indústria e comunicação e que deve ser considerada no conjunto das formulações de políticas setoriais (OMS, 1986; BRASIL, 1996; BUSS, 2000).

Procurando aprofundar o conhecimento sobre o tema, a Organização Panamericana de Saúde (OPS) realizou, em cooperação técnica com países da América Latina e Caribe, uma série de estudos de casos nos anos de 1983, 1984, 1989 e 1990. Os resultados dessas experiências revelam que a maioria das ações desenvolvidas entre os diversos setores eram atividades conjuntas, não sendo consideradas ações intersetoriais, exceto aquelas analisadas em Cuba (OPS, 1984; OPS, 1989; OPS, 1990; NOVAES, 1990).

No Brasil, a proposta da intersetorialidade existe desde a década de 70, no II Plano Nacional de Desenvolvimento Econômico (PND), para o período de 1975 a 1979. Já na VI Conferência Nacional de Saúde, surge como objetivo da Política Nacional, tendo sido incluída no Programa de Interiorização de Ações de Saúde e Saneamento para o Nordeste (PIASS) e no Programa Nacional de Alimentação e Nutrição (PRONAN) (BRASIL, 1977).

Posteriormente, na década de 90, foram desenvolvidas algumas experiências de descentralização, em vários estados do país, que incorporaram, em alguma medida, as ações intersetoriais como: o Caso de Camaçari (Vieira da Silva, 1991), o Projeto Saúde, Meio Ambiente e luta contra a pobreza (OPS, 1991), Plano de Ação Intersetorial para melhoria da qualidade de vida em Campinas (MENDES, 1995), a experiência de uma gestão descentralizada intersetorial: o caso de Fortaleza e o Fórum de Combate à Violência do Projeto UNI-BA (BAHIA-UFBA/PROJETO UNI, 1998).

Para Inojosa e Junqueira (1997), alguns desses projetos intersetoriais oferecem a oportunidade de reflexão sobre o desafio da articulação intersetorial, questão que extrapola os limites de eventuais ações conjuntas a partir de determinadas estruturas organizacionais específicas para se apresentar como um problema mais amplo nos três níveis de governo. Ademais, referem que a implantação desse tipo de estratégia de trabalho no aparelho governamental requer decisão política, o que implica romper com o antigo padrão de prestação de serviços que reflete determinada estrutura de poder onde impera a fragmentação, setorialização e centralização.

Estas experiências referem-se a tentativas de consolidação de uma reforma administrativa municipal, tendo como eixo articulador o enfoque da descentralização, da intersetorialidade e da formação de redes, e como 
imagem/objetivo a implementação de um novo modelo de gestão das políticas públicas que possibilite a otimização de recursos municipais para o melhoramento da qualidade de vida dos cidadãos através da introdução de novas tecnologias de gestão e de alterações nas relações de poder que se estabelecem no nível individual e das instituições.

Dentre as perguntas que emergem da síntese feita, destaca-se aquela referente às razões desta proposição não ter sido implementada extensivamente, a despeito da sua presença em planos e programas nas últimas quatro décadas. A resposta a essa questão requer a investigação da implantação da estratégia da intersetorialidade em diferentes contextos.

Na Bahia, a partir de 1995, a Secretaria Estadual de Saúde desenvolveu o Programa de Redução da Mortalidade na Infância (PRMI), utilizando como metodologia o desenvolvimento de ações intersetoriais com o objetivo de articular ações conjuntas, coordenadas e integradas entre os diversos setores para intervir nos problemas de saúde e necessidades sociais da população com a finalidade de diminuir a mortalidade materno-infantil e melhorar a qualidade de vida nos municípios considerados como de risco.

Visando contribuir para o esclarecimento da questão acima mencionada, foi realizada uma análise acerca dos processos envolvidos na implantação das ações intersetoriais, em município selecionado, do Projeto de Redução da Mortalidade na Infância (PRMI) da Diretoria Regional de Saúde (DIRES) de Galiléia-BA. Essa análise constou da caracterização do grau de implantação das referidas ações intersetoriais, da identificação dos fatores facilitadores e restritivos à sua implantação, bem como da descrição das concepções sobre intersetorialidade dos diversos atores sociais no município selecionado.

\section{MODELO TEÓRICO}

O estudo da intersetorialidade envolveu o desenvolvimento das seguintes categorias analíticas (TESTA, 1982): o poder, as políticas de saúde e as instituições. A partir dessas categorias, tornou-se necessário tratar de outras, correlacionadas e adjacentes, que auxiliaram na operacionalização das primeiras, a saber: governo, estratégia, situação, política e atores sociais.

O referencial teórico escolhido para abordar essas categorias foi desenvolvido, principalmente, a partir de Matus (1997), Testa (1981, 1982, 
1992 e 1995), Denis e Champagne (1997) e Yin (1994). A análise do grau de implantação e dos fatores aí envolvidos requer uma compreensão acerca da estrutura de poder setorial, bem como o estudo sobre a articulação entre os componentes do triângulo de governo (MATUS, 1997) e de como se conforma o poder local (FISCHER, 1993; COSTA, 1996; NUNES, 1996; SOUZA, 1996; BLUMM; SOUZA, 1998).

\section{TOTALIDADE DO REAL}

A realidade social, por ser complexa, dinâmica e conflitante, está sempre em movimento, impondo mudanças na trajetória dos acontecimentos, independentemente de nossa vontade. Para compreendê-la, Matus (1997), propõe que a analisemos tal como é, indivisível. Para esse autor, enquanto a realidade opera com problemas complexos e mal-estruturados, as instituições se organizam por setores e as universidades fragmentam o saber em departamentos.

Essa concepção de mundo tem impossibilitado um aprofundamento do olhar para além dos fatos mais visíveis, sejam estes fatos econômicos, políticos, sociais ou ideológicos, dificultando a abstração e elaboração de pensamentos totalizantes que possam dar conta dos problemas presentes na sociedade mediante sua interconexão com o espaço de sua inserção geral, particular ou singular - e das relações desenvolvidas nos planos situacionais - genoestruturas, fenoprodução e fenoestruturas (MATUS, 1997).

Testa (1981/1982) também chama a atenção para as limitações da noção de setor na interpretação do real, considerando necessário vincular a análise setorial ao seu contexto social, o que corresponde ao reconhecimento do social como totalidade histórica.

Embora a ciência necessite delimitar e recortar o real para ser possível apreendê-lo, o movimento inverso também faz parte do processo de produção do conhecimento. Já no âmbito das intervenções sociais, a apreensão do real enquanto totalidade de múltiplas determinações permite que a ação seja direcionada aos determinantes estruturais e tenha, conseqüentemente, maior possibilidade de ser efetiva. 


\section{INTERSETORIALIDADE, ESTRATÉGIA E POLÍTICAS DE SAÚDE}

A intersetorialidade em saúde será compreendida como parte de um conjunto de estratégias que consistem em ações mobilizadoras e articuladoras de práticas e projetos entre o setor saúde e os demais setores do desenvolvimento, no planejamento, organização, direção, implementação, monitoramento e avaliação de intervenções voltadas para modificação do modelo assistencial (PAIM, 1994; MENDES, 1996). Nesse sentido, pode representar uma ação intencional mediante a qual os atores sociais, produtores de ações, esperam consciente ou inconscientemente alcançar determinados efeitos em situações de cooperação e/ou conflito com outros (MATUS, 1997).

Assim sendo, sua implementação consiste em incorporar pensamentos e concepções que informem uma nova maneira de planejar, executar e controlar a prestação de serviços voltados para uma nova prática sanitária. Isso significa alterar toda uma forma de articulação dos diversos segmentos governamentais e seus interesses (JUNQUEIRA, 1997). Sua efetivação exige disponibilidade e interesse por parte dos atores envolvidos em desenvolverem uma ação comunicativa (RIVERA, 1995) isto é, em praticar um diálogo permanente com representantes de outros setores, órgãos ou instituições e com representantes dos grupos sociais existentes, em um trabalho coletivo cujo propósito maior é promover a saúde na medida em que a ação intersetorial permite a intervenção em fatores condicionantes da mesma.

A estratégia pode ser considerada como uma forma de implementação de uma política mediante o comportamento de um ator - indivíduo, grupo, instituição - cujo propósito é adquirir certa liberdade de ação, que lhe permita ganhar um espaço de manobra para implementar os objetivos buscados. Esses objetivos são o conteúdo específico da política que, por sua vez, é definida como uma forma de distribuição de poder na sociedade ou num setor, como é o caso da saúde (TESTA, 1995); também, refere-se aos processos sociais que conduzem à adoção e execução de decisões através das quais se atribui valores para toda a sociedade (OPS, 1975).

Por outro lado, uma política de saúde pode ser compreendida como uma decisão de uma autoridade formal (OPS, 1975) como também uma intenção ou consolidação de poder para grupos sociais concretos, através de certos conteúdos específicos (programas ou projetos da política) e de certas ações viabilizadoras (a estratégia) dirigidas para conseguir alianças, 
consensos ou para lutas que debilitem o poder dos oponentes contrários a essa política.

A intersetorialidade enquanto parte de uma proposta do conteúdo político de um plano pode ser considerada como uma estratégia por apontar a direção do deslocamento de poder (TESTA, 1982) e possibilitar às forças sociais envolvidas liberdade e oportunidade de ação para perseguir os objetivos pretendidos.

\section{PODER, GOVERNO E SITUAC̣ÃO}

A importância da apreciação do grau de implantação de uma intervenção relaciona-se com a cisão existente entre a fase decisória e a de implantação de uma política, chamando a atenção para a distância entre o pensamento e a ação, a decisão e a aplicação e a execução e sua eficácia política (TESTA, 1982; GERSCHMAN,1989; MATUS,1997).

Nesse particular, o nível local reveste-se de grande importância por favorecer, ao menos em tese, uma maior participação política, maior controle social, maior proximidade do cidadão e melhor distribuição dos serviços (BLUMM; SOUZA, 1998), além de ser considerado locus privilegiado para implementação das políticas de saúde em nosso país. É neste contexto de valorização positiva que se dá a ressignificação do poder local (COSTA, 1996) como poder municipal (DAVIDOVICH, 1993). Sua análise remete ao estudo do poder enquanto relações de força entre atores inseridos em um conjunto de redes sociais articuladas onde existem relações de cooperação ou conflito em torno de interesses, recursos e valores, em um espaço, que não é apenas fisicamente localizado, mas que também é socialmente construído (FISCHER, 1993).

Para alguns autores como Davidovich (1993), a subordinação do local aos níveis superiores dificulta a soberania do poder local no que diz respeito à tomada de decisão por excluir a possibilidade de sua atuação devido a determinações que escapam de seu controle e estão ligadas a interesses externos. Nessa perspectiva, o nível local nada mais seria do que mero suporte de instâncias superiores de gestão e que sua efetivação só teria êxito em regimes de base popular.

Não obstante essas proposições, outros autores como Blumm e Souza (1998) e Nunes (1996) referem que um dos principais problemas enfren- 
tados pelo governo local resulta da sua dupla responsabilidade: a de ser veículo da democracia local, fornecendo serviços adequados às necessidades e, por outro lado, de servir de suporte para o aparelho administrativo do Estado Nacional, executando políticas em áreas prioritárias, tendo como objetivo a eficiência burocrática.

A articulação e a interrelação que se estabelece entre o poder local e o poder em âmbito mais global, requer que a investigação sobre o primeiro leve em conta essa complexa dinâmica. Isto implica que o poder local, por conter elementos comuns ao poder Nacional, nos remete a falar em Estado e suas organizações. Sendo o Estado produto da institucionalização progressiva de uma estrutura política, não se pode desconhecer que a esfera local faça parte da mesma. Por seu lado, as organizações, que podem ser entendidas, no sentido de Testa (1997), como a forma de relação que se estabelece entre as pessoas para realização de determinada tarefa ou 0 cumprimento de uma função, podem também ser consideradas como componentes do poder local.

Dessa forma, torna-se necessária uma análise sobre as relações de poder existentes no governo e nas organizações, posto que as ações intersetoriais são permeadas por um jogo estratégico entre os distintos atores e forças sociais, pertencentes aos diversos setores. As relações de poder que se estabelecem no interior das organizações e entre as forças sociais são complexas e conflitantes, expressando interesses múltiplos e contraditórios. A análise acerca das possibilidades de mudança dessa realidade a partir de intervenção externa deve levar em conta essa determinação.

Para Testa $(1981,1982,1995)$ a interpretação da estrutura do poder no setor saúde permite elucidar o comportamento dos grupos sociais no que diz respeito ao processo de tomada de decisão, o qual possui três grandes propósitos: promover mudanças, crescimento ou reprodução e legitimação. Para tanto, caracterizou três tipos particulares de poder: o político, o técnico e o administrativo. O poder técnico é a capacidade de gerar, aceder, lidar com a informação de características distintas. O poder administrativo é a capacidade de apropriar e de atribuir recursos, e o poder político é a capacidade de mobilizar grupos sociais em demanda ou reclamação de suas necessidades e interesses. Essas caracterizações expressam a capacidade de manipular recursos, informações e interesses, que acumulam determinadas pessoas, grupos sociais e/ou instituições. 
Para análise das características do governo, foi utilizado como referência o triângulo de governo proposto por Matus (1997). Este autor destaca que para governar, as forças sociais necessitam da articulação de três componentes, a saber: a) projeto de governo; b) capacidade de governo; e c) governabilidade do sistema.

O Projeto de Governo (P) refere-se ao conteúdo propositivo do plano, que contém o conjunto de propostas de ações que um ator pretende realizar para alcançar seus objetivos. Expressa o capital político e intelectual dos atores que planejam e sua aplicação no desenho de uma proposta de ação; tem relação com a direcionalidade do plano.

A Capacidade de Governo (C) diz respeito ao capital teórico, instrumental e experiência acumulada que tem um ator e sua equipe de governo para conduzir, gerenciar, administrar e controlar o processo mediante a destreza para conceber e executar estratégias e táticas eficazes para resolver os problemas e aproveitar as oportunidades.

A Governabilidade do Sistema $(G)$ está relacionada à liberdade de ação que dispõem os atores sociais em situação frente as variáveis as quais controlam ou não controlam no processo de governo, ou seja, refere-se à possibilidade de ação e ao controle sobre seus efeitos o que the permitirá maior liberdade de ação e controle de um maior número de variáveis. Governar é uma situação bastante complexa, pois requer dos atores sociais em questão habilidades para conduzir um processo que envolve definição clara dos objetivos pretendidos, os quais poderão ser reformulados ou abandonados de acordo com o andamento dos resultados.

O conceito de situação será aquele desenvolvido por Matus (1997), segundo o qual, a situação é formada por atores e problemas, sendo que pode ser objeto de múltiplas explicações, a depender da posição ocupada pelo ator que a descreve, em função de seus interesses, visões de mundo, crenças, ideologias, do papel que desempenha na sociedade e da luta que estabelece com outras forças sociais.

A categoria ator social pode se referir a uma pessoa, a uma organização ou agrupamento humano que, de forma estável ou transitória, tem capacidade de acumular força, desenvolver interesses e necessidades e atuar produzindo fatos na situação (MATUS, 1997).

A implantação de um programa supõe mudanças organizacionais que envolvem processos complexos de adaptação e de apropriação das políti- 
cas e/ ou programas nos diferentes meios em questão e requer, para sua análise, a escolha de um modelo teórico explicativo do contexto de sua implantação. Optou-se pelo modelo político e contingente, que corresponde à abordagem política e estrutural, proposta por Denis e Champagne (1997), onde a organização é considerada uma arena política no interior da qual os atores perseguem estratégias diferentes.

A abordagem política parte de uma perspectiva crítica dialética de análise das organizações, considerando a implantação de uma intervenção como um jogo de poder organizacional, cujo resultado constitui um ajuste às pressões internas e externas. Refere que um contexto favorável à implantação e eficácia de uma intervenção depende do suporte dado pelos agentes de implantação; do controle organizacional que detenham para operacionalizar e tornar eficaz a intervenção; e de uma forte coerência entre seus objetivos e os associados à intervenção que se quer implantar. Paralelamente a este, considera que as dificuldades ligadas à implantação dependem de interesses particulares dos atores influentes na organização (DENIS; CHAMPAGNE, 1997).

\section{ESTRATÉGIA DA PESQUISA}

Foi realizado um estudo de caso, com múltiplos níveis de análise, sobre a implantação das ações intersetoriais em município selecionado do Projeto de Redução da Mortalidade na Infância (PRMI) no período de 1998 a 1999. A escolha dessa estratégia de investigação justificou-se por se tratar de um estudo empírico que investiga um fenômeno contemporâneo em seu contexto real, quando os limites entre o fenômeno e o contexto não estão claramente definidos e no qual são utilizadas várias fontes de evidências (YIN, 1993).

Foram selecionados os seguintes níveis de análise: a) gestão estadual e regional do programa: grupo de trabalho intersetorial estadual (GTIE) e regional (GTIR); b) governo municipal e a gestão municipal do programa: o grupo de trabalho intersetorial municipal (GTIM); c) instituições participantes e executoras do programa.

Para caracterização da "situação inicial", foi elaborado um fluxograma situacional (Figura 1) a partir das informações obtidas no documento institucional do Projeto de Redução da Mortalidade na Infância (PRMI) 
acerca do contexto político, sanitário e organizacional vigente e de indicadores de morbi-mortalidade, socioeconômicos e de serviços.

A seguir, foram elaborados os fluxogramas referentes à gestão setorial (Figuras 3, 4, 5, 6 e 7), o que possibilitou uma visão global das ações que deveriam ser desenvolvidas, e a partir deles foi construído um modelo do que seria a gestão intersetorial (Figura 2).

Para descrição do grau de implantação das ações intersetoriais, do município de Alvorecer-BA ${ }^{1}$, foram selecionados quatro componentes ou dimensões e treze critérios de avaliação com suas respectivas atividades: I) Organização do Grupo de Trabalho Intersetorial Municipal do Projeto de Redução da Mortalidade na Infância (GTIM/PRMI), com quatro critérios; II) Gestão, com três critérios; III) Desenvolvimento das Ações Setoriais, com cinco critérios; e IV) Articulação entre as Ações Intersetoriais, com um critério.

Foram considerados quatro graus de implantação das ações intersetoriais: I) Implantado (I); II) Parcialmente implantado (PI); III) Incipiente (IN); e IV) Não implantado (NI), com seus respectivos níveis, para apreciação do grau de implantação de cada critério ou atividade dos componentes do programa. Para cada critério selecionado, foram atribuídos pontos numa escala de zero (0) a dez (10). Foi feita também uma ponderação dos critérios a partir da importância atribuída a eles no programa, o que resultou na diferenciação da pontuação máxima para cada item (Quadro I).

Para a atribuição dos pontos, foram usadas diversas fontes de informação: documentos, entrevistas e diário de campo. Uma versão preliminar foi submetida à apreciação de alguns membros grupo de trabalho intersetorial regional (GTIR) e estadual (GTIE), que concordaram com a seleção de critérios e com a ponderação dos mesmos.

A aferição do grau de implantação foi feita a partir do escore final obtido:

Pontuação obtida
Escore final $=\longrightarrow \times 100$
Pontuação máxima

Pontuação obtida $=\sum$ da pontuação obtida de cada critério

Pontuação máxima $=\sum$ da pontuação máxima de cada critério 
Para a conclusão acerca do grau de implantação, utilizou-se a seguinte classificação do escore final:

\begin{tabular}{|c|c|}
\hline Classificação & Escore final \\
\hline Implantado & $75-100 \%$ \\
\hline Parcialmente implantado & $50-75 \%$ \\
\hline Incipiente & $25-50 \%$ \\
\hline Não Implantado & $0-25 \%$ \\
\hline
\end{tabular}

A seleção do município "caso" foi realizada através de entrevistas semiestruturadas realizadas com a coordenação e secretaria do projeto que participavam do grupo de trabalho intersetorial regional do Programa de Redução da Mortalidade na Infância (GTIR/PRMI) no período de 1998 a 1999, dos instrumentos de avaliação das ações básicas do Programa de Assistência Integral à Saúde da Criança e da Mulher (PAISC e PAISM) da Secretaria de Saúde do Estado da Bahia e dos seminários de avaliação regional e estadual realizados, respectivamente, em novembro e dezembro de 1999. Importa salientar que a exposição feita pelo vice-coordenador do município selecionado teve peso significativo para escolha do mesmo, pois de acordo com relato dele, o município encontrava-se em um grau avançando de implantação das ações intersetoriais.

\section{PROCEDIMENTOS PARA COLETA E FONTES DE INFORMAÇÃO}

$\mathrm{Na}$ fase exploratória da pesquisa, foi feito contato com o gestor municipal, secretário de saúde, diretor da Diretoria Regional de Saúde (DIRES) e membros do grupo de trabalho intersetorial estadual, regional e municipal (GTIE, GTIR e GTIM) para apresentar a proposta de investigação, solicitar permissão para realizar o estudo e utilizar os documentos existentes sobre o projeto.

A coleta dos dados foi realizada em duas etapas: uma antes da seleção do município (1998) e outra após (1999), envolvendo análise documental, entrevistas semi-estruturadas abertas e observação direta (YIN, 1994; MINAYO, 1996). 
A seleção dos informantes-chave deu-se a partir da indicação dos membros dos grupos de trabalho estadual, regional e municipal (GTIE, GTIR e GTIM) e envolveu os seguintes critérios: a) gestor municipal e de saúde no ano da implantação do projeto, em 1998; b) os representantes das instituições e/ou organizações do grupo de trabalho intersetorial estadual, regional e municipal (GTIE, GTIR e GTIM) do Projeto de Redução da Mortalidade na Infância (PRMI); c) alguns profissionais de saúde que trabalhavam e/ou estivessem trabalhando no município nos anos de 1998 a 1999; d) lideranças da comunidade; e) coordenadores do GTIE, GTIR e GTIM no período de 1998 e 1999.

A identificação dos entrevistados foi realizada após as primeiras visitas ao município e as entrevistas foram agendadas e realizadas posteriormente, de acordo com a disponibilidade dos entrevistados. Do grupo de trabalho intersetorial municipal (GTIM), foram entrevistados quatorze componentes, exceto a secretária de saúde, que se recusou a conceder a entrevista e não permitiu que os funcionários daquela secretaria o fizessem. Foram ainda entrevistados dez representantes do grupo de trabalho intersetorial regional (GTIR) e nove do grupo de trabalho intersetorial estadual (GTIE). Importa destacar que a entrevista foi realizada com o chefe de gabinete, filho do gestor municipal, porque o mesmo não teve condições de concedê-la por motivo de saúde.

Foram elaborados roteiros específicos para entrevistar o gestor municipal, assessores do prefeito, a secretária de saúde, a coordenadora e secretária do projeto, os representantes do grupo de trabalho intersetorial e lideranças populares. Contudo, para alguns profissionais das setoriais envolvidas e outros atores, foi realizada entrevista aberta. Foram também listados alguns tópicos para observação. As entrevistas foram gravadas pela pesquisadora com a colaboração da bolsista de iniciação científica e transcritas por um profissional habilitado. Durante sua realização, foi solicitado consentimento verbal para utilização da informação, tendo sido assegurada a condição necessária para sua realização (anonimato, privacidade e sigilo). Importa destacar que foram dados nomes fictícios a todos os entrevistados e a todos os municípios, bairros, povoados e distritos, exceto o município de Salvador.

Foi ainda utilizado roteiro de acordo com a dinâmica da narrativa do entrevistado, considerando-se que algumas informações surgiram esponta- 
neamente e outras foram estimuladas pelo entrevistador. Esse roteiro conteve os seguintes itens: experiência no Grupo de Trabalho Intersetorial Regional (GTIR), implementação das ações intersetoriais, funcionamento do Grupo de Trabalho Intersetorial Municipal (GTIM), planejamento conjunto e ações efetivamente implantadas, existência de relatórios, atas, avaliações.

A utilização da observação direta com registros em diário de campo foi concentrada em alguns momentos, bem como foram realizadas visitas aos locais de intervenção e entrevistas abertas com os assessores do gestor municipal, líderes da comunidade e padre da paróquia. Foram também tiradas fotos de determinados locais do município considerados relevantes para o trabalho de pesquisa.

\section{ANÁLISE DOS DADOS}

Após ordenamento, seleção e leitura dos documentos, procedeu-se a análise do material empírico que teve como base os elementos teóricos do estudo e a articulação entre as categorias analíticas, estabelecidas a priori, e operacionais, a fim de estabelecer um conjunto de evidências que possibilitassem responder as questões do estudo, tendo como referência os objetivos.

A análise das informações obtidas a partir das diversas fontes utilizadas envolveu dois momentos: a)apreciação do grau de implantação das ações intersetoriais e b)identificação dos obstáculos e concepções sobre intersetorialidade.

A organização da informação presente nas entrevistas foi feita manualmente de forma seqüencial, com cada entrevista isoladamente, através de codificação, utilizando-se unidades de registro para classificar extratos do texto que expressassem os pensamentos e ações dos atores sociais. Para tanto, foram utilizadas as categorias analíticas presentes no quadro teórico do estudo que serviram de referência para interpretação dos achados empíricos e seleção das categorias operacionais (MINAYO, 1996). Esse processo levou em conta os três níveis de análise descritos.

Especificamente para apreciação do grau de implantação, as entrevista do Grupo de Trabalho Intersetorial Municipal (GTIM) ainda foram analisadas tendo em vista os critérios estabelecidos no Quadro I, para classificar o grau de implantação das ações intersetoriais. Nessa direção, foi realizada a redução dos textos em unidades de registros que contivessem trechos de 
falas relacionadas aos critérios e atividades dos componentes da implantação, selecionados para a análise.

O ordenamento do material empírico coletado possibilitou a identificação de convergências e divergências entre os diversos discursos dos atores sociais que foram comparadas com outras entrevistas, observações registradas em diário de campo e evidências retiradas dos documentos analisados.

A triangulação feita entre as evidências encontradas e as diversas fontes de informação utilizadas teve como objetivo reduzir os vieses das autoras e buscar proceder a construção do objeto de análise tendo por referência os pressupostos inicias do estudo.

\section{O PROGRAMA DE REDUÇÃO DA MORTALIDADE NA INFÂNCIA (PRMI): O MUNICÍPIO “CASO"}

O Projeto Redução da Mortalidade na Infância (PRMI) foi implantado no Estado da Bahia em junho de 1995, tendo como objetivo geral melhorar a qualidade de vida nos municípios baianos considerados de maior risco para sobrevivência infantil, selecionados a partir de critérios de renda familiar, grau de instrução materna, prevalência da desnutrição e condições de saneamento básico dos domicílios.

Utilizou como metodologia o desenvolvimento de ações intersetoriais e a criação de Grupos de Trabalho Intersetoriais Estadual, Regional e Municipal (GTIE, GTIR e GTIM) que, sob a coordenação da Secretaria Estadual de Saúde (SESAB), deveriam atuar conjuntamente com outras áreas governamentais no planejamento, implantação e/ou implementação de ações e estratégias visando a redução da mortalidade materna e na infância, a saber: Saúde e Saneamento, Assistência Social e Judiciária, Educação e Produção (BAHIA, 1995).

Em 1998, com a ampliação do projeto no nível estadual, o município "caso" passa a integrá-lo, cabendo a decisão final de aceitação ao gestor municipal. A deflagração do processo deu-se a partir da aceitação do município de Alvorecer em realizar o seminário de implantação e criar Grupo de Trabalho Intersetorial Municipal (GTIM), que ocorreu em novembro do referido ano.

O processo eleitoral no município de Alvorecer deu-se através de coligações dos partidos de situação ligados ao governo estadual. Não obstante 
outros partidos de situação estarem ligados ao partido governista, no âmbito local, estes não apoiaram a candidatura do prefeito que era então candidato da situação.

Em 1997, com a vitória dos partidos governistas, assumiu o governo local o Partido Trabalhista Brasileiro (PTB). No entanto, devido a um grave problema de saúde, o prefeito eleito não foi empossado e o vice-prefeito, do Partido Liberal (PL), assumiu o governo por noventa dias. Após esse período, apesar de o estado de saúde do prefeito não ter melhorado, o vice é arbitrariamente afastado do poder e a condução da prefeitura é assumida pelo chefe de gabinete, o filho do prefeito. Frente à nova situação irregular, ocorrem as dissidências, o vice rompe com o prefeito e os seis vereadores que o apoiavam o acompanham. Esse fato teve grande repercussão no município e todos os entrevistados, sem exceção, referiram-se ao acontecimento e afirmaram que quem governava não era o prefeito e, sim, sua família.

[...] O prefeito, a gente sabe que ele é doente, ele não participa de quase nada, então inicialmente começou o vice-prefeito. 0 vice-prefeito administrou durante três meses. Mas eles mesmos se desentenderam e os próprios filhos do prefeito chegaram lá e tomaram o poder do vice-prefeito. [...] E.1(p.10)/GTIM

Frente a tal situação, a base de legitimidade e legalidade do poder municipal que poderiam dar sustentação ao projeto no âmbito municipal encontrava-se bastante prejudicado, tendo em vista a diminuição da adesão de seus munícipes por força dos acontecimentos. A partir de então, verificou-se uma recomposição da base política do governo municipal: seis vereadores passaram a apoiar o prefeito, seis, o vice, e um ficou independente. Diante desse quadro, ocorreu outra recomposição da base política do governo local com a vinda de um dos vereadores que apoiava o viceprefeito, ficando o prefeito com a maioria na câmara, ou seja, sete vereadores. Esse fato possibilitou o "retorno" do prefeito, que passou a "governar" assessorado pelos filhos.

[...] São treze vereadores. Depois, com as negociações, ninguém sabe lá, como eu não sei, o prefeito conseguiu, a maioria fazer. Conseguiu trazer mais um vereador para o lado dele, com isso ficou, ele ficou com sete, o outro ficou com cinco e ficou um que trabalha de forma independente [...] E.1 (p.10)/GTIM 
Alvorecer situa-se na região econômica do litoral sul, possuindo uma extensão territorial de cerca de $200 \mathrm{Km}^{2}$ (BAHIA, 1996). Com uma população estimada de aproximadamente 17.000 habitantes em 1991. Possuía quatro bairros, um distrito e um povoado, ambos localizados na zona rural. Tinha como principal atividade econômica a agricultura e em relação ao mercado informal de trabalho, observava-se um crescimento gradativo em decorrência do desemprego e da crise da monocultura do cacau (ALVORECER, 1997). O poder aquisitivo da população era baixo e o grande empregador era a prefeitura.

O município dispunha de cerca de 5.000 unidades domiciliares cadastradas. Na zona urbana, as construções eram, na sua maioria, de alvenaria simples, e na zona rural havia predominância de construções de adobe. O sistema de eletrificação da Companhia de Eletricidade da Bahia (COELBA) atendia a 3.760 domicílios (94\%) na zona urbana e 240 (6\%) na zona rural (BAHIA, 2000).

O Sistema de captação, tratamento e distribuição de água era feito pela Empresa Baiana de Água e Saneamento (EMBASA) através de duas subestações, abastecendo cerca de 4.000 domicílios, distribuídos na sede, três bairros e um distrito. O povoado Jardim Bela Vista possuía rede distribuidora municipal com dois reservatórios, porém a água não recebia nenhum tipo de tratamento. De acordo com levantamento feito, em janeiro daquele ano, pelo escritório local da Empresa Baiana de Água e Saneamento (EMBASA), só no centro do município existiam 170 imóveis que se abasteciam de água de cisternas, sem nenhum tratamento.

De acordo dados do Instituto Brasileiro de Geografia e Estatística e Fundo das Nações Unidas para Infância (IBGE/UNICEF, 1994) baseado no CENSO/1991, 100\% dos domicílios do município apresentavam esgotamento sanitário inadequado, não possuindo rede coletora nos mesmos. Os dejetos e águas residuárias eram lançadas no rio ou em terrenos próximos às moradias e/ou a céu aberto. O serviço de limpeza pública fazia coleta do lixo na sede, de segunda a sábado; nos bairros, de duas a três vezes por semana e no povoado e distrito, de uma a duas vezes na semana. O lixo era depositado em um terreno baldio, no povoado Jardim Bela Vista, a céu aberto.

O Sistema Educacional era composto por cerca de cinqüenta escolas. O município possuía quarenta escolas com 4.000 alunos matriculados no ensino fundamental, da $1^{\mathrm{a}}$ a $4^{\mathrm{a}}$ série. O sistema estadual de educação 
dispunha de cinco escolas, com um total de 3.000 alunos matriculados no ensino fundamental e no ensino médio. O sistema educacional privado tinha uma escola com 600 alunos matriculados no ensino médio (ALVORECER, 1999).

A rede de serviços de saúde era constituída por cinco unidades de saúde, sendo três na zona urbana (Centro de Saúde tipo II) e dois na zona rural (Posto de Saúde tipo I), um hospital privado, três consultórios médicos na zona rural e doze na urbana (destes, dez eram do município e dois privados). Havia ainda dois consultórios odontológicos na zona urbana, dois na zona rural, além de dois laboratórios de análises clinicas: um do município e outro privado, ambos na zona urbana.

Ao assumir a Secretaria Municipal de Saúde, a nova gestora tomou medidas para habilitar o município na Gestão Plena da Atenção Básica, o que ocorreu em julho de 1998. O Conselho Municipal de Saúde foi reorganizado e a secretária foi eleita presidente do mesmo.

Conforme relatório de gestão, foram feitas as seguintes realizações pela secretária de saúde: ampliação do quadro de recursos humanos, inicialmente, através da realização de concurso e, posteriormente, por meio de contratações; implantação, em novembro de 1997, do Programa de Agentes Comunitários de Saúde (PACS), com cobertura superior a $80 \%$ da população (Bahia, 2000); informatização e implementação do sistema de informação em saúde: SIM, SINASC, SINAN, SIABMUN, SISVAN, SIGAB, BPA, PNI, e o SIA/SUS, implementação das ações de vigilância epidemiológica e sanitária, realização da I Conferência Municipal de Saúde, em 1999, readequação da rede física e da capacidade instalada com aquisição de materiais e equipamentos, implantação do Programa Saúde da Família (PSF), com duas equipes, com uma cobertura de cerca de 30\% (BAHIA, 2000); foi implantado o Plano de Combate às Carências Nutricionais (PCCN) em 1999 e foram implementados programas de assistência na área materno-infantil, dentre eles o Projeto de Redução da Mortalidade na Infância (PRMI) em 1998 (ALVORECER, 1999).

A despeito dessas mudanças, o nível de organização e participação da população era tímido, devido principalmente ao fato de que a maioria dos representantes da população no Conselho Municipal de Saúde eram funcionários da prefeitura. Com referência a esse fato, um dos atores sociais entrevistados afimou: 
[...] na Secretaria de Saúde, existe ali um número pequeno de pessoas que não são vinculadas ao poder.[...]. Então, as ações ficam centralizadas todas ali, porque os servidores nunca vão, jamais, de encontro às ações da própria secretaria, né? [...] o próprio Conselho fica inibido de dizer assim: Olha ... se a senhora tivesse participado da Conferência Municipal de Saúde [...] E.1 (p.12)/GTIM

Importa ressaltar que, apesar da reestruturação da vigilância sanitária, as ações voltadas para o controle dos riscos ambientais e dos serviços efetivamente não vinham ocorrendo.

O plano municipal de saúde (1997 a 2000), tinha como diretrizes a descentralização, hierarquização, controle social, articulação interinstitucional e intersetorial, ações prioritárias na promoção de saúde, melhoria da qualidade da assistência, implantação do sistema de informação em saúde e recursos humanos. No entanto, não especificava as ações voltadas para o controle dos problemas de saúde da criança, como também no relatório de gestão de 1998 nada constava sobre o projeto (ALVORECER, 1997).

\section{A IMPLANTAC̣ÃO DAS AC̣ÕES INTERSETORIAIS}

A análise feita revelou que as ações intersetoriais encontravam-se em um estágio incipiente de implantação no município "caso", com uma proporção global de adequação entre o previsto e o realizado de 47\% (Quadro 2 e Figura 7 ).

A Figura 7 mostra que a incipiência dessas ações devia-se, em grande parte, à não implantação de algumas atividades ou critérios relacionados aos seguintes componentes:

- Observava-se no componente I, organização do grupo de trabalho intersetorial municipal do Projeto de Redução da Mortalidade na Infância (GTIM/PRMI), que a não realização da feira de saúde, evento considerado como importante estratégia de sensibilização da comunidade e envolvimento de diversos setores, correspondente ao critério/atividade 3, não foi organizada. Nas entrevistas realizadas, a maioria dos entrevistados desconhecia essa ação e a possibilidade de sua execução. 
- No componente III, desenvolvimento das ações setoriais, apenas o setor saúde desenvolveu parcialmente suas ações. Os outros setores: educação, saneamento, produção e ação judiciária e social desenvolveram de forma incipiente e/ou não desenvolveram nenhuma das atividades previstas, tais como (Quadro 2 e Figura 7):

- Educação - não foram contempladas, nas diversas disciplinas curriculares, conteúdos referentes à temática da mortalidade na infância, conforme pode ser observado no item 9.3;

- Saneamento - a setorial responsável pelo "saneamento" não implantou, ampliou e/ou readequou a rede de esgoto sanitário, não executou obras voltadas para o aterro sanitário, não promoveu reciclagem do lixo e não implantou oficinas municipais de saneamento, conforme itens 10.2, 10.4, 10.5 e 10.6;

- Produção - o setor encarregado da "produção" não desenvolveu nenhuma ação de apoio às organizações comunitárias, não implementou o funcionamento das comissões tripartite e paritárias de emprego, não promoveu capacitação e treinamento para os pequenos produtores rurais, nem cursos profissionalizantes em parcerias com a Secretaria do Trabalho e Ação Social (SETRAS) e/ou universidade, de acordo com os itens 11.2, 11.3 e 11.4;

- Assistência social e jurídica - o setor encarregado não realizou capacitações e oficinas em articulação e parceria com Secretaria do Trabalho e Ação Social (SETRAS) e/ou outros órgãos envolvendo recursos humanos dos cartórios, saúde e creches, não estimulou ações de assessoria previstas para implementação dos conselhos de assistência social e da criança e adolescente e não promoveu a divulgação das ações pertinentes ao PRMI à população, conforme itens 12.1, 12.2 e 12.3;

- Saúde - o setor "saúde" não desenvolveu práticas educativas, conforme previsto no item 8.8 .

- Em relação ao componente IV, articulação entre as ações intersetoriais, não foram realizadas ações conjuntas, integradas, e 
articuladas, de acordo com o previsto no critério/atividade 13 (Quadro 2 e Figura 7). Essa incipiência pode ser inferida através da análise do discurso de alguns entrevistados que, quando inquiridos sobre aspectos relacionados ao projeto e as ações conjuntas desenvolvidas, eram incapazes de mencionar os mesmos.

[...] nós consideramos assim ainda o grupo assim até como uma coisa muito [...] é o trabalho que está sendo feito [...] não, é chamado ainda de embrião. [...] A gente ainda vê uma coisa muito prematura, muitas coisas ficam nas discussões e de forma conjunta, [...] E. 1(p.2)/GTIM

Apenas puderam ser consideradas como "implantadas" algumas ações setoriais de saúde do componente III referentes às atividades 8.1 (Cobertura vacinal), 8.7 (Assistência ao Planejamento Familiar) e 8.11 (Acompanhamento do Crescimento e Desenvolvimento) e a atividade 2 do componente I, organização do Grupo de Trabalho Intersetorial Municipal (GTIM)/ PRMI que diz respeito à realização do seminário de sensibilização e implantação com a participação dos representantes do GTIR.

Observa-se que todas as três atividades do componente II, gestão, itens 5 (características do planejamento), 6 (coordenação e direção) e 7 (acompanhamento e avaliação) encontravam-se em um estágio de desenvolvimento incipiente, bem como algumas ações setoriais de saúde, itens 8.3 (Controle das Infecções Respiratórias Agudas), 8.6 (Assistência ao prénatal, parto e puerpério), 8.9 (Implantação e/ou implementação do sistema de informação em saúde) e 8.10 (Implantação e/ou implementação do PACS) (Quadro I-A e Figura 7).

Em relação às características do processo de gestão (planejamento, coordenação, direção, acompanhamento e avaliação), essa incipiência pode ser observada, também, a partir dos discursos dos atores sociais entrevistados:

\section{[...] Ficou naquele planejamento do Seminário e pouco foi feito em termos de dizer assim: vamos planejar, vamos planejar as ações, vamos discutir, vamos analisar o que foi feito, vamos analisar nossas debilidades, vamos ver porque não fizemos, qual o potencial que nós temos para fazer. E.1 (p.19)/GTIM}

Dentre os componentes analisados, a condução do processo que consiste na organização e estruturação do Grupo de Trabalho Intersetorial Municipal (GTIM) foi o único que conseguiu ser parcialmente implantado. 
Observou-se que em relação à percepção dos atores sociais envolvidos, a realização do seminário marcou positivamente seus membros, criando uma grande expectativa em torno do projeto pela possibilidade de desenvolvimento de um trabalho que iria ajudar a reduzir a mortalidade na infância e melhorar as condições de vida de grupos populacionais específi$\cos$ (E. 1, 2, 4, 5, 6, 7, 1012 e 14).

Para os membros do grupo de trabalho intersetorial municipal (GTIM) as visitas preliminares realizadas pelo grupo de trabalho intersetorial regional (GTIR) e Secretaria de Saúde para sensibilização, tanto dos representantes institucionais quanto das organizações populares, foram insuficientes do ponto de vista de apoio e participação efetiva necessária para operacionalização das ações (E.4, 6, 8, 13, 14,).

0 fato de o funcionamento do grupo de trabalho intersetorial municipal (GTIM) ocorrer de forma esporádica e irregular pode ter contribuído para não implantação e/ou insuficiência de algumas atividades dos diversos componentes, como também ser responsável pela desmobilização dos representantes do grupo de trabalho.

[...] às vezes dois meses, três meses, fica sem reunir. 0 bom seria se a gente tivesse mais reuniões, mais constantes e ativas. [...] E.14 (p.6)/GTIM

A figura 7 expressa claramente que do ponto de vista da implantação do programa, houve um estímulo relacionado ao componente organizacional e algumas ações setoriais de saúde e que as limitações de sua incipiência estão ligadas à pequena implementação das ações setoriais e da articulação intersetorial.

Nesse sentido, a ausência de apoio e/ou não participação das secretarias de infra-estrutura, agricultura, educação, bem estar social e administração contribuiu decisivamente para essa incipiência, visto que se tratava de um projeto interinstitucional. Fato este que pode ser observado pela análise do grau de implantação realizado das diversas atividades ligadas aos componentes do projeto.

A despeito dos resultados observados no âmbito municipal, os diversos discursos de membros do GTIR e GTIE consideravam que concretamente a intersetorialidade não aconteceu. 


\section{OBSTÁCULOS À IMPLANTAC̣ÃO DAS AC̣ÕES INTERSETORIAIS}

Para identificação dos fatores restritivos à implantação das ações intersetoriais, trabalhou-se com os resultados das entrevistas realizadas com o GTIM, por ser foco principal de análise, e posteriormente com as do GTIR e GTIE, tendo como base os referenciais teóricos e conceituais relacionados aos níveis de análise anteriormente citados.

Nessa direção, foram inicialmente identificados os seguintes obstáculos à implantação do programa:

\section{PROJETO DE GOVERNO}

\section{INCORPORAÇÃO DO PROGRAMA AO PROJETO DE GOVERNO}

No discurso dos entrevistados vinculados ao governo, aparece muito claramente uma sensação de externalidade e distanciamento em relação ao projeto que não é incorporado como "seu" pelo governo municipal e suas instituições, exceto a Secretaria de Saúde, associações e organizações da sociedade civil envolvidas. Esse fato é observado inclusive em relação ao "prefeito em exercício", para o qual, o projeto não parece pertencer ao "seu" programa de governo, a ser algo "de sua gestão", e sim como algo externo que, porém, ele apóia.

Igualmente, e em conseqüência, as secretarias municipais, com exceção da saúde e as instituições estaduais envolvidas, não reconhecem o projeto como importante e necessário, não o incorporando em seus planos operativos e orçamentários, ou têm uma participação "pró-forma".

Ademais, também se reproduz nas associações e organizações da sociedade civil uma percepção vaga e genérica acerca do projeto, bem como de algo que "vem de cima para baixo", decorrente de uma política federal.

[...] é mais uma coisa empurrada. Porque hoje há imposição do Governo Federal que tudo só vem através de grupo. [...] não é a questão local, é uma questão mais que vem de fora para [...] vem de cima para baixo. Não parte muito bem da questão política daqui, e sim de lá de fora. [...] E.1 (p.12)/GTIM 
Evidenciou-se, então, que o grupo de trabalho intersetorial municipal não foi assumido pelas demais secretarias, o que o caracterizou como um projeto setorial da saúde apoiado por algumas associações populares.

Observou-se, principalmente nas entrevistas dos representantes dos grupos de trabalho intersetorial regional e estadual, a mesma percepção de não incorporação do Programa de Redução da Mortalidade na Infância (PRMI) pelo governo estadual e suas secretarias, especialmente no que se refere às áreas ligadas à produção: agricultura, trabalho e ação social e a justiça. Este fato pode ter influenciado a implantação do programa nos níveis regional e municipal, o que se revelou na adesão formal e pela pouca importância e prioridade dadas ao projeto.

[...] essa proposta foi uma proposta imposta. Foi fruto de um decreto governamental. Não foi, pelo que eu tenho conhecimento, não partiu das secretarias, como um todo, a necessidade de um trabalho intersetorial não. [...] E.6 (p.1)/GTIE

Contrariamente a esses depoimentos, foi identificada apenas a fala do representante da Empresa Baiana de Água e Saneamento Regional E.8 (p.6, 11 e 13) que considerava ter havido uma adesão e envolvimento do governo estadual ao Projeto de Redução da Mortalidade na Infância através de sua incorporação ao plano de governo e de suas respectivas instituições hierárquicas.

Importa salientar que o apoio e comprometimento institucional restringia-se à indicação e liberação do representante para participar das reuniões, realização de seminário e feiras de saúde nos grupos de trabalho intersetorial municipal, regional e estadual. A partir dos depoimentos dos entrevistados, supõe-se que o projeto teve um pequeno grau de institucionalização nos três âmbitos de governo. Entretanto, outras limitações também contribuíram para essa incipiência:

\section{REPRESENTAÇÕES DOS DIVERSOS ATORES ACERCA DO SIGNIFICADO E POTENCIAL DO PROJETO}

A concepção de intersetorialidade e/ou trabalho intersetorial difere um pouco nos três âmbitos de gestão do projeto. Nos discursos dos diversos 
atores municipais, a intersetorialidade aparece como um movimento social, expresso pelas idéias de trabalho como missão, militância, tarefa, algo para ajudar as crianças e integrar a comunidade. Quer dizer, algo relacionado à caridade, sonho, ideal, filantropia e assistência social. Além disso, no que diz respeito ao conteúdo das ações, as mesmas freqüentemente eram referidas como atenção básica.

Essas falas revelam um equívoco na concepção desses atores ao não considerarem o grupo de trabalho como uma instância interinstitucional de governo para implementar ações institucionais tais como: saneamento básico, ampliar a cobertura e resolver os problemas de saúde, de educação, de agricultura e geração de emprego e renda, capazes de influir nos determinantes sociais da saúde.

Nesse sentido, o projeto passou a ser considerado como um espaço de articulação de forças políticas para a luta e não como uma instância de poder que tem representantes institucionais e que se omitem de sua responsabilidade enquanto governo, criando, assim, uma justificativa para o imobilismo. Na medida em que o grupo de trabalho intersetorial municipal (GTIM) passou a funcionar como um movimento popular que aglutinava as forças para resolver os problemas da população através de soluções simplificadas e ações individualizadas, ocorreu uma desinstitucionalização do projeto, não só na concepção como na prática. Além disso, as ações referidas eram de cunho "assistencialistas" voltadas para atenção primária.

Essas estratégias de mobilização e divulgação, como a "feira de saúde", que apareciam como substitutas da ação governamental, correspondiam a soluções simplificadas e paliativas para o problema de geração de emprego e renda, deslocando a responsabilidade da esfera governamental para o âmbito dos indivíduos.

Em alguns discursos, a viabilidade de concretização desse trabalho era dada pela negação da vinculação institucional do grupo de trabalho intersetorial municipal (GTIM) à prefeitura. Reconhecer que o programa fazia parte do projeto de governo municipal significava conferir créditos que podiam resultar em acumulação de poder para prefeitura. 0 que implicou relacioná-lo com um ente suprapartidário, como se fosse possível subtrairIhe qualquer conotação política, despolitizando-o. Ou seja, o governo municipal era visto como algo "político-partidário" e não como uma instituição pública. 
Embora a concepção de membros do grupo de trabalho intersetorial regional (GTIR) fosse adequada em relação à determinação complexa e social da saúde e do que seria a intersetorialidade, as idéias sobre a estratégia de atuação do projeto eram semelhantes àquelas do Grupo de trabaIho intersetorial municipal (GTIM), ou seja, o projeto de "organizar" a sociedade, atenção básica e assistência social. Desse modo, verificou-se um distanciamento entre objetivos e atividades desenvolvidas.

Apesar da percepção de membros do grupo de trabalho intersetorial estadual (GTIE) também ser adequada em relação a determinação social e complexa da saúde, as idéias sobre estratégias de implementação do projeto oscilavam entre ação governamental considerada como "forte" e assistência social. Aparecia nos discursos dos entrevistados E.4 (p.3, 4, 17) e E.2 (p. 5) a concepção de intersetorialidade como trabalho em rede e comunicativo, ou seja, uma ação dialógica.

A noção de trabalho conjunto, presente em diversas formulações, remete às idéias de integração, parcerias, união, colaboração e participação do senso comum. Observaram-se, também, percepções diferenciados sobre a participação dos diversos atores no processo de implantação do trabalho intersetorial.

\section{GOVERNABILIDADE}

\section{GOVERNABILIDADE NA GESTÃO DO PROGRAMA}

\section{As características da composição do Grupo de Trabalho Intersetorial Municipal (GTIM) comprometem a governabilidade do Projeto}

Observou-se, na composição do grupo de trabalho intersetorial municipal (GTIM), uma participação prioritária das organizações da sociedade civil, o que não seria problemático, se não estivessem ausentes, exatamente, instituições governamentais-chave para o desenvolvimento das ações intersetoriais, como a Secretaria de Educação, Agricultura e Produção. A pouca importância atribuída ao grupo de trabalho intersetorial municipal (GTIM) pelas instituições revelava-se ainda na prática comum de delegação da participação nas reuniões a suplentes, inclusive a delegação da coordenação do próprio projeto. 
Além disso, era freqüente a indicação de pessoas que ocupavam cargos secundários nas instituições, bem como a ausência de apoio institucional para tomar decisão por parte dos representantes, desconhecimento sobre o funcionamento e organização de seu próprio órgão e ausência de clareza sobre o seu papel, os objetivos e ações desenvolvidas pelo programa.

Caso o projeto fosse relevante e prioritário para prefeitura, haveria uma cobrança do "gestor" em exercício e as instituições indicariam pessoaschave e com autonomia de decidir. Nesse contexto, tanto os representantes quanto as instituições teriam interesse não só em participar como incorporálo como parte de seus planos operativos pela possibilidade das acumulações políticas que este fato poderia gerar.

A composição dos grupos de trabalho intersetorial regional e estadual (GTIR e GTIE), diferem do municipal apenas por serem formados, em sua grande maioria, por mulheres e instituições governamentais. Não obstante a indicação dos representantes estaduais ter ocorrido através de decreto governamental, isso não significou apoio e adesão à proposta pelas secretarias, nem respaldo institucional que implicasse em uma delegação de poder para os seus membros.

Da mesma forma que no grupo de trabalho intersetorial municipal (GTIM), também ocorreu nos grupos de trabalho intersetoriais regional e estadual (GTIR e GTIE) a indicação de pessoas que não ocupavam posições importantes nas suas instituições e não tinham poder de decisão.

Todas essas questões são indicativas do pequeno grau de institucionalização e do pequeno valor que a proposta teve para os diversos atores, principalmente por não atender a suas estratégias individuais ou coletivas de acumulação e capitalização de recursos de poder político, econômico e social.

Em relação à participação efetiva nos três âmbitos de gestão do programa, ela era limitada observando-se a presença de uma representatividade por vezes formal. Os problemas relacionados ao funcionamento do grupo de trabalho intersetorial regional e estadual (GTIR e GTIE) repercutiram no grupo de trabalho intersetorial municipal (GTIM), contribuindo para seu funcionamento inadequado. Desse modo, a execução das ações contempladas nos planos operativos não foram asseguradas, visto que os representantes das instituições estaduais não tinham apoio institucional nem autonomia de decisão, o que dificultava a sua implantação. 
Ademais, o caráter transitório, circunstancial e informal da gestão do programa possibilitou uma desarticulação e funcionamento precário, dificultando a implementação das ações e atividades nos níveis estadual, regional e municipal, expresso principalmente pelo manejo insuficiente dos instrumentos que compõem o processo de gestão do programa.

\section{PROBLEMAS RELACIONADOS COM A COORDENAÇÃO DO PROGRAMA NO ÂMBITO MUNICIPAL, REGIONAL E ESTADUAL.}

A coordenação do programa foi delegada a um técnico nos grupos de trabalho intersetorial municipal, regional e estadual (GTIM, GTIR e GTIE). A falta de liderança política do coordenador dificultou a aglutinação dos gestores municipais e sua adesão ao projeto. Na verdade, a tarefa da coordenação política do processo foi deslocada para o campo técnico, o que gerou incompreensão e comprometeu a governabilidade do projeto. Por outro lado, a dificuldade de coordenação interinstitucional, até pela ausência de experiência em desenvolver esse tipo de trabalho, muito contribuiu para a não operacionalização do projeto.

Observou-se, também, que os conflitos relacionados com a distribuição e disputa de poder entre as secretarias de governo pela condução do projeto implicava no afastamento de algumas instituições e, conseqüentemente, em uma diminuição da adesão, o que interferiu na governabilidade do programa.

\section{ESTABILIDADE DAS DIREÇÕES}

As mudanças constantes das pessoas responsáveis pela condução do processo dificultaram a sua implementação ou causaram um retrocesso do mesmo, porque os novos representantes que chegavam não detinham conhecimento acerca do projeto. Por outro lado, as mudanças ocorridas também nas direções das instituições influenciaram em muito a dinâmica do processo, levando, inclusive, na regional, a uma paralisação quase que total das atividades.

A mudança dos dirigentes das instituições, de representantes das setoriais e da coordenação do projeto está relacionada à inexistência de uma burocracia estável no sentido weberiano, pois caso existisse, não ha- 
veria problema decorrente das mudanças no governo. Porém, como o Estado é patrimonialista e clientelista, os projetos pertencem a determinados grupos, e quem assume os cargos públicos faz questão de trazer seus projetos, descartando os existentes, como também faz freqüentemente uma ampla substituição de técnicos nos diversos postos de trabalho.

Outro problema enfrentado pelos grupos municipal, regional e estadual refere-se à ausência de direção estável. No plano estadual, a delegação da coordenação a terceiros traduziu uma ausência de prioridade ao programa por parte da Secretaria de Saúde do Estado.

A desmotivação, o desencantamento, a ausência de estímulo, a participação "pró-forma" ou pequena dos representantes foram expressões utilizadas pelos diversos atores frente à impotência do não comprometimento institucional, bem como as mudanças freqüentes de coordenação e irregularidade das reuniões. A adesão dos técnicos das regionais e do grupo estadual foi um fator fundamental para a continuidade do projeto, apesar de tudo.

\section{COMPOSIÇÃO POLÍTICA DO MUNICÍPIO}

Por fim, problemas relacionados com a própria governabilidade do município comprometeram a implantação do projeto. De acordo com o "prefeito em exercício" e com o coordenador municipal, a divisão política da câmara dificultou e gerou diversos problemas administrativos e financeiros à prefeitura, o que vinha obstaculizando a implementação das políticas municipais. No entanto, as entrevistas analisadas, inclusive entrevistas abertas realizadas com o vice-prefeito e vereadores de oposição, não apontavam concretamente para a possibilidade de um boicote ao projeto. Além do que, o executivo tinha maioria na câmara, ou seja, tinha uma base de sustentação política que lhe permitia certa liberdade de ação para atuar e implementar o programa. Segundo informações desses atores, o legislativo desconhecia a proposta e não foram convidados para participar do seminário de implantação do projeto no município. 


\section{CAPACIDADE DE GOVERNO}

\section{DESCONHECIMENTO ACERCA DO PROJETO E INCIPIÊNCIA DA ORGANIZAÇÃO MUNICIPAL DE SAÚDE}

As diversas entrevistas revelam a pouca clareza ou ausência de entendimento sobre a proposta da intersetorialidade. Considerar como evidências da implantação das ações intersetoriais a realização de seminários, feiras de saúde, elaboração do plano de ação e regimento interno corresponde a uma redução do projeto aos seus aspectos formais e às atividades "meio", o que, em última análise, corresponde ao pequeno grau de acumulação de poder técnico por parte dos membros dos grupos de trabalho.

Além do mais, o fato de que membros do grupo de trabalho intersetorial regional desconheciam a variação dos coeficientes da mortalidade infantil nesses quatro anos é indicativo de que não foram feitas avaliações sistemáticas e, ao mesmo tempo, considerar que a pastoral tem mais experiência de trabalho intersetorial revela o não entendimento da intersetorialidade como uma proposta governamental que deveria intervir nos determinantes complexos e sociais da saúde.

Nessa direção, observou-se uma dissociação entre o plano e as necessidades, ocorrendo, em alguns casos, dispersão e fragmentação das ações e percepção vaga, genérica e difusa sobre o projeto e suas atividades. Percebe-se que os obstáculos relacionados ao poder técnico referem-se, principalmente, ao pequeno grau de conhecimento acerca do projeto, a não socialização das informações e as mudanças constantes de representantes nos três âmbitos de gestão do projeto. Verificou-se ainda a não utilização do planejamento como um instrumento de gestão o que dificultou a priorização dos problemas.

Foi observado, com certa regularidade, o aparecimento de idéias voltadas para uma consciência sanitária em um estágio atrasado, com ênfase na ideologia da atenção primária e ações extrasetoriais simplificadas, como horta comunitária, distribuição de tanques, cestas básicas.

A ausência de secretarias municipais e a precária organização das existentes levaram o grupo de trabalho intersetorial regional (GTIR) a assumir o papel que seria das secretarias de saúde, ocorrendo uma dispersão das ações e um deslocamento do objetivo do projeto. 


\section{DISTRIBUIÇÃO E DISPUTA PELO PODER LOCAL}

Em relação a distribuição do poder local as secretarias municipais não dispunham de recursos para gerenciar autonomamente, exceto saúde e educação que recebiam verbas federais. Verificou-se uma centralização e concentração de recursos na prefeitura ficando as secretarias com papel de executoras o que dificultava a implantação de ações que não fossem priorizadas pela primeira.

Observou-se também que a disputa de poder entre os grupos políticos que governavam pelo controle de uma fatia dos recursos repassados ao município pelo Sistema Único de Saúde (SUS) gerava conflitos entre as instituições que compunham o sistema de serviços de saúde municipal: a Secretaria Municipal de Saúde, o Sindicato Patronal e o Hospital Santa Rita, conveniado ao SUS. Essa situação acabava interferindo na atenção à saúde prestada à população. Esses conflitos revelavam uma desarticulação no interior do próprio setor saúde e entre as diversas instituições que o compunham na condução das políticas setoriais.

Em relação à distribuição do poder entre as secretarias municipais, o fato desse projeto ter tido sua origem na saúde, fazia com que fosse visto como projeto setorial pertencente a um determinado grupo político e, conseqüentemente, com capacidade de produzir acumulações para o mesmo. A decisão ou não de adesão ao projeto estava relacionada às possibilidades concretas de acumulação política.

Importa ressaltar que a inexistência de recursos específicos para o projeto, com exceção daqueles destinados à setorial "saúde", além de gerar conflitos interinstitucionais, estimulou a disputa pela condução do mesmo e pela distribuição de recursos no interior do próprio setor saúde.

\section{PODER LOCAL}

Na esfera municipal, o exercício do poder político local revelava-se através de uma prática patrimonialista e clientelista que dificultava a continuidade na gestão do projeto, conforme análise feita anteriormente. Além disso, dar autonomia para as secretarias correspondia a distribuir poder político no município. Transferir esse poder para o grupo de trabalho intersetorial municipal (GTIM) correspondia a diminuir as parcelas de poder de cada secretaria. 
Dentre as características do poder político, observaram-se aspectos relacionados à legalidade e legitimidade do governo municipal, já mencionadas anteriormente, e que comprometiam a implantação de políticas públicas.

[...] o envolvimento do prefeito, eu não digo nem do prefeito, porque eu não sei quem é o prefeito. Existe um prefeito eleito, que é o Leandro Matis, e agora existem os prefeitos que mandam na prefeitura, que é o filho de Leandro. Então, com relação, estou colocando, dos prefeitos, né [...] E.8 (p.4)/GTIM

\section{CONCLUSÕES}

A reorganização da atenção à saúde a partir de uma mudança do modelo assistencial centrada na estratégia do desenvolvimento de ações intersetoriais vem enfrentando dificuldades de diversas naturezas. A presente análise reúne indicações de que os principais obstáculos responsáveis pela incipiência da implantação dessa estratégia, no município estudado, estão relacionados com as características do poder local, o projeto de governo, a capacidade de governo, com a distribuição e a luta pelo poder entre as diversas forças que governam, a governabilidade, e com o poder técnico e político.

A dominância de características patrimonialistas e clientelistas no exercício do poder local dificultaram o desenvolvimento do projeto em decorrência das mudanças constantes das pessoas responsáveis pela coordenação do programa, dos dirigentes institucionais e representantes das setoriais. Esse fato revela a inexistência de uma burocracia e direção estáveis no sentido weberiano.

Já a não incorporação da estratégia da intersetorialidade, pelo governo local, enquanto parte do Projeto de Governo, influiu no pequeno grau de envolvimento e participação de instituições municipais importantes e, ao mesmo tempo, pode ser explicada, por um lado, pelo mesmo não ter sido gestado no âmbito local e não ser uma expressão das necessidades sentidas pelos atores sociais na sua busca por autonomia.

Também pode ter influenciado a incipiência do processo de implantação da intersetorialidade o fato de o governo estadual não ter desenvolvido esforços visando viabilizar a coordenação e articulação entre as distintas instituições governamentais, e assim dar materialidade aos objetivos do 
projeto. Esses fatos conduziram à reprodução, nos três âmbitos de gestão do programa, de uma série de problemas que dificultaram a sua implantação, particularmente a participação formal, da maioria dos representantes das instituições, em decorrência da ausência de maior envolvimento dos seus dirigentes.

Além de ser visto como algo externo, que não era assumido pela gestão municipal, mas apenas pela Secretaria de Saúde e, portanto, "setorial", o projeto também era concebido como "movimento social". Como conseqüência, a grande maioria das ações referidas eram de cunho assistencialista, oscilando entre a atenção primária, realização de feiras e a simples reivindicação de melhorias.

Em relação à governabilidade, foram observados problemas relacionados tanto com a gestão do programa quanto com a composição das forças políticas do município, expressos pela própria composição do grupo de trabalho intersetorial municipal (GTIM), que além de conter uma participação majoritária das organizações da sociedade civil, verificava-se uma prática freqüente de delegação a suplentes e a terceiros que ocupavam cargos secundários nas instituições.

Também problemas relacionados com a governabilidade do município, como a escassa maioria na câmara de vereadores, a ocupação de espaços importantes nas instituições de saúde por parte da oposição, bem como a pequena legitimidade do "prefeito em exercício" aparecia como limitações ao exercício do governo e, conseqüentemente, a implantação de programas.

Ademais, a dificuldade de coordenação por parte da Secretaria de Saúde, as irregularidades das reuniões, o caráter transitório e informal da gestão do programa e os conflitos relacionados com a distribuição e disputa pelo poder entre as secretarias de governo pela condução do projeto interferiram nas possibilidades de pactuação e articulação, o que dificultou a operacionalização das ações.

Em relação à distribuição e disputa pelo poder local, verificou-se uma centralização/concentração de recursos na prefeitura, ficando as secretarias sem autonomia, exceto Saúde e Educação, para implantar ações que não fossem priorizadas pela primeira. Dar autonomia a essas secretarias significaria distribuir poder político no município. E deslocar parte desse poder para o grupo de trabalho intersetorial correspondia a diminuir ainda mais as parcelas de poder de cada secretaria. 
No que se refere à capacidade de governo, o pequeno grau de conhecimento acerca do projeto e acumulação de poder técnico por parte dos representantes dos grupos de trabalho revelaram uma redução do programa aos seus aspectos formais e às atividades meio, e um não entendimento da proposta como uma ação governamental que deveria intervir nos determinantes complexos e sociais da saúde.

Em conseqüência, percebe-se uma distância entre o plano e as necessidades, e entre as atividades efetivamente desenvolvidas e o plano. O manejo inadequado e insuficiente dos instrumentos que compõem o processo de gestão do projeto, especificamente a não utilização do planejamento como instrumento de trabalho, reflete escassa acumulação de poder técnico.

Apesar da limitação da análise sobre o contexto organizacional, muitos dos entrevistados apontavam a cultura institucional com excesso de centralização política e seus análogos, ou seja, suas leis, regras, normas, como obstáculos à implantação do programa. Além disso, a precária organização municipal da saúde levou o grupo de trabalho a uma dispersão das ações e a um deslocamento dos objetivos do projeto.

A comparação da presente investigação com outras experiências publicadas, que incorporaram a proposta da intersetorialidade, revela semelhanças no que diz respeito à grande parte dos obstáculos encontrados neste trabalho (OPS, 1980; SCHAEFER, 1981; GUNATILEKE, 1984; GROMPONE, 1988; ROMERO, 1988; OPS, 1984; GOMEZ, 1987; OPS, 1989, 1990; NOVAES, 1990; CHILE, 1991; OPS, 1992).

As limitações desta investigação estão relacionadas ao tipo de estratégia de pesquisa escolhida, as dificuldades existentes na operacionalização da categoria "poder", dada sua complexidade, e o insuficiente estudo do contexto organizacional limitaram as possibilidades de explicação acerca das razões para a incipiência da implantação. Além disso, o processo de criação de consenso em relação ao instrumento de avaliação foi tímido devido a problemas operacionais.

A análise dos processos relacionados à implantação das ações intersetoriais permitiu a formulação de algumas questões que poderão tornar-se objeto de futuras pesquisas: em que medida o contexto organizacional e institucional facilita e/ou dificulta a implantação das ações intersetoriais?; Até que ponto a existência de mecanismos formais influencia a institucionalização desse tipo de proposta? 
Para finalizar, a partir dos achados e das reflexões decorrentes do desenvolvimento do presente estudo, foi possível a formulação de proposições que poderão contribuir para equacionar estratégias de superação de alguns dos obstáculos identificados: assegurar maior envolvimento político com a proposta; mobilizar lideranças político-institucionais e promover a sua estabilidade na condução do processo; definir mecanismos financeiros e orçamentários integrados; adotar medidas técnicas e administrativas coordenadas, articuladas e integradas e desenvolver mecanismos de coordenação interinstitucional e intersetorial pactuados.

\section{NOTA}

${ }^{1}$ Nome fictício.

\section{REFERÊNCIAS}

ALVORECER, Prefeitura Municipal de. Secretaria Municipal de Saúde. Relatório de Gestão. Alvorecer, 1999.

ALVORECER, Prefeitura Municipal de. Secretaria Municipal de Saúde. Relatório de avaliação do grupo de trabalho intersetorial municipal (GTIM). Alvorecer, 1999.

ALVORECER, Prefeitura Municipal de. Secretaria Municipal de Saúde. Plano Municipal de Saúde de Alvorecer - 1997 a 2000 - . Alvorecer, 1997.

ALVORECER, Secretaria Municipal de Educação de. Alunos matriculados na rede municipal de educação. Alvorecer, 1999.

BAHIA, Secretaria de Saúde do Estado da. Avaliação preliminar do processo de implantação do Projeto de Redução da Mortalidade na Infância (PRMI). Salvador, 1995/1998. (mimeo)

BAHIA, Secretaria de Saúde do Estado da. Centro de Informação em Saúde. Estimativa da população residente de Alvorecer em 1999. Salvador, 2000.

BAHIA, Secretaria de Saúde do Estado da. Coordenação de Desenvolvimento da Atenção Básica. Sistema de Informação de Atenção Básica. Salvador, 2000.

BAHIA, Secretaria de Saúde do Estado da. Programa de Redução da Mortalidade na Infância. Salvador, 1995.

BAHIA, Secretaria de Saúde do Estado da. Relatório do Projeto de Redução da Mortalidade Infantil nas áreas de maior risco de sobrevivência. Salvador, maio de 1995. (mimeo)

UFBA, Universidade Federal da/Projeto UNI. O rastro de violência em Salvador. Mortes violentas de residentes em Salvador, 1997: sistema de vigilância das violências. Salvador, 1998. 
BLUMM, M.; SOUZA, C. Autonomia política local: uma revisão de literatura. Foz de Iguaçu, XXII ENANPAD, 1998 (impresso em CD-ROM).

BRASIL. IBGE/UNICEF. Municípios brasileiros: crianças e suas condições de sobrevivência. Censo Demográfico. Brasília, 1994.

BRASIL. Ministério da Saúde. Projeto para Redução da Mortalidade na Infância. Brasília, 1995.

BRASIL. Ministério da Saúde. Promoção da saúde: Carta de Ottawa, Declaração de Adelaide, Declaração de Sundsvall, Declaração de Bogotá. Brasília, 1996.

BRASIL/UNICEF. Relatório da Conferência sobre Cuidados Primários de Saúde Alma - Ata. URSS, 1978.

BUSS, P.M. Promoción de la salud y la salud pública: una contribuición para el debate entre las escuelas de salud pública de América Latina y el Caribe. Rio de Janeiro, 2000.

CHILE. Ministério de Salud Programa Interinstitucional MAQUEHUE: propuesta para un desarrollo local autosustentable. TEMUCO, 1991.

CHILE. Ministerio de Salud. Analisis estrategica (AE) y desarrollo participativo en salud pública: proposiciones metodologicas (documento de trabalho). Santiago, 1991.

COSTA, J.B.A. A ressignificação do local: o imaginário político brasileiro pós-80. In: O novo município: economia e política local. São Paulo em perspectiva, FSEAD, v. 10, n. 3, p. 113-118, jul/set, 1996.

DAVIDIVICH, F. Poder local e município, algumas considerações. RAP, Rio de Janeiro, v. 27, n. 1, p. 5-14, 1993.

DENIS, J.L.; CHAMPAGNE, F. Análise de implantação. In: HARTZ, Z.M. de A. (Org.) Avaliação em saúde: dos modelos conceituais à prática na análise da implantação de programas. Rio de Janeiro: FIOCRUZ, 1997, 131 p.

FISCHER, T. Poder local. Rio de Janeiro: FIOCRUZ,1993.

GERSCHMANN, S. Sobre a formulação de políticas sociais. In: FLEURY, S.(Org.) Reforma Sanitária: em busca de uma teoria. São Paulo: CORTEZ/ABRASCO, 1989.

GOMEZ, D.J. Intersectorialidad en salud en el proceso de decentralización y desconcentración y regionalización en el departamento de Cajamarca. Organización Panamericana de la Salud y Ministerio de Salud de Perú. Projeto Intersetorialidad en salud. Perú, 1987.

GROMPONE, R. Intersectorialidad, decentralización y su efecto en la dimensión salud: informe de actividades realizadas en el Cono Sur de Lima en el período de octubre de 1987 a enero de 1998. Organización Panamericana de la Salud y Ministerio de Salud de Perú. Projecto Intersetoria-lidad en salud. Perú, 1988.

GUANATILEKE, G. Intersectoral linkages and health development: case studies in India (Kerala State), Jamaica, Norway, Sri Lanka, and Thailand. Geneva: OMS, 1984. (Publication n. 83).

JUNQUEIRA, L.A.P.; INIJOSA, Rose Marie. Desenvolvimento social e intersetorialidade: a cidade solidária. São Paulo : FUNDAP, 1997. 
JUNQUEIRA, L.A.P. Novas formas de gestão na saúde: descentralização e intersetorialidade. Saúde e Sociedade. v. 6, n. 2, p. 31-46, 1997.

MATUS, C. Política, planejamento e governo. 3. ed., Tomo I. Brasília: IPEA, 1997. MENDES, E.V. Uma agenda para a saúde. São Paulo: Hucitec, 1996.

MINAYO, M.C.O desafio do conhecimento: pesquisa qualitativa em saúde. 4. ed. São Paulo-Rio de Janeiro: Hucitec, 1996.

NOVAES, H. de M. Acciones integradas en los sistemas locales de salud: analisis conceptual y apreciación de programas selecionados en América Latina. In: Organización Panamericana de Salud. (Cuaderno técnico n. 31). Washington D. C., 1990.

NUNES, E. Poder local, descentralização e democratização: um encontro difícil. In: O novo município: economia e política local. São Paulo em Perspectiva, Fundação SEAD, v. 10, n. 3, p. 32 - 39, 1996.

ORGANIZACION PANAMERICANA DE SALUD (OPS). Glosario de términos empleados en la série "Salud para Todos", n. 1-8. Ginebra,1984.

ORGANIZACION PANAMERICANA DE SALUD (OPS). Desarrollo y fortalecimento de los sistemas locales de salud. La intersectorialidad. Washington. D. C., 1989.

ORGANIZACION PANAMERICANA DE SALUD (OPS). Desarrollo y fortalecimento de Ios sistemas locales de salud: la participacion social. Washington,1990. HSD/SILOS-3.

ORGANIZACION PANAMERICANA DE SALUD (OPS). Desarrollo y fortalecimento de los sistemas locales de salud: la participacion social. Estudios de casos. Washington, 1990. HSD/SILOS-7.

ORGANIZACION PANAMERICANA DE SALUD (OPS). Desarrollo y fortalecimiento de los sistemas locales de salud en la transformacion de los sistemas nacionales de salud : la administracion estrategica. El sector salud y el dasarrollo intersectorial. Washington, D. C., 1992.

ORGANIZACION PANAMERICANA DE SALUD (OPS). Estrategia salud para todos en el año 2000. La articulación intersectorial. Washington D. C., 1980. (Documento Oficial n. 173).

ORGANIZACION PANAMERICANA DE SALUD (OPS). Oficina Sanitaria Panamericana, Oficina Regional de La Organización Mundial de La Salud. Formulación de Políticas de Salud. Centro Panamenricano de Planificación de La Salud. Santiago-Chile, 1975. (Documento Oficial n. 173).

ORGANIZACION PANAMERICANA DE SALUD (OPS). Las condiciones de salud en las Americas. Publicación cientifica No 524. Seção: infraestructura de los sistemas de salud. Articulación intersectorial. Washington, D. C., 1990.

ORGANIZACION PANAMERICANA DE SALUD (OPS). Participación de la comunidad y el desarrollo en las Américas: Análisis de estudios de casos selecionados. (Publicación Cientifica, n. 473). Washington D. C. 1984. 
ORGANIZACION PANAMERICANA DE SALUD (OPS). Plan Decenal de Salud Pública de la Carta de Punta del Este. Boletim da Oficina Panamericana de Saúde, v. 51, n. 5, p. 473-494, 1961.

ORGANIZACION PANAMERICANA DE SALUD (OPS). Plan Decenal de Salud para las Américas: informe final da III Reunión Especial de Ministros de salud de las Américas. (Documento Oficial n. 118). Santiago, Chile, 1972.

ORGANIZAÇÃO PANAMERICANA DE SAÚDE; ITÁLIA. Coordenação de projetos de saúde do Brasil. Saúde, meio ambiente e luta contra a pobreza (SMALP): vigilância à saúde no processo de distritalização, plano operativo. Brasil. Salvador, 1991.

PAIM, J.S. Reforma sanitária e modelos sssistenciais. In: ROUQUAYROL, M. Z. Epidemiologia e Saúde. 4. ed. Rio de Janeiro: MEDSI, 1994.

RIVERA, F.J.U. Agir comunicativo e pensamento social: uma crítica ao enfoque estratégico, Rio de Janeiro: FIOCRUZ, 1995.

ROMERO, G.E. Anális del proceso de desconcentración y descentralización y su impacto en la intersectorialidad en salud en la micro-región de Huari. OPAS y M. S.de Perú. Projeto Intersetorialidad en salud. Perú, 1988.

SCHAEFER, M. Coordinacion intersectorial y aspectos sanitarios de la ordenacion del medio ambiente: examen de la experiencia de distintos países. Cuad Sal. 74, Spain, OMS, 1981.

SOUZA, C. Reinventando o poder local: limites e possibilidades do federalismo e da descentralização. In: O município: economia e política local. São Paulo em Perspectiva, Fundação SEAD, v. 10, n. 3, p. 103-111, 1996.

SUARÉZ, J. Contribuição ao marco teórico para o desenvolvimento da ação intersetorial. Saúde, Educação, Medicina, v. 26, n. 2, p. 225-241, 1992.

TESTA, M. Estructura de poder en el sector salud. CENDES-UCV, 1982.

TESTA, M. Pensamento estratégico e lógica de programação: o caso saúde. São Paulo-Rio de Janeiro: HUCITEC/ABRASCO, 1995.

TESTA, M. Pensar em saúde. Porto Alegre: Artes Médicas, 1992. 226p.

TESTA, M. Planificacion estrategica en el sector salud. CENDES-UCV, 1981.

WORLD HEALTH ORGANIZATION. Report of the International Conference on Intersectorial Action for Health : a cornerstone for health - for - all in the twenty first century. Halifax, Nova Scotia, Canada, 1997.

VIEIRA-DA-SILVA, L.M. As AIS/SUDS no município. Repercussões e obstáculos: 0 caso de Camaçari. Saúde em Debate, CEBES, v. 31, p. 72-82, 1991.

YIN, R. Case study research, design an methods. 2. ed. Ann Arbor, Michigan. Health Administration Press, 1993. 
Figura 1

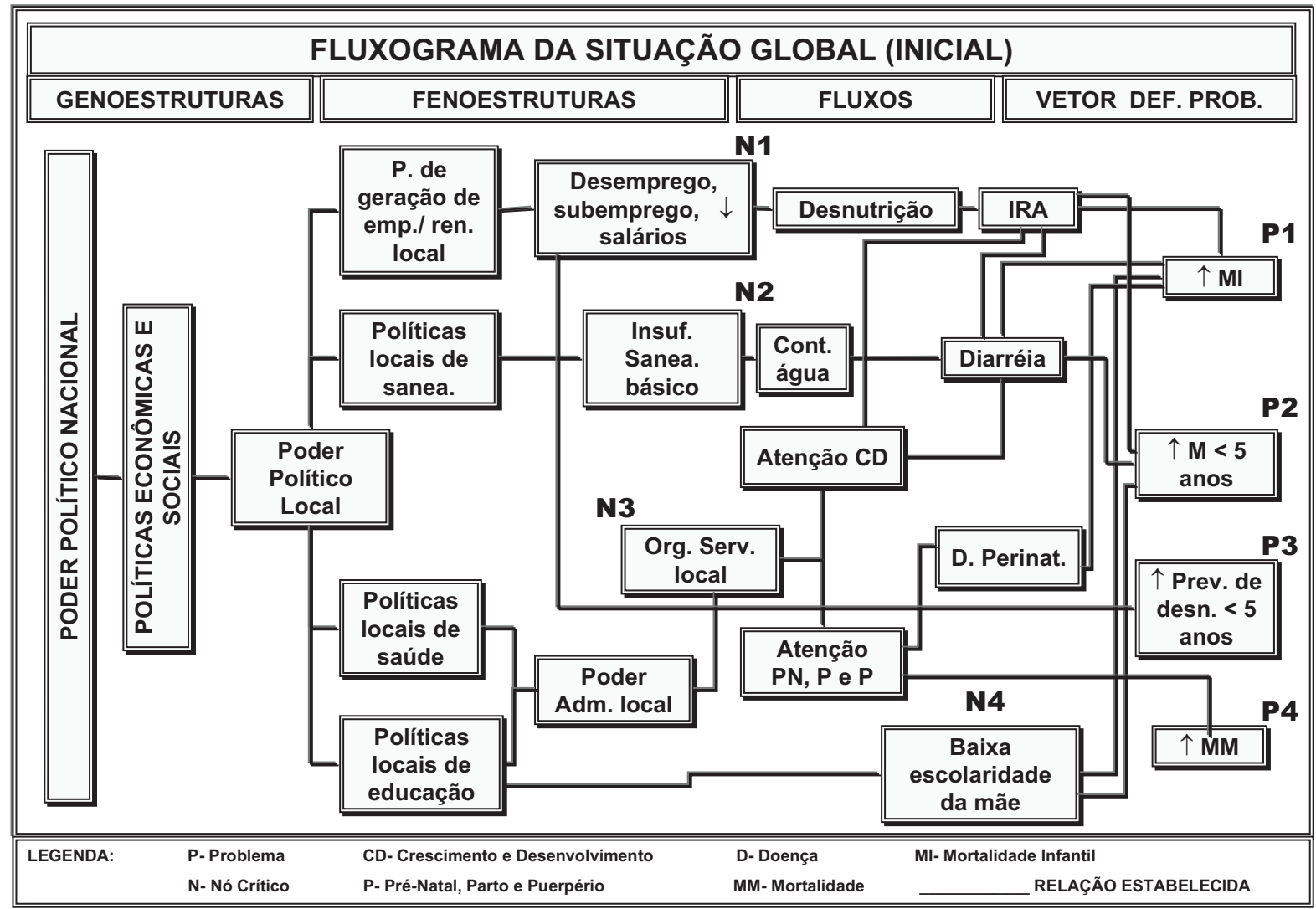


Figura 2

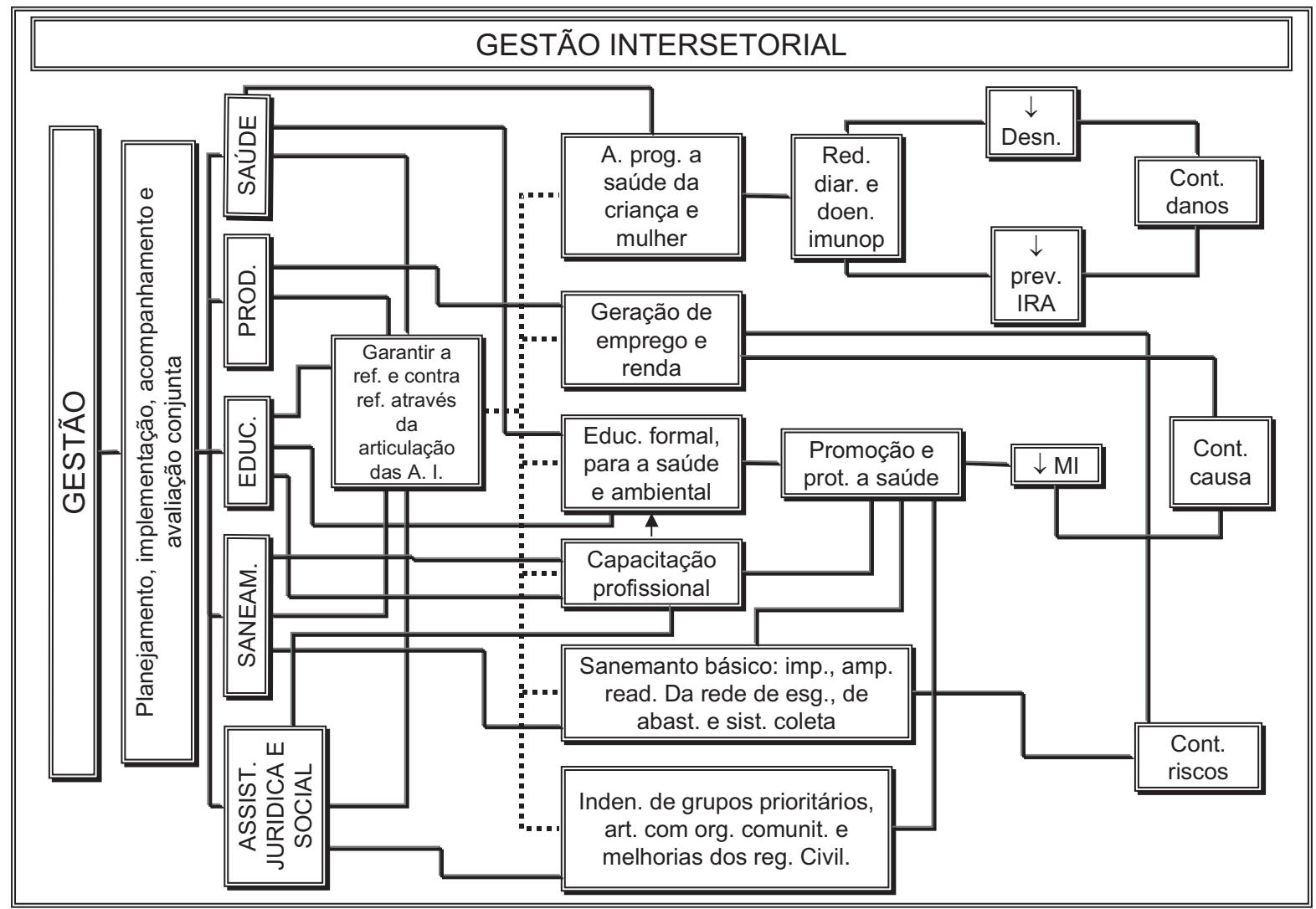


Figura 3

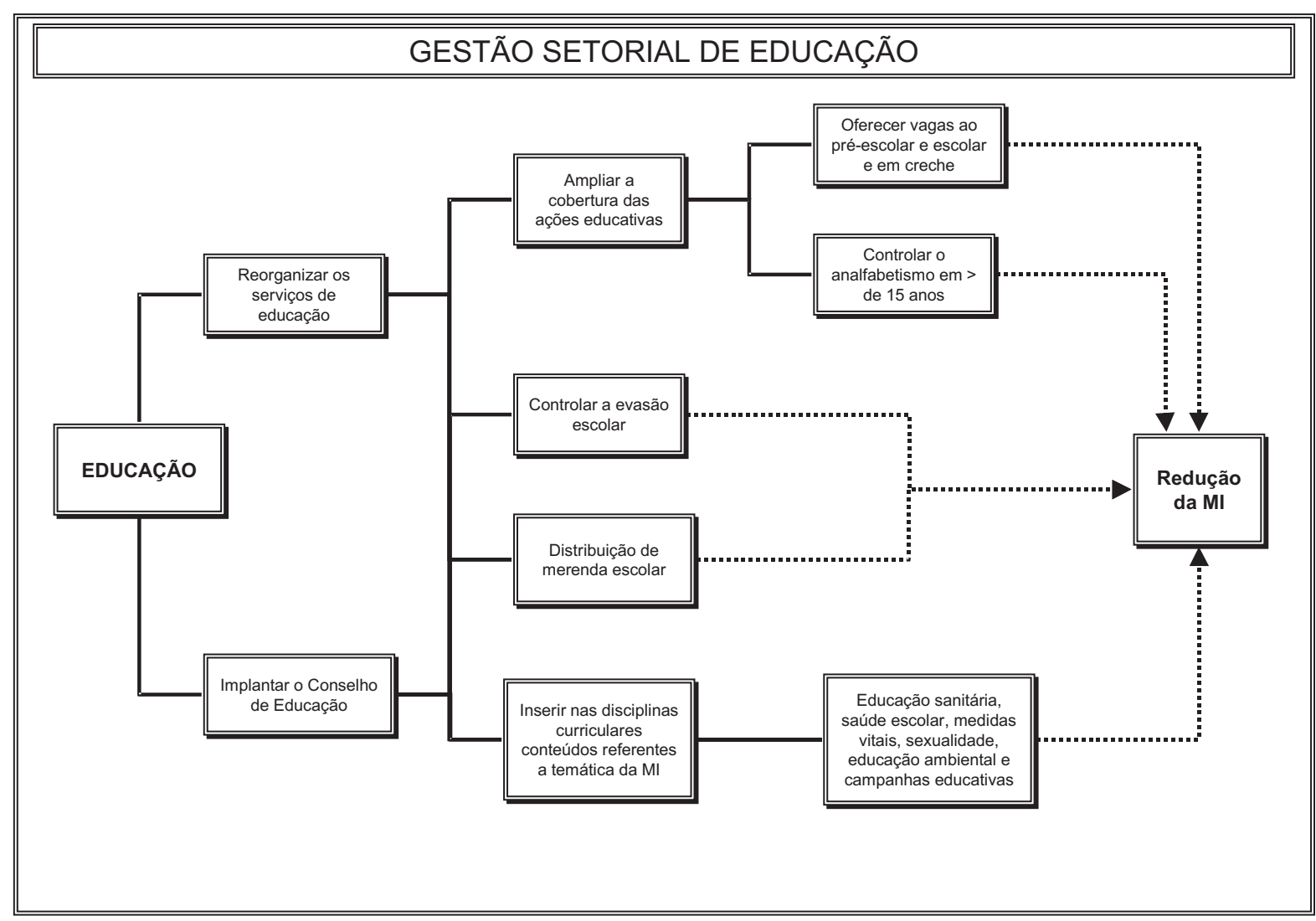


Figura 4

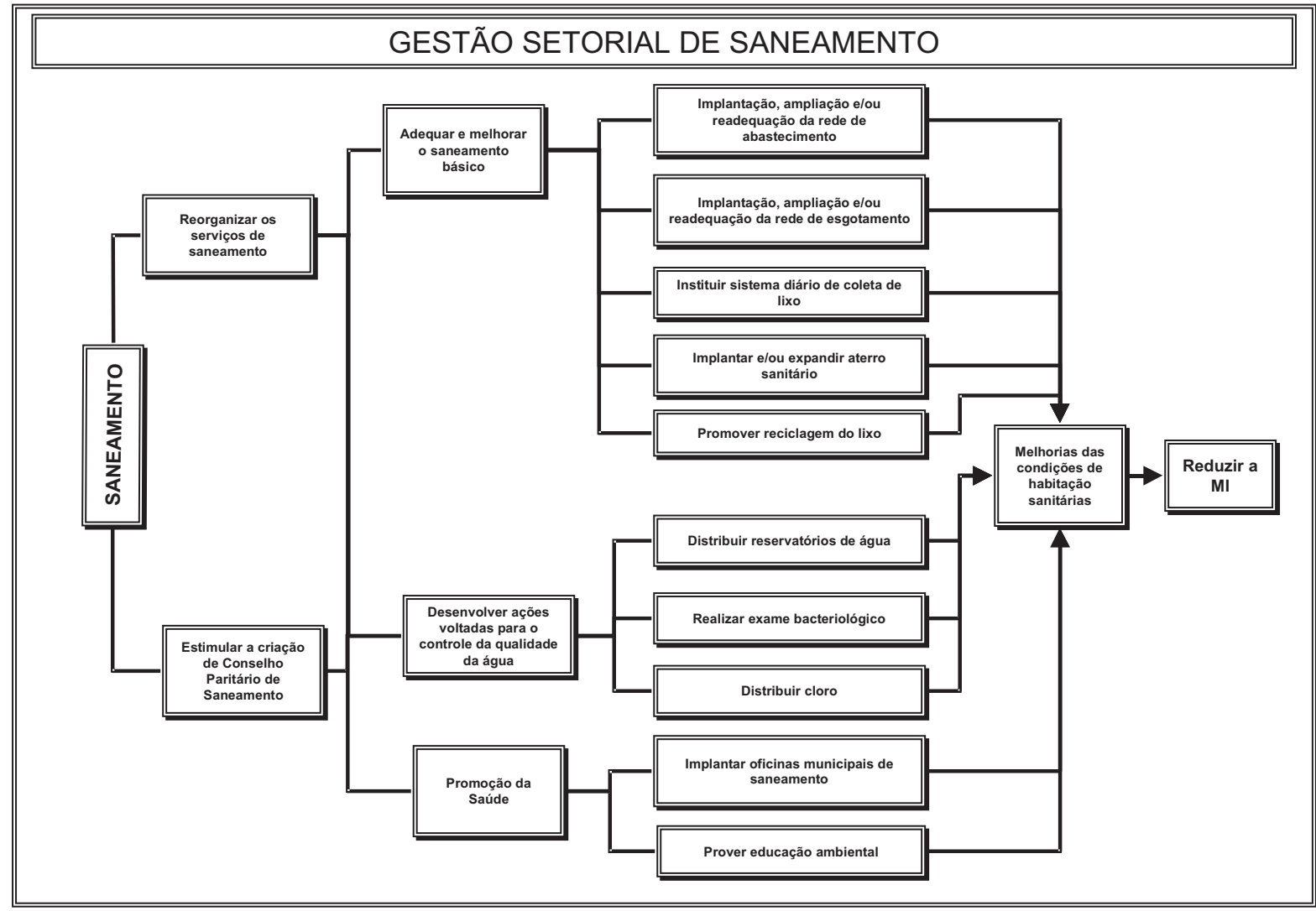


Figura 5

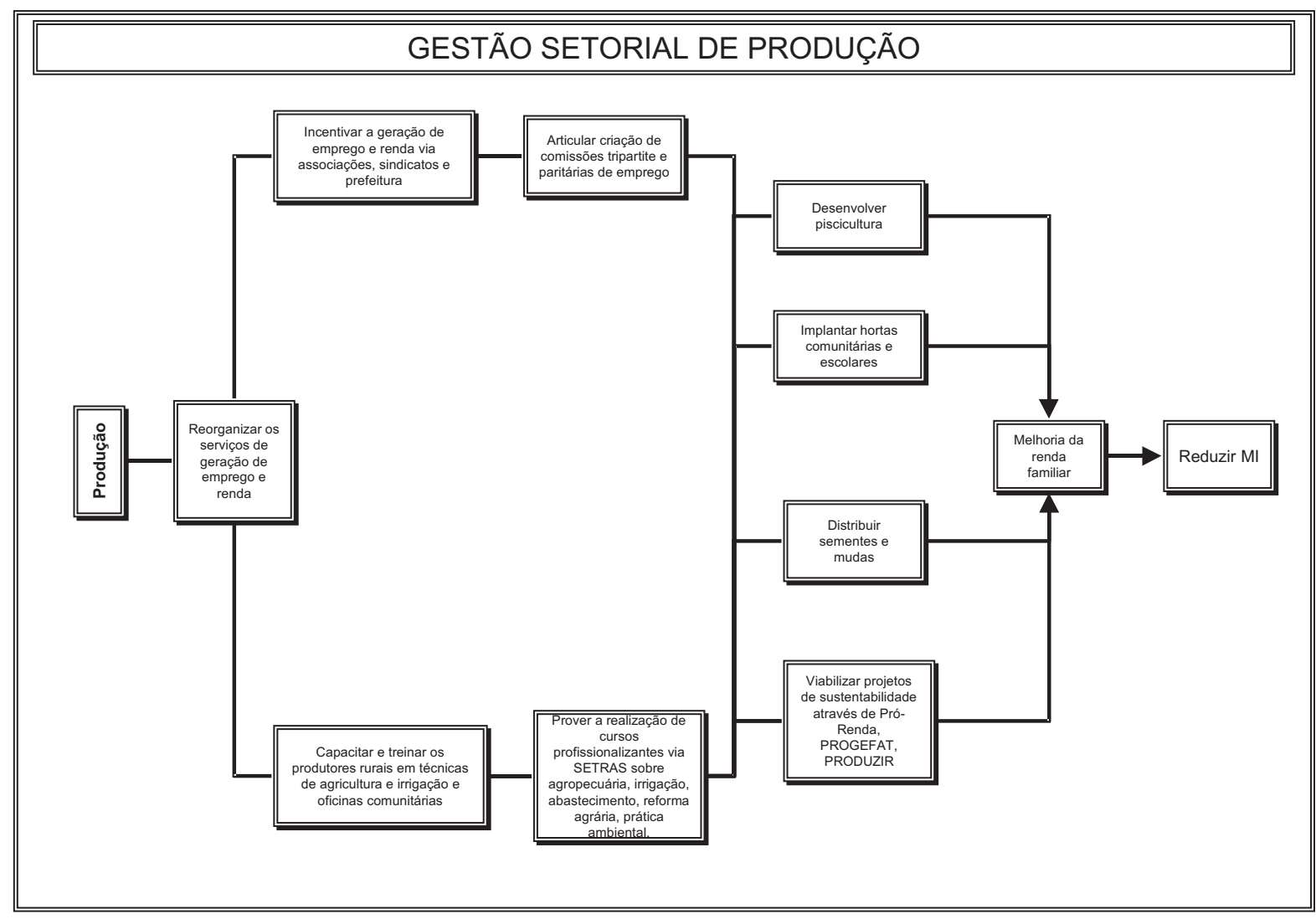


Figura 6

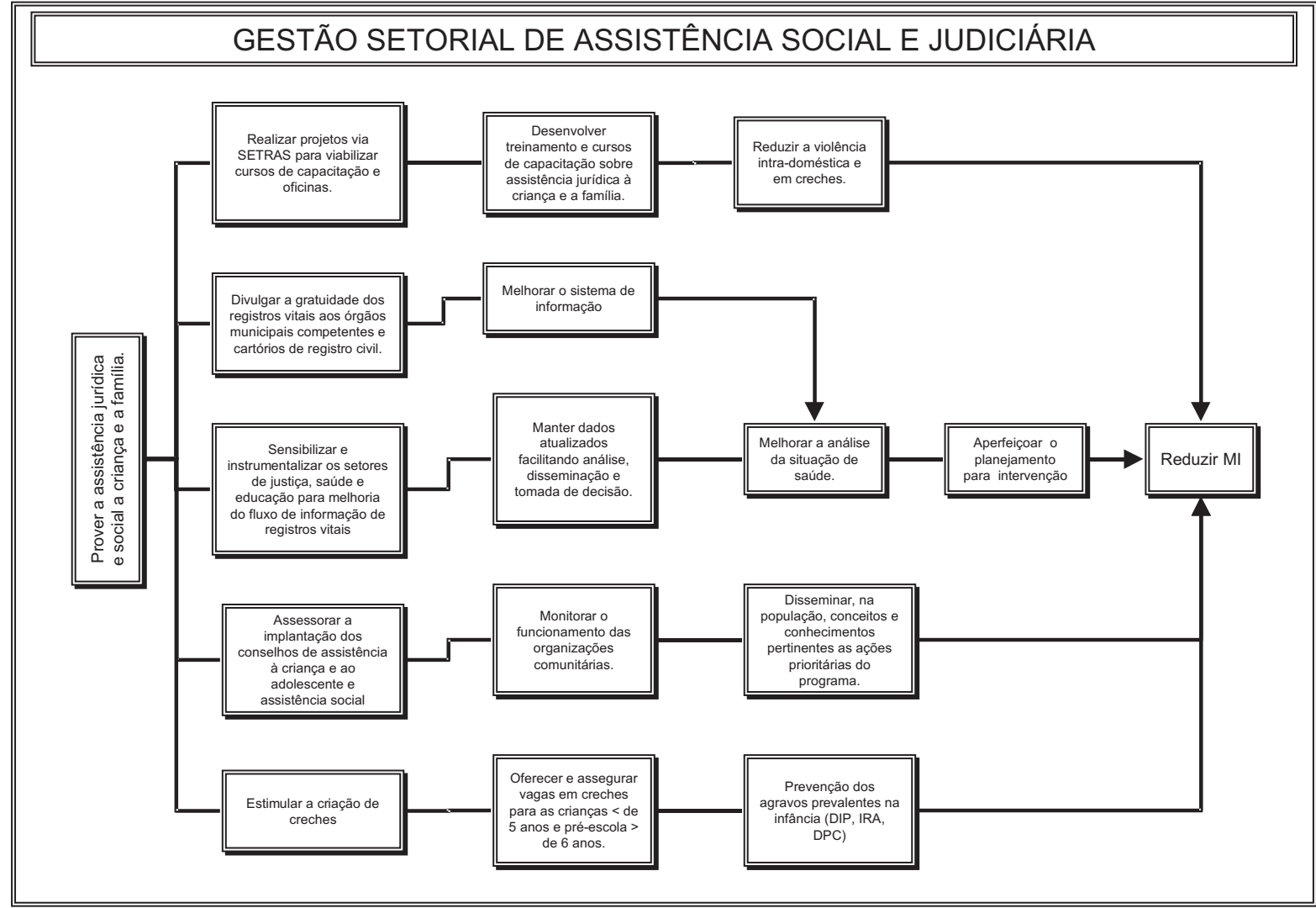


Figura 7

GRAU DE IMPLANTAÇ̃̃O DAS AÇ̃̃ES INTERSETORIAIS, MUNICÍPIO "CASO“, 1998 - 1999
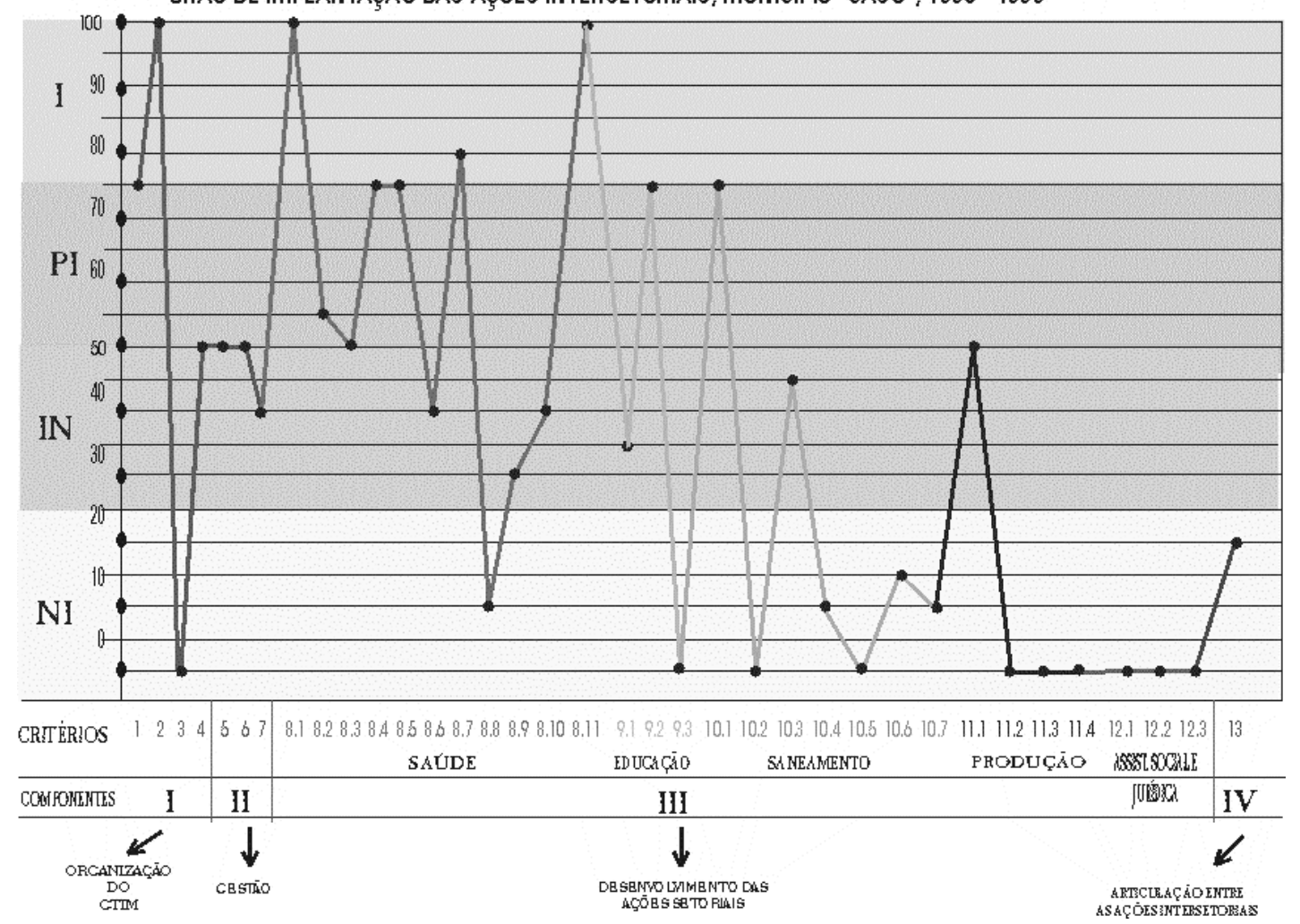
Quadro 1

Matriz de medidas do grau de implantação das ações intersetoriais

\begin{tabular}{|c|c|c|c|c|c|c|c|}
\hline \multirow{2}{*}{ COMPONENTES } & \multirow{2}{*}{$\begin{array}{l}\text { CRITÉRIOS DE } \\
\text { AVALIAÇÃO }\end{array}$} & \multicolumn{2}{|c|}{$\begin{array}{l}\text { PONTUAÇÃO } \\
\text { ATRIBUIDA } \\
\text { CRITÉRIOS } \\
\end{array}$} & \multicolumn{4}{|c|}{ GRADUAÇÃO (Exemplos) } \\
\hline & & Máxima & Obtida & IMPLANTADO (IM) & $\begin{array}{l}\text { PARCIALMENTE } \\
\text { (PI) }\end{array}$ & INCIPIENTE (IN) & $\begin{array}{c}\text { NÁO } \\
\text { IMPLANTADO } \\
(\mathrm{NI}) \\
\end{array}$ \\
\hline \multirow{5}{*}{$\begin{array}{l}\text { I. Organização do } \\
\text { GTIM/PRMI } \\
\text { municipal }\end{array}$} & $\begin{array}{l}\text { 1.Visita e contato no } \\
\text { município acerca dos } \\
\text { objetivos do PRMI }\end{array}$ & 4 & 3 & $\begin{array}{c}\text { Realizado visita feito } \\
\text { contatos e propósitos } \\
\text { discutidos }\end{array}$ & & & \\
\hline & $\begin{array}{l}\text { 2.Realização do } \\
\text { seminário }\end{array}$ & 10 & 10 & $\begin{array}{c}\text { Realizado com } \\
\text { presença de todos } \\
\text { setores }\end{array}$ & & & \\
\hline & $\begin{array}{l}\text { 3.Realização feira } \\
\text { saúde }\end{array}$ & 4 & 0 & & & & $\begin{array}{c}\text { Não realizou } \\
\text { feira saúde }\end{array}$ \\
\hline & $\begin{array}{l}\text { 4.Funcionamento do } \\
\text { GTIM }\end{array}$ & 10 & 5 & & $\begin{array}{l}\text { Tem plano de ação } \\
\text { e sabem informar } \\
\text { sobre projeto }\end{array}$ & & \\
\hline & & 28 & 18 & & PARCIALMENTE I & MPLANTADO & \\
\hline \multirow{4}{*}{$\begin{array}{l}\text { II. Gestão } \\
\text { (característica do } \\
\text { planejamento) }\end{array}$} & $\begin{array}{l}\text { 5.Elaboração do plano } \\
\text { de ação }\end{array}$ & 10 & 5 & & $\begin{array}{c}\text { Centralizado, } \\
\text { porém discutido e } \\
\text { modificado. }\end{array}$ & & \\
\hline & $\begin{array}{l}\text { 6.Coordenação e } \\
\text { direção }\end{array}$ & 10 & 5 & & $\begin{array}{c}\text { Decisões chaves } \\
\text { tomadas } \\
\text { setorialmente }\end{array}$ & & \\
\hline & $\begin{array}{l}\text { 7.Acompanhamento e } \\
\text { avaliação }\end{array}$ & 10 & 4 & & & $\begin{array}{l}\text { Não objetiva, usa } \\
\text { critérios implícitos }\end{array}$ & \\
\hline & & 30 & 14 & \multicolumn{4}{|c|}{ INCIPIENTE } \\
\hline
\end{tabular}




\begin{tabular}{|c|c|c|c|c|c|c|c|}
\hline \multirow{4}{*}{$\begin{array}{l}\text { III. } \\
\text { Desenvolvimento } \\
\text { das ações setoriais }\end{array}$} & $\begin{array}{l}\text { 8. Saúde } \\
\text { 8.1.Cobertura vacinal } \\
\text { 8.2. Controle diarréia } \\
\text { 8.3.Controle IRA } \\
\text { 8.4.Controle DPC } \\
\text { 8.5. Incen. aleitamento } \\
\text { 8.6.Assist. PN, P e P } \\
\text { 8.7.Assistência PF } \\
\text { 8.8.Prática educativa } \\
\text { 8.9.Implemen. SIS } \\
\text { 8.10.Implant. PACS } \\
\text { 8.11.ACD } \\
\end{array}$ & $\begin{array}{l}10 \\
10 \\
10 \\
10 \\
10 \\
10 \\
10 \\
4 \\
4 \\
4 \\
10\end{array}$ & $\begin{array}{c}10 \\
5.5 \\
5 \\
7.5 \\
7.5 \\
4 \\
8 \\
1 \\
3 \\
4 \\
10 \\
\end{array}$ & $\begin{array}{l}\text { Cobertura superior } \\
80 \% \text { e utiliza } \\
\text { instrumentos de } \\
\text { avaliação }\end{array}$ & $\begin{array}{c}\text { Cobertura }>50 \% \text { e } \\
<80 \%\end{array}$ & Cobertura $\leq 50 \%$ & $\begin{array}{l}\text { Não desenvolve } \\
\text { ação prevista ou } \\
\text { não implantada }\end{array}$ \\
\hline & & 92 & 65.5 & \multicolumn{4}{|c|}{ PARCIALMENTE IMPLANTADO } \\
\hline & $\begin{array}{l}\text { 9.Educação } \\
\text { 9.1. } \square \text { nível alfabetização } \\
\text { pop.>15 anos } \\
\text { 9.2. } \square \mathrm{r} \mathbf{n}^{\circ} \text { vagas pré- } \\
\text { escola e creches } \\
\text { 9.3. Inserir \# disciplinas } \\
\text { conteúdos referente MI }\end{array}$ & $\begin{array}{l}10 \\
10 \\
4\end{array}$ & $\begin{array}{c}3 \\
7.5 \\
0\end{array}$ & & $\begin{array}{c}\text { Cobertura }>50 \% \text { e } \\
<80 \%\end{array}$ & Cobertura $<50 \%$ & $\begin{array}{c}\text { Não foram } \\
\text { inseridos } \\
\text { referentes a MI }\end{array}$ \\
\hline & & 24 & 10.5 & \multicolumn{4}{|c|}{ INCIPIENTE } \\
\hline & $\begin{array}{l}\text { 10.Saneamento } \\
\text { 10.1.Implantar, } \\
\text { readequar ou ampliar } \\
\text { rede abast.água } \\
\text { 10.2. Implantar, } \\
\text { readequar ou ampliar } \\
\text { rede esg. Sanitário } \\
\text { 10.3.Coleta diária de lixo } \\
\text { 10.4.Implantar/implemen } \\
\text { tar aterro sanitário } \\
10.5 . \text { Promoção } \\
\text { reciclagem lixo } \\
\text { 10.6.Implantar oficinas } \\
\text { saneamento } \\
\text { 10.7.Promover educação } \\
\text { ambiental }\end{array}$ & $\begin{array}{l}10 \\
10 \\
10 \\
4 \\
10 \\
4 \\
4\end{array}$ & $\begin{array}{c}7.5 \\
0 \\
0 \\
4.5 \\
\\
1 \\
0 \\
1.5 \\
1\end{array}$ & & $\begin{array}{l}\text { Cobertura }>50 \% \text { e } \\
<80 \% \text { e desenvolve } \\
\text { ações controle água }\end{array}$ & $\begin{array}{c}\text { Coleta de lixo } \\
\text { centro } 3 X \text { na } \\
\text { semana e nos } \\
\text { bairros } 2 X \text { na } \\
\text { semana }\end{array}$ & $\begin{array}{l}\text { Não desenvolve } \\
\text { ações previstas } \\
\text { e não possui } \\
\text { aterro,usina nem } \\
\text { promove ações } \\
\text { p/ recicla lixo }\end{array}$ \\
\hline & & 52 & 15.5 & \multicolumn{4}{|c|}{ INCIPIENTE } \\
\hline
\end{tabular}




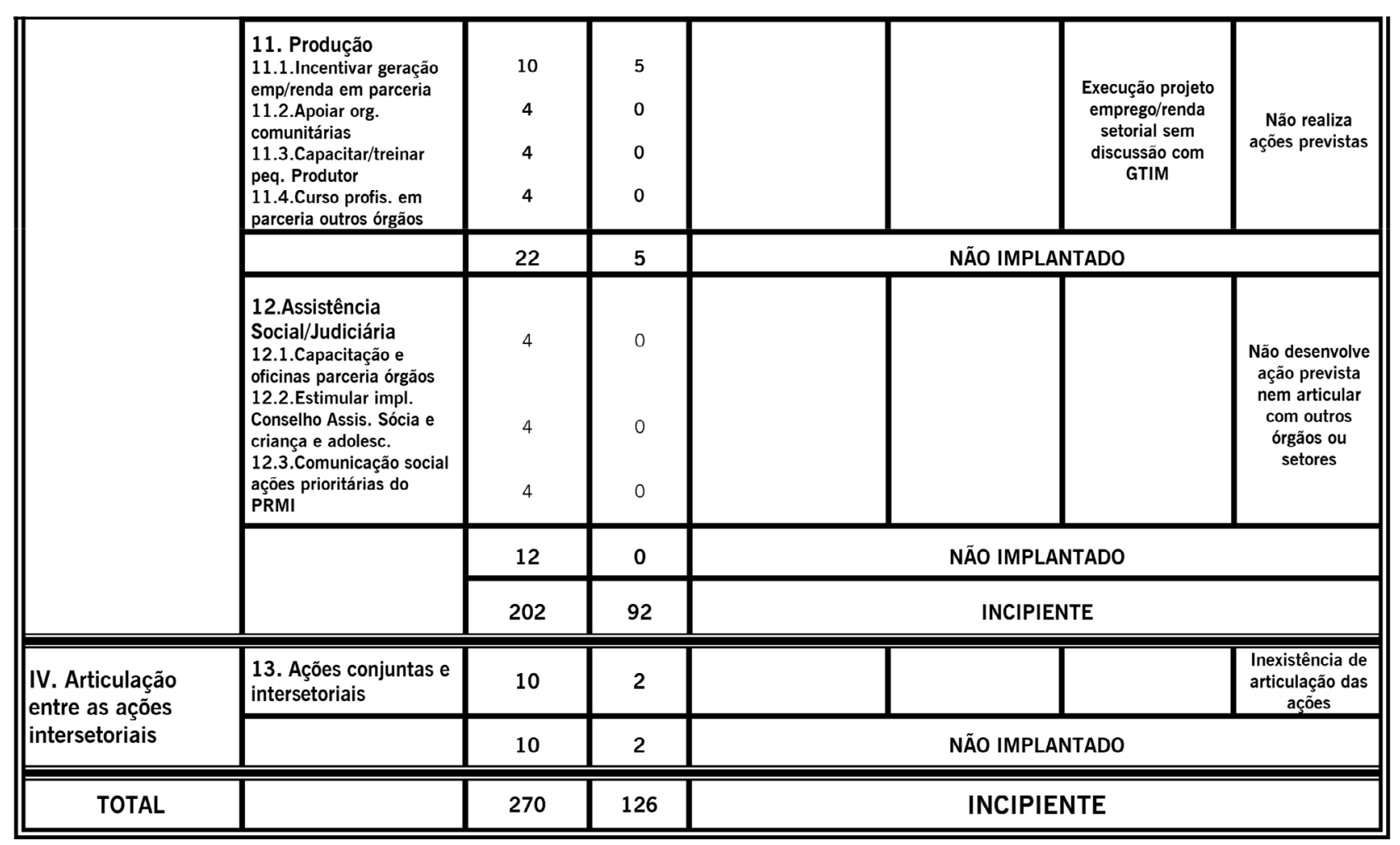




\section{Quadro 2}

Síntese da avaliação do grau de implantação das ações intersetoriais, Município "Caso", 19981999

\begin{tabular}{|c|c|c|c|c|}
\hline \multirow{2}{*}{ COMPONENTES } & \multicolumn{2}{|c|}{ PONTUAÇÃO } & \multirow{2}{*}{ \% DE ADEQUAÇÃO } & \multirow{2}{*}{ CLASSIFICAÇÃO } \\
\hline & MÁXIMA & OBTIDA & & \\
\hline $\begin{array}{l}\text { I. ORGANIZACCÃO DO } \\
\text { GTIM/PRMI MUNICIPAL }\end{array}$ & 28 & 18 & $64,3 \%$ & $\begin{array}{l}\text { PARCIALMENTE } \\
\text { IMPLANTADO (PI) }\end{array}$ \\
\hline II. GESTÃO & 30 & 14 & $46,7 \%$ & INCIPIENTE (IN) \\
\hline $\begin{array}{l}\text { III. DESENVOLVIMENTO } \\
\text { DAS AÇÕES SETORIAIS }\end{array}$ & 202 & 92 & $45,5 \%$ & INCIPIENTE (IN) \\
\hline $\begin{array}{l}\text { IV. ARTICULAÇÕES ENTRE } \\
\text { AS AÇÕES INTERSETORIAIS }\end{array}$ & 20 & 02 & $10,0 \%$ & NÃO IMPLANTADO \\
\hline TOTAL & 270 & 126 & $46,7 \%$ & INCIPIENTE \\
\hline
\end{tabular}




\title{
AVALIAÇÃO DA IMPLANTAÇÃO DE UM PROJETO PARA REDUÇÃO DA MORTALIDADE INFANTIL ${ }^{1}$
}

\author{
Paulo Germano de Frias \\ Pedro Israel Cabral de Lira \\ Zulmira Maria de Araújo Hartz
}

\section{INTRODUÇÃO}

O Coeficiente de Mortalidade Infantil (CMI), medida do risco de uma criança vir a morrer antes de completar o primeiro ano de vida, tem sido um indicador largamente utilizado para avaliar o nível global de saúde, as condições de vida de uma população e a eficácia dos serviços de saúde. Esta medida pode revelar grandes disparidades ao se proceder comparações de diferentes áreas geográficas, sendo um bom estimador de iniqüidades (MURNAGHAN, 1981; ROUQUAYROL; KEER-PONTES, 1994; UNICEF, 1998; UNICEF, 2001b). No entanto, alguns autores têm relativizado o seu uso com a constatação de que, mesmo em conjunturas de concentração de rendas e enormes desigualdades sociais, o CMI pode manter sua tendência decrescente (REICHENHEIM; WERNECK, 1994).

No Brasil, os inúmeros trabalhos publicados abordando a mortalidade infantil e na infância, apontam para um declínio destes indicadores nas três últimas décadas (MONTEIRO, 1982; BARROS e outros, 1987; VICTORA e outros, 1988; MONTEIRO; ZUÑIGA, 1995; SIMÕES, 1997; UNICEF, 2001b). Em contrapartida, as publicações do UNICEF (1998; 2001a) mostraram que nenhum país com renda per capita similar ao Brasil detêm taxas tão altas. Agravando a situação, diversos estudos têm enfatizado a persistência de diferenciais importantes entre regiões do país, estados e 
microrregiões (BECKER; LECHTIG, 1986; SIMÕES; OLIVEIRA, 1986; SZWARCWALD e outros, 1992; PAIM; COSTA, 1993; LEAL, 1996; SIMÕES, 1997; SIMÕES, 1999; UNICEF, 2001b).

Seguindo o padrão caracterizado pela desigualdade de distribuição dos riscos de morte, o estado de Pernambuco apresentou diferenciais importantes nas diversas microrregiões (SIMÕES, 1999), municípios (CARDOSO, 2001) e até nos espaços intraurbanos (HOLMES e outros, 1994; GUIMARÃES, 1998). Para o ano de 1998, estimativas apontavam para os extremos de 39,3 a 98,5 óbitos/1000 nascidos vivos (nv) na microrregião do Recife e Brejo pernambucano, respectivamente (SIMÕES, 1999). Para os municípios Cardoso (2001) estima diferenciais que oscilam de 16 a 111 óbitos/1000 nv.

Quanto ao padrão de mortalidade segundo causas, identifica-se que em localidades com precárias condições de vida predominam os óbitos provocados pelas Gastroenterites e Infecções Respiratórias, quase sempre associadas às carências nutricionais que ocorrem, sobretudo, nos maiores de 28 dias. Observa-se, no entanto, que localidades com extrema pobreza, onde as condições sócio-ambientais são bastante adversas, muitas vezes essas causas acometem também os menores de 28 dias.

À medida que melhoram as condições de vida, incluindo-se o acesso aos serviços de saúde, as doenças infecciosas e nutricionais tendem a declinar e a ganhar importância proporcional o componente neonatal representado pelas Afecções Perinatais, as Malformações Congênitas e Afecções de Origem Genética (ROUQUAYROL; KERR-PONTES, 1994; PERNAMBUCO, 1996c; PERNAMBUCO, 1998c).

Nos países desenvolvidos, a modificação nos níveis de saúde e nos perfis de morbi-mortalidade que caracterizou a transição epidemiológica ocorreu há algumas décadas (LAURENTI, 1990). Hoje, nestes países, a maioria dos óbitos são classificados como inevitáveis e se deve basicamente às Malformações Congênitas. Nos países em desenvolvimento, a exemplo do Brasil, onde não se investiu em políticas públicas capazes de reduzir as iniqüidades, a transição epidemiológica não foi concluída. Talvez por isso, mais adequado seria falar em polarização epidemiológica, em especial no Nordeste, bem evidenciada no grupo dos menores de um ano (ARAÚJO, 1992; SILVA, 2000).

Os diferentes comportamentos da Mortalidade Infantil, da magnitude do indicador ao perfil segundo Causa Básica, estão relacionadas a um conjunto de fatores condicionantes e determinantes que interagem entre si e se 
manifestam através de uma conformação peculiar a cada espaço geográfico, porém passível de intervenções.

No Brasil, início dos anos 70, foi implantado o Plano Nacional de Saneamento (PLANASA), responsável pela rápida expansão dos serviços de saneamento, sobretudo a rede de abastecimento de água (FERREIRA, 1992). Vinculada ao II Plano Nacional de Desenvolvimento, uma série de políticas públicas compensatórias são progressivamente implantadas, entre as quais ressaltam-se os Programas de Saúde Materno-infantil e o de Nutrição em Saúde. Ao mesmo tempo, as modernizações na área da medicina preventiva e os avanços na área da farmacologia potencializaram os efeitos destas políticas de saúde (OLIVEIRA; SIMÕES, 1986).

A partir de 1980, as campanhas de vacinação em massa, as medidas de estímulo ao aleitamento materno, a terapia de reidratação oral, o combate às Infecções Respiratórias e Doenças Diarréicas, entre outras, somamse em um efeito sinérgico, contribuindo com o decréscimo da mortalidade infantil (OLIVEIRA; SIMÕES, 1986).

A estes aspectos duas outras situações são referidas como responsáveis indiretos pela queda da mortalidade infantil: a acelerada queda da fecundidade (SZWARCWALD e outros, 1992) e o processo de urbanização observados nas últimas décadas (TEIXEIRA, 1996).

No entanto, no Brasil, a estrutura social caracterizada pelas desigualdades e a ausência de melhorias efetivas nas condições de vida impuseram limitações importantes nos ganhos gerados pelo incremento das políticas públicas. Ressaltam-se ainda que os aspectos relacionados ao acesso e qualidade da assistência prestada pelos serviços de saúde, de alguma forma reproduziram e intensificaram as desigualdades existentes no interior da sociedade (OLIVEIRA; SIMÕES, 1986; LEAL, 1996).

Diante da situação, parece existir um consenso que a persistência de enormes desigualdades sociais entre regiões, estados e municípios brasileiros obriga as autoridades do país a definirem uma agenda mínima de compromissos com a transformação social das áreas submetidas a piores condições de vida. A execução de políticas públicas compensatórias, mesmo não alterando a estrutura social, permite melhorar em algum grau as condições de sobrevivência (PERNAMBUCO, 1997).

Após a Declaração de Alma - Ata que definiu a Atenção Primária em Saúde como "a chave para obtenção de um nível de saúde que possa per- 
mitir às comunidades se desenvolverem e levarem uma vida socialmente e economicamente produtiva [...]" (DECLARAÇÃO, 1979), o Brasil implantou, a partir de 1984, o Programa de Assistência Integral à Saúde da Criança (PAISC), como estratégia de enfrentamento das altas taxas de mortalidade prevalentes na infância (BRASIL, 2000g).

No início da década de noventa, o Programa de Agentes Comunitários de Saúde (PACS), foi instituído na região Nordeste como instrumento de intensificação das ações voltadas para crianças e mulheres. Em 1994, surgiu o Programa de Saúde da Família (PSF) apresentado como uma estratégia capaz de estimular a mudança do modelo assistencial e, no ano seguinte, passou a ser considerado projeto prioritário de governo. A adscrição de famílias e a definição da responsabilidade territorial, de alguma forma, contribuiu para o estabelecimento de vínculos entre os serviços, profissionais e comunidade (BRASIL, 1997b).

Em 1995, ao lançar o Projeto de Redução da Mortalidade Infantil (PRMI), o governo inseriu na sua agenda política o problema da sobrevivência infantil e reafirmou os compromissos assumidos nesta década em encontros nacionais e internacionais (BRASIL, 2000a).

O PRMI objetivava a redução dos óbitos infantis e a melhoria da situação de saúde das crianças através do incremento dos diversos programas governamentais, promovendo a articulação intersetorial (saúde, educação, agricultura, saneamento, habitação, trabalho, comunicação social, justiça e orçamento) com instituições internacionais, UNICEF e Organização PanAmericana de Saúde (OPAS), organizações não-governamentais, sociedades científicas de classe, conselhos de secretários de saúde nos três níveis de governo e a sociedade (BRASIL, 1995b).

Com o lançamento do PRMI, ocorreu uma grande mobilização nacional através de seminários regionais e nacionais envolvendo as Secretarias Estaduais de Saúde (SES) e as Instituições parceiras. Nestas se apresentavam as diretrizes e os componentes da intervenção: Assistência à Saúde Materno-infantil, Alimentação e Nutrição, Imunização, Saneamento, PACS (Programa de Agentes Comunitários de Saúde) e PSF (Programa de Saúde na Família), Informação, Educação e Comunicação e Recursos Humanos. As SES eram orientadas a adaptar o Projeto às suas realidades locais a partir das diretrizes propostas (BRASIL, 1995b; BRASIL, 1996a). 
Em Pernambuco, algumas experiências de combate à mortalidade infantil estavam acontecendo nos municípios da região metropolitana do Recife. Simultaneamente, o governo do estado lançou, em março de 1995, um projeto com o mesmo objetivo, denominado Salva-Vidas (PERNAMBUCO, 1997).

O Salva-Vidas diferenciava-se do projeto nacional por adotar o enfoque de risco não só nos critérios de seleção dos municípios, como também na seleção das crianças alvo da intervenção. Embutia ainda a avaliação entre os seus objetivos e adotava, como estratégia de envolvimento das Secretarias Municipais de Saúde, as discussões sobre temas relevantes que favorecessem o processo de municipalização em andamento (FRIAS e outros, 2001).

O processo de implantação neste Estado foi idealizado em seis etapas, com a participação de amplos setores da sociedade, buscando uma melhor adequação à realidade local, a partir do envolvimento da comunidade e estimulando a autonomia municipal (PERNAMBUCO, 1997).

A fase de implantação do Projeto foi iniciada com a sensibilização dos políticos, gestores e profissionais de saúde dos municípios através de seminários estaduais, regionais e municipais. Seguiu-se um processo de sensibilização/capacitação para os municípios e regionais de saúde. Estes desenvolveram nos seus respectivos municípios diagnósticos preliminares sobre a situação de saúde, as condições estruturais de funcionamento das Unidades e Instituições envolvidas com a prestação de serviços e a produção de dados relevantes (FRIAS e outros, 2001).

De posse do diagnóstico preliminar, foi realizada uma grande mobilização local com a participação das várias instituições e parceiros estaduais e municipais, para divulgação ampla dos resultados, realização de oficinas de trabaIho setoriais e montagem de um Plano de Intervenção Local, com a apreciação do Conselho Municipal de Saúde. Em seguida, a Secretaria Estadual de Saúde passou a prestar assessoria às Secretarias Municipais de Saúde. A etapa de monitoramento, supervisão e avaliação completava a programação prevista (FRIAS e outros, 2001; Pernambuco, 1997).

A incorporação de municípios ao PRMI foi maior no primeiro ano (1995), com 43 municípios contemplados, diminuindo o ritmo nos anos subseqüentes, chegando a 60 municípios em 1998 (FRIAS e outros, 2001). Ao longo do ano de 1999, o PRMI, com as novas gestões estaduais e o insuficiente estímulo do Ministério, sofreu uma desaceleração importante no seu processo de implementação. 
Neste cenário, e a despeito do grande número de programas, projetos e ações desenvolvidos nos últimos anos, poucas avaliações foram realizadas, não se conhecendo minimamente o grau da integralidade das ações ofertadas, sua eficiência, eficácia e efetividade (HARTZ; POUVOURVILLE, 1998). A ABRASCO (1995), reconhecendo a insuficiência dos estudos epidemiológicos que permitam avaliar a necessidade, adequação e efetividade dos serviços prestados, tendo como ponto crítico o desconhecimento do grau de implantação das ações programáticas nos serviços, propõe para superação desta dificuldade, a realização de estudos locais e regionais sobre a análise de implantação dos programas e sua correlação com os indicadores de impacto.

Considerando que as mortes infantis ainda constituem um grave problema de saúde pública no Brasil e em particular na região Nordeste; que os diferenciais de risco de morte entre os diversos espaços geográficos não têm se reduzido como o desejável; que as políticas públicas de saúde podem exercer um reconhecido papel na redução dos índices de mortalidade infantil, na redução das iniqüidades sociais e na melhoria das condições de vida deste grupo populacional; que diversas ações governamentais e nãogovernamentais vêm sendo desenvolvidas para fazer frente a este quadro; que os programas especiais, voltados para a assistência à saúde da mulher e da criança no país, em especial no interior do Nordeste, pouco foram avaliados em sua implantação, se elegeu o foco do presente estudo.

Por outro lado, considerando o conjunto de critérios de elegibilidade prioritários para avaliação, contidos no Guia dos Serviços Humanos da Saúde da Divisão de Avaliação de Programas do General Accounting Office (HARTZ; POUVOURVILLE, 1998), este estudo pode ser relevante porque: o PRMI é de interesse local, porém compatível com as prioridades nacionais; pode ter um valor de demonstração ao desenhar a teoria do programa, contribuindo para a reprodutibilidade de intervenções governamentais e/ou reestruturação organizacional de outras localidades; testa e desenvolve modelos de avaliação para um programa específico, podendo contribuir para a elaboração/ validação de manuais ou guias metodológicos; contribui para implementar e validar alguns sistemas de informação; com o processo de descentralização do SUS, efetivado através da municipalização e a crise político-financeira do sistema, a avaliação de programas ganha importância como elemento essencial ao planejamento, na redefinição de prioridades e no redirecionamento das ações; há necessidade da constituição de avaliadores locais pela 
possibilidade de melhor utilização dos resultados e proposição de estratégias adequadas às intervenções.

Nesta pesquisa onde se pretende confrontar um modelo teórico com a realidade empírica, e as variáveis são interdependentes, foram elaborados os pressupostos teóricos sobre a investigação. O pressuposto básico pode ser descrito como: "O perfil de adoecimento e morte dos menores de um ano está relacionado ao grau de implantação das ações de atenção à mulher e criança".

Este trabalho objetiva, portanto, caracterizar a influência do grau de implantação das ações do Projeto de Redução da Mortalidade Infantil (PRMI) sobre os seus efeitos, utilizando indicadores de resultados, em dois municípios pernambucanos com semelhantes condições de vida em 1999.

\section{PROCEDIMENTOS METODOLÓGICOS}

\section{ESTRATÉGIA DA PESQUISA}

A abordagem metodológica selecionada foi a pesquisa sintética e o estudo de casos múltiplos, com níveis de análises imbricados (YIN, 1993; YIN, 1994; CONTANDRIOPOULOS e outros, 1997b; HARTZ e outros, 1997). Para tanto, procedeu-se à investigação, utilizando métodos quantitativos e qualitativos, privilegiando a avaliação normativa e aspectos ligados à cobertura dos subprogramas.

Na pesquisa sintética é utilizada uma abordagem dedutiva, onde parte-se de pressupostos teóricos e a realidade empírica observável é documentada. A compreensão dos casos está relacionada com a profundidade da análise e com a coerência na construção do modelo teórico (também chamado de modelo lógico), considerando todos os componentes envolvidos, e não o número de unidades estudadas (DENIS; CHAMPAGNE, 1997).

A unidade de análise utilizada foi o PRMI (na sua dimensão unitária) e seus componentes (representado por alguns subprogramas) nos municípios-caso. Quanto aos níveis de análise, optou-se pelo imbricamento destes, através da observação dos processos de organização técnico-normativa do PRMI e seus componentes nos diferentes casos estudados. Os principais níveis de análise estudados foram os indicadores operacionais do PRMI (estrutura, processo e resultados) e os tipos de cuidados disponibilizados (primário, secundário e terciário). 
A modelagem utilizada para verificação do grau de implantação das ações do Projeto de Redução da Mortalidade Infantil incorporou diversos métodos, fontes de dados e informações, procurando construir uma cadeia de evidências com informações válidas e confiáveis, visando aumentar a validade de construção do estudo. A avaliação técnico-normativa e aspectos ligados à cobertura tiveram atenção particular na análise de implantação realizada neste estudo, o componente dois. Este corresponde à "Análise da influência da variação na implantação sobre os efeitos observados" na tipologia proposta por Denis e Champagne (1997). O modelo do estudo de casos múltiplos utilizado envolveu o desenvolvimento da teoria, a construção do protocolo de coleta de dados, a seleção dos casos, o relato individual deles, o confronto da realidade empírica observada com o modelo teórico e a posterior extração das conclusões sobre a implantação e desenvolvimento das recomendações para as políticas públicas.

\section{MUNICÍPIOS-CASO}

Foi definido que os municípios do interior do estado seriam privilegiados pela coerência com o desenho do estudo e pela carência de pesquisas avaliativas nessa região. O município de Brejo da Madre de Deus foi selecionado como caso-índice em função dos investimentos realizados no setor saúde através do Projeto "Saúde Pública no Nordeste: a experiência de Pernambuco" (UFPE; JICA, 1999).

Os indicadores escolhidos para selecionar o município similar em condições de vida ao município de Brejo da Madre de Deus foram: o Índice de Desenvolvimento Humano Municipal, IDH-M (IPEA; FUNDAÇÃO JOÃO PINHEIRO, 1996), o Índice de Condição de Vida, ICV (IPEA; FUNDAÇÃO JOÃO PINHEIRO, 1996) e o Índice de Condição de Sobrevivência, ICS (UNICEF; FIBGE, 1994).

Estes indicadores foram escolhidos por representarem um conjunto de variáveis relacionadas à determinação das condições de vida e sobrevivência da população, da disponibilidade e da facilidade no manuseio, além do reconhecimento da comunidade científica nacional e internacional.

Entre as limitações dos indicadores selecionados, destacam-se os dados primários que são do Censo Demográfico de 1991, que não captam as mudanças ocorridas posteriormente, representando médias que escondem 
variações intramunicipais e, por sua natureza quantitativa, não permitem identificar aspectos qualitativos importantes (UNICEF; FIBGE, 1994; IPEA; FUNDAÇÃO JOÃO PINHEIRO, 1996).

Primeiro procedeu-se à hierarquização dos municípios de Pernambuco para cada um dos indicadores selecionados, seguido da construção de decis e identificação dos municípios que se enquadraram no mesmo decil do município-índice, Brejo da Madre de Deus. Encontraram-se 41 municípios que estavam no mesmo decil em pelo menos um indicador e apenas o município de Bom Conselho nos três indicadores, sendo o escolhido para o estudo.

O estudo compreendeu o período de 1 de janeiro a 31 de dezembro de 1999, nas duas cidades selecionadas. No Quadro 1 observam-se algumas variáveis sócio-demográficas relacionadas aos municípios em questão.

\section{MODELO TEÓRICO}

Existem várias formas de elaborar hipóteses e pressupostos de uma pesquisa antes de selecionar as variáveis que devem ser estudadas. Uma delas é a elaboração de um modelo teórico. Este tem sido descrito com uma terminologia diversificada: modelo hipotético causal (BEGHIN e outros, 1989), modelo explicativo ou ainda modelo lógico (HARTZ, 1999). O termo, segundo Beghin e outros, (1989), sugere a idéia de "representação simplificada de um processo ou sistema", enquanto para Graham (1994) é um método estruturado para definir o fundamento lógico do programa.

O modelo lógico trata de uma série de eventos organizados de forma hierárquica, onde os componentes do programa dispostos em um diagrama apresentam o seu funcionamento teórico. O objetivo é proporcionar uma explicação, uma compreensão dos mecanismos implicados na construção dos resultados do programa (BEGHIN e outros, 1989). Uma de suas vantagens é possibilitar a ligação do processo aos resultados através de uma seqüência de passos, além de valorizar a interação dos efeitos dos componentes com o impacto do programa (CDC, 1999).

Na elaboração de um modelo, deve estar explicitado o problema, a população-alvo, o contexto e os componentes essenciais do programa para produzir de forma isolada ou integrada os efeitos desejáveis. O programa deve ser tratado no seu todo e na particularidade de seus componentes (subprogramas), nunca se tendo apenas um efeito desejado, mas uma sé- 
rie de efeitos hierarquicamente articulados (HARTZ, 1999). Na diagramação do modelo, pode ainda aparecer a infra-estrutura necessária à operacionalização do programa. Geralmente estão incluídos os insumos (inputs), as atividades, os produtos (outputs) e os efeitos de curto, médio e longo prazos (outcomes) (CDC, 1999; Hartz e outros, 1997).

Beghin e outros, (1989) afirmam que "o exercício de construir um modelo não é somente uma via para gerar novos conhecimentos, mas também constitui um processo por meio do qual se organiza e compartilha os conhecimentos e as formas de compreensão". Eles fornecem uma estrutura de referência para as avaliações (CDC, 1999) e, uma vez construído, ainda pode ser aperfeiçoado no decorrer do processo de avaliação, na busca de uma maior consistência dos resultados obtidos (COSENDEY, 2000). Para Hartz (1999) esta é uma etapa essencial na apreciação da "avaliabilidade" de qualquer programa.

Uma vez definido o modelo lógico, o tempo disponível e os recursos da pesquisa, a definição dos indicadores fica mais fácil. No entanto, quase sempre é necessária uma grande seletividade (BEGHIN e outros, 1989). A seleção dos indicadores comporta informações quantitativas ou qualitativas na dependência da questão formulada, disponibilidade do dado e o seu uso planejado. Durante o processo avaliativo, pode haver necessidade de incorporação de novos indicadores ou modificação dos previamente escolhidos (CDC, 1999).

O modelo apresentado na Figura 1, adotado como referência neste estudo, foi adaptado do proposto por Hartz e outros (1997) ao estudarem a análise de implantação do Programa Materno-Infantil em Sistemas Locais de Saúde.

Ao modelo originalmente proposto foram incorporados alguns componentes após detida análise documental do Projeto Salva-Vidas, buscando-se identificar e especificar o seu conteúdo (BRASIL, 1995b; FELISBERTO e outros, 1995; PERNAMBUCO, 1996a; PERNAMBUCO, 1996c; PERNAMBUCO, 1997; PERNAMBUCO, 1998c).

Foram considerados os componentes: Educação para a Saúde, Programa de Atenção Integral à Saúde da Mulher (PAISM), Programa de Atenção Integral à Saúde da Criança (PAISC), Programa de Agentes Comunitários de Saúde (PACS), Programa Estadual de Parteiras Tradicionais (PEPT), Ações de Assistência ao Parto Hospitalar, Ações de Assistência à Criança Hospitalizada, Sistema de Informação em Saúde e Vigilância de Óbitos. 
Apesar da incorporação de alguns componentes como as Afecções Perinatais e, em função das particularidades do objeto avaliado, as principais causas de óbito ou de "fragilização" consideradas por Hartz e outros (1997), o baixo peso ao nascer, a desnutrição e as doenças infecciosas, foram mantidas.

\section{ELENCO DE VARIÁVEIS}

O Quadro 2 apresenta a relação de variáveis, suas definições e os indicadores operacionais com as respectivas formas de obtenção.

\section{FONTE E COLETA DOS DADOS}

\section{GRAU DE IMPLANTAÇÃO DO PRMI}

Os dados referentes ao Grau de Implantação do PRMI tiveram como fonte dados primários coletados especificamente para este fim e dados secundários, de documentação oficial, obtidos nas Secretarias Municipais e Estadual. Foram coletados, através de diferentes técnicas, utilizando-se documentos escritos oficiais, observação sistemática, observação ligada à entrevista, e entrevista dirigida semi-estruturada, variando de acordo com a viabilidade e operacionalidade dos indicadores utilizados para cada componente do PRMI. A coleta dos dados ocorreu no período de janeiro a maio do ano 2000. O Quadro 3 apresenta, para cada componente do PRMI, os tipos de dados, as técnicas de coleta e os instrumentos/documentos utilizados.

\section{COEFICIENTES DE MORTALIDADE INFANTIL E MORTALIDADE PROPORCIONAL}

Os dados referentes aos óbitos não fetais de menores de um ano dos residentes de Brejo da Madre de Deus e Bom Conselho tiveram como fonte a Declaração de Óbito (DO). Excepcionalmente, as Secretarias Municipais de Saúde emitiram DO para os casos não notificados ao SIM, após a conclusão de busca ativa de óbitos não fetais de menores de um ano em cemitérios oficiais e clandestinos, unidades de saúde, nas comunidades, através dos agentes comunitários de saúde e parteiras tradicionais e compatibilização dos sistemas de informação do PACS e PEPT. A coleta das DO's envolveu os óbitos fetais e não fetais de menores de um ano. A finalidade da incorpora- 
ção dos óbitos fetais no universo da coleta foi para possibilitar a posterior validação do tipo de óbito.

Os dados referentes aos nascidos vivos tiveram como fonte as Declarações de Nascidos Vivos (DNV) de residentes em Brejo da Madre de Deus e Bom Conselho. Após a conclusão de busca ativa de nascidos vivos em livros de registros em unidades de saúde, nas comunidades, através dos agentes comunitários de saúde e parteiras tradicionais, e compatibilização dos sistemas de informação do PACS e PEPT, foram emitidas cópias de DNV.

\section{QUALIDADE DOS INSTRUMENTOS DE MEDIDA}

A verificação da qualidade dos instrumentos de medida pode ser aferida pela sua confiabilidade e sua validade. 0 primeiro está relacionado à medição fiel do objeto estudado e o segundo à precisão (Contandriopoulos e outros, 1997b).

Neste estudo, foram trabalhados alguns instrumentos: Instrumento Gerencial da Mulher, da Criança e do Adolescente: avaliação, sistema de informação e programação (BRASIL, 1995a), Condições de Eficiência dos Serviços de Atenção Materno Infantil- modelo de avaliação, internação em obstetrícia e em pediatria (OPAS; OMS, 1987) e Instrumento de investigação de óbitos em menores de um ano (PERNAMBUCO, 1998h). A opção de trabalhar com estes instrumentos foi decorrente do conhecimento das suas qualidades métricas, possibilidade de estabelecer comparação com outros estudos realizados em tempos e/ou localidades distintas, redução do tempo para conclusão do estudo com repercussões no custo final da pesquisa, associados à experiência prévia do autor.

Diversos estudos apontam a pertinência e limitações dos instrumentos utilizados nesta pesquisa. O instrumento Gerencial da Mulher, da Criança e Adolescente objetiva identificar o grau de implantação e/ou implementação das ações programáticas envolvidas na assistência à muIher e criança (Brasil, 1995a), possibilitando traçar o perfil de implantação assistencial nas Unidades de Saúde (PERNAMBUCO, 1996a; PERNAMBUCO, 1996b; VIDAL e outros, 2001). O que aborda as Condições de Eficiência dos Serviços de Atenção Materno-Infantil - modelo de avaliação, internação em obstetrícia e em pediatria, tem como finalidade analisar a estrutura e a organização geral do serviço de saúde em sua dota- 
ção física e de pessoal (OPAS; OMS, 1987), havendo muitos estudos realizados durante a última década que o utilizaram (IMIP; SUDENE, 1990; Hartz e outros, 1997; ALVES; SILVA, 2000). Finalmente, o instrumento de Investigação de óbitos em menores de um ano (PERNAMBUCO, 1998h) objetiva identificar o perfil de mortalidade infantil, reconstituindo a causa básica do óbito e o percurso das famílias em busca de assistência. Este instrumento corresponde a uma adaptação do utilizado por Puffer e Serrano (1973), e posteriormente aplicado por Duchiade e outros (1989), Hartz e outros (1996), Hartz e outros (1997), Secretaria de Saúde de Pernambuco (PERNAMBUCO, 1998h) e Barreto e Pontes (2000).

Para discutir a validade dos instrumentos de medida, adotou-se a nomenclatura usada por Contandriopoulos e outros (1997b): validade de conteúdo, de construção e de critério.

A validade de conteúdo, relacionada à capacidade de julgar se a construção teórica representa todos os aspectos do conceito a ser medido (CONTANDRIOPOULOS e outros, 1997b), foi testado por diversos autores, conforme descrição anterior, e incorporou o conceito de validade aparente, ou seja, abordando a coerência aparente existente entre o objeto a ser medido e o instrumento. Para não afetar a validade de conteúdo, os questionários referentes à avaliação de Unidades Básicas e Serviços de Obstetrícia e Pediatria foram aplicados pelo autor do estudo e as investigações de óbitos passaram previamente por uma adequação de linguagem e capacitação dos técnicos envolvidos com o procedimento.

Quanto à validade de construção, relacionada à operacionalização dos conceitos teóricos (CONTANDRIOPOULOS e outros, 1997b), foi abordada pela forma teórica ou nomológica. Nesta forma de validação, segundo Contandriopoulos e outros (1997b), levantam-se "hipóteses sobre os resultados que deveriam ser observados com a ajuda do instrumento, em certas condições e para certas populações", para destacar em seguida que "toda hipótese que se baseia em uma abordagem teórica pode ser formulada, a priori, para testar a validade nomológica de um instrumento". A confirmação da hipótese consolida a suposição da adequação do instrumento, porém a não confirmação não o invalida necessariamente. Para este estudo foram identificadas as dimensões que mais se aproximavam dos resultados que deveriam ser observados e promoviam uma adequada apreensão conceitual. A validade da construção está apresentada graficamente na Figura 1 referente ao modelo lógico. 
Por fim, a validade de critério, relacionada à capacidade do instrumento em medir um fenômeno com critérios definidos (CONTANDRIOPOULOS e outros, 1997b), foi abordada avaliando-se a consistência das relações entre os indicadores escolhidos para representar o grau de implantação com os de efeito do PRMI. A inexistência de coerência era indicativo de problemas no instrumento utilizado.

Nesta pesquisa, os instrumentos selecionados objetivaram uma maior validade de conteúdo e de construção, viabilizando uma maior potência ao estudo.

\section{PROCEDIMENTOS DE VERIFICAC̣ÃO DA CONFIABILIDADE DOS DADOS}

\section{COMPONENTES DO PRMI}

A forma de verificação da confiabilidade dos dados relacionada à capacidade de reprodução dos resultados obtidos (CONTANDRIOPOULOS e outros, 1997b) dos componentes do PRMI variou de acordo com os instrumentos e métodos utilizados para cada um deles.

Foi utilizada a análise documental para os componentes PACS, PEPT, Educação em Saúde e Vigilância de Óbitos, procedendo-se à máxima diversificação possível das fontes de informações. Neste tipo de análise, as múltiplas fontes são desejáveis, pois a reprodução dos resultados sugere uma maior confiabilidade dos dados (YIN, 1994).

Os resultados encontrados foram submetidos aos gerentes dos subprogramas (componentes), na tentativa de identificar problemas de interpretação. Ajustes se fizeram necessários apenas com relação ao PACS. Apesar da maioria da documentação oficial referir o mesmo número de Agentes Comunitários de Saúde (ACS), houve pequenas flutuações, decorrentes dos movimentos de saída e substituição que ocorrem ao longo do ano. Adotou-se, em função do exposto, o número de ACS existentes em julho de 1999 para os dois municípios.

Quanto aos componentes PAISC, PAISM, Assistência ao Parto e Recém-nascido e Assistência à Criança Hospitalizada, adotou-se uma das recomendações de Contandriopoulos e outros (1997b): "a apreciação da equivalência dos resultados obtidos, quando um mesmo fenômeno é me- 
dido por vários observadores ao mesmo tempo". Os observadores selecionados, além do próprio autor, foram técnicos de nível superior das Secretarias Municipais de Saúde, previamente treinados. As diferenças apontadas nos instrumentos pelos observadores não interferiram na classificação final do grau de implantação das ações.

Para o componente Sistema de Informação em Saúde, que foi avaliado a partir do subregistro de óbitos de menores de um ano, utilizou-se a busca ativa em múltiplas fontes, conforme a descrição que se segue.

\section{DECLARAÇÕES DE ÓBITO}

\section{REVISÃO DO QUANTITATIVO DE DECLARAÇÕES DE ÓBITO, TIPO DE ÓBITO E IDADE DECLARADA}

A revisão do quantitativo de DO envolveu dois procedimentos: o primeiro relacionado à busca ativa de DO's emitidas por médicos ou cartórios e o segundo relacionado às DO's não emitidas e as não registradas em cartórios de registro civil.

Objetivando identificar falhas no processo de coleta das Declarações de Óbito emitidas, procedeu-se busca ativa deste instrumento nos cartórios e Unidades de Saúde dos dois municípios, nos da sede da Diretoria Regional de Saúde e órgãos processadores da DO. Para realização desta etapa da pesquisa foi necessária a identificação e cadastramento dos cartórios existentes nos municípios. Para os óbitos que não foram registrados em cartórios e nem emitidas as DO's, procedeu-se à busca ativa em cemitérios oficiais e clandestinos, Unidades de Saúde dos municípios-casos e sede das Regionais de Saúde, além da utilização de informações do PACS, PSF e PEPT.

Para consecussão desta etapa, foi necessária a identificação e cadastramento de cemitérios oficiais e clandestinos existentes nos dois municípios. Nas Unidades de Saúde, nesta etapa, foram utilizadas apenas as informações escritas de acordo com a disponibilidade. Para a obtenção dos dados do PACS e PSF, foram utilizadas informações escritas (ficha D do Sistema de Informação da Atenção Básica - SIAB) e verbais documentadas posteriormente pelas enfermeiras instrutoras do PACS. Para as informações das parteiras tradicionais, utilizaram-se informações escritas, quando dis- 
poníveis, e verbais também registradas pela enfermeira instrutora do PACS. A investigação dos óbitos foi adotada para confirmação das informações coletadas. Após a busca ativa, procedeu-se à confrontação das informações disponíveis, através do software Epi-info versão 6.0, sendo, desta forma, identificados os óbitos que não tiveram a DO emitida.

A totalidade das Declarações de Óbito de menores de um ano fetais e não fetais coletadas foram submetidas a uma avaliação buscando identificar erros de classificação do tipo de óbito. Este procedimento permitiu identificar um óbito fetal entre os não fetais em Bom Conselho, sendo conseqüentemente eliminado do estudo, e um não fetal entre os fetais em Brejo da Madre de Deus, sendo incorporado aos óbitos deste município.

A consistência da idade declarada foi observada a partir dos dados informados nos campos data do nascimento e data do óbito. As diferenças verificadas foram sobretudo relacionadas às idades registradas em horas e dias completos.

As regras utilizadas para seleção da causa básica foi a proposta pela 10ª revisão da Classificação Internacional de Doenças (OMS; OPAS, 1999) realizadas por codificadores dos municípios, revisadas e corrigidas por codificador da Secretaria Estadual de Saúde, que identificou algumas variáveis que poderiam melhor especificar a causa do óbito. O número de DO's com Sinais, Sintomas e Afecções Mal Definidas foi elevado, fato que inviabilizaria estabelecer a relação entre o grau de implantação das ações do PRMI e seus efeitos. Este fato determinou a necessidade de esclarecimentos destes aspectos, realizando-se uma investigação dos óbitos de menores de um ano conforme descrição que se segue.

\section{INVESTIGAC̣ÃO DOS ÓBITOS NÃO FETAIS DE MENORES DE UM ANO}

Para solucionar o elevado número de DO's com Sinais, Sintomas e Afecções Mal Definidas foi investigada a totalidade dos óbitos, na tentativa de resgatar informações relevantes para a codificação da causa básica e para reconstituir a história do adoecimento e morte da criança e seu percurso em busca de assistência, criando uma cadeia de evidências que possibilitasse a melhor definição possível da causa da morte da criança.

Para tanto, foram realizadas visitas aos domicílios e aos hospitais. Nos domicílios, as mães foram entrevistadas, e nos Serviços de Saúde, foram consultados prontuários e/ou fichas de atendimento. 
No município de Brejo da Madre de Deus, foi identificado que as investigações de óbito de menores de um ano haviam sido incorporadas parcialmente à rotina de serviço, sendo identificados 30 óbitos investigados em domicílio. Quanto ao município de Bom Conselho, tem sido um procedimento ocasional, sendo identificados 11 óbitos investigados em domicílio.

\section{CRITÉRIOS UTILIZADOS PARA DEFINIC̣ÃO DA CAUSA BÁSICA APÓS A INVESTIGAÇÃO}

Para definição da causa básica dos óbitos não fetais de menores de um ano, inicialmente codificadas como Sinais, Sintomas e Afecções Mal Definidas, utilizou-se, além da DO e da DNV, o instrumento de investigação de óbitos e o resumo dos casos obtidos em documentação nos Serviços de Saúde, na dependência da sua existência. A multiplicidade de documentos utilizados na definição da causa básica dos óbitos foi uma tentativa de resgatar o maior número de evidências que permitisse reconstituir, com alguma precisão, os fatos relevantes para o adoecimento e morte da criança.

A documentação foi disponibilizada, independentemente, a três pediatras sanitaristas, mestres em Saúde Materno-infantil, sendo um codificador de causa básica. Estes profissionais, a partir de critérios implícitos de qualidade técnico-científica, reconstituíram a causa de óbito.

Os critérios explícitos, aqueles onde são especificados detalhada e previamente antes do início da avaliação são preferíveis (CHASSIN, 1988). No entanto, optou-se por critérios implícitos, aqueles onde especialistas, a partir de seus conhecimentos e experiências pessoais, julgam o caso, submetendo-se, portanto, a maior influência do julgamento e da integridade dos analistas (DONABEDIAN, 1981) por diversos motivos. Destaca-se a multiplicidade de patologias possíveis de ocorrer, associada à falta de uniformidade de informações disponíveis para os casos e o elevado número de combinações diagnósticas. A utilização de critérios explícitos pressuporiam a existência de definições escritas com precisão e detalhes específicos para cada doença, uniformidade de informações e susceptibilidade de verificação (DONABEDIAN, 1982).

O número absoluto de casos que necessitaram desta avaliação foi de 13 em Brejo da Madre de Deus e 57 em Bom Conselho, possibilitando uma visão mais aprofundada e abrangente da história de vida, do 
adoecimento, da peregrinação dos responsáveis em busca de assistência e da morte da criança, não se restringindo a alguns aspectos pré-estabelecidos, fatos já considerados na escolha de critérios implícitos por outros autores (FORMIGLI e outros, 1996). Nos casos onde houve discordância entre os pediatras quanto à causa básica, o autor funcionou como árbitro.

Com a adoção de busca ativa não só das Declarações de Óbito emitidas, mas também daqueles óbitos ocorridos sem o devido registro civil, obteve-se um incremento considerável no número de óbitos identificados, 51 em Brejo da Madre de Deus e 72 em Bom Conselho. O sub-registro de óbitos, após busca ativa, foi de $11,8 \%$ e 45,8\%, respectivamente. Tal procedimento, ao incorporar diversas fontes e formas de coleta, além de aumentar a confiabilidade dos dados, conferiu maior consistência ao estudo.

\section{DECLARAC̣ÕES DE NASCIDOS VIVOS}

\section{REVISÃO DO QUANTITATIVO DE DECLARAÇÕES DE NASCIDOS VIVOS}

A realização da revisão do quantitativo de DNV envolveu dois procedimentos: o primeiro relacionado à coleta de instrumentos emitidos e o segundo relacionado aos nascidos vivos sem a correspondente emissão do documento básico.

Visando identificar as DNV's efetivamente emitidas, procedeu-se uma busca ativa dos instrumentos nos cartórios e Unidades de Saúde. Para identificar os nascidos vivos que não foram registrados em cartório nem emitidas DNV's, procedeu-se uma busca ativa em Unidades de Saúde dos municípios-caso e nos sabidamente receptores de nascimentos, inclusive em outros estados. Utilizou-se ainda as informações do PACS, PSF e PEPT.

Nas Unidades de Saúde, buscaram-se as informações escritas em livros de registro diversos. Para a obtenção dos dados do PACS e PSF foram utilizadas as informações verbais documentadas pelas enfermeiras instrutoras do PACS. Quanto às informações do PEPT, utilizaram-se informações escritas que constavam na ficha de notificação do nascimento e verbais registradas pela enfermeira instrutora do PACS. Após a busca ativa, foi feita a confrontação das informações disponíveis através do software Epi-info versão 6.0 e identificados os nascidos vivos que não tiveram a DNV emitida. 
A adoção da busca ativa dos nascidos vivos, independente da emissão da DNV, possibilitou a identificação de um número considerável de nascidos vivos sem o correspondente instrumento. Brejo da Madre de Deus e Bom Conselho, 1004 e 1020 nascidos vivos, respectivamente. A subenumeração de nascidos vivos encontrada para estes municípios foi, respectivamente, $2,9 \%$ e 10,9\%. Com as medidas adotadas, visando reduzir o sub-registro dos nascidos vivos, os dados apresentados ganharam em confiabilidade e em potência explicativa para o estudo de caso.

\section{PROCESSAMENTO DOS DADOS}

\section{GRAU DE IMPLANTAÇÃO DO PRMI}

Os dados dos componentes do PRMI relacionados ao PAISC e PAISM foram codificados segundo padrão proposto pelo Ministério da Saúde e organizados em um banco de dados único para todas as ações programáticas, utilizando-se o programa EPI-INFO versão 6.0. Com relação ao PACS, PEPT e Vigilância de Óbitos após coleta dos dados previamente descritos (Quadro 3), calculou-se manualmente as coberturas específicas de cada componente. Para os componentes Assistência ao Parto e Recém-nascido e Assistência à Criança Hospitalizada, a consolidação dos dados foi feita manualmente pela simplicidade do processo e pequeno número de unidades envolvidas (uma em cada município). Para o Sistema de Informação, foi utilizado o programa EPI-INFO versão 6.0. Para o componente Educação em Saúde, utilizou-se a análise documental extensiva em diversas fontes com enquadramento nas categorias previamente definidas.

\section{DECLARAC̣ÕES DE ÓBITO E DE NASCIDOS VIVOS}

O conjunto das variáveis das DO's e DNV's emitidas previamente e após busca ativa foram codificadas segundo normas adotadas pela Secretaria de Saúde de Pernambuco. A codificação da causa básica foi feita de acordo com a CID 10 (OMS; OPAS, 1999). Foi construído um banco de dados único para os óbitos e outro para os nascidos vivos, que contemplaram as informações das DO's e DNV's além de outras referentes aos mecanismos que possibilitaram a sua identificação, utilizando-se o programa EPI-INFO versão 6.0. 


\section{PLANO DE ANÁLISE}

\section{CONSTRUÇÃO DO INDICADOR GRAU DE IMPLANTAÇÃO DO PRMI (CRITÉRIOS DEFINIDOS PARA SUA MEDIDA)}

O Grau de Implantação do PRMI, indicador sintético, foi definido a partir dos seus componentes. A seleção dos componentes principais do Projeto ocorreu após análise documental das publicações do Ministério da Saúde, Secretarias de Saúde de Pernambuco e Municipais de Brejo da Madre de Deus e Bom Conselho.

Foi observado que para alguns componentes do Projeto (subprogramas) existiam um conjunto de ações programáticas e estas, por sua vez, continham diversas atividades normatizadas. Para outros componentes, as ações eram implícitas, muitas delas ainda não suficientemente normatizadas. Como a definição adotada para o Grau de Implantação foi de que este corresponde à medida da integralidade das ações programáticas que compõem o PRMI, alguns ajustes foram necessários para operacionalizar a construção do indicador sintético.

O Quadro 4 apresenta os componentes do PRMI, os critérios e os pontos de corte adotados na definição dos respectivos graus de implantação.

Para a estimação numérica do grau de implantação do PRMI, padronizou-se a atribuição de pesos específicos para cada estágio alcançado pelos seus componentes. Assim, para os componentes com as ações implantadas, atribuiram-se 2 pontos, para parcialmente implantadas, 1 ponto, e para não implantadas, 0 ponto. 0 cálculo do escore do grau de implantação do PRMI foi obtido pelo somatório dos valores encontrados para cada um dos seus componentes.

A partir do escore alcançado, classificou-se o Grau de Implantação do PRMI em 4 categorias:

Satisfatório: escores entre 15 e 18 pontos

Aceitável: escores entre 11 e 14 pontos

Regular: escores entre 7 e 10 pontos

Crítico: escores menores ou iguais a 6.

\section{CONSTRUÇÃO DOS INDICADORES DE EFEITO DO PRMI}

Para os indicadores relativos à mortalidade infantil, peso ao nascer e local de ocorrência dos óbitos, utilizou-se o programa EPI-INFO versão 6.0, 
obedecendo-se às operações necessárias para sua construção. Foi calculado para os dois municípios-caso os coeficientes de mortalidade infantil e a mortalidade proporcional por componentes (neonatal e pós-neonatal) e causa básica. Procedeu-se também ao cálculo dos coeficientes de mortalidade infantil e a mortalidade proporcional por causa básica, agrupadas segundo sua redutibilidade por medidas de atenção à saúde, de acordo com a classificação proposta pela Fundação SEADE (CONJUNTURA DEMOGRÁFICA, 1991) e adequada à 10 a Classificação Internacional de Doenças (OMS; OPAS, 1999).

\section{A RELAÇÃO ENTRE O GRAU DE IMPLANTAÇÃO DO PRMI E OS INDICADORES DE EFEITO}

Para a análise do estudo de casos, o pareamento do modelo lógico com a configuração empírica observada foi a abordagem escolhida. Partindo-se dos pressupostos teóricos e com a documentação da realidade empírica observada, obteve-se a compreensão dos casos, considerando os componentes isoladamente e a dimensão unitária do PRMI.

A análise da influência da variação no grau de implantação do PRMI sobre os seus efeitos nos municípios-caso se baseou, fundamentalmente, no conhecimento da configuração dos efeitos produzidos por intervenções com características similares. Denis e Champagne (1997) afirmam que "é pouco útil buscar especificar o conjunto e a diversidade de outros fatores, que não a intervenção, implicados na produção dos efeitos, se estes não variam entre os vários meios de implantação". Nesta pesquisa, reconhecendo a rede de causalidade envolvida na determinação do adoecimento e morte do grupo alvo do PRMI, e que os serviços de saúde deveriam ser mais acessíveis e eficientes em localidades onde persistem as precárias condições socioeconômicas, optou-se por trabalhar em dois municípios com semelhantes condições de vida, de forma a valorizar as diferenças encontradas no grau de implantação da intervenção e nos resultados encontrados, minimizando os viéses de confusão.

Portanto, a identificação de pontos coincidentes e discordantes entre os municípios-caso, as inter-relações entre os dados observados em cada um deles e a sua confrontação com o modelo lógico criaram uma estrutura explicativa dos fatos observados. 


\section{RESULTADOS}

\section{PRMI: O GRAU DE IMPLANTAÇÃO DOS SEUS COMPONENTES E A SUA DIMENSÃO UNITÁRIA}

A construção do indicador grau de implantação do PRMI se deu a partir dos componentes PAISC, PAISM, Assistência ao Parto e ao RN, Assistência à Criança Hospitalizada, PACS, PEPT, Sistema de Informação, Educação em Saúde e Vigilância de Óbitos.

Utilizando a proposição dos Critérios adotados para definição do Grau de Implantação do Componente (PAISC) contido no Quadro 4, o município de Brejo da Madre de Deus atingiu o escore de $84,6 \%$ ao se somar os valores alcançados pelas ações programáticas implantadas (7,7\%) e parcialmente implantadas (76,9\%), classificando-se na condição de PAISC implantado. Quanto a Bom Conselho, enquadrou-se na condição PAISC parcialmente implantado, pois a soma destes valores foi de 60\% (6\% implantado e 54\% parcialmente implantado).

Com relação ao enquadramento do Grau de Implantação do PAISM nos municípios de Brejo da Madre de Deus e Bom Conselho, considerando os critérios adotados, descritos no Quadro 4, o primeiro atingiu o grau parcialmente implantado com um escore de 71,9\% (19,3\% implantado e $52,6 \%$ parcialmente implantado). Bom Conselho ficou na condição de PAISM não implantado, na medida em que o somatório das ações implantadas (2,2\%) e parcialmente implantadas (13\%) não ultrapassaram 15,2\%.

A análise da Assistência ao Parto foi considerada na sua perspectiva estrutural e de Organização de Serviços disponíveis para o atendimento à mulher e ao RN. Para o conjunto dos itens avaliados, os dois municípios obtiveram comportamentos similares, exceto ao ser observada a assistência ao parto como um todo, situação que conferiu a Brejo da Madre de Deus a classificação parcialmente implantado $(45,6 \%)$ e a Bom Conselho não implantado (37,9\%).

A análise da Assistência à Criança Hospitalizada foi considerada na sua perspectiva estrutural e de Organização de Serviços disponíveis para o atendimento à criança enferma. A Tabela 4 aponta a situação dos municípios relativa aos itens selecionados como descritores das condições estruturais da assistência oferecida à criança internada. Para o município de 
Brejo da Madre de Deus, a pior performance foi do item Recursos Humanos $(31,6 \%)$ e o melhor foi Material de Consumo (70\%), enquanto Bom Conselho apresentou os itens Recursos Humanos e Programação e Administração, sem cumprimento de nenhum dos requisitos da avaliação e Material de Consumo com um desempenho de 75\%. Na classificação do Componente Assistência à Criança Hospitalizada, Brejo da Madre de Deus enquadrou-se como parcialmente implantado $(44,6 \%)$ e Bom Conselho como não implantado (28,4\%) (Tabela 4).

0 indicador selecionado para representar o componente PACS foi a cobertura do Programa. Quanto ao tempo de funcionamento do PACS nos dois municípios foi superior a 6 anos, tendo o município de Brejo da Madre de Deus aderido ao Programa um ano antes de Bom Conselho. O Grau de Implantação considerado para os municípios, a partir dos critérios adotados, foi de parcialmente implantado. Cobertura de 48,4\% e 70,6\% em Brejo da Madre de Deus e Bom Conselho, respectivamente.

$\mathrm{O}$ indicador selecionado para representar o componente PEPT foi a cobertura das atividades de cadastramento e capacitação das parteiras tradicionais. Considerou-se também o envolvimento das Secretarias Municipais de Saúde na coordenação do Programa. A cobertura das capacitações atingiu a totalidade das parteiras tradicionais em Brejo da Madre de Deus e 90,9\% das de Bom Conselho. Quanto ao Grau de Implantação do Programa, os dois municípios foram classificados como PEPT implantado.

O indicador selecionado para representar o Componente Sistema de Informação foi a cobertura do Sistema de Informação sobre Mortalidade (SIM). Foram identificados 51 óbitos não fetais de menores de um ano em Brejo da Madre de Deus e 72 em Bom Conselho, o que confere uma cobertura de $88,2 \%$ e $54,2 \%$, respectivamente. Estes valores classificam os municípios no componente Sistema de Informação de Brejo da Madre de Deus em implantado e de Bom Conselho em parcialmente implantado.

O Componente Educação em Saúde foi avaliado a partir da categorização das atividades relacionadas ao tema. A análise documental para o município de Brejo da Madre de Deus sugere a preocupação e priorização da Educação em Saúde como instrumento fundamental das ações de saúde. Quanto ao município de Bom Conselho, a análise documental sugere a inexistência de um Núcleo de Educação em Saúde, apesar do desenvolvimento de ações assistemáticas e focada em campanhas. As 
descrições acima sugerem o município de Brejo da Madre de Deus e Bom Conselho classificados no componente Educação em Saúde como ação implantada e parcialmente implantada, respectivamente.

O indicador escolhido para representar o Componente Vigilância de Óbitos foi a cobertura de óbitos infantis investigados no período anterior a esta pesquisa. A cobertura de óbitos infantis investigados foi de 58,8\% e 15,2\% para Brejo da Madre de Deus e Bom Conselho, respectivamente. Quanto ao Grau de Implantação, o primeiro município foi classificado em parcialmente implantado e o segundo em não implantado.

O PRMI na sua dimensão unitária foi avaliado a partir da consolidação das informações obtidas de cada um dos seus componentes. Estes escores classificam como dispondo de um Grau de Implantação do PRMI aceitável para o município de Brejo da Madre de Deus e crítico para Bom Conselho, conforme pontos de corte descritos nos procedimentos metodológicos (Quadro 5).

\section{PRMI: EFEITOS OBSERVADOS}

Para observação da realidade empírica, foi selecionado um conjunto de indicadores que expressassem as condições de nascimento e morte dos residentes nos municípios estudados. A diversidade encontrada entre os municípios-caso para os indicadores são apresentados de forma agregada para o nível municipal.

Na classificação adotada para observação do Grau de Implantação do PRMI, o município de Brejo da Madre de Deus obteve 13 pontos, sendo enquadrado na categoria Aceitável, enquanto Bom Conselho obteve 6 pontos, sendo categorizado como Implantação Crítica.

Na Figura 2, pode ser vista a sumarização da avaliação referente ao grau de implantação dos componentes do PRMI e alguns resultados da intervenção para os dois municípios analisados. A figura está apresentada em três colunas que tentam reproduzir o modelo lógico de forma simplificada. Na primeira coluna, referente aos componentes do PRMI, observa-se que o município de Brejo da Madre de Deus apresentou maior aderência às propostas do PRMI, com grau de implantação igual ou superior ao município de Bom Conselho. Como exceção apenas do componente PACS, onde Bom Conselho apresentou melhor performance, apesar de enquadrado na mesma condição de implantação em função do ponto de corte. 
A segunda coluna retrata a estrutura e processo de quatro componentes: o PAISC, o PAISM, a Assistência à Criança Hospitalizada e a Assistência ao Parto Hospitalar. Para os componentes PAISC, PAISM e Assistência à Criança Hospitalizada, o município de Brejo da Madre de Deus apresentou sempre uma condição de implantação igual ou superior a Bom Conselho, exceto a ação programática Imunização do PAISC. Quanto à Assistência ao parto hospitalar, a situação dos aspectos estruturais e de processo foram similares nos dois municípios, apesar de, após agregados, possibilitarem o enquadramento de Brejo da Madre de Deus em melhor situação do grau de implantação.

A terceira coluna mostra os resultados alcançados nos dois municípios, onde Brejo da Madre de Deus apresentou menores proporções de óbitos domiciliares, de crianças nascidas com peso inferior a 2.500 gramas, de óbitos por Pneumonias e Doenças Diarréicas. Enquanto Bom Conselho apresentou menor proporção de óbitos por Afecções Perinatais.

No Quadro 6, encontra-se o conjunto de indicadores que sintetizam a situação encontrada nos dois municípios com relação aos resultados. Enquanto na Figura 3 apresenta-se, a partir dos resultados encontrados (realidade empírica), uma simulação, considerando o modelo lógico adotado, de como poderia ser a realidade nos dois municípios (realidade alcançável) se todos os óbitos evitáveis por medidas de atenção à saúde fossem adequadamente conduzidos e prevenidos.

\section{DISCUSSÃO}

Considerando a importância demográfica, social e biológica do grupo populacional representado pelas mulheres e crianças, este segmento representa um dos grupos de interesse dominante em termos de Saúde Pública. A vulnerabilidade social e biológica deste contingente condiciona a susceptibilidade a um conjunto de doenças de alta prevalência, porém, a maioria delas, de fácil controle através de medidas de promoção, prevenção, diagnóstico e tratamento precoces (IMIP; SUDENE, 1990; BARANCHUK, 1971). Parte expressiva destas medidas, mesmo em localidades onde predomina um quadro estrutural de pobreza, são atribuições inerentes ao setor saúde (LEAL, 1996; IMIP; SUDENE, 1990). 
A reestruturação do sistema nacional de saúde, após a promulgação da Constituição de 1988 , tem privilegiado as políticas públicas relacionadas à municipalização das ações e serviços de saúde, visando a implementação de mudanças que culminem com a melhoria das condições de saúde e redução das iniqüidades (SILVA, 1999; ACURCIO e outros, 1991).

A partir da diversidade de experiências que foram surgindo no âmbito do Sistema Único de Saúde, o acompanhamento e monitoramento de políticas e programas pelos serviços de saúde implicou na recomendação da ABRASCO (1995) para a importância da avaliação de serviços, aprimoramento dos sistemas de informação de base nacional e a necessidade de integração pesquisa-serviços de saúde. O mesmo documento reconhece que as práticas dos serviços de saúde têm exigido do campo da Saúde Pública a focalização dos problemas de múltiplas perspectivas.

No entanto, é importante ressaltar algumas implicações embutidas em todo processo avaliativo como as reduções sucessivas entre a escolha do tema, do objeto, seu recorte para o trabalho, a definição de critérios e padrões, a eleição de indicadores para operacionalização e o julgamento do programa ou serviço. Nemes (1996) já destacava o "reducionismo" ao se proceder uma avaliação. Porém, todas as reduções sucessivas procedidas na avaliação são submetidas à prova quando da totalização do trabalho avaliativo.

Neste trabalho não foi diferente: a seleção da questão, métodos e técnicas para definição de critérios, indicadores e padrões utilizados implicaram em sucessivas reduções. No entanto, o plano de reduções verificadas parecem já estar claros e validados, o que, no dizer de Schraiber e outros (1999), permite

abstrair parcialmente a escolha prévia e a normatividade emanada desta própria escolha, avaliando imediatamente os padrões da operação técnica. Trata-se de uma clareza de regras que, contudo, não evidencia a racionalidade de sua construção; esta já está dada e validada como ‘bem' tecnológico.

Vale mensionar ainda que o município, como uma esfera de governo complexa, onde a área da saúde dispõe de uma autonomia relativa, em que as relações dos atores e organizações envolvidas na construção do SUS estão intimamente relacionados ao poder, o estudo do contexto municipal possibilitaria uma melhor compreensão dos processos envolvidos, aspecto não contemplado neste texto. 
A discussão que se segue vem confrontar o modelo lógico com a realidade empírica observada, enfocando os componentes da intervenção e as suas relações de interdependência com a produção dos efeitos.

A fragilidade dos serviços de atenção à saúde da mulher e da criança vem sendo observada e documentada ao longo da última década. As diferentes metodologias, com enfoque centrado em diversos níveis de complexidade, têm em comum a insuficiente condição de implantação para a maioria das unidades de saúde analisadas, ao se tomar o referencial de $80 \%$ ou mais de aderência ao preconizado como satisfatório. Alguns estudos avaliam os aspectos estruturais e de processo da assistência à mulher e recémnascidos durante a gestação e parto, e outros tomam como foco de atuação as ações programáticas do PAISC e PAISM (IMIP; SUDENE, 1990; OJEDA, 1992; RATTNER, 1996; PERNAMBUCO, 1996a; PERNAMBUCO, 1996b; HARTZ e outros, 1997; ALVES; SILVA, 2000; ARAGÃO e outros, 2000; PAES; MACEDO, 2000; VIDAL e outros, 2001).

Por outro lado, historicamente, a análise dos efeitos finais de programas tem sido feita pela epidemiologia, desconsiderando cada etapa do seu desenvolvimento, quando o desejável seria considerar todas as etapas do processo (ABRASCO, 1995). Esta abordagem, o "modelo da caixa preta", no dizer de Denis e Champagne (1997), não permite a vinculação dos efeitos ao programa, por desconsiderar os processos envolvidos e os meios de implantação.

Uma etapa anterior de avaliação sobre a elaboração dos programas, as estruturas organizacionais e a implantação possibilita a seleção das variáveis que, a partir de um modelo teórico, representem os efeitos finais (ABRASCO, 1995). Hartz (1999) apontou a aferição dos efeitos como "o eixo das preocupações, dada à prioridade político-institucional e à complexidade das intervenções e de suas abordagens teórico-metodológicas". Citando Scriven (1993), relata que a avaliação dos efeitos de programas freqüentemente "produz muito pouco, muito tarde" (HARTZ, 1999).

Travassos e outros (1999) afirmam que as medidas dos efeitos representam uma forma indireta de verificar a assistência prestada e que o óbito só é uma medida apropriada em certas condições mórbidas. E exemplificam através de situações onde uma baixa taxa de mortalidade pode expressar um bom atendimento, como nos casos de doenças tratáveis. Ao contrário, quando a morte é inevitável, em algumas doenças terminais, anomalias 
congênitas ou genéticas, as taxas de mortalidade podem não refletir a qualidade da assistência prestada.

Diferenças entre taxas de mortalidade podem estar relacionadas a um amplo conjunto de fatores, desde as iniqüidades nas condições de vida a erros aleatórios, passando pelo acesso a serviços, adequação dos cuidados prestados, variações na eficácia das tecnologias médicas utilizadas, entre outras (TRAVASSOS e outros, 1999; DUARTE e outros, 2002).

Neste estudo, o caminho para construir a explicação nas variações dos indicadores de resultados teve a preocupação inicial de selecionar dois municípios do interior de Pernambuco, os mais parecidos do ponto de vista de condições de vida. Esta foi uma tentativa para deixar as ações dos serviços locais de saúde, como a variação remanescente, valorizando não só os diferenciais de implantação como também os efeitos obtidos.

\section{A IMPLANTAÇÃO E SUA RELAÇÃO COM OS EFEITOS DO PRMI: O CONFRONTO COM O MODELO LÓGICO}

A proposição do modelo lógico subentende que os programas e serviços só terão a eficácia esperada quando se constituírem em uma ação integrada de seus vários componentes (LEAL, 1996). As relações entre os componentes são de complementariedade e interdependência entre si. A articulação e a interação das equipes que trabalham nos diversos subprogramas pode qualificar a atenção prestada no nível local. Para tanto, impõe-se o conhecimento e reconhecimento da importância de cada ação por parte dos diversos atores envolvidos na prestação do cuidado de saúde (SCHRAIBER e outros, 1999).

Considerando o modelo lógico referenciado, presume-se a possibilidade de intervenção com impacto positivo sobre os indicadores de morbimortalidade infantil, mesmo considerando as amplas possibilidades de intervenções através de políticas públicas externas ao setor saúde. Em alguns estados, a exemplo do Rio de Janeiro, tem sido apontado o "esgotamento dos ganhos sociais" com intervenções externas ao setor saúde para a redução da mortalidade infantil e apresentada como alternativa para manutenção da tendência decrescente deste indicador, intervenções setoriais da saúde (LEAL, 1996). Mesmo para estas situações, imagina-se a adequação do modelo proposto com ênfase maior ou menor em determinados subprogramas na dependência do perfil local encontrado. 
1- A implantação das ações relacionadas ao Controle das Doenças Diarréicas e Controle das Infecções Respiratórias e a Mortalidade por estas Causas

Os componentes mais diretamente relacionados com o Controle da Doença Diarréica e com o Controle das Infecções Respiratórias Agudas são o PAISC, a Assistência à Criança Hospitalizada, o PACS e a Educação em Saúde. Nas comunidades, o trabalho se desenvolve através dos componentes PACS e Educação em Saúde e nas Unidades de Saúde através do PAISC e Assistência à Criança Hospitalizada.

Os componentes Sistema de Informação e Vigilância dos Óbitos contribuem com este e os demais indicadores utilizados, através da avaliação e monitoramento das condições de adoecimento e morte, oferecendo subsídios para identificação de problemas na assistência e a tomada de decisões, visando a reversão do quadro (HARTZ, 1995; AERTS, 1997).

Na Figura 2, através do modelo lógico, pode-se observar, de forma simplificada, a interrelação entre os componentes e os resultados relativos à Doença Diarréica.

O confronto entre o grau de implantação das ações relacionadas ao Controle das Doenças Diarréicas parece compatível com os efeitos observados nos dois municípios. Brejo da Madre de Deus atingiu sempre um grau de aderência às normas igual ou maior que Bom Conselho e, conseqüentemente, menores Coeficientes de Mortalidade por esta causa. O Coeficiente chega a ser 3,7 vezes maior em Bom Conselho que em Brejo da Madre de Deus. A Mortalidade Proporcional em Bom Conselho teve maior importância em virtude da precária condição de implantação das atividades, sobretudo da ação programática CDD, parte integrante do PAISC, considerada implantada em apenas 20\% das Unidades existentes no município.

A exemplo da situação encontrada para Doença Diarréica, a situação das Infecções Respiratórias apresenta grande coerência entre a condição de implantação da ação e os resultados observados na mortalidade por esta causa. Os componentes mais diretamente relacionados com os óbitos pelas Pneumonias e Broncopneumonias estão apresentados, simplificadamente, na Figura 2. Nesta, pode-se evidenciar o mais baixo grau de aderência às normas por parte de Bom Conselho, refletindo no padrão de mortalidade observado. O Coeficiente de Mortalidade por Pneumonias foi de 10\%o nv 
em Bom Conselho e de 2\%o nv em Brejo da Madre de Deus, representando um coeficiente 5 vezes maior no primeiro município. A participação proporcional das Infecções Respiratórias no total de óbitos foi também maior em Bom Conselho (14\%), enquanto em Brejo da Madre de Deus representou 4\%.

2- A implantação das ações relacionadas ao Controle das Afecções Perinatais e a Mortalidade por estas Causas

Quanto às ações relacionadas ao Controle das Afecções Perinatais, o PAISM, a Assistência ao Parto e ao Recém-nascido, o Programa de Parteiras Tradicionais, o PACS e a Educação em Saúde estão mais diretamente relacionados a estas causas.

O PACS e os núcleos de Educação em Saúde trabalham nas comunidades buscando a conscientização e a adesão às práticas de reconhecido efeito benéfico, alertando para os sinais de risco e vinculando as pessoas aos Serviços de Saúde. No caso dos partos domiciliares, as parteiras tradicionais assumem papel relevante na condução dos casos, reconhecimento de complicações e distorções, assegurando assistência às mulheres e recém-nascidos em localidades de difícil acesso, onde o poder público nem sempre se faz presente (BRASIL, 1997b; BRASIL; GRUPO CURUMIN GESTAÇÃO e PARTO, 2000; PERNAMBUCO, 1998f).

Nas unidades de saúde, as ações ficam por conta dos componentes PAISM, sobretudo das ações programáticas relacionadas ao Pré-natal e Planejamento Familiar e Assistência ao parto hospitalar.

O confronto da situação de implantação com os indicadores de resultados representando as Afecções Perinatais são apresentados de forma simplificada na Figura 2.

A implantação das ações relacionadas ao PAISM, Assistência ao parto hospitalar e Educação em Saúde são melhores em Brejo da Madre de Deus e as do PACS e Programa de Parteiras são similares nos dois municípios. Quanto aos Coeficientes de Mortalidade por Afecções Perinatais e por Malformações Congênitas, apresentam-se elevados nos dois municípios, com Brejo da Madre de Deus se sobrepondo a Bom Conselho nos dois indicadores.

A aparente incompatibilidade entre o observado na implantação das ações e os resultados encontrados pode ser atribuído a alguns aspectos que 
descreveremos a seguir. O primeiro aspecto é inerente ao estudo como um todo e não apenas a este item, o reconhecido "efeito dos pequenos números" de óbitos e nascidos vivos que pode determinar flutuações importantes das taxas. O segundo aspecto está relacionado à precariedade da assistência à saúde da mulher. No município de Bom Conselho, a implantação do PAISM é de tal forma deficitária que não contribui para que as mulheres levem as suas gestações adiante, devendo, neste caso, o município apresentar altíssimas taxas de mortalidade perinatal, representada sobretudo pelos óbitos fetais e incidência elevada de abortos. Favorável a esta hipótese está o grau de implantação do PAISM em Bom Conselho, que se apresenta como não implantado para o conjunto das ações programáticas, exceto a assistência ao parto domiciliar. No entanto, este estudo não trabalhou os óbitos fetais e os abortos, o que não permite a constatação das taxas de mortalidade perinatal e a incidência de abortos.

Um terceiro aspecto a ser considerado está relacionado aos conceitos de nascido vivo, nascido morto, óbito fetal e aborto e suas implicações jurídico-econômicas e sociais (SILVEIRA, 1996; HOLMES e outros, 1994; BRASIL, 1996b; BRASIL, 1996c; LAURENTI; MELLO JORGE, 1996). Mesmo neste estudo, tendo se procedido uma busca ativa exaustiva e identificado níveis de subregistro de óbitos em menores de um ano alarmantes em Bom Conselho, há de se considerar a não identificação de óbitos neonatais em virtude da rotulação de "nascido morto" para aqueles casos de nascidos com sinais débeis de vida, e para os casos onde se "economizou" o registro de nascimento.

Com relação à Mortalidade proporcional por Causas, a participação das Afecções Perinatais, em 51\% dos óbitos de Brejo da Madre de Deus parece ser compatível em virtude da menor importância proporcional de óbitos por Diarréia e Pneumonias. Em Bom Conselho, a baixa participação proporcional das Afecções Perinatais (18\%) está relacionada ao elevado número de óbitos por Diarréias e Pneumonias e ainda, possivelmente, influenciada pela subenumeração, conforme hipótese levantada no parágrafo anterior.

\section{A IMPLANTAC̣ÃO DAS AC̣ÕES E O BAIXO PESO AO NASCER}

As ações relacionadas ao peso ao nascer estão mais ligadas, no modelo lógico utilizado, com o PAISM, PACS, Programa de Parteiras Tradicionais e 
Educação em Saúde. No nível comunitário, a participação dos Agentes de Saúde no acompanhamento das gestantes, identificação/monitoramento de sinais de risco e encaminhamento para as unidades de saúde, em trabalho articulado com as parteiras tradicionais e as demais ações de Educação em Saúde, são importantes na prevenção dos partos prematuros e na vigilância nutricional das gestantes. Nas unidades de saúde, as ações programáticas do PAISM e as ações de vigilância e recuperação nutricional e de carências específicas, que têm maior peso, completam o ciclo de atuação.

Através da Figura 2, pode-se observar as interrelações dos componentes envolvidos e os resultados relativos ao baixo peso encontrados para os dois municípios.

As proporções de crianças nascidas com peso inferior a 2.500 gramas, nos dois municípios, parecem ser coerentes com as informações obtidas quanto ao grau de implantação dos componentes supracitados. Sobretudo ao se incorporar informação complementar obtida dos profissionais de saúde dos municípios estudados, não documentadas sistematicamente neste estudo, referente à descontinuidade dos programas de recuperação nutricional de gestantes.

O município de Bom Conselho apresentou grau de implantação similar a Brejo da Madre de Deus para os componentes PACS e Programa de Parteiras e inferior nos componentes Educação em Saúde e PAISM. Neste último, o diferencial de implantação variou de 15 a 72\%. Quanto à proporção de baixo peso, oscilou de $8 \%$ a 10\%, com Bom Conselho alcançando uma proporção 20\% superior a Brejo da Madre de Deus.

Outro aspecto a ser considerado é que as informações foram obtidas de banco secundário (SINASC) e o resgate/correção de informações ocorreu apenas para os casos de óbito, obtendo-se informações da mãe da criança e nos livros de registro dos hospitais para os casos em que não houve emissão da Declaração de Nascido Vivo. O número de nascidos com peso ignorado, após os procedimentos listados, ficou em $1 \%$ para o municípioíndice e 4,2\% para o de comparação.

\section{A IMPLANTAÇÃO DAS AÇÕES E OS ÓBITOS DOMICILIARES}

O local de ocorrência dos óbitos está relacionado a um conjunto de fatores que vai de questões geográficas, econômicas, disponibilidade e qua- 
lidade dos serviços prestados e acolhimento a questões socioculturais. No entanto, parece indiscutível que este é um bom indicador para avaliar a existência e funcionamento, qualidade dos serviços nas suas múltiplas dimensões e o acolhimento do sistema de saúde aos problemas da população (DUCHIADE e outros, 1989; HARTZ e outros, 1996; BARRETO; PONTES, 2000; FRIAS e outros, 2002).

No modelo teórico referencial deste estudo, o conjunto dos componentes influenciam a "opção" de expressivo contingente pelo óbito domiciliar. A maioria dos componentes mais diretamente ligados à prestação dos cuidados médicos, o PAISM, a Assistência à Criança Hospitalizada e a Assistência ao Parto, exceto o PAISC, obtiveram baixos graus de implantação, sobretudo no município de Bom Conselho. Para este município foi observado, durante as avaliações normativas das unidades, a grande demanda ao hospital local e uma unidade do PSF, e a quase ausência da população nas demais unidades. Este acontecimento foi explicado pelos funcionários, em função da inexistência de profissionais na maioria dos horários de funcionamento das unidades. Em Brejo da Madre de Deus houve referência de tal fato em apenas uma unidade. Chamou atenção ainda o fato de duas das dez unidades visitadas em Bom Conselho estarem fechadas durante o horário de funcionamento regular, nos dias agendados para realização da avaliação.

Por outro lado, a proporção de Declarações de Óbito com Causa Básica classificada como Sinais, Sintomas e Afecções Mal Definidas (SSAMD) antes da investigação dos casos em domicílio e unidades de saúde, independente do local de ocorrência, reforçam a impressão da precariedade da assistência, e mais compreensível a "opção" pelo morrer em casa (PERNAMBUCO, 1996c). A proporção de SSAMD em Brejo da Madre de Deus e Bom Conselho, antes e depois da investigação, foi de $26 \%$ e $6 \%$, e $78 \%$ e $6 \%$, respectivamente.

A proporção de óbitos ocorridos em domicílio foi de $24 \%$ em Brejo da Madre de Deus e de 68\% em Bom Conselho. Este conjunto de evidências suportam a hipótese que o grau de implantação das ações está relacionado a uma maior ou menor proporção de óbitos em domicílio sem assistência médica. 


\section{A CONFORMAÇÃO DO PERFIL DE MORTALIDADE POR GRUPO ETÁRIO INFLUENCIADA PELA IMPLANTAÇÃO DO PRMI (DIMENSÃO UNITÁRIA)}

As diferenças na situação de implantação de cada um dos componentes do PRMI determinou distintas conformações no perfil de mortalidade por causa básica dos óbitos e por grupos etários de menores de um ano, conforme discutido nas sessões anteriores. As Doenças Diarréicas e Pneumonias acometeram, mais freqüentemente, os maiores de 28 dias entre os óbitos infantis, nos dois municípios. Entretanto, em Bom Conselho, os óbitos por estas causas também tiveram uma contribuição na mortalidade neonatal tardia, em virtude das condições sociais adversas e do baixíssimo nível de implantação das ações programáticas do PAISC relacionadas ao Controle da Doença Diarréica.

As Afecções Perinatais e Malformações Congênitas estiveram mais relacionadas aos óbitos de menores de 28 dias, como era de se esperar. As Afecções Perinatais no município de Brejo da Madre de Deus também contribuíram, em pequena escala, com a mortalidade pós-neonatal, fato indicativo do uso da tecnologia médica na postergação de alguns óbitos e provável sobrevivência de outro contingente.

As elevadas proporções de baixo peso ao nascer certamente contribuíram para o aumento do risco de morte entre os menores de um ano (ALMEIDA, 1994; HARTZ e outros, 1997; SARINHO, 1998). O processo de fragilização decorrente da elevada incidência de episódios diarréicos e de infecções respiratórias durante os primeiros meses de vida, associados a uma baixa prevalência de aleitamento materno documentado para o interior de Pernambuco em diversos estudos (BRASIL e outros, 1998; BATISTA FILHO; ROMANI, 2000) e as precárias condições da assistência ao prénatal, parto e ao recém-nascido (PERNAMBUCO, 1996b; PERNAMBUCO, 1998d; BATISTA FILHO; ROMANI, 2000; PAES; MACEDO, 2000), criaram o cenário favorável às altas taxas de mortalidade encontrada nos dois municípios estudados.

Os elevados Coeficientes de Mortalidade Infantil por grupo etário de menores de um ano, obviamente não foram determinados pelos serviços de saúde; porém, estas unidades, apresentando baixo grau de implantação das ações, decorrente de estrutura e processos de trabalho inadequados, mesmo existindo disponibilidade de tecnologias, muitas delas de baixo cus- 
to e comprovada efetividade, são de responsabilidades inerentes ao setor saúde. Neste sentido, o monitoramento do risco de morte e a maior ou menor sobrevivência das crianças são de responsabilidade do setor saúde, sem, no entanto, desconsiderar as suas mais profundas determinações econômicas, sociais e culturais.

Para Brejo da Madre de Deus e Bom Conselho, o padrão de mortalidade foi de $70,6 \%$ o e $50,8 \%$ o nv para o óbito infantil, $29,9 \%$ e e $20,6 \%$ o nv para os óbitos neonatais e, 20,9\% e 50,0\%o nv para os pós-neonatais. Estes coeficientes são coerentes com o grau de implantação das ações observadas. O município que apresentou mais baixo grau de implantação das ações deteve os mais elevados coeficientes, indicando, por um lado, a precariedade da assistência prestada à população e por outro, as amplas possibilidades que se descortinam para o enfrentamento da questão.

\section{VALIDADES INTERNA E EXTERNA}

As validades interna e externa têm sido descritas como instrumentos úteis para avaliar a qualidade da estratégia de pesquisa, assim como o modelo teórico selecionado para explicar a realidade empírica observada (CONTANDRIOPOULOS e outros, 1997b).

A apreciação da validade interna, neste tipo de estudo, está vinculada às características do modelo lógico, a partir da garantia de relações de causalidade entre as variáveis dependentes e independentes que não possam ser explicadas por outras variáveis que as contidas no modelo selecionado. Está relacionada com a qualidade e complexidade da articulação teórica em que se baseou o estudo, além da adequação entre o modo de análise selecionado e o modelo lógico (CONTANDRIOPOULOS e outros, 1997b; DENIS; CHAMPAGNE, 1997).

A apreciação da validade externa está relacionada com a adequação da teoria subjacente ao estudo, baseando-se no confronto das observações empíricas com o quadro teórico selecionado (HARTZ e outros, 1997). Nos estudos de caso se almeja a generalização analítica (YIN, 1994; DENIS; CHAMPAGNE, 1997) antes que a estatística. A generalização é, portanto, do quadro teórico vinculado à compreensão da questão da pesquisa em diferentes situações e não vinculado ao processo amostral (YIN, 1993; DENIS; CHAMPAGNE, 1997; HARTZ e outros, 1997). 


\section{CONCLUSÕES}

Os achados e principais conclusões deste estudo nos remete a diferentes dimensões a serem consideradas: o estágio de implantação dos diversos subprogramas (componentes) integrantes do PRMI, o perfil da mortalidade infantil, a relação entre o grau de implantação observado e os resultados encontrados, e o papel das políticas setoriais, mais especificamente de saúde, no enfrentamento do problema das mortes infantis.

O principal achado na implantação dos subprogramas do PRMI foi, em geral, a baixa aderência às normas preconizadas e a situação desejável. Dos nove componentes do PRMI, apenas quatro em Brejo da Madre de Deus e um em Bom Conselho foi considerado implantado.

Com relação aos efeitos do PRMI, foram evidenciados elevados Coeficientes de Mortalidade Infantil nos dois municípios, porém com diferenciais importantes para o conjunto de indicadores estudados. 0 perfil da mortalidade dos menores de um ano por causa básica caracterizou-se pela convivência simultânea de causas de morte compatível com localidades subdesenvolvidas e outro mais comum em localidades desenvolvidas.

Os problemas no acesso aos bens, serviços e tecnologias, associados à mais baixa qualidade de cuidados técnico-científicos estiveram relacionados com a alta proporção de óbitos domiciliares. No município de Bom Conselho, estas características foram mais evidenciadas.

A insuficiente adesão e precária utilização de tecnologias simplificadas normatizadas nos subprogramas mais intimamente relacionados à prevenção, promoção, diagnóstico e tratamento precoces dos diversos eventos estudados foi determinante da maior mortalidade infantil.

No aspecto referente ao confronto do grau de implantação dos diversos subprogramas integrantes do PRMI com os resultados encontrados, considerando o modelo lógico, ficou evidenciada a estreita relação entre a maior ou menor aderência aos subprogramas/dimensão unitária do PRMI e o perfil de morbimortalidade dos municípios.

Com relação à reflexão necessária sobre o papel das políticas e atividades setoriais da saúde no enfrentamento das elevadas taxas de mortalidade infantil, ao se observar o número e proporção de óbitos potencialmente evitáveis, e as desiguais oportunidades de sobrevivência entre os nascidos nas diversas regiões, fica evidente o insuficiente compromisso com a vida e com as reduções das iniqüidades. 
Por fim, cabe destacar que mesmo sem negar as determinações sociais mais amplas da mortalidade infantil, as ações do setor saúde, no início do século XXI, precisam criar condições que revertam a persistência de um sem número de mortes de crianças, muitas das quais ainda invisíveis, e a sobrevivência de outras tantas que crescerão sem dignidade por se subtrair a possibilidade de um adequado desenvolvimento infantil em toda sua plenitude.

\section{NOTA}

${ }^{1}$ Trabalho desenvolvido no Mestrado de Pediatria da UFPE. Parcialmente financiado pelo CENEPI.

\section{REFERÊNCIAS}

ABRASCO (Associação Brasileira de Pós-Gradução em Saúde Coletiva). I/ Plano Diretor para o Desenvolvimento da Epidemiologia no Brasil 1995-1999. Rio de Janeiro, 1995. $52 \mathrm{p}$.

ACURCIO, F.A.; CHERCHIGLIA, M.L.; SANTOS, M.A. Avaliação de qualidade de serviços de saúde. Saúde em Debate, Rio de Janeiro, n. 33, p. 50-53, dez. 1991.

AERTS, R.G.C. Investigação dos óbitos perinatais e infantis: seu uso no planejamento de políticas públicas de saúde. Jornal de Pediatria, Rio de Janeiro, v.73, n.6, p.364366, nov./dez. 1997.

ALMEIDA-FILHO, N. Anotações sobre a história da Epidemiologia. In: ROUQUAYROL, M.Z. Epidemiologia e saúde. 4. ed. Rio de Janeiro: MEDSI, 1994. p.1-6.

ALMEIDA, M.F. Mortalidade neonatal em Santo André. 1994. 135p. Tese (Doutorado em Epidemiologia) - Faculdade de Saúde Pública, Universidade de São Paulo, São Paulo, 1994.

ALVES, M.T.S.S.B.; SILVA, A.A.M. Qualidade da assistência ao parto. In: ALVES, MTSSB; SILVA, A.A.M. (Org.). Avaliação de qualidade de maternidades: assistência à mulher e ao seu recém-nascido no Sistema Único de Saúde. São Luís: Universidade Federal do Maranhão, Fundo das Nações Unidas para a Infância (UNICEF), 2000. p. 37-46.

ARAGÃO,V.M.F; SILVA, A.A.M; FILHO, F.L. Qualidade da assistência ao recém-nascido. In: ALVES, M.T.S.S.B.; SILVA, A.A.M. (Org.). Avaliação de qualidade de maternidades: assistência à mulher e ao seu recém-nascido no Sistema Único de Saúde. São Luís: Universidade Federal do Maranhão, Fundo das Nações Unidas para a Infância (UNICEF), 2000.

ARAÚJO, J.D. Polarização epidemiológica no Brasil. Informe Epidemiológico do SUS, Brasília, v. 1, n. 2, p. 5-16, jul. 1992. 
BARANCHUK, N.S. (Coord.). Condiciones de eficiencia de los serviços de atención materno infantil- guias de evaluacion y su adecuacion a los niveles de complejidad hospitalaria. 2. ed. Buenos Aires: SMI, 1971. 206p.

BARRETO, I.C.H.C; PONTES, L.K. Vigilância de óbitos infantis em sistemas locais de saúde avaliação da autópsia verbal e das informações dos ACS. Revista Panamericana de Salud Publica, Washington, v. 7, n. 5, p. 303-312, 2000.

BARROS, F.C.; VICTORA, C.G.; VAUGHAN, G.P.; TEIXEIRA, A.M.B.; ASHWORTH, A. Infant mortality in southern Brazil a population based study of causes of death. Archives of Disease in Childhood, Londres, v. 62, p.487-490, 1987.

BATISTA FILHO, M.; ROMANI, S.A.M. (Eds.). Atenção à saúde materno-infantil no estado de Pernambuco. Recife: Ministério da Saúde, Instituto Materno Infantil de Pernambuco (IMIP), Departamento de Nutrição da Universidade Federal de São Paulo, Secretaria de Saúde de Pernambuco, 2000. 124p.

BECKER, R.A.; LECHTIG, A. Brasil: evolução da mortalidade infantil no período 1977-1984. Brasília, DF: Centro de Documentação do Ministério da Saúde, 1986. [Série C: Estudos e Projetos, 3]

BEGHIN, I.; CAP, M.; DUJARDIN, B. Guia para evaluar el estado de nutricion. Washington: Organização Pan-Americana de la Salud (OPAS), 1989. [Publicação científica, 515].

BENFAM (Sociedade Civil Bem Estar Familiar no Brasil). Pesquisa nacional sobre demografia e saúde: 1996. Rio de Janeiro: A Sociedade, 1997.

BOM CONSELHO (Pernambuco). Secretaria de Saúde. Atas das reuniões de 1999 do Conselho Municipal de Saúde. Bom Conselho: A Secretaria, 1999a.

BOM CONSELHO (Pernambuco). Secretaria de Saúde. Plano Municipal de Saúde 1999. Bom Conselho: A Secretaria, 1999b.

BOM CONSELHO (Pernambuco). Secretaria de Saúde. Plano Plurianual da Saúde 1998-2001. Bom Conselho: A Secretaria, 1999c.

BOM CONSELHO (Pernambuco). Secretaria de Saúde. Relatório da // Conferência Municipal de Saúde. Bom Conselho: A Secretaria, 1999d.

BOM CONSELHO (Pernambuco). Secretaria de Saúde. Sala de situação do município. Bom Conselho: A Secretaria, 2000.

BRASIL. Ministério da Saúde. Instrumento gerencial da saúde da mulher, da criança e do adolescente: avaliação, sistema de informação e programação. Brasília, DF: 0 Ministério, 1995a. 3v.

BRASIL. Ministério da Saúde. Projeto para redução da mortalidade na infância. Brasília, DF: O Ministério, 1995b. 40p.

BRASIL. Ministério da Saúde. Avaliação do projeto para redução da mortalidade na infância - PRMI. Brasília: O Ministério, DF, 1996a. 78p.

BRASIL. Ministério da Saúde. Manual de instruções para o preenchimento da declaração de nascido vivo. 2. ed. Brasília, DF: Fundação Nacional de Saúde, 1996b. $28 p$. 
BRASIL. Ministério da Saúde. Manual de instruções para o preenchimento da declaração de óbito. Brasília, DF: Fundação Nacional de Saúde, 1996c. 40p.

BRASIL. Ministério da Saúde. Metas da Cúpula Mundial em Favor da Infância avaliação de meia década, 1990-1995. Brasília, DF: O Ministério, 1997a. 40p.

BRASIL. Ministério da Saúde. Portaria nº 1886 de 18 de dezembro de 1997. Aprova as normas e diretrizes do Programa de Agentes Comunitários de Saúde e do Programa de Saúde da Família. Diário Oficial da República Federativa do Brasil, Brasília, DF, 22 dez. 1997b. Seção 1, p. 11-13.

BRASIL. Ministério da Saúde. Atenção Integrada às Doenças Prevalentes na Infância. Disponível em: http://www.saúde.gov.br/programas/scriança/criança/aidpi.htm. Acesso em: 01 dez. 2000a.

BRASIL. Ministério da Saúde. Relatório de dados para pagamento dos incentivos PACS e PSF: unidade federada, Pernambuco. [Programa: Cadastro de Pessoal no Sistema de Informação-CapSI, 1999]. Acesso em: 24 out. 2000b.

BRASIL. Ministério da Saúde. Relatório de quantidade de profissionais do Sistema de Informação de Atenção Básica-SIAB: unidade federada Pernambuco [Programa: Cadastro de Pessoal no Sistema de Informação-CapSI, 1999]. Acesso em: 24 out. 2000c.

BRASIL. Ministério da Saúde. Criança saudável. Disponível em: http:// www.saúde.gov.br/programas/scriança/criança/sauda.htm. Acesso em: 30 nov. 2000d.

BRASIL. Ministério da Saúde. Sistema de Informação de Atenção Básica (SIAB): relatório de controle de informações de saúde 1994 a 2000 - unidade federada Pernambuco. Acesso em: 24 out. 2000f.

BRASIL. Ministério da Saúde. Situação da criança no Brasil. Disponível em: http:// www.saúde.gov.br/programas/scriança/criança/situação.htm. Acesso em: 30 nov. 2000g.

BRASIL. Ministério da Saúde. Grupo Curumin Gestação e Parto. Trabalhando com parteiras tradicionais. 2. ed. Brasília, DF: O Ministério, 2000. 86p.

BRASIL. Ministério da Saúde; INAN (Instituto Nacional de Alimentação e Nutrição); IMIP (Instituto Materno Infantil de Pernambuco); UFPE (Universidade Federal de Pernambuco); PERNAMBUCO. Secretaria de Saúde. I/ Pesquisa estadual de saúde e nutrição: saúde nutrição, alimentação e condições sócioeconômicas no estado de Pernambuco. Recife: O Ministério, 1998

BREJO DA MADRE DE DEUS (Pernambuco). Secretaria de Saúde. Atas das reuniões de 1999 do Conselho Municipal de Saúde. Brejo da Madre de Deus: A Secretaria, 1999a.

BREJO DA MADRE DE DEUS (Pernambuco). Secretaria de Saúde. Planejamento do Núcleo de Educação em Saúde. Brejo da Madre de Deus: A Secretaria, 1999b.

BREJO DA MADRE DE DEUS (Pernambuco). Secretaria de Saúde. Plano Municipal de Saúde. Brejo da Madre de Deus: A Secretaria, 1999c. 
BREJO DA MADRE DE DEUS (Pernambuco). Secretaria de Saúde. Relatório do Núcleo de Educação em Saúde. Brejo da Madre de Deus: A Secretaria, 1999d.

BREJO DA MADRE DE DEUS (Pernambuco). Secretaria de Saúde. Sala de Situação do município. Brejo da Madre de Deus: A Secretaria, 2000.

CARDOSO, M.C.S. Mortalidade infantil: uma abordagem da diversidade espacial na perspectiva dos sistemas de informações de mortalidade e nascimentos. 2001. Dissertação (Mestrado em Saúde Pública) - Departamento de Medicina Social do Centro de Ciências da Saúde, Universidade Federal de Pernambuco, Recife, 2001. CASTIEL, L.D. Considerações acerca da utilização da epidemiologia na avaliação dos sistemas de saúde. Cadernos de Saúde Pública, Rio de Janeiro, v. 2, n. 2, p 184-190, abr./jun.1986.

CDC (Centers for Disease Control and Prevention). Framework for program evaluation in public health. Morbidity and Mortality Weekly Report (MMWR), Atlanta, v. 8, n. RR11, p. 1-40, 1999.

CESAR, C.L.G.; TANAKA, O.Y. Inquérito domiciliar como instrumento de avaliação de serviços de saúde: um estudo de caso na região Sudoeste da área metropolitana de São Paulo, 1989-1990. Cadernos de Saúde Pública, Rio de Janeiro, v.12, supl. 2, p. 59-70, 1996.

CHASSIN, M.R. Standards of care in medicine. Inquiry, v. 25, p. 437-453, 1988.

CHEN, H.T. Theory-driven evaluations. London: Sage, 1990.

CHEN, H.T. Applying mixed methods under the framework of the theory-driven evaluations. New Directions for Evaluation, n. 74, p. 61-72, Summer 1997.

CLEMENHAGEN, C.; CHAMPAGNE, F. Quality assurance as part of program evaluation: guidelines for manegers and departamental heads. Journal of Quality Assurance, v. 12, p. 383-387, 1986.

COIMBRA, L.C.; SILVA, A.A.M. Características das mulheres e assistência pré-natal. In: ALVES, M.T.S.S.B.; SILVA, A.A.M. (Org.). Avaliação de qualidade de maternidades: assistência à mulher e ao seu recém-nascido no Sistema Único de Saúde. São Luís: Universidade Federal do Maranhão, Fundo das Nações Unidas para a Infância (UNICEF), 2000. p. 25-30.

CONJUNTURA DEMOGRÁFICA, São Paulo, n.14/15, jan./jun.1991.

CONTANDRIOPOULOS, A.P.; CHAMPAGNE, F.; DENIS, J.L.; PINEAULT, R. A avaliação na área da saúde: conceitos e métodos. In: HARTZ, Z.M.A. (Org.). Avaliação em saúde: dos modelos conceituais à prática na análise da implantação de programas. Rio de Janeiro: Fundação Oswaldo Cruz (FIOCRUZ), 1997a. p. 29-48.

CONTANDRIOPOULOS, A.P.; CHAMPAGNE, F.; POTVIN, L.; DENIS, J.L.; BOYLE, P. Saber preparar uma pesquisa-definição, estrutura, financiamento. 2. ed. São Paulo: HUCITEC; Rio de Janeiro: Associação Brasileira de Pós-Graduação em Saúde Coletiva (ABRASCO), 1997b.

COUTINHO, S.B. Mortalidade neonatal em cinco maternidades da cidade do Recife, 1994. Recife: Fundo das Nações Unidas para a Infância (UNICEF), 1996. 94p. 
COSENDEY, M.A.E. Análise de implantação do programa farmácia básica: um estudo multicêntrico em cinco estados do Brasil. 2000. 175p. Tese (Doutorado em Saúde Pública) - Escola Nacional de Saúde Pública (ENSP), Fundação Oswaldo Cruz (FIOCRUZ), Rio de Janeiro, 2000.

DECLARAÇÃO de Alma-Ata. In: CONFERÊNCIA INTERNACIONAL SOBRE CUIDADOS PRIMÁRIOS DE SAÚDE, 1978, Alma-Ata, Cazaquistão, União das Repúblicas Socialista Soviéticas. Relatório. Brasília, DF: Organização Mundial da Saúde (O.M.S), Fundo das Nações Unidas para a Infância (UNICEF), 1979. p.2-5.

DENIS, J.L.; CHAMPAGNE, F. Análise de implantação. In: Hartz, Z.M.A. (Org.). Avaliação em saúde: dos modelos conceituais à prática na análise da implantação de programas. Rio de Janeiro: Fundação Oswaldo Cruz (FIOCRUZ), 1997. p.4988.

DONABEDIAN, A. Basic approaches to assessment: structure, process and outcome. In: DONABEDIAN, A. Explorations in quality assesment and monitoring. Ann Arbor, Michigan: Health Administration, 1980. v. 1, p.77-125.

DONABEDIAN, A. Advantages and limitations of explicit criteria for assessing the quality health care. Health and Society, v. 59, p. 99-106, 1981.

DONABEDIAN, A. Explorations in quality assessment and monitoring. Ann Arbor: Health Administration, 1982. 2v.

DUARTE, E.C.; SCHINEIDER, M.C.; PAES-SOUZA, R.; RAMALHO,W.M.; SARDINHA, L.M.V.; SILVA JUNIOR, J.B.; CASTILHO-SALGADO, C. Epidemiologia da Desigualdades em Saúde. Um estudo exploratório. OPAS. Brasília. 2002,118p.

DUCHIADE, M.P.; CARVALHO, M.L.; LEAL, M.C. As mortes em "domicílio de menores de 1 ano na região metropolitana de Rio de Janeiro em 1986 - um " evento sentinela" na avaliação dos serviços de saúde. Cadernos de Saúde Pública, Rio de Janeiro, v. 5, n. 3, 251-263, jul./set. 1989.

FELISBERTO, E.; FRIAS, P.G.; FERNANDES, A.S.; BELTRÃO, A.B.; FIGUEIRÓ, A.C.; HOLMES, C.; MELO FILHO, DA, ANTUNES, MBC, LYRA, TM. Projeto de redução da mortalidade infantil do estado de Pernambuco. Revista do IMIP, Recife, v. 9, n. 1, p. 56-63, jun. 1995.

FERREIRA, C.E.C. Saneamento e mortalidade infantil. São Paulo em Perspectiva, São Paulo (Capital), v. 6, n. 4, p. 62-69, out./dez. 1992.

FIAM (FUNDAÇÃO DO DESENVOLVIMENTO DO INTERIOR DE PERNAMBUCO). Perfil municipal do interior de Pernambuco - 1996. Recife: A Fundação, 1996.

FIBGE (Fundação Instituto Brasileiro de Geografia e Estatística). População residente. Disponível em: www.datasus.gov.br/cgi/ibge/popmap.htm. Acesso em: 28 out. 2000.

FORMIGA, J.F.N.F. Políticas de saúde reprodutiva no Brasil: uma análise do PAISM. In: DÍAZ, J. Saúde sexual e reprodutiva no Brasil: dilemas e desafios. São Paulo: HUCITEC; Population Council, 1999.

FORMIGLI, V.L.A.; SILVA, L.M.V.; CERDEIRA, A.J.P.; PINTO, C.M.F.; OLIVERIA, R.S.A.; CALDAS, A.C.; VILAS BOAS, M.J.B.; FONSECA, A.C.; SOUZA, L.S.F.; SILVA, L.R.; 
PAES, M.S.F. Avaliação da atenção à saúde através da investigação de óbitos infantis. Cadernos de Saúde Pública, Rio de Janeiro, v. 12, Supl. 2, p. 33-41, 1996.

FRIAS, P.G.; LEAL, M.C.; CARDOSO, M.C.S.; RODRIGUES, C.R. Projeto de redução da mortalidade infantil em Pernambuco: critérios de seleção dos municípios, estratégias para estabelecimento de parcerias e alguns resultados preliminares. Revista Pediátrica de Pernambuco. Recife, 2001.

FRIAS, P.G.; LIRA, P.I.C.; VIDAL, S.A.; VANDERLEI, L.C. Vigilância de óbitos infantils como indicador da efetividade do sistema de saúde-estudo de caso em município do interior do Nordeste brasileiro. Jornal de Pediatria, Rio de Janeiro, v. 78, n. 6, p. 509-516, 2002.

GRAHAM, K. The evaluation casebook: using evaluations techiniques to enhance program quality in addictions. Toronto: Addiction Research Formulations (ARF), 1994.

GUIMARÃES, M.J.B. Mortalidade infantil e condições de vida: uma análise da desigualdade espacial no Recife. 1998. 149p. Dissertação (Mestrado em Saúde Materno-Infantil) - Instituto Materno Infantil de Pernambuco (IMIP), Recife, 1998.

HARTZ, Z.M.A. Vigilância epidemiológica da mortalidade infantil. Contribuição a planificação dos programas de saúde da criança. Pediatria Atual, Rio de Janeiro, v. 8, p. 31-34, 1995.

HARTZ, Z.M.A.; CHAMPAGNE, F.; LEAL, M.C.; CONTANDRIOPOULOS, A.P. Mortalidade infantil "evitável" em duas cidades do Nordeste do Brasil: indicador da qualidade do sistema local de saúde. Revista de Saúde Pública, São Paulo, v. 30, n. 4, p. 310-318, ago. 1996.

HARTZ, Z.M.A. Explorando novos caminhos na pesquisa avaliativa das ações de saúde. In: HARTZ, Z.M.A. (Org.). Avaliação em saúde: dos modelos conceituais à prática na análise da implantação de programas. Rio de Janeiro: Fundação Oswaldo Cruz (FIOCRUZ), 1997. p.19-28.

HARTZ, Z.M.A.; CHAMPAGNE, F.; CONTANDRIOPOULOS, A.P.; LEAL, M.C. Avaliação do programa materno-infantil: análise de implantação em sistemas locais de saúde no Nordeste do Brasil. In: Hartz, Z.M.A. (Org.). Avaliação em saúde: dos modelos conceituais à prática na análise da implantação de programas. Rio de Janeiro: Fundação Oswaldo Cruz (FIOCRUZ), 1997. p. 89-131.

HARTZ, Z.M.A.; POUVOURVILLE, G. Avaliação dos programas de saúde: a eficiência em questão. Ciência e Saúde Coletiva, Rio de Janeiro, v. 3, n. 1, p. 68-82, 1998.

HARTZ, Z.M.A. Avaliação dos programas de saúde: perspectivas teórico metodológicas e políticas institucionais. Ciência e Saúde Coletiva, Rio de Janeiro, v. 4, n. 2, p. 341-353, 1999.

HOLMES, C.E.; RODRIGUES, C.; FRIAS, P.G.; HOLMES, S.M. Mortalidade infantil: uma análise da heterogeneidade espacial em Olinda. 1994. 31p. Monografia (Especialização) - Núcleo de Estudos em Saúde Coletiva, Centro de Pesquisa Aggeu Magalhães, Fundação Oswaldo Cruz, (FIOCRUZ), Recife, 1994.

IMIP (Instituto Materno Infantil de Pernambuco); SUDENE (Superintendência do Desenvolvimento do Nordeste). Relatório da pesquisa avaliação das condições de 
eficiência de serviços de atenção materno-infantil e planejamento familiar. Recife: O Instituto, SUDENE, 1990.

INFORMA SAÚDE, Bom Conselho (Pernambuco), v. 2, n. 8, jan./mar. 1999a. INFORMA SAÚDE, Bom Conselho (Pernambuco), v. 2, n. 9, abr./jun. 1999b.

IPEA (Instituto de Pesquisa Aplicada); Fundação João Pinheiro. Desenvolvimento humano e condições de vida: indicadores brasileiros. Brasília: O Instituto, 1996.

LANNES, R. Responsabilidade partilhada - o papel das instâncias do SUS na organização da assistência perinatal. Tema, Rio de Janeiro, n. 17, p. 2-5, fev. 1999.

LAURENTI, R. Transição demográfica e epidemiológica. In: CONGRESSO BRASILEIRO DE EPIDEMIOLOGIA, 1., set., 1990, Campinas, São Paulo. Anais. Rio de Janeiro: Associação Brasileira de Pós-Graduação em Saúde Coletiva (ABRASCO), 1990. p.143-165.

LAURENTI, R.; MELLO JORGE, M.H. O atestado de óbito. 3. ed. São Paulo: Organização Mundial da Saúde (OMS), Centro Brasileiro para Classificação de Doenças em Português. São Paulo, 1996. 87p.

LEAL, M.C. Evolução da mortalidade infantil no estado do Rio de Janeiro na década de 80: o componente neonatal. 1996. 101p. Tese (Doutorado em Saúde Pública) Escola Nacional de Saúde Pública (ENSP), Fundação Oswaldo Cruz (FIOCRUZ), Rio de Janeiro, 1996.

LEITE, A.J.M.; MARCOPITO, L.F.; DINIZ, R.L.P.; SILVA A.V.S.; SOUZA, L.C.B.; BORGES, J.C.; SÁ, H.L.C. Mortes perinatais no município de Fortaleza, Ceará: 0 quanto é possível evitar? Jornal de Pediatria, Rio de Janeiro, v. 73, n.6, p. 367382, nov./dez. 1997.

MARANHÃO, A.G.K.; JOAQUIM, M.M.C.; SIU, C. Mortalidade perinatal e neonatal no Brasil. Tema, Rio de Janeiro, n. 17, p. 6-17, fev. 1999.

MENEZES, A.M.B.; VICTORA, C.G.; BARROS, F.C.; MENEZES, F.S.; JANNKE, H.; ALBERNAZ, E.; HALPERN, R.; GRACE, P.; OLIVEIRA, A.L.B. Estudo populacional de investigação de óbitos perinatais e infantis: metodologia, validade do diagnóstico e sub-registro. Jornal de Pediatria, Rio de Janeiro, v. 73, n. 6, p. 383-387, nov./ dez. 1997.

MINAYO, M.C.S.; SANCHES, O. Quantitativo-qualitativo: oposição ou complementariedade. Cadernos de Saúde Pública, Rio de Janeiro, v. 9, n. 3, p. 239-248, jul./set. 1993.

MONTEIRO, C.A. Contribuição para o estudo do significado da evolução do coeficiente da mortalidade infantil no Município de São Paulo, SP (Brasil) nas três últimas décadas (1950-1979). Revista de Saúde Pública, São Paulo, v. 16, n. 1, p. 7-18, fev. 1982.

MONTEIRO, C.A.; ZUÑIGA, H.P.P. Uma nova hipótese para a ascensão da mortalidade infantil da cidade de São Paulo nos anos 60. In: MONTEIRO, C.A. (Org.). Velhos e novos males da saúde no Brasil. São Paulo: HUCITEC, 1995. p. 157-172.

MURNAGHAN, J.H. Health indicators and information systems for the year 2000. Ann Rev Public Health, n. 2, p. 299-361, 1981. 
NEMES, M.I.B. Avaliação do trabalho programático na atenção primária à saúde. 1996. 120p. Tese (Doutorado em Medicina) - Departamento de Medicina Preventiva, Faculdade de Medicina da Universidade de São Paulo, São Paulo, 1996.

OJEDA, N.S. Evaluación de servicios de salud maternoinfantil en América Latina. Foro Mundial de la Salud, Genebra, v. 13, n. 2/3, p. 140-143, 1992.

OLIVEIRA, L.A.P.; SIMÕES, C.C.S. O papel das políticas de saúde e saneamento na recente queda da mortalidade infantil: significado, alcance e limitações estruturais. In: FIBGE (Fundação Instituto Brasileiro de Geografia e Estatística). Perfil estatístico de crianças e mães no Brasil: aspectos socioeconômicos da mortalidade infantil em áreas urbanas. Rio de Janeiro: A Fundação, 1986. p.51-57.

OMS (Organização Mundial da Saúde); OPAS (Organização Pan-Americana da Saúde). Classificação estatística internacional de doenças e problemas relacionados à saúde. 10. rev. São Paulo: Editora da Universidade de São Paulo (EDUSP), 1999. v.1.

OPAS (Organização Pan-Americana da Saúde); OMS (Organização Mundial da Saúde). Condições de eficiência dos serviços de atenção materno-infantil. Brasília, DF: OPAS, 1987. 2v.

OSIS, M.J.M.D. PAISM: um marco na abordagem da saúde reprodutiva no Brasil. Cadernos de Saúde Pública, Rio de Janeiro, n. 1, Supl. 14, p. 25-32, 1998.

PAES, C.V.; MACEDO, V.C. Avaliação do Programa de Assistência Integral à Saúde da Mulher no município de Brejo da Madre de Deus - PE. 2000. 70p. Monografia (Graduação em Enfermagem) - Departamento de Enfermagem, Centro de Ciências da Saúde, Universidade Federal de Pernambuco, Recife, 2000.

PAIM, J.S.; COSTA, M.C.M. Decline and uneveness of infant mortality in Salvador, Brazil, 1980-1988. Bulletin of the Pan-American Health Organization, Washington, v. 27, n. 1, p. 1-14, 1993.

PATTON, M.Q. Practical evaluation. Beverly Hills: Sage, 1982.

PERNAMBUCO. Secretaria de Saúde. Avaliação das ações de atenção integral à saúde da criança (1995): situação atual - grau de implantação e de gestão municipal. Recife: A Secretaria, 1996a. 156p. (Cadernos de Avaliação, Série Projeto Salva-Vidas, 4).

PERNAMBUCO. Secretaria de Saúde. Hygeia. Recife: A Secretaria, 1996b. (Cadernos de Avaliação, Série Saúde da Mulher e do Adolescente).

PERNAMBUCO. Secretaria de Saúde. Mortalidade infantil em Pernambuco (19801991): geografia, magnitude e significados. Recife: A Secretaria, 1996c. 312p. (Cadernos de Avaliação, Série Projeto Salva-Vidas, 2).

PERNAMBUCO. Secretaria de Saúde. Coletânea de projetos relacionados com a redução da mortalidade infantil. Recife: A Secretaria, 1997. 86p. (Cadernos de Avaliação, Série Projeto Salva-Vidas, 7).

PERNAMBUCO. Secretaria de Saúde. AIDPI - Atenção Integrada às Doenças Prevalentes na Infância, processo de implantação da estratégia em Pernambuco. Recife: A Secretaria, 1998a. 83p. (Cadernos de Avaliação, Série Projeto SalvaVidas, 14). 
PERNAMBUCO. Secretaria de Saúde. Avaliação sobre o manejo das infecções respiratórias agudas em menores de 5 anos no Município de Recife/PE. Recife: A Secretaria, 1998b. 85p. (Cadernos de Avaliação, Série Projeto Salva-Vidas, 10).

PERNAMBUCO. Secretaria de Saúde. Condições de vida e mortalidade infantil em Pernambuco: uma descrição dos municípios integrantes do Projeto Salva-Vidas. Recife: A Secretaria, 1998c. 220p. (Cadernos de Avaliação, Série Projeto SalvaVidas, 15).

PERNAMBUCO. Secretaria de Saúde. Diagnóstico estrutural das maternidades do estado de Pernambuco - 1997. Recife: A Secretaria, 1998d. 182 p. (Cadernos de Avaliação, Série Projeto Salva-Vidas, 12).

PERNAMBUCO. Secretaria de Saúde. Relatório de avaliação do Programa de Parteiras Tradicionais da Secretaria de Saúde de Pernambuco, 1998. Recife: A Secretaria, $1998 f$.

PERNAMBUCO. Secretaria de Saúde. Relatório de implantação do Programa de Agentes Comunitários de Saúde em Pernambuco de 1991 a 1997. Recife: A Secretaria, 1998g.

PERNAMBUCO. Secretaria de Saúde. Relatório de pesquisa: investigação de óbitos de menores de 1 ano em 3 municípios de Pernambuco. Recife: A Secretaria, 1998h. 51p.

POST, C.L.A.; VICTORA, C.G.; VALENTE, J.G.; LEAL, M.C.; NIOBEY, F.M.L.; SABROZA, P.C. Fatores prognósticos de letalidade hospitalar por diarréia ou pneumonia em menores de um ano de idade. Estudo de caso e controle. Revista Saúde Pública, São Paulo, v. 26, n. 6, p. 369-378, dez. 1992.

PUFFER, R.R.; SERRANO, C.V. Patterns of mortality in childhood. Washington, DC: Panamerican Health Organization (PAHO), 1973. [Scientific Publication, 262].

RATTNER, D. A epidemiologia na avaliação da qualidade: uma proposta. Cadernos de Saúde Pública, Rio de Janeiro, v. 12, supl. 2, p. 21-32, 1996.

REICHENHEIM, M.G.; WERNECK, G.L. Adoecer e morrer no Brasil dos anos 80: perspectivas e novas abordagens. In: GUIMARÃES, R; TAVARES, R. (Orgs.). Saúde e sociedade no Brasil - anos 80. Rio de Janeiro: Relume/Dumará, 1994.

RIBEIRO, V.S.; SILVA, A.A.M.; BARBIERE, M.A.; BETTIOL, H.; GALVÃO, C.C.A. Baixo peso e prematuridade em coortes populacionais de duas cidades brasileiras de diferentes regiões. Jornal de Pediatria, Rio de Janeiro, v. 76, Supl. 1, p. 73, 2000. [Apresentado no Congresso Brasileiro de Pesquisa em Saúde da Criança e do Adolescente, mar. 2000, São Paulo, SP.].

ROMERO, D.E.; SZWARCWALD, C.L. Crisis económica y mortalidad infantil en Latinoamérica desde los años ochenta. Cadernos de Saúde Pública, Rio de Janeiro, v.16, n.3, p. 799-814, jul./set. 2000.

ROUQUAYROL, M.Z.; KERR-PONTES, L.R. A medida da saúde coletiva. In: ROUQUAYROL, M.Z. Epidemiologia e saúde. 4. ed. Rio de Janeiro: MEDSI, 1994. p. 23-76.

RUTSTEIN, D.D.; BERENBERG, W.; CHALMERS, T.C.; CHILD, C.G.; FISHMAN, A.P.; PERRIN, E.B. Measuring the quality of medical care: a clinical method. The New England Journal of Medicine, Boston, v. 294, n. 11, p. 582-588, mar. 1976. 
SARINHO, S.W. Mortalidade neonatal na cidade do Recife: um estudo caso-controle. 1998. 136p. Tese (Doutorado em Medicina) - Centro de Ciências da Saúde. Universidade Federal de Pernambuco, Recife, 1998.

SARINHO, S.W.; SILVA, G.A.P.; FILHO, D.A.M.; GUIMARÃES, M.J.B. Causas de óbito neonatais na cidade do Recife segundo critério de evitabilidade. Anais da Faculdade de Medicina, Recife, v.43, n. 2, p. 112-115, 1998.

SCHRAIBER, L.B.; PEDUZZI, M.; SALA, A.; NEMES, M.I.B.; CASTANHERA, E.R.; KON, R. Planejamento, gestão e avaliação em saúde: identificando problemas. Ciência e Saúde Coletiva, Rio de Janeiro, v. 4, n. 2, p. 221-242, 1999.

SEGRE, C.A.M; GUILLAUMON, M.R.; SEVERINO, J.A.O. Indicadores perinatais de qualidad.e. Revista de Pediatria do Ceará, Fortaleza, v. 1, Supl. 1, p. 284, 2000. [Apresentado no Congresso Brasileiro de Pediatria, 31., out. 2000, Fortaleza. Resumo n. P254].

SILVA JR., J.B. Diferenciais intra-urbanos de saúde em Olinda/PE. 1995. 119p. Dissertação (Mestrado em Saúde Coletiva) - Faculdade de Ciências Médicas, Universidade Estadual de Campinas, Campinas, 1995.

SILVA, L.M.V. Avaliação do processo de descentralização das ações de saúde. Ciência e Saúde Coletiva, Rio de Janeiro, v. 4, n. 2, p. 331-339, 1999.

SILVA, L.M.V.; FORMIGLI, V.L.A. Avaliação em saúde: limites e perspectivas. Cadernos de Saúde Pública, Rio de Janeiro, v. 10, n. 1, p. 80-91, jan./mar. 1994.

SILVA, L.M.V. Uma agenda para investigação em políticas e sistemas de saúde no Nordeste. Cadernos de Saúde Pública, Rio de Janeiro, v. 16, n. 3, p. 857-861, jul./ set. 2000.

SILVEIRA, R.M.J. Atestado médico falso. São Paulo: Centro Brasileiro da Organização Mundial de Saúde (OMS) para classificação de doenças em português, 1996. 61p. (Divulgação, 9).

SIMÕES, C.C.S.; OLIVEIRA, L.A.P. Evolução da mortalidade infantil. In: FIBGE (Fundação Instituto Brasileiro de Geografia e Estatística). Perfil estatístico de crianças e mães no Brasil: aspectos sócio-econômicos da mortalidade infantil em áreas urbanas. Rio de Janeiro: 0 Instituto, 1986. p. 29-48.

SIMÕES, C.C.S. A mortalidade infantil na transição da mortalidade no Brasil: um estudo comparativo entre o Nordeste e o Sudeste. 1997. 182p. Tese (Doutorado em Demografia) - Faculdade de Ciências Econômicas, Universidade Federal de Minas Gerais, Belo Horizonte, 1997.

SIMÕES, C.C.S. Estimativas da mortalidade infantil por microrregiões e municípios. Brasília, DF: Ministério da Saúde, 1999. 81p.[+ 101 sem numeração]

SZWARCWALD, C.L.; LEAL, M.C.; JOURDAN, A.M.F. Mortalidade infantil: o custo social do desenvolvimento brasileiro. In: LEAL, M.C.; SABROZA, P.C.; RODRIGUEZ, R.H.; BUSS, P.M. (Orgs.). Saúde, ambiente e desenvolvimento. São Paulo: HUCITEC, Rio de Janeiro: Associação Brasileira de Pós-Graduação em Saúde Coletiva (ABRASCO), 1992. v.2, p.251-278.

TEIXEIRA, P. Mortalidade na infância no Nordeste dos anos trinta aos noventa: um estudo de tendências. In: SEMINÁRIO SOBRE MORTALIDADE INFANTIL NO NOR- 
DESTE DO BRASIL: sistemas de registros, aspectos metodológicos e resultados, set. 1996, Recife.

TRAVASSOS, C.; NORONHA, J.C.; MARTINS, M. Mortalidade hospitalar como indicador de qualidade: uma revisão. Ciência e Saúde Coletiva, Rio de Janeiro, v. 4, n. 2, p. 367-381, 1999

UNICEF (Fundo das Nações Unidas para a Infância); FIBGE (Fundação Instituto Brasileiro de Geografia e Estatística). Municípios brasileiros, crianças e suas condições de sobrevivência. Brasília, DF: A Fundação, 1994. 248p.

UNICEF (Fundo das Nações Unidas para a Infância). Situação mundial da infância: 1998. Brasília, DF: A Fundação, 1998. 135p.

UNICEF (Fundo das Nações Unidas para a Infância). Situação mundial da infância: 2001. Brasília, DF: A Fundação, 2001a. 116p.

UNICEF (Fundo das Nações Unidas para a Infância). Situação da infância brasileira: 2001. Brasília, DF: A Fundação, 2001b. 159p.

UFPE (Universidade Federal de Pernambuco); JICA (Agência de Cooperação Internacional do Japão). Relatório da avaliação conjunta referente à cooperação técnica no âmbito do Projeto "Saúde Pública no Nordeste: a experiência de Pernambuco". Recife: A Universidade, 1999.

VICTORA, F.C.; BARROS, F.C.; VAUGHAN, J.P. Epidemiologia da desigualdade: um estudo longitudinal de 6000 crianças brasileiras. 2.ed. São Paulo: HUCITEC, 1988. $187 p$.

VIDAL, S.A. Avaliação do Programa de Infecção Respiratória Aguda nos serviços públicos ambulatoriais do Recife. 1996. 147p. Dissertação (Mestrado em Saúde Materno-Infantil) - Instituto Materno Infantil de Pernambuco (IMIP), Recife, 1996.

VIDAL, S.A.; FRIAS, P.G.; MARQUES, N.M. Avaliação normativa das ações do Programa de Assistência Integral à Saúde da Criança. Revista Brasileira de Saúde Materno Infantil, Recife, v. 1, n. 2, maio/ago. 2001.

VUORI, H. A qualidade da saúde. Divulgação em saúde para debate. Cadernos de Ciência e Tecnologia, n. 1, p. 17-25, fev. 1991.

YIN, R.K. Applications of case study research. Newbury Park, CA: Sage, 1993.

YIN, R.K. Discovering the future of the case study method in evaluation research. Evaluation Practice, v. 15, n. 3, p. 283-90, 1994. 


\section{ANEXOS}

Figura 1

Modelo lógico do Projeto de Redução da Mortalidade Infantil

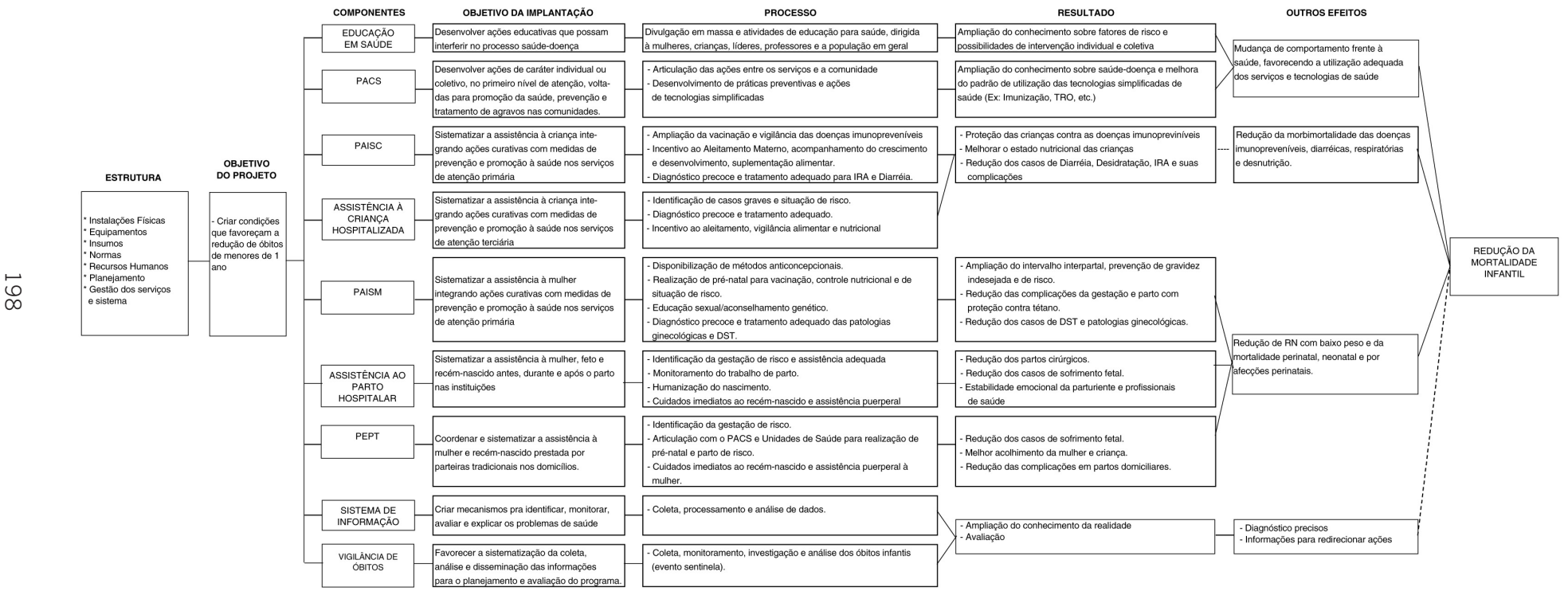




\section{Figura 2}

Sobreposição da avaliação do grau de implantação dos componentes do PRMI e seus resultados com o modelo lógico

Brejo da Madre de Deus e Bom Conselho, 1999

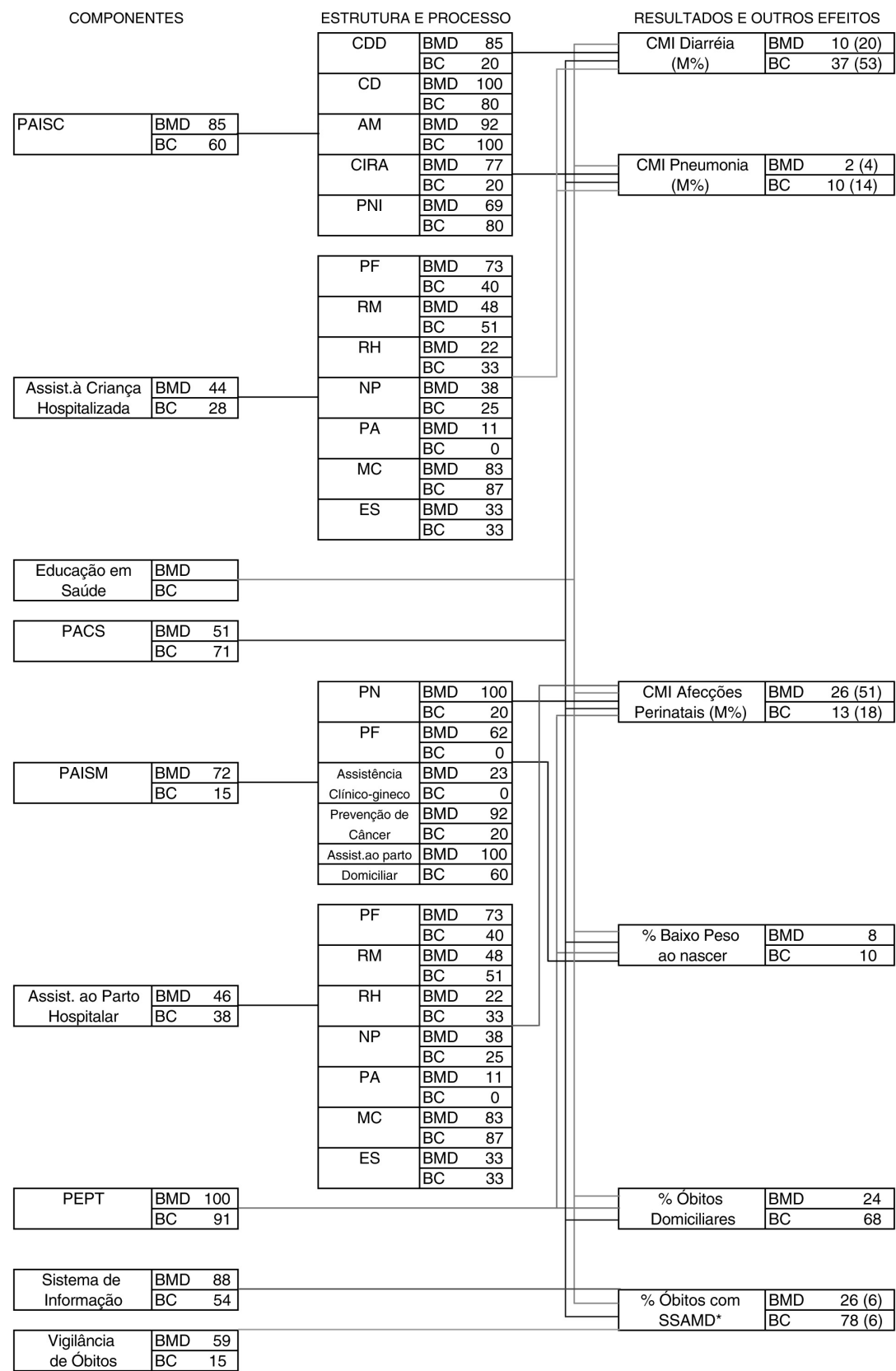




\section{Figura 3}

Coeficiente de Mortalidade Neonatal, Pós-Neonatal e Infantil Observados e possibilidade de redução a partir de medidas de atenção à saúde

Brejo da Madre de Deus e Bom Conselho, 1999

\begin{tabular}{|c|c|c|c|c|c|c|c|}
\hline \multicolumn{3}{|c|}{ Realidade Empírica } & \multicolumn{2}{|c|}{$\begin{array}{l}\text { Valores esperados a partir } \\
\text { do Modelo Lógico }\end{array}$} & & \multicolumn{2}{|c|}{$\begin{array}{l}\text { Redução } \\
\text { alcançável }\end{array}$} \\
\hline \multirow{2}{*}{$\begin{array}{l}\text { CMNN } \\
(\mathrm{M} \%)\end{array}$} & BMD & $29,9(58,8)$ & \multirow{2}{*}{$\begin{array}{l}\text { CMNN reduzível por medidas } \\
\text { de Atenção à Saúde }\end{array}$} & $\mathrm{BML}$ & 24,9 & \multirow{2}{*}{$\begin{array}{l}\text { CMNN } \\
\text { possível }\end{array}$} & BMD 5 \\
\hline & $\mathrm{BC}$ & $20,6(29,2)$ & & $\mathrm{BC}$ & 17,6 & & $\mathrm{BC}$ \\
\hline \multirow{2}{*}{$\begin{array}{l}\text { CMPN } \\
(\mathrm{M} \%)\end{array}$} & $\mathrm{BMD}$ & $20,9(41,2)$ & \multirow{2}{*}{$\begin{array}{l}\text { CMPN reduzível por medidas } \\
\text { de Atenção à Saúde }\end{array}$} & BML & 14,9 & \multirow{2}{*}{$\begin{array}{l}\text { CMPN } \\
\text { possível }\end{array}$} & BMD 6 \\
\hline & $\mathrm{BC}$ & $50,0(70,8)$ & & $\mathrm{BC}$ & 46,1 & & $\mathrm{BC}$ \\
\hline \multirow[t]{2}{*}{$\mathrm{CMI}$} & BMD & 50,8 & \multirow{2}{*}{$\begin{array}{l}\text { CMI reduzível por medidas } \\
\text { de Atenção à Saúde }\end{array}$} & $\mathrm{BML}$ & 39,8 & \multirow{2}{*}{$\begin{array}{l}\text { CMI } \\
\text { possível }\end{array}$} & BMD \\
\hline & $\mathrm{BC}$ & 70,6 & & $B C$ & 63,7 & & $B C$ \\
\hline
\end{tabular}

\section{Tabela 1}

Grau de implantação (\%) das ações do PAISC nas unidades de saúde

Brejo da Madre de Deus e Bom Conselho, 1999

\begin{tabular}{|c|c|c|c|c|c|c|}
\hline $\begin{array}{l}\text { Ações } \\
\text { Grau de Implantação }\end{array}$ & $\begin{array}{l}\text { CD } \\
\%\end{array}$ & $\begin{array}{c}\text { AM } \\
\%\end{array}$ & $\begin{array}{c}\text { CDD } \\
\%\end{array}$ & $\underset{\%}{\text { CIRA }}$ & $\begin{array}{l}\text { PNI } \\
\%\end{array}$ & $\begin{array}{l}\text { TOTAL } \\
\%\end{array}$ \\
\hline $\begin{array}{l}\text { Implantado } \\
\text { Brejo da Madre de Deus } \\
\text { Bom Conselho }\end{array}$ & - & $\begin{array}{l}23,1 \\
10,0\end{array}$ & $\begin{array}{l}- \\
-\end{array}$ & 10,0 & $\begin{array}{l}15,4 \\
10,0\end{array}$ & $\begin{array}{l}7,7 \\
6,0\end{array}$ \\
\hline $\begin{array}{l}\text { Parcialmente implantado } \\
\text { Brejo da Madre de Deus } \\
\text { Bom Conselho }\end{array}$ & $\begin{array}{r}100,0 \\
80,0\end{array}$ & $\begin{array}{l}69,2 \\
90,0\end{array}$ & $\begin{array}{l}84,6 \\
20,0\end{array}$ & $\begin{array}{l}76,9 \\
10,0\end{array}$ & $\begin{array}{l}53,8 \\
70,0\end{array}$ & $\begin{array}{l}76,9 \\
54,0\end{array}$ \\
\hline $\begin{array}{l}\text { Não implantado } \\
\text { Brejo da Madre de Deus } \\
\text { Bom Conselho }\end{array}$ & $20,0^{-}$ & $\begin{array}{r}7,7 \\
-\end{array}$ & $\begin{array}{l}15,4 \\
80,0\end{array}$ & $\begin{array}{l}23,1 \\
80,0\end{array}$ & $\begin{array}{l}30,8 \\
20,0\end{array}$ & $\begin{array}{l}15,4 \\
40,0\end{array}$ \\
\hline $\begin{array}{l}C D \text { - Crescimento e Desenvolvimento } \\
\text { AM - Aleitamento Materno } \\
\text { CDD - Controle de Doenças Diarréicas }\end{array}$ & & $\begin{array}{l}\text { CIRA } \\
\text { PNI - }\end{array}$ & $\begin{array}{l}\text { ntrole de Inf } \\
\text { grama Nacio }\end{array}$ & $\begin{array}{l}\text { ções Respira } \\
\text { l de Imuniza }\end{array}$ & ias Agudas & \\
\hline
\end{tabular}


Tabela 2

Grau de implantação (\%) das ações do PAISM nas unidades de saúde

Brejo da Madre de Deus e Bom Conselho, 1999

\begin{tabular}{|c|c|c|c|c|c|c|}
\hline $\begin{array}{l}\text { Ações } \\
\text { Grau de Implantação }\end{array}$ & $\begin{array}{l}\mathrm{PN} \\
\%\end{array}$ & $\begin{array}{l}\mathrm{PF} \\
\%\end{array}$ & $\begin{array}{c}\text { Assist.Clínico- } \\
\text { Gineco. DST } \\
\%\end{array}$ & $\begin{array}{c}\text { Prev. De } \\
\text { Câncer } \\
\%\end{array}$ & $\begin{array}{c}\text { Assist. parto } \\
\text { domiciliar* } \\
\%\end{array}$ & $\begin{array}{l}\text { Total } \\
\%\end{array}$ \\
\hline \multicolumn{7}{|l|}{ Implantado } \\
\hline Brejo da Madre de Deus & 46,2 & - & - & - & 100,0 & 19,3 \\
\hline Bom Conselho & - & - & - & - & 16,7 & 2,2 \\
\hline \multicolumn{7}{|l|}{ Parcialmente implantado } \\
\hline Brejo da Madre de Deus & 53,8 & 61,5 & 23,1 & 92,3 & - & 52,6 \\
\hline Bom Conselho & 20,0 & - & - & 20,0 & 33,3 & 13,0 \\
\hline \multicolumn{7}{|l|}{ Não implantado } \\
\hline Brejo da Madre de Deus & - & 38,5 & 76,9 & 7,7 & - & 28,1 \\
\hline Bom Conselho & 80,0 & 100,0 & 100,0 & 80,0 & 50,0 & 84,8 \\
\hline
\end{tabular}

Tabela 3

Avaliação da estrutura disponível para o atendimento ao parto

Brejo da Madre de Deus e Bom Conselho, 1999

\begin{tabular}{|c|c|c|c|c|c|}
\hline \multirow{2}{*}{$\begin{array}{l}\text { Municípios/pontuação } \\
\text { Aspectos avaliados }\end{array}$} & \multirow{2}{*}{$\begin{array}{l}\text { Pontuação } \\
\text { máxima } \\
\text { possível }\end{array}$} & \multicolumn{2}{|c|}{$\begin{array}{c}\text { Brejo da Madre de } \\
\text { Deus }\end{array}$} & \multicolumn{2}{|c|}{ Bom Conselho } \\
\hline & & $\begin{array}{l}\text { Pontos } \\
\text { obtidos }\end{array}$ & $\%$ & $\begin{array}{l}\text { Pontos } \\
\text { obtidos }\end{array}$ & $\%$ \\
\hline Planta Física & 200 & 145 & 72,5 & 80 & 40,0 \\
\hline Recursos Materiais & 120 & 58 & 48,3 & 61 & 50,8 \\
\hline Recursos Humanos & 180 & 40 & 22,2 & 60 & 33,3 \\
\hline Normas e Procedimentos & 240 & 90 & 37,5 & 60 & 25,0 \\
\hline Programação e Administração & 90 & 10 & 11,1 & - & . \\
\hline Material de Consumo & 115 & 95 & 82,6 & 100 & 87,0 \\
\hline Educação para Saúde & 60 & 20 & 33,3 & 20 & 33,3 \\
\hline TOTAL & 1005 & 458 & 45,6 & 381 & 37,9 \\
\hline
\end{tabular}


Tabela 4

Avaliação da estrutura disponível para o atendimento à criança hospitalizada

Brejo da Madre de Deus e Bom Conselho, 1999

\begin{tabular}{lrrrrrr}
\hline \multirow{2}{*}{ Municípios/pontuação } & \multirow{2}{*}{$\begin{array}{c}\text { Pontuação } \\
\text { máxima }\end{array}$} & \multicolumn{2}{c}{ Brejo da Madre de Deus } & \multicolumn{2}{c}{ Bom Conselho } \\
\cline { 5 - 8 } possível & Pontos & obtidos & $\%$ & $\begin{array}{c}\text { Pontos } \\
\text { obtidos }\end{array}$ & \multicolumn{2}{c}{$\%$} \\
\hline Planta Física & 170 & 85 & 50,0 & 65 & 38,2 \\
Recursos Materiais & 150 & 50 & 33,3 & 50 & 33,3 \\
Recursos Humanos & 190 & 60 & 31,6 & - & - \\
Normas e Procedimentos & 230 & 120 & 52,2 & 80 & 34,8 \\
Programação e Administração & 90 & 40 & 44,4 & - & - \\
Material de Consumo & 100 & 70 & 70,0 & 75 & 75,0 \\
Educação para Saúde & 90 & 30 & 33,3 & 20 & 22,2 \\
\hline TOTAL & 1020 & 455 & 44,6 & 290 & 28,4 \\
\hline
\end{tabular}

\section{Quadro 1}

Características sociodemográficas dos municípios selecionados

\begin{tabular}{|c|c|c|}
\hline VARIÁVEIS & BREJO DA MADRE DE DEUS & BOM CONSELHO \\
\hline Data da emancipação & $4 / 2 / 1879$ & $7 / 6 / 1898$ \\
\hline Distância da Capital & $204 \mathrm{Km}$ & $282 \mathrm{Km}$ \\
\hline Área Geográfica & $782,6 \mathrm{Km}^{2}$ & $798,1 \mathrm{Km}^{2}$ \\
\hline Mesorregião & Agreste & Agreste \\
\hline Microrregião & Vale do Ipojuca & Garanhuns \\
\hline Clima/ temp. média & Semiárido quente $/ 25^{\circ} \mathrm{C}$ & Semiárido quente $/ 25^{\circ} \mathrm{C}$ \\
\hline Densidade Demográfica & 47,4 & 50,9 \\
\hline $\begin{array}{l}\text { População total (1999) } \\
\text { Zona urbana } \\
\text { Zona rural }\end{array}$ & $\begin{array}{c}37.123 \\
(62,5 \%) \\
(37,5 \%)\end{array}$ & $\begin{array}{c}40.662 \\
(50,6 \%) \\
(48,6 \%)\end{array}$ \\
\hline $\begin{array}{l}\text { Imóveis rurais (total) (1991) } \\
<10 \text { há } \\
10-100 \text { há } \\
100-<1000 \text { há } \\
>1000 \text { há }\end{array}$ & $\begin{array}{r}2.418(100 \%) \\
1.421(58,7 \%) \\
884(36,6 \%) \\
112(4,6 \%) \\
1(0,1 \%) \\
\end{array}$ & $\begin{array}{r}2.896(100 \%) \\
1.623(56,0 \%) \\
1.050(36,4 \%) \\
217(7,5 \%) \\
1(0,1 \%) \\
\end{array}$ \\
\hline $\begin{array}{l}\text { Renda Chefe Domicílio (1991) } \\
\text { Salário Médio (em salário mínimo) } \\
\text { Até } 1 \mathrm{SM} \\
1 \text {-3 SM } \\
\text { > } 3 \mathrm{SM}\end{array}$ & $\begin{array}{r}1,6 \\
60,5 \% \\
33,9 \% \\
5,6 \% \\
\end{array}$ & $\begin{array}{r}1,6 \\
71,5 \% \\
21,7 \% \\
6,8 \% \\
\end{array}$ \\
\hline $\begin{array}{l}\text { População maior de } 15 \text { anos } \\
\text { alfabetizada (1991) }\end{array}$ & $50,5 \%$ & $45,0 \%$ \\
\hline $\begin{array}{l}\text { Instrução Chefe Domicílio (1991) } \\
\text { Sem instrução } \\
1-3 \text { anos }\end{array}$ & $\begin{array}{r}67,9 \% \\
14,1 \% \\
\end{array}$ & $\begin{array}{l}64,8 \% \\
14,3 \% \\
\end{array}$ \\
\hline Atividade econômica predominante & Agropecuária & Agropecuária \\
\hline $\begin{array}{l}\text { Saneamento (1991) } \\
\text { Abastecimento de água adequado } \\
\text { Esgotamento sanitário adequado } \\
\text { Coleta de lixo }\end{array}$ & $\begin{array}{r}33,7 \% \\
4,1 \% \\
32,8 \%\end{array}$ & $\begin{array}{c}34,2 \% \\
0,1 \% \\
42,1 \%\end{array}$ \\
\hline Unidades de Saúde & $\begin{array}{r}1 \text { hospital } \\
3 \text { Centros de Saúde } \\
4 \text { Postos de Saúde } \\
6 \text { Unidades de Saúde da Família }\end{array}$ & $\begin{array}{r}1 \text { hospital } \\
8 \text { Postos de Saúde } \\
\text { 1Unidade de Saúde da } \\
\text { Família }\end{array}$ \\
\hline
\end{tabular}

Fonte: FIAM (Fundação do Desenvolvimento do Interior de Pernambuco). Perfil municipal do interior de Pernambuco-1996. Recife: A Fundação, 1996. 
Quadro 2

Elenco de variáveis e indicadores básicos utilizados no estudo

\begin{tabular}{|c|c|c|c|}
\hline Variável & Definição & Indicador & Cálculo dos Indicadores \\
\hline $\begin{array}{l}\text { Implantação } \\
\text { do RMI }\end{array}$ & $\begin{array}{l}\text { Corresponde à integralidade das ações } \\
\text { programáticas que compõem o PRMI }\end{array}$ & Grau de Implantação do PRMI & $\begin{array}{l}\text { Somatório das pontuações obtidas pelos componentes do PRMI } \\
\text { segundo escala de valores atribuídos (1) }\end{array}$ \\
\hline Óbito Infantil & $\begin{array}{l}\text { Óbito não fetal de menores de } 1 \text { ano de } \\
\text { idade }\end{array}$ & Coeficiente de Mortalidade Infantil & ( $\mathrm{N}^{\circ}$ de óbitos de $<1$ ano $/ \mathrm{N}^{\circ}$ de nascidos vivos) $\mathrm{X} 1000$ \\
\hline $\begin{array}{l}\text { Óbito } \\
\text { Neonatal }\end{array}$ & Óbito não fetal de menores de 28 dias & $\begin{array}{l}\text { Coeficiente de Mortalidade Neonatal } \\
\text { Mortalidade Proporcional Neonatal }\end{array}$ & $\begin{array}{l}\text { ( } \mathrm{N}^{\circ} \text { de óbitos de }<28 \text { dias } / \mathrm{N}^{\circ} \text { de nascidos vivos) } \mathrm{X} 1000 \\
\text { ( } \mathrm{N}^{\circ} \text { de óbitos de }<28 \text { dias } / \mathrm{N}^{\circ} \text { de óbitos de }<1 \text { ano) } \times 100\end{array}$ \\
\hline $\begin{array}{l}\text { Óbito } \\
\text { Pós-neonatal }\end{array}$ & $\begin{array}{l}\text { Óbito não fetal com idade maior ou igual a } \\
28 \text { dias e menor que } 12 \text { meses }\end{array}$ & $\begin{array}{l}\text { Coeficiente de Mortalidade Pós-Neonatal } \\
\text { Mortalidade Proporcional Pós-Neonatal }\end{array}$ & $\begin{array}{l}\text { ( } N^{\circ} \text { de óbitos entre } 28 \text { dias e menores de } 1 \mathrm{ano} / \mathrm{N}^{\circ} \text { de nascidos } \\
\text { vivos) X } 1000 \\
\left(\mathrm{~N}^{\circ} \text { de óbitos entre } 28 \text { dias e menores de } 1 \text { ano/ } \mathrm{N}^{\circ} \text { de óbitos de < }\right. \\
1 \text { ano) } \mathrm{X} 100\end{array}$ \\
\hline $\begin{array}{l}\text { Causa Básica } \\
\text { do óbito } \\
\text { infantil }\end{array}$ & $\begin{array}{l}\text { "Doença ou lesão que iniciou a cadeia de } \\
\text { acontecimentos patológicos que conduziram } \\
\text { diretamente à morte, ou as circunstâncias } \\
\text { do acidente ou violência que produziram a } \\
\text { lesão fatal" (OMS, OPAS, 1999) em } \\
\text { menores de } 1 \text { ano (2) }\end{array}$ & $\begin{array}{l}\text { Coeficiente de Mortalidade Infantil por Causa } \\
\text { Básica do óbito } \\
\text { Mortalidade Proporcional em menores de } 1 \text { ano por } \\
\text { Causa Básica }\end{array}$ & $\begin{array}{l}\text { ( } N^{\circ} \text { de óbitos de }<1 \text { ano por grupo específico de causa básica/ } N^{\circ} \\
\text { de nascidos vivos) X } 1000 \\
\text { ( No de óbitos de }<1 \text { ano por grupo específico de causa básica/ No } \\
\text { de óbitos de }<1 \text { ano) X } 100\end{array}$ \\
\hline $\begin{array}{l}\text { Causa Básica } \\
\text { de óbito } \\
\text { infantil } \\
\text { reduzível por } \\
\text { medidas de } \\
\text { atenção à } \\
\text { saúde }\end{array}$ & $\begin{array}{l}\text { Causa Básica de óbito neonatal ou pós- } \\
\text { neonatal classificada como reduzível } \\
\text { considerando os critérios adotados pela } \\
\text { FSEADE (3) }\end{array}$ & $\begin{array}{l}\text { Coeficiente de Mortalidade Neonatal por Causas } \\
\text { Reduzíveis por medidas de Atenção à Saúde } \\
\text { Mortalidade Proporcional Neonatal por Causas } \\
\text { Reduzíveis por medidas de Atenção à Saúde } \\
\text { Coeficiente de Mortalidade Pós-Neonatal por } \\
\text { Causas Reduzíveis por medidas de Atenção à } \\
\text { Saúde } \\
\text { Mortalidade Proporcional Pós-Neonatal por Causas } \\
\text { Reduzíveis por medidas de Atenção à Saúde }\end{array}$ & $\begin{array}{l}\text { ( No de óbitos de }<28 \text { dias por causas reduzíveis por medidas de } \\
\text { atenção à saúde/ } N^{\circ} \text { de nascidos vivos) X } 1000 \\
\text { ( } N^{\circ} \text { de óbitos de }<28 \text { dias por causas reduzíveis por } \\
\text { medidas de atenção à saúde / } N^{\circ} \text { de óbitos de }<1 \text { ano) X } \\
100 \\
\text { ( } N^{\circ} \text { de óbitos entre } 28 \text { dias e menores de } 1 \text { ano por causas } \\
\text { reduzíveis por medidas de atenção à saúde/ } N^{\circ} \text { de nascidos } \\
\text { vivos) X } 1000 \\
\text { (No de óbitos entre } 28 \text { dias e menores de } 1 \text { ano por causas } \\
\text { reduzíveis por medidas de atenção à saúde/ } N^{\circ} \text { de óbitos de }<1 \\
\text { ano) X } 100\end{array}$ \\
\hline $\begin{array}{l}\text { Óbito Infantil } \\
\text { domiciliar }\end{array}$ & $\begin{array}{l}\text { Óbito não fetal de menores de } 1 \text { ano } \\
\text { ocorridos em domicílio ou via pública }\end{array}$ & Mortalidade Proporcional dos Óbitos Domiciliares & $\begin{array}{l}\text { ( No de óbitos de }<1 \text { ano ocorridos em domicílio ou via pública/ No } \\
\text { de óbitos de }<1 \text { ano) X } 100\end{array}$ \\
\hline $\begin{array}{l}\text { Baixo Peso ao } \\
\text { nascer }\end{array}$ & $\begin{array}{l}\text { Nascidos vivos com peso inferior a } 2500 \\
\text { gramas }\end{array}$ & Proporção de nascidos vivos com Baixo Peso & $\begin{array}{l}\text { ( } N^{\circ} \text { de nascidos vivos com peso }<2500 \text { gramas/ } N^{\circ} \text { total de } \\
\text { nascidos vivos) } X 100\end{array}$ \\
\hline
\end{tabular}

(1) - Escala de Valores atribuídos aos componentes do PRMI para estimação do grau de implantação: Ações Implantadas: 2 pontos, parcialmente implantadas: 1 ponto, Ações não implantadas: 0 ponto

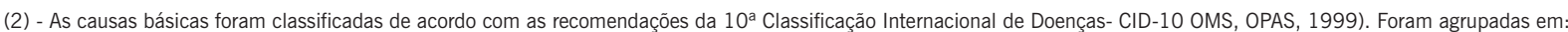
Doenças Infecciosas Intestinais (A00 a A09), Broncopneumonias (J10 a J22), Afecçōes Perinatais (P00 a P96), Malformações Congênitas (Q00 a Q99), Sinais, Sintomas e Afecções mal definidas (R00 a R99) e demais causas (demais códigos da CID-10).

(3) - FSEADE- Fundação Sistema Estadual de Análise de Dados, São Paulo (Conjuntura Demográfica, 1991). 


\section{Quadro 3}

Componentes do PRMI segundo tipo de dados, técnicas de coleta e instrumentos/documentos utilizados

\begin{tabular}{|c|c|c|c|}
\hline $\begin{array}{l}\text { Componentes do } \\
\text { Indicador }\end{array}$ & $\begin{array}{c}\text { Tipo de } \\
\text { Dado }\end{array}$ & Técnica de Coleta & Instrumento/Documentos utilizados \\
\hline PAISC & Primário & $\begin{array}{l}\text { Observação sistemática e } \\
\text { observação ligada à entrevista }\end{array}$ & $\begin{array}{l}\text { Instrumento gerencial da mulher, da criança e do adolescente: avaliação, sistema de informação e } \\
\text { programação (Brasil, 1995a) }\end{array}$ \\
\hline PAISM & Primário & $\begin{array}{l}\text { Observação sistemática e } \\
\text { observação ligada à entrevista }\end{array}$ & $\begin{array}{l}\text { Instrumento gerencial da mulher, da criança e do adolescente: avaliação, sistema de informação e } \\
\text { programação (Brasil, 1995a) }\end{array}$ \\
\hline PACS & Secundário & $\begin{array}{l}\text { Análise Documental (meios } \\
\text { escritos e eletrônico oficial) }\end{array}$ & $\begin{array}{l}\text { População residente (FIBGE, 2000); Relatório de implantação do PACS em Pernambuco (Pernambuco, } \\
\text { 1998g); Relatório de dados para pagamento dos incentivos PACS e PSF (Brasil, 2000b); Relatório de } \\
\text { Quantidade de Profisssonais do Sistema de Informação de Atenção Básica (Brasil, 2000c); Relatório de } \\
\text { controle de informações de saúde } 1994 \text { a } 2000 \text { do SIAB (Brasil, 2000f); Diário Oficial da União (Brasil, } \\
\text { 1997b); Plano Plurianual 1998-2001 (Bom Conselho, 1999c); Planos municipais de saúde de Brejo da } \\
\text { Madre de Deus e Bom Conselho (Bom Conselho, 1999b; Brejo da Madre de Deus, 1999c); Relatórios das } \\
\text { salas de situação de Brejo da Madre de Deus e Bom Conselho, } 1999 \text { (Bom Conselho, 2000; Brejo da Madre } \\
\text { de Deus, 2000); Relatório final de avaliação do projeto "Saúde Pública no Nordeste: a experiência de } \\
\text { Pernambuco" (UFPE e JICA, 1999) }\end{array}$ \\
\hline PEPT & Secundário & $\begin{array}{l}\text { Análise Documental (meios } \\
\text { escritos) }\end{array}$ & $\begin{array}{l}\text { Plano Plurianual 1998-2001 (Bom Conselho, 1999c); Plano municipal de saúde de Brejo da Madre de Deus } \\
\text { e Bom Conselho (Bom Conselho, 1999b; Brejo da Madre de Deus, 1999c); Relatórios das salas de situação } \\
\text { de Brejo da Madre de Deus e Bom Conselho, } 1999 \text { (Bom Conselho, 2000; Brejo da Madre de Deus, 2000); } \\
\text { Relatório de avaliaçãao do Programa de Parteiras Tradicionais da Secretaria de Saúde de Pernambuco } \\
\text { (Pernambuco, 1998f); Relatório final de avaliação do projeto "Saúde Pública no Nordeste: a experiência de } \\
\text { Pernambuco" (UFPE e JICA, 1999) }\end{array}$ \\
\hline $\begin{array}{l}\text { Assistência ao parto } \\
\text { hospitalar }\end{array}$ & Primário & $\begin{array}{l}\text { Observação sistemática e } \\
\text { observação ligada à entrevista }\end{array}$ & $\begin{array}{l}\text { Condições de eficiência dos serviços de atenção materno infantil - modelo de avaliação, internação de } \\
\text { obstetrícia (OPAS e OMS, 1987) }\end{array}$ \\
\hline $\begin{array}{l}\text { Assistência à } \\
\text { criança } \\
\text { hospitalizada }\end{array}$ & Primário & $\begin{array}{l}\text { Observação sistemática e } \\
\text { observação ligada à entrevista }\end{array}$ & $\begin{array}{l}\text { Condições de eficiência dos serviços de atenção Materno infantil - modelo de avaliação, internação em } \\
\text { pediatria (OPAS e OMS, 1987) }\end{array}$ \\
\hline Educação em Saúde & Secundário & $\begin{array}{l}\text { Análise documental (meios } \\
\text { escritos) }\end{array}$ & $\begin{array}{l}\text { Plano Plurianual 1998-2001(Bom Conselho,1999c); Planos municipais de saúde de Brejo da Madre de Deus } \\
\text { e Bom Conselho (Bom Conselho, 1999b; Brejo da Madre de Deus,1999c); Relatório final de avaliação do } \\
\text { projeto "Saúde Pública no Nordeste: a experiência de Pernambuco" (UFPE e JICA, 1999); Planejamento do } \\
\text { núcleo de educação em saúde, } 1999 \text { (Brejo da Madre de Deus, 1999b); Relatório do núcleo de educação em } \\
\text { saúde de } 1999 \text { (Brejo da Madre de Deus, 1999d); Atas das reuniôes de } 1999 \text { do Conselho Municipal de } \\
\text { Saúde (Bom Conselho, 1999a; Brejo da Madre de Deus, 1999a); Informa Saúde (1999a; 1999b) }\end{array}$ \\
\hline $\begin{array}{l}\text { Sistema de } \\
\text { Informação }\end{array}$ & $\begin{array}{l}\text { Primário } \\
e \\
\text { Secundário }\end{array}$ & $\begin{array}{l}\text { Entrevista semi-estruturada e } \\
\text { Análise Documental (meios } \\
\text { escritos) }\end{array}$ & $\begin{array}{l}\text { Instrumento de investigação de óbitos de menores de um ano (Pernambuco, 1998h) } \\
\text { Cópias das Declarações de Óbito de residentes nos municípios e transcrição de livros de registros de } \\
\text { internamentos e/ou de autorização de internamento hospitalar e/ou da sala de parto das unidades de saúde em } \\
\text { que ocorreram óbitos de residentes, ficha D do Sistema de Informação da Atenção Básica }\end{array}$ \\
\hline
\end{tabular}




\section{Quadro 4}

Componentes do PRMI, critérios e pontos de corte adotados na definição do grau de implantação

\begin{tabular}{|c|c|c|c|c|c|c|c|c|c|}
\hline $\begin{array}{c}\text { Componentes } \\
\text { Grau de } \\
\text { Implantação }\end{array}$ & $\operatorname{PACS}(1)$ & PEPT(2) & PAISC & PAISM & $\begin{array}{c}\text { Assistência ao } \\
\text { Parto e Recém- } \\
\text { nascido }\end{array}$ & $\begin{array}{c}\text { Assistência à } \\
\text { Criança } \\
\text { Hospitalizada }\end{array}$ & $\begin{array}{c}\text { Educação em } \\
\text { Saúde }\end{array}$ & $\begin{array}{l}\text { Sistema de } \\
\text { Informação }\end{array}$ & $\begin{array}{l}\text { Vigilância de } \\
\text { Óbitos }\end{array}$ \\
\hline Implantado & $\begin{array}{l}\text { Cobertura } \\
\text { de } 80 \% \text { ou } \\
\text { mais }\end{array}$ & $\begin{array}{l}\text { Cobertura de } \\
80 \% \text { ou } \\
\text { mais de } \\
\text { parteiras } \\
\text { tradicionais } \\
\text { cadastradas } \\
\text { e treinadas }\end{array}$ & $\begin{array}{l}80 \% \text { ou mais } \\
\text { das ações } \\
\text { programáticas } \\
\text { nas US* } \\
\text { implantadas ou } \\
\text { parcialmente } \\
\text { implantadas }\end{array}$ & $\begin{array}{l}80 \% \text { ou mais } \\
\text { das ações } \\
\text { programáticas } \\
\text { nas US } \\
\text { implantadas ou } \\
\text { parcialmente } \\
\text { implantadas }\end{array}$ & $\begin{array}{l}\text { Adequação } \\
\text { superior a } 80 \% \\
\text { da estrutura } \\
\text { disponível para } \\
\text { atendimento ao } \\
\text { parto e RN }\end{array}$ & $\begin{array}{l}\text { Adequação } \\
\text { superior a } 80 \% \\
\text { da estrutura } \\
\text { disponível para } \\
\text { atendimento à } \\
\text { criança } \\
\text { hospitalizada } \\
\end{array}$ & $\begin{array}{l}\text { Núcleo ou } \\
\text { grupo } \\
\text { mobilizado e } \\
\text { funcionando } \\
\text { na SMS }\end{array}$ & $\begin{array}{l}\text { Cobertura do } \\
\text { sistema de } \\
\text { informação } \\
\text { sobre } \\
\text { mortalidade } \\
\text { (SIM) superior } \\
\text { a } 80 \%\end{array}$ & $\begin{array}{l}80 \% \text { ou mais de } \\
\text { óbitos infantis } \\
\text { investigados }\end{array}$ \\
\hline $\begin{array}{l}\text { Parcialmente } \\
\text { implantado }\end{array}$ & $\begin{array}{l}\text { Cobertura } \\
\text { entre } 40 \text { e } \\
79 \%\end{array}$ & $\begin{array}{l}\text { Cobertura } \\
\text { entre } 40 \text { e } \\
79 \% \text { de } \\
\text { parteiras } \\
\text { tradicionais } \\
\text { cadastradas } \\
\text { e treinadas } \\
\end{array}$ & $\begin{array}{l}\text { Entre } 40 \text { e } 79 \% \\
\text { das ações } \\
\text { programáticas } \\
\text { nas US } \\
\text { implantadas ou } \\
\text { parcialmente } \\
\text { implantadas }\end{array}$ & $\begin{array}{l}\text { Entre } 40 \text { e } 79 \% \\
\text { das ações } \\
\text { programáticas } \\
\text { nas US } \\
\text { implantadas ou } \\
\text { parcialmente } \\
\text { implantadas }\end{array}$ & $\begin{array}{l}\text { Adequação } \\
\text { entre } 40 \text { e } 79 \% \\
\text { da estrutura } \\
\text { disponível para } \\
\text { atendimento ao } \\
\text { parto e RN }\end{array}$ & $\begin{array}{l}\text { Adequação } \\
\text { entre } 40 \text { e } 79 \% \\
\text { da estrutura } \\
\text { disponível para } \\
\text { atendimento à } \\
\text { criança } \\
\text { hospitalizada }\end{array}$ & $\begin{array}{l}\text { Desenvolve } \\
\text { ações } \\
\text { sistemáticas } \\
\text { porém } \\
\text { isoladas }\end{array}$ & $\begin{array}{l}\text { Cobertura do } \\
\text { SIM entre } 40 \\
\text { e } 80 \%\end{array}$ & $\begin{array}{l}\text { Entre } 40 \text { e } 80 \% \\
\text { dos óbitos } \\
\text { infantis } \\
\text { investigados }\end{array}$ \\
\hline $\begin{array}{l}\text { Não } \\
\text { implantado }\end{array}$ & $\begin{array}{l}\text { Cobertura } \\
\text { inferior a } \\
40 \%\end{array}$ & \begin{tabular}{|l} 
Cobertura \\
inferior a \\
$40 \%$ de \\
parteiras \\
tradicionais \\
cadastradas \\
e treinadas \\
ou não \\
cadastradas \\
\end{tabular} & $\begin{array}{l}\text { Menos de } 40 \% \\
\text { das ações } \\
\text { programáticas } \\
\text { nas US } \\
\text { implantadas ou } \\
\text { parcialmente } \\
\text { implantadas }\end{array}$ & $\begin{array}{l}\text { Menos de } 40 \% \\
\text { das ações } \\
\text { programáticas } \\
\text { nas US } \\
\text { implantadas ou } \\
\text { parcialmente } \\
\text { implantadas }\end{array}$ & $\begin{array}{l}\text { Adequação } \\
\text { inferior a } 40 \% \\
\text { da estrutura } \\
\text { disponível para } \\
\text { atendimento ao } \\
\text { parto e RN }\end{array}$ & $\begin{array}{l}\text { Adequação } \\
\text { inferior a } 40 \% \\
\text { da estrutura } \\
\text { disponível para } \\
\text { atendimento à } \\
\text { criança } \\
\text { hospitalizada }\end{array}$ & $\begin{array}{l}\text { Desenvolve } \\
\text { ações } \\
\text { assistemáticas } \\
\text { e ocasionais }\end{array}$ & $\begin{array}{l}\text { Cobertura do } \\
\text { SIM inferior a } \\
40 \%\end{array}$ & $\begin{array}{l}\text { Menos de } 40 \% \\
\text { dos óbitos } \\
\text { investigados }\end{array}$ \\
\hline
\end{tabular}

(1) - PACS (Programa de Agentes Comunitários de Saúde). Os pontos de corte são válidos quando a implantação ocorreu há dois ou mais anos ininterruptos. Tempo inferior a este o município deve ser enquadrado na categoria imediatamente anterior.

(2) - PEPT (Programa Estadual de Parteiras Tradicionais). Os pontos de corte são válidos quando as parteiras estiverem sob coordenação da Secretaria Municipal de Saúde. Quando a coordenação for da Secretaria Estadual o município deve ser enquadrado na categoria imediatamente anterior. 


\section{Quadro 5}

Componentes do PRMI, critérios e pontos de corte adotados na definição do grau de implantação

\begin{tabular}{|c|c|c|}
\hline $\begin{array}{c}\text { Municípios } \\
\text { Componentes }\end{array}$ & $\begin{array}{c}\text { Brejo da Madre } \\
\text { de Deus }\end{array}$ & $\begin{array}{c}\text { Bom } \\
\text { Conselho }\end{array}$ \\
\hline PAISC & 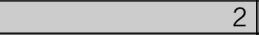 & 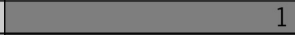 \\
\hline PAISM & 1 & 0 \\
\hline Assistência ao Parto & 1 & 0 \\
\hline Assistência à criança hospitalizada & 1 & 0 \\
\hline PACS & 1 & 1 \\
\hline PEPT & 2 & 2 \\
\hline Sistema de Informação & 2 & 1 \\
\hline Educação em saúde & 2 & 1 \\
\hline Vigilância de Óbitos & 1 & 0 \\
\hline ESCORE & 13 & 6 \\
\hline
\end{tabular}

Implantado

Parcialmente Implantado

Não Implantado

\section{Quadro 6}

Síntese dos resultados dos indicadores de saúde infantil Brejo da madre de Deus e Bom Conselho, 1999

\begin{tabular}{|c|c|c|}
\hline $\begin{array}{l}\text { Municípios } \\
\text { Resultados }\end{array}$ & $\begin{array}{c}\text { Brejo da Madre } \\
\text { de Deus }\end{array}$ & $\begin{array}{c}\text { Bom } \\
\text { Conselho }\end{array}$ \\
\hline Proporção de baixo peso ao nascer & 7,7 & 10,4 \\
\hline Proporção de Óbitos Domiciliares & 23,5 & 68,1 \\
\hline $\begin{array}{l}\text { Coeficiente de Mortalidade } \\
\text { Infantil (1000 nascidos vivos) } \\
\text { Neonatal } \\
\text { Pós-neonatal }\end{array}$ & $\begin{array}{l}50,8 \\
29,9 \\
20,9\end{array}$ & $\begin{array}{l}70,6 \\
20,6 \\
50,0\end{array}$ \\
\hline $\begin{array}{l}\text { Mortalidade \% grupo etário } \\
\text { Neonatal } \\
\text { Pós-neonatal }\end{array}$ & $\begin{array}{l}58,8 \\
41,2 \\
\end{array}$ & $\begin{array}{l}29,2 \\
70,8 \\
\end{array}$ \\
\hline $\begin{array}{l}\text { Coef. de Mortalidade por Causa Básica (1000 nascidos } \\
\text { vivos) } \\
\text { Afecções Perinatais } \\
\text { Malformações Congênitas } \\
\text { Doenças Infecciosas Intestinais } \\
\text { Pneumonias }\end{array}$ & $\begin{array}{r}25,9 \\
7,0 \\
10,0 \\
2,0\end{array}$ & $\begin{array}{r}12,7 \\
3,0 \\
37,3 \\
9,8\end{array}$ \\
\hline $\begin{array}{l}\text { Mortalidade \% Causas(1) } \\
\text { Afecções Perinatais } \\
\text { Malformações Congênitas } \\
\text { D. Infecciosas Intestinais } \\
\text { Pneumonias } \\
\text { Demais Causas } \\
\text { SSAMD }\end{array}$ & $\begin{array}{rr}47,1 & (51,0) \\
7,8 & (13,7) \\
17,6 & (19,6) \\
0 & (3,9) \\
2,0 & (5,9) \\
25,5 & (5,9)\end{array}$ & $\begin{array}{r}4,2(18,0) \\
1,4 \quad(4,1) \\
6,9(52,8) \\
5,5(13,9) \\
4,2(5,6) \\
77,8(5,6)\end{array}$ \\
\hline $\begin{array}{l}\text { CMI por grupo etário e Causa Básica Reduzível por } \\
\text { Medidas de Atenção à Saúde } \\
\text { Infantil } \\
\text { Neonatal } \\
\text { Pós-neonatal }\end{array}$ & $\begin{array}{l}39,8 \\
24,9 \\
14,9\end{array}$ & $\begin{array}{l}63,7 \\
17,6 \\
46,1\end{array}$ \\
\hline $\begin{array}{l}\text { Mortalidade \% por Causa Básica Reduzível por Medidas } \\
\text { de Atenção à Saúde } \\
\text { Infantil } \\
\text { Neonatal } \\
\text { Pós-neonatal }\end{array}$ & $\begin{array}{l}78,4 \\
83,3 \\
71,4\end{array}$ & $\begin{array}{l}90,3 \\
85,7 \\
92,2\end{array}$ \\
\hline
\end{tabular}

(1) - Os números entre parênteses correspondem à mortalidade proporcional posterior a investigação 


\title{
METODOLOGIA PARA ANÁLISE DA IMPLANTAÇÃO DE PROCESSOS RELACIONADOS À DESCENTRALIZAÇÃO DA ATENÇÃO À SAÚDE NO BRASIL'
}

\author{
Ligia Maria Vieira da Silva \\ Zulmira M. Araújo Hartz \\ Sônia Cristina Lima Chaves \\ Gerluce Alves Pontes da Silva
}

\section{INTRODUĈ̣̃O}

A reorganização das práticas de atenção à saúde no Brasil, a partir das diretrizes aprovadas na VIII Conferência Nacional de Saúde, vem se constituindo em um complexo processo que envolve múltiplas dimensões (PAIM e outros, 1999). Dentre as diretrizes acima mencionadas e inscritas posteriormente na Constituição Federal, a que foi implementada de forma mais consistente foi aquela referente à descentralização da gestão da saúde. Embora este processo remonte à década de oitenta, com as AIS (Ações Integradas de Saúde) e o SUDS (Sistema Unificado e Descentralizado de Saúde) (VIEIRA-DA-SILVA, 1990), o mesmo institucionalizou-se, ganhando maior abrangência e densidade a partir da aprovação das leis e da publicação das Normas Operacionais Básicas 01/93 e da NOB 01/96 (BRASIL, 1997). A NOB 96 aumentou a viabilidade da reorganização setorial de base municipal na medida em que assegurou o repasse fundo a fundo e ampliou a transferência de responsabilidades federais e estaduais para os municípios que optassem pela gestão plena (BRASIL, 1997).

Esse processo de descentralização, embora atinja hoje cerca de 4.973 municípios (99,6\% do total), desenvolveu-se de forma assimétrica e 
diversificada no que diz respeito à reorganização das práticas assistenciais (BRASIL, 2003). Estudos preliminares sobre os efeitos das NOBs 93 e 96 revelaram aumento na oferta de serviços e incremento de recursos financeiros originados do tesouro municipal (HEIMANN e outros, 1998; CLAUS; CAPRA, 2001; SOLLA e outros, 2002). Outras análises de experiências municipais têm registrado redução de custos (JIMENEZ; SHIMAZAKI, 2002; SOLLA e outros, 2002) e aumento da satisfação dos usuários (SOLLA e outros, 2002; JIMENEZ; SHIMAZAKI, 2002). Investigação abrangente realizada sobre os 523 municípios em gestão plena do sistema entre 1998 e 2000 revelou que o processo de descentralização induzida pelo governo federal ampliou a oferta de serviços com ênfase na atenção à média e alta complexidade (VIANA e outros, 2002). Contudo, poucos estudos têm se preocupado em investigar as relações entre a descentralização e as práticas de atenção à saúde.

Este fenômeno tem sido observado em outros países com reformas em curso nos sistemas de saúde que têm focado a atenção em torno dos ajustes financeiros e administrativos e pouca importância tem sido dada aos efeitos sobre a saúde da população e sobre as práticas de saúde propriamente ditas (VIENONEN, 1999) aqui compreendidas como o núcleo duro para a mudança dos sistemas e serviços de saúde (PAIM, 2002).

Na Bahia, do total de 417 municípios, 397 deles estão habilitados na gestão plena da atenção básica $(95,2 \%)$ e apenas dezenove cidades atingiram a gestão plena do sistema municipal $(4,6 \%)$, percentual inferior ao processo de descentralização observado no Nordeste e no país como um todo (BRASIL, 2003).

A descentralização não pode ser vista como uma "panacea" (MATUS, 1989), nem como algo intrinsecamente bom ou ruim (MULLER NETO, 1992; FLEURY, 1992), corresponde a um termo ambíguo (MARTíN, 1997) que corre o risco de ser descontextualizada ao se desconsiderar os fatores de ordem econômica, política, ideológica, cultural e social desencadeadores e sustentáculos deste processo (PAIM, 2002).

Quais as razões para essa diversidade de resultados relacionados com uma mesma intervenção sanitária, no caso a descentralização da gestão da saúde? A resposta a essa complexa questão requer o desenvolvimento concomitante de investigações complementares. 0 presente projeto se propõe a contribuir para com a compreensão desse fenômeno a partir da aná- 
lise da influência dos contextos político-governamentais e históricos em relação à gestão municipal da saúde e seus efeitos na reorganização das práticas assistenciais. Será apresentado, neste capítulo, a metodologia utilizada e os resultados preliminares do estudo-piloto.

\section{METODOLOGIA}

\section{ESTRATÉGIA DA PESQUISA E SELEÇ̃̃O DOS CASOS}

Esta investigação fez parte de um projeto mais amplo intitulado "Avaliação da descentralização da atenção à saúde na Bahia" (VIEIRA-DA-SILVA e outros, 2002), cujo objetivo central foi avaliar os efeitos do processo de descentralização da atenção à saúde em municípios selecionados no estado da Bahia através de estratégias metodológicas complementares. Dois subprojetos foram desenvolvidos concomitantemente: o primeiro analisou uma amostra de 68 municípios, estratificada segundo condições de vida; o segundo consistiu em um estudo de casos múltiplos com níveis de análise imbricado (YIN, 1993). Os cinco municípios escolhidos encontravam-se todos classificados como na "gestão plena do sistema" de acordo com critérios derivados da Norma Operacional Básica (NOB)-96 (BRASIL, 1997). Esses municípios foram escolhidos a partir de informações obtidas junto a informantes-chave da Secretaria Estadual de Saúde e Conselho Nacional de Secretários Municipais de Saúde (CONASEMS) quanto ao êxito do processo de descentralização. Dos cinco municípios, dois foram considerados "exitosos", dois "não-exitosos" e um foi escolhido como piloto.

O estudo iniciou-se no município denominado como "A", que foi considerado como piloto para fins de teste dos instrumentos utilizados na coleta de dados, bem como da estratégia da pesquisa. Este município foi escolhido como piloto por estar na gestão plena do sistema de saúde, por apresentar um histórico de descentralização das ações de saúde desde a década de oitenta, e possuir uma rede estruturada de serviços públicos.

\section{MODELO LÓGICO}

Foi elaborado um modelo teórico-lógico (Figura 1), tendo em conta a proposta de análise de implantação elaborada por (DENIS; CHAMPAGNE, 1997). Esse modelo corresponde à definição de uma "imagem-objetivo" 
da descentralização da saúde em municípios, visando funcionar como referência para apreciação do grau de implantação dos componentes da descentralização (Figura 1).

A descentralização na gestão da saúde, conforme instrumentos legais anteriores à Norma Operacional de Assistência à Saúde (NOAS) (BRASIL, 2003), deveria ocorrer na direção dos governos federal e estadual para os municípios. Nesse sentido, sua análise requer o seu enquadramento em um "Espaço geral" referente ao contexto nacional, em um "Espaço particular" referente ao contexto estadual e no "Espaço singular" do município em estudo (Figura 1 ).

No contexto local do município, onde a descentralização se efetiva, três componentes de governo constituem um sistema singular interdependente denominado por Matus de "triângulo de governo": a) projeto de governo; b) capacidade de governo e c) governabilidade (MATUS, 1997). Para a implantação de uma dada proposta, seria necessária uma relação sinérgica entre esses três componentes. 0 projeto de governo se refere ao conjunto de proposições elaborados pelos dirigentes locais visando o alcance dos seus objetivos. A capacidade de governo corresponderia aos recursos relacionados com a condução e gerenciamento adequado das ações. Já a governabilidade diz respeito às condições necessárias à implementação das ações propostas, como respostas e antecipações, considerando os obstáculos e oportunidades que o meio oferece a essas propostas.

A capacidade de governo, segundo Matus (1997), depende do capital intelectual acumulado pelos dirigentes, e este capital tem crescido muito mais lentamente que a complexidade do sistema social. O capital intelectual é aqui entendido como o conjunto de capital teórico, instrumental e de experiência acumulada pelo dirigente e sua equipe. A governabilidade dependeria de vários fatores e, entre eles, se destacaria o capital político, ou seja, seu poder ou peso político no governo em curso. O projeto de governo expressaria a conjunção do capital político e intelectual aplicados numa proposta de ação (MATUS, 1997).

A descentralização, quando ocorre em adequada articulação entre os componentes do triângulo de governo, corresponde a um fortalecimento do poder local, das instituições públicas e da capacidade de gestão do sistema de saúde. A atuação conjunta dos três componentes pode resultar em me- 
Ihor organização dos serviços de saúde, viabilizando maior acesso e cobertura; também as condições seriam favoráveis a um maior controle sobre os prestadores privados com otimização do uso dos recursos públicos visando assegurar maior integralidade e resolutividade. Esse contexto é favorável a um maior controle social, no sentido de maior participação popular, o que poderia aproximar os gestores das necessidades da população e melhorar a capacidade de intervenção do sistema.

O aperfeiçoamento da gestão da saúde pode ter um efeito positivo tanto em relação à reorientação das práticas setoriais de atenção, individuais e coletivas, quanto no que diz respeito a iniciativas de ação intersetorial. No âmbito setorial, as possibilidades de modificação podem ocorrer relacionadas com o aumento da acessibilidade, com a humanização do acolhimento, com o aumento da resolutividade e da melhoria na qualidade técnicocientífica do cuidado. Por outro lado, o desenvolvimento de projetos intersetoriais, no âmbito do desenvolvimento de políticas públicas saudáveis, envolvendo, além da saúde, a esfera do trabalho, da educação, da comunicação e da infra-estrutura urbana, poderia viabilizar ações de alcance coletivo voltadas para a promoção da saúde. Esse conjunto de intervenções poderia contribuir para uma melhoria no estado de saúde da população através da redução dos indicadores de internação hospitalar e dos coeficientes de mortalidade, além de maior satisfação dos usuários com os serviços de saúde, garantindo, portanto, maior qualidade de vida para os mesmos (Figura 1).

\section{NÍVEIS, DIMENSÕES E CRITÉRIOS}

A partir do modelo lógico acima descrito, que corresponde a uma "imagem-objetivo" no sentido de Matus (1997), foram selecionados para análise os seguintes níveis: I) governo; II) gestão da saúde; III) práticas assistenciais. Para cada nível, foram selecionadas dimensões, subdimensões e critérios que foram sumarizados numa matriz contendo a descrição do padrão esperado para cada um dos mesmos (Quadro 1). Essa matriz, elaborada pela equipe de pesquisa, foi submetida a um grupo de dirigentes e técnicos do Ministério da Saúde ${ }^{2}$ para uma atribuição inicial de pesos. A técnica do grupo nominal foi utilizada (DONABEDIAN, 1988). Foram os seguintes os níveis, dimensões, subdimensões e critérios: 


\section{COMPONENTES DE GOVERNO}

\section{PROJETO DE GOVERNO}

- Prioridade para saúde. Foi verificado se a saúde era prioridade tanto no plano de governo quanto no discurso dos entrevistados. Além disso, observou-se no plano municipal de saúde se havia consistência entre problemas priorizados e ações propostas.

- Características do financiamento setorial:

- Percentual de gastos com saúde em relação ao total de receitas de tributos do município. Corresponde ao somatório das receitas municipais, estaduais e federais (Previsto na Emenda Constitucional 29). Classificação:

Incipiente - municípios cujo percentual de gastos com saúde foi inferior a $7 \%$;

Intermediário - municípios cujo percentual de gastos com saúde situa-se entre $7 \%$ e $8 \%$;

Avançado - municípios cujo percentual de gastos com saúde foi superior a $8 \%$.

- Gasto per capita em saúde - em reais $(R \$)$ e em dólar (U\$):

Foi feita a conversão de real para dólar, considerando uma relação de 2:1. Foi calculada a razão entre o gasto total em saúde (gasto municipal, estadual e federal) e a população total do município para aquele ano.

Classificação:

Incipiente - municípios com gasto per capita inferior a $\cup \$ 80$;

Intermediário - municípios com gasto per capita entre U\$80 e U\$150;

Avançado - municípios com gasto per capita superior a U\$150 (cento e cinqüenta dólares). 
- Existência de iniciativas intersetoriais. Foram consideradas iniciativas intersetoriais aquelas ações articuladas entre a saúde e outros setores para os quais existisse ou planejamento integrado ou comitê gestor misto entre dois ou mais setores do governo, com orçamento próprio para os projetos. Verificou-se se havia, pelo menos, um projeto implantado.

\section{CAPACIDADE DE GOVERNO}

- Perfil do gestor. As características do gestor foram analisadas no que diz respeito à liderança e formação na área de saúde coletiva;

- Adequação do quadro técnico às necessidades do sistema municipal de saúde. Verificou-se se os assessores diretos possuíam formação ou especialização em saúde coletiva; se havia um número adequado de profissionais qualificados em suas áreas específicas de atuação;

- Política de Recursos Humanos. Verificou-se acerca da existência de um Plano de Cargos e Salários, contratação através de concurso público ou seleção pública, do incentivo à capacitação ligado à remuneração ou, pelo menos, de iniciativas de capacitação sem vínculo com remuneração.

\section{GOVERNABILIDADE}

. Existência de base de apoio político. Verificou-se acerca da existência tanto de base de apoio parlamentar quanto da sociedade civil organizada;

- Autonomia financeira do setor saúde em relação à Prefeitura. Verificou-se acerca da existência de Comissão própria da SMS para realizar os processos licitatórios, bem como de profissional responsável pela gestão financeira do Fundo Municipal de Saúde;

- Características do relacionamento entre gestores. Procurou-se identificar se havia articulação e trabalho colaborativo entre os diversos níveis de gestão do sistema para definição e implementação de políticas, com destaque para iniciativas relacionadas com a inovação; 
Adesão dos profissionais à gestão. Indagou-se acerca da existência de satisfação dos profissionais com o trabalho desenvolvido (realização profissional e pessoal) bem como sobre a existência de percepção de "participação" na gestão.

\section{GESTÃO E ORGANIZAC̣ÃO DO SISTEMA DE SAÚDE}

\section{PLANEJAMENTO E AVALIAÇÃO}

- Características do planejamento. Verificou-se acerca da existência de práticas de planejamento situacional local em saúde, da regularidade do planejamento e sua utilização como instrumento de gestão;

- Institucionalização da avaliação. Verificou-se acerca das características do processo de avaliação: se a avaliação era realizada de forma regular e utilizada para a tomada de decisões; se os sistemas de informação oficiais eram usados na monitorização das ações implementadas.

\section{ORGANIZAÇÃO DO SISTEMA}

- Relação público-privado. Verificou-se se a gestão das ações de média e alta complexidade era feita pelo setor público; se existiam serviços públicos de referência para regulação da oferta; se as ações de média e alta complexidade eram referenciadas para o setor privado contratado e conveniado;

- Adequação da oferta às necessidades da população. Análise acerca da incorporação de ações programáticas de saúde e oferta de serviços adequada ao perfil epidemiológico e social ou, pelo menos, implementação dos programas definidos pelo nível federal;

- Acesso. Verificou-se acerca da existência de sistema de marcação de consultas, incluindo serviços de diferente complexidade e internação, com sistema de referência e central de vagas; aumento da proporção de população adscrita na rede básica e melhoria da acessibilidade geográfica, ou seja, distribuição espacial das unidades ou existência de sistemas de comunicação e transporte; 
- Cobertura assistencial. A cobertura assistencial potencial (oferta de serviços) foi estimada através do número de unidades de saúde, bem como da concentração de profissionais/população (médicos, enfermeiros, odontólogos e pessoal auxiliar). Já a cobertura assistencial real (utilização de serviços) foi estimada através da produção ambulatorial do SUS, por ano de competência, pela população, no período compreendido entre 1994 e 2001;

- Organização e integração da rede de serviços em uma lógica hierarquizada e regionalizada. Verificou-se acerca da existência de adequação entre a qualificação dada pelo nível federal (NOAS, 2001) como sede de um módulo assistencial ou pólo de uma microrregião e a existência de um sistema de referência e contra referência com fluxo formalizado, registro de atendimento e controle de pacientes;

- Participação popular e controle social. A participação popular foi entendida enquanto participação da sociedade nas decisões sobre a política de saúde onde os seguintes aspectos foram observados:

- Presença de Conselho Municipal representativo, propositivo e atuante (controle da aplicação de recurso e funcionamento regular);

- Convocação de Conferências Municipais sobre a política de saúde;

- Membros dos Conselhos Municipal e Local de Saúde capacitados adequadamente para o exercício da função;

- Existência de conselhos locais de saúde atuantes e com funcionamento regular.

\section{PRÁTICAS ASSISTENCIAIS}

\section{CARACTERÍSTICAS DAS PRÁTICAS}

- Ações de promoção da saúde. Existência de ações intersetoriais voltadas para os problemas priorizados no território; incorporação por parte do nível central e local de tecnologias de comunicação social; 
- Ações de vigilância de riscos e danos à saúde. Existência da utilização dos dados dos sistemas de informação para monitoramento da situação de saúde e tomada de decisões no nível local e existência de estruturação de um sistema de vigilância da saúde com integração/articulação entre as ações de Vigilância Epidemiológica e Vigilância Sanitária;

- Articulação entre os níveis de proteção, recuperação e reabilitação da saúde. Existência de integração dos níveis de prevenção, recuperação e reabilitação para os agravos/problemas priorizados no município. Existência de estratégias de diagnóstico precoce e prevenção pelo menos para grupos de risco de hipertensão arterial; coerência entre as ações de prevenção e controle (ações sobre os riscos) realizadas e os problemas priorizados;

- Assistência Farmacêutica. Referiu-se à disponibilidade de medicamentos para doenças de maior prevalência e/ou gravidade/custo e desenvolvimento de ações de promoção do uso racional de medicamentos;

- Atenção à saúde bucal. Existência de programação e intervenção sobre os problemas relacionados com a saúde bucal a partir do perfil epidemiológico do município. Ênfase nas ações preventivas e coletivas. Disponibilidade de atendimento restaurador;

- Existência de protocolos de atenção para agravos específicos priorizados. Existência de protocolos específicos para o nível local ou, pelo menos, a utilização sistemática dos protocolos de atenção para agravos de prioridade estadual/nacional;

- Estratégias de acolhimento. Existência de iniciativas referentes à melhoria do acolhimento aos usuários da própria Secretaria Municipal e Saúde e dos profissionais do nível local. Essas iniciativas dizem respeito a estratégias que incluem instalações físicas com conforto mínimo (bancos e cadeiras suficientes, área coberta com acesso a banheiros e água potável e garantia da privacidade do atendimento). Existência de diálogo e flexibilidade na rotina da rede de serviços. Existência de triagem realizada por profissional de saúde; 
- Práticas com equipes multidisciplinares. Existência de atividades de promoção e proteção à saúde através de técnicas envolvendo trabalho com grupos de usuários (terapêuticos, preventivos, e educativos) e com equipes multiprofissionais.

\section{EFETIVIDADE DAS PRÁTICAS}

\section{ESTUDOS DE SÉRIES HISTÓRICAS DE TRAÇADORES SELECIONADOS}

Para apreciação da efetividade das práticas, foram analisadas as séries temporais de agravos-traçadores no período compreendido entre 1980 e 1999 para os municípios estudados. Foram os seguintes os indicadores selecionados: a) Coeficiente de Mortalidade Infantil; b) Coeficiente de Mortalidade Infantil evitável; c) Proporção de óbitos infantis evitáveis; d) Mortalidade Infantil por diarréia; e) Mortalidade Infantil por infecção respiratória aguda; f) Coeficiente Padronizado de Mortalidade por tuberculose e Coeficiente Padronizado de Mortalidade por doença cérebro-vascular. Esses últimos quatro indicadores foram selecionados como condições traçadoras conforme critérios propostos por Kessner e Kalk (KESSNER e outros, 1992).

Foi analisada a evolução das médias quinqüenais dos coeficientes de mortalidade dos agravos considerados como traçadores, entre 1990 e 1999. Como valor de referência, foram consideradas as médias quinqüenais dos coeficientes de mortalidade para os mesmos agravos referentes ao estrato de municípios do município-caso ${ }^{3}$.

Os seguintes indicadores de morbidade para os municípios-caso no período compreendido entre 1995 e 2001 foram escolhidos: a) Taxa de internação hospitalar por causa específica (tuberculose e hipertensão arterial); b)Taxa de internação hospitalar por diarréia e infecção respiratória aguda, para menores de um ano. Esses indicadores foram comparados com a mesma taxa do estrato de municípios de referência.

A análise foi feita através da inspeção visual das curvas da série histórica frente a fatos e eventos relacionados com o processo de descentralização no município. Para melhor visualização da tendência, as variabilidades verificadas nestas curvas foram suavizadas pelo emprego do método das médias-móveis de ordem cinco no caso da mortalidade, e de ordem 3 para os internamentos. Calculou-se também a velocidade da variação média 
anual (b) dos coeficientes para todo o período analisado, utilizando a análise de regressão linear bivariada, na qual o ano calendário foi a variável independente. Além disso, estimou-se a variação percentual ( $D$ \%) anual e das médias quinqüenais dos referidos indicadores. Uma pontuação progressiva foi utilizada caso o município apresentasse uma redução nos indicadores e se essa redução mostrava-se maior que a redução verificada no estrato de municípios de referência. Optou-se pela análise da variação percentual ( $D$ \%) para as médias dos dois últimos quinqüênios para a mortalidade e para toda a série histórica na morbidade.

\section{SATISFAÇÃO DOS USUÁRIOS}

A satisfação do usuário foi aferida através de entrevistas semiestruturadas onde se buscou observar a percepção do entrevistado em relação ao acolhimento na unidade básica de saúde, à capacidade de resolução das suas queixas (problemas de saúde) na atenção básica, ao atendimento nas especialidades (forma de encaminhamento e acesso a outros procedimentos), às ações preventivas desenvolvidas dos agentes comunitários de saúde no seu domicílio e na área, e à criação de vínculo com a equipe da unidade e profissionais de saúde da rede.

A coleta de dados foi realizada a partir das seguintes fontes de dados (Tabela 1):

1. Análise documental do (a):

a) Plano de Saúde de Município A (1998-2001);

b) Relatórios de Gestão de Município A (1999 e 2000);

c) Repasses federais ao município A entre 1997 e 2001. As informações referentes aos recursos financeiros federais destinados ao município foram obtidas no DATASUS/Recursos Federais do SUS e englobam todo o volume de recursos destinados ao município pela União.

2. Sistema de Informação Ambulatorial e Hospitalar do Sistema Único de Saúde (SIA/SIH-SUS) para: 
- morbidade ambulatorial e hospitalar para agravos selecionados (Tuberculose, Hipertensão Arterial, Doença Cérebro-vascular, internação por diarréia e Infecção Respiratória Aguda) no período de 1998 a 2000;

- produção ambulatorial dos serviços de atenção básica odontológica (consultas, procedimentos coletivos, preventivos individuais, restauradores, cirúrgicos e periodontais no período entre 1994 a 2001).

2. Dados de mortalidade para agravos específicos: Tuberculose, Hipertensão Arterial, Doença Cérebro-vascular e Mortalidade Infantil disponíveis no Sistema de Informação de Mortalidade (SIM).

3. Trajetórias das condições traçadoras. Foram descritas as trajetórias assistenciais de eventos considerados como indesejáveis, tais como óbitos e internações por diarréia, IRA, tuberculose e DCV a partir de entrevistas com parentes e análise de prontuários.

4. Entrevistas semi-estruturadas a partir de roteiros elaborados, tendo por referência o quadro teórico.

5. Elaboração de diário de campo.

Foram realizadas 19 entrevistas com os seguintes atores:

a) Gestor do sistema;

b) Coordenadores das seguintes áreas no nível central: a) assistência à Saúde; b) vigilância à saúde e c) PACS/PSF);

c) Um representante dos usuários ou prestadores no Conselho Municipal de Saúde;

d) Nível local: Médico, enfermeira, um agente comunitário de saúde e quatro usuários do serviço da unidade de observação considerada "satisfatória";

e) Nível local: Médico, enfermeira, um agente comunitário de saúde e quatro usuários do serviço da unidade de observação consideradas "não satisfatória". 
As unidades de saúde selecionadas para observação e realização das entrevistas foram caracterizadas como "satisfatórias" e "não satisfatórias". Essa caracterização foi feita a partir de entrevistas abertas com técnicos do nível Central da Secretaria Municipal de Saúde.

As entrevistas foram transcritas e analisadas segundo as dimensões propostas, cujas evidências mais relevantes foram transportadas para a matriz de análise do grau de implantação (Quadro 1).

Dois pesquisadores, isoladamente, a partir da leitura das evidências, pontuaram cada um dos critérios propostos para cada uma das sub-dimensões. Após isso, buscaram um consenso sobre a pontuação e o valor de cada critério.

A classificação do grau de implantação das dimensões analisadas à luz do grupo de evidências obtidas foi feita através da atribuição de pontos (Tabela 2). A pontuação obtida em cada critério foi comparada com o total de pontos máximos. A diferença percentual entre a pontuação máxima e aquela obtida classificava cada critério em:

1. Incipiente: $\geq 0$ e $\leq 33,3 \%$

2. Intermediário: $>33,3 \%$ e $\leq 66,6 \%$

3. Avançado: $>66,6 \%$

Para cada dimensão, sub-dimensão e na pontuação geral, o município que atingiu menos de 33,3\% da pontuação máxima proposta foi considerado Incipiente. Foi considerado Intermediário aquele que atingiu entre $33,3 \%$ e $66,6 \%$ da pontuação máxima. Um percentual igual ou acima de $66,6 \%$ foi considerado como Avançado no grau de implantação a partir da “imagem-objetivo" proposta (VIEIRA-DA-SILVA, 1999).

\section{RESULTADOS}

\section{CARACTERÍSTICAS DO MUNICÍPIO-PILOTO}

O município "A" possui cerca de 150 mil habitantes, sendo que aproximadamente $90 \%$ dos moradores vivem em zona urbana. A partir de um processo de industrialização iniciado na década de 70, profundas transformações ocorreram no seu perfil populacional com um processo migratório intenso de mão-de-obra pouco qualificada e técnicos da administração pú- 
blica não residentes no município. O processo de urbanização acelerada não foi suficiente para atender as demandas da população por programas habitacionais, infra-estrutura urbana e de saneamento, apresentando cerca de $20 \%$ dos moradores sem instalação sanitária no domicílio, 40\% dos moradores sem abastecimento de água interno, segundo dados do censo do IBGE em 1991 (BARROS e outros, 1996). Em relação à renda per capita, dados do censo de 1991 apontam para um decréscimo da renda familiar per capita média na década de noventa, aumento no suprimento de água potável, instalações adequadas de esgoto e construções habitacionais com materiais duráveis.

No que se refere aos aspectos políticos e de organização do setor saúde, existem relatos segundo os quais após um período de investimentos na construção de uma rede básica de centros e postos de saúde na década de 70, houve um grande período sem aporte de recursos para a sua manutenção. Em meados da década de 80, com as eleições diretas para prefeito, assume o poder uma frente de centro-esquerda. Coincidindo com a realização da VIII Conferência Nacional de Saúde, foram implantadas as primeiras ações programáticas em saúde no contexto da descentralização propiciado pela estratégia das Ações Integradas de Saúde (AIS) e particularmente do Sistema Unificado e Descentralizado de Saúde (SUDS), o que resultou na reforma, ampliação da rede, bem como no aumento da cobertura assistencial. Desde então, há contextos políticos diferenciados com recuos e avanços no setor saúde, conforme relato dos sujeitos da presente investigação. O município assume a gestão plena do sistema de saúde em 1997. Neste mesmo ano, a primeira equipe de saúde da família inicia a atuação no município. Atualmente, são 20 equipes de saúde da família atuando, além de agentes comunitários de saúde.

Na década de oitenta, a rede de serviços de saúde existentes era exclusivamente municipal, com treze estabelecimentos, sendo que inexistiam unidades pertencentes ao INAMPS ou à Secretaria Estadual de Saúde. Em 2000, a rede de serviços de saúde contava com 35 estabelecimentos de vários tipos (BRASIL, 2000b).

O município apresenta uma pirâmide etária com base larga, onde a maioria da população se concentra entre os 10 e 29 anos de idade, ou seja, considerada uma população jovem. A taxa de alfabetização está em torno de $72,2 \%$ dos residentes, sendo que a menor taxa está entre aqueles com 
idade acima dos 50 anos, refletindo a migração iniciada na década de oitenta em função da industrialização (BARROS e outros, 1996).

A principal causa de internação tem sido as doenças relacionadas ao aparelho respiratório, com $12 \%$ dos casos, principalmente na faixa entre um e quatro anos de idade, seguidas pelas doenças do aparelho circulatório, com 6\% das internações no ano de 1999. Dados de mortalidade proporcional, em 1999, apontam como principal causa de morte as doenças do aparelho circulatório (hipertensão, doença cérebro-vascular e acidente vascular-cerebral), com $27 \%$ das ocorrências, seguida das causas externas (homicídios, suicídios, acidentes de trânsito e de trabalho) com 17,8\%, além das neoplasias com 11,7\% dos casos (BRASIL, 2001).

O município A atingiu um escore global de $45.8 \%$, tendo sido classificado em intermediário no processo de descentralização das ações de saúde a partir da imagem-objetivo proposta. Contudo, o escore na dimensão contexto político foi num patamar superior a $50 \%$, sendo considerado entre intermediário e avançado. O menor grau de implantação foi encontrado nas práticas assistenciais com 31.5\%, seguido da efetividade com $37.0 \%$ e da gestão na saúde com 49.5\% (Tabela 2, Figuras 2 e 3).

No que se refere ao contexto político, o município apresentou uma boa governabilidade (81.8\%), razoável pontuação no Projeto de governo (54\%) e baixa na Capacidade de governo (33.3\%).

Chama a atenção entre as sub-dimensões analisadas a não pontuação do item iniciativas intersetoriais, sendo que a política de Recursos Humanos obteve $10 \%$ porque minimamente o município desenvolve capacitações freqüentes às equipes do PSF, conforme Relatórios de Gestão.

Assim, das oito sub-dimensões analisadas (prioridade para a saúde, iniciativas intersetoriais, perfil da direção, adequação do quadro técnico, política de $\mathrm{RH}$, base de apoio político, autonomia financeira e relacionamento entre gestores), o município foi considerado "Avançado" na autonomia financeira e base de apoio político e "Intermediário" no item prioridade para saúde, principalmente em função do gasto per capita. Nos demais itens, o município foi considerado "Incipiente", a partir da imagem-objetivo proposta.

Na gestão da saúde, entre os aspectos pesquisados do planejamento e avaliação, da Organização do sistema e da participação popular, o município obteve 10\%, 50\% e 50\%, respectivamente. 
Entre as sub-dimensões, observam-se lacunas na relação público-privado (30\%), com baixa regulação da oferta e compra da média e alta complexidade para o setor privado, no Planejamento das ações (40\%), onde este tem sido normativo e, principalmente na institucionalização da avaliação (25\%), predominando um modelo de avaliação pontual assistemático de monitorização de alguns indicadores, especialmente de produtividade da produção ambulatorial. Nas demais subdimensões (processo de trabaIho, adequação da oferta às necessidades da população, acesso, cobertura assistencial, organização da rede e controle social) os resultados mostraram-se intermediários, com pontuação em torno de 50\%. Assim, do total de nove subdimensões pesquisadas, o município mostrou-se intermediário em oito delas, principalmente devido à ampliação na oferta de serviços nos últimos anos e incorporação de ações programáticas dos programas definidos pelo nível federal, principalmente hipertensão arterial, diabetes, atendimento à gestante e à criança. Nos demais itens, os resultados foram considerados incipientes.

Quanto às práticas assistenciais, núcleo-duro de observação do presente estudo, entre aquelas relacionadas à integralidade das ações, chama atenção a falta de pontuação do item ações de promoção da saúde, onde nenhuma iniciativa foi observada quanto a ações intersetoriais locais e utilização de tecnologias inovadoras de comunicação social, além da atenção à saúde bucal (16.7\%), onde, apesar de um histórico de ações preventivas entre escolares no município desde a década de 70, mantidas de forma isolada e pontual sem grande ênfase nas ações coletivas, o município mantém apenas o atendimento restaurador tradicional. Nos demais itens, ações de vigilância a riscos e danos, articulação entre níveis, assistência farmacêutica, uso de protocolos para agravos priorizados, estratégias de acolhimento e práticas multidisciplinares, o município obteve 58.3\%, 50\%, $50 \%, 23.4 \%, 26.7 \%$ e $26.7 \%$, respectivamente. Assim, dos oito itens observados no que se refere à integralidade das ações e abordagem integral do indivíduo, apenas em três deles o município foi considerado "Intermediário". Nos demais itens, o grau de implantação foi "Incipiente".

No que se refere à dimensão da efetividade das práticas sobre o impactos das ações (redução da mortalidade infantil e materna), o município atingiu 40\% e $16.7 \%$ dos critérios de avaliação propostos. A análise da série histórica sobre os coeficientes de mortalidade Infantil por grupo de 
causas aponta para um declínio acentuado na mortalidade por diarréia, principalmente a partir da década de noventa, com a inserção do PACS no município, e em menor grau, mas também relevante, o declínio na mortalidade por Infecção Respiratória Aguda em menores de cinco anos. A análise da série histórica das demais condições traçadoras aponta para um declínio discreto na mortalidade por tuberculose, mas a manutenção de altos coeficientes de morbi-mortalidade por DCV e Hipertensão Arterial.

Na subdimensão satisfação do usuário, o município atingiu 45\%, principalmente no que se refere à resolução das queixas na atenção básica e vínculos estabelecidos com a equipe de saúde das unidades básicas. Todos os aspectos pesquisados nessa dimensão foram considerados com grau de implantação "incipiente".

Quanto à análise qualitativa dos dados das entrevistas, diários e observações em campo, alguns aspectos devem ser enfatizados no que se refere:

1) Verificaram-se diferenças de vínculos, aqui entendidos como relações afetivas e pessoais entre usuários e profissionais e vice-versa capazes de promover maior adesão e satisfação nas atividades cotidianas do trabalho, na unidade de observação A1 (satisfatória) em relação à unidade A2 (não satisfatória). Onde há êxito, há vínculo estabelecido e este é bilateral, ou seja, tanto por parte dos profissionais quanto por parte dos pacientes. Essas observações podem ser evidenciadas especialmente no discurso dos usuários hipertensos (Anexo 1);

2) Verificaram-se diferenças de práticas preventivas e de relações interpessoais entre profissionais e usuários na unidade A1 em relação à unidade A2. Onde há êxito, se estabelecem ações preventivas com adesão e, conseqüentemente, relações interpessoais entre pacientes, pessoal de nível médio e os profissionais. Este dado pode ser evidenciado nas entrevistas com os trabalhadores de saúde da unidade A1 (Anexo 1).

3) O uso assistemático do planejamento e avaliação por parte do nível central e local demonstra a pouca importância que se dá às atividades eminentemente de saúde pública, sendo que o sistema de informação tem sido visto mais como um depositário de dados 
para evitar o corte de recursos federais do que necessariamente um instrumento de trabalho para tomada de decisões.

4) Atualmente, no município $A$, convivem dois modelos de atenção básica: um minimamente "resolutivo", no que se refere à ação sobre danos específicos e ações programáticas e um outro "resolutivo" quanto aos danos, criador de vínculos e timidamente atuante sobre riscos específicos relacionados aos danos. Observase que, quanto mais este segundo modelo se aproxima dos riscos, maior necessidade se percebe do planejamento e do sistema de informação e novas práticas pedagógicas em saúde. Contudo, o sistema de informação existente não tem sido utilizado em sua potencialidade para aprimorar novas práticas no nível local. Sugere-se que unidades de saúde com esse perfil sejam estimuladas através de treinamento específico nessa área considerada lacuna, para poderem avançar em direção a práticas assistenciais verdadeiramente promotoras de saúde.

\section{DISCUSSÃO}

O município $\mathrm{A}$ apresentou um grau intermediário de implantação da descentralização quando comparado com a imagem-objetivo proposta, que, ao lado da influência das políticas centrais de controle de alguns agravos de saúde específicos, apontam para os limites no desenvolvimento de um modelo de atenção com práticas assistenciais mais promotoras de saúde.

A discussão sobre os limites dos modelos de atenção à saúde vigentes no Brasil e a busca por modelos voltados para a qualidade, efetividade e necessidades prioritárias de saúde passaram a fazer parte da agenda nacional, sendo escolhido como a temática da XI Conferência Nacional de Saúde (BRASIL, 2000a) (RELATÓRIO DA CNS, 2000). Assim, o presente estudo aponta para alguns avanços importantes na medida em que há tentativas de superação dos limites do modelo hegemônico assistencial privatista centrado na atenção médico-hospitalar, principalmente em relação à gestão municipal. O estudo aponta para um avanço do modelo proposto como estratégia de reorientação do modelo de atenção básica com maior humanização e qualidade na assistência.

A análise das características do governo, a partir da proposta de Carlos Matus, aponta que o mesmo possui boa governabilidade, mas há fragilida- 
de no projeto e principalmente na capacidade de governo, o que muito provavelmente tem interferido na forma como as mudanças das práticas de saúde estão ocorrendo no referido município. Essa observação também se aplica ao contexto organizacional do setor saúde no município $A$.

No que se refere aos aspectos metodológicos, a utilização da estratégia da análise de implantação mostrou-se bastante útil ao permitir a observação mais ampla do processo de descentralização no município como um todo, bem como possibilitou a identificação dos componentes específicos com maiores lacunas.

\section{COMENTÁRIOS FINAIS}

O estudo-piloto revelou ser adequada a estratégia, bem como os instrumentos testados, que sofreram algumas modificações, visando tornálos mais claros. A matriz elaborada foi submetida a uma conferência de consenso ${ }^{4}$ que se desenvolveu concomitantemente à coleta de dados, o que impediu que seus resultados pudessem ser utilizados para o redirecionamento do estudo. A conferência, contudo, revelou elevado grau de consenso em relação aos critérios e pesos atribuídos às práticas assistenciais e dissenso em relação à gestão, o que foi consistente com os achados do estudo-piloto.

Os achados desse estudo-piloto foram ainda consistentes com as análises de outros autores a respeito dos limites da descentralização, particularmente no que toca às deficiências na gestão do sistema. As resistências políticas e institucionais, a carência de recursos humanos capacitados e a fragilidade técnico-administrativa dos municípios, reduzindo sua capacidade de realização, a dependência da maioria dos municípios brasileiros com relação às transferências de recursos financeiros de nível federal, perpetuação de práticas clientelistas e patrimonialistas afastando potencialidades democráticas na relação Estado-Sociedade, falta de transparência na administração da "coisa pública", indefinição de papéis, repercutindo em concorrência ou omissões entre as três esferas, inclusive no âmbito da descentralização fiscal e financeira têm sido apontadas como obstáculos a esse processo (PAIM, 2002; CARVALHO, 1997).

No presente estudo, observou-se uma baixa capacidade técnica, pouca compreensão das características de um modelo público em saúde em 
todos os níveis, o que pode ter influenciado na classificação final do grau de implantação como "intermediário". Há limitado sentimento de participação na gestão por parte dos técnicos e trabalhadores de saúde, aqui entendida como sinergia entre os trabalhadores e a organização, muito provavelmente associado ao não desenvolvimento de atividades de integração da organização em torno de objetivos e estratégias comuns, muito relacionadas ao próprio perfil do gestor, pouco preparado para lidar com práticas participativas e mais vinculado às questões político-partidárias.

\section{NOTAS}

${ }^{1}$ Trabalho realizado com o apoio financeiro do Ministério da Saúde.

${ }^{2}$ O grupo de dirigentes e técnicos, na época, cursava disciplina de avaliação do Mestrado Profissional em Saúde Coletiva, da Secretaria de Assistência à Saúde/Universidade Estadual do Rio de Janeiro, no ano de 2001.

${ }^{3}$ Ver relatório Vieira-da-Silva e outros. "Avaliação da descentralização da atenção à saúde na Bahia". Subprojeto "Avaliação dos efeitos da descentralização em relação a condições traçadoras da atenção à saúde“. ISC-MS Relatório de pesquisa, 2002.

${ }^{4}$ Ver a análise da conferência no capítulo 3 do presente livro.

\section{REFERÊNCIAS}

BARROS, R.P., e outros. Relatório sobre o desenvolvimento humano no Brasil, PNUD, IPEA, 1996.

BRASIL, Ministério da Saúde. Norma operacional básica do sistema único de saúde - NOB-SUS-96, Brasília, 1997. 36 p.

BRASIL, Ministério da Saúde. Site www.saude.gov.br/datasus acessado em 04/05/ 2002, 2000a.

BRASIL, Ministério da Saúde. Relatório da IX Conferência Nacional de Saúde, Brasília DF, 2000b.

BRASIL, M. Informaçãoes de saúde: mortalidade e morbidade hospitalar, DATASUS/ SIA-SUS, 2001.

BRASIL. Norma operacional da assistência à saúde NOAS-SUS 01/2002, portaria n 373, de 27 de fevereiro de 2002. Ministério da Saúde/GM, 2002.

BRASIL. Habilitação de municípios por condição de gestão e por estado conforme a NOB SUS 1/96, Ministério da Saúde. Site www.saude.gov.br/sas/ddga/habilitação/habilit.MUN.NOB.htm. 2003.

CARVALHO, Inaiá Maria Moreira de. Descentralização e políticas sociais na Bahia. Caderno CRH, n.1. Salvador: Centro de Recursos Humanos/UFBA, 1997. 
CLAUS, S.M.; CAPRA, M.L.P. Elaboração de um protocolo de ações básicas de saúde: subsídio para a reorganização de processos de trabalho para a implementação do SUS. Divulgação para Saúde em Debate. v. 24, p. 44-51, 2001.

CONTANDRIOPOULOS, A.P.; CHAMPAGNE, F.; DENIS, J.L.; AVARGUES, M.C. "Evaluation in the health sector: a conceptual framework." Revue de Epidemiologie et de Santé Publique, v. 48, n. 6, p. 517-539, 2000.

DENIS, J.; CHAMPAGNE, F. Análise da implantação de programas. Avaliação em saúde: dos modelos conceituais à prática na análise da implantação de programas. H. Z. (ed.). Rio de Janeiro: FIOCRUZ, 1997, p. 49- 88.

DONABEDIAN, A. Methods of deriving the criteria. In: Explorations in quality assessment and monitoring, Michigan: H.A. Press, 1988. 504 p.

FLEURY, Sônia. Descentralização dos serviços de saúde: dimensões analíticas. Cadernos da Nona Conferência Nacional de Saúde. Brasília, p.27-38, 4-9 agosto,1992.

HEIMANN, L.S.; CASTRO, I.E.d.N.; KAYANO, J.; ROCHA, J.L.; RIEDEL, L.F.; TERENCE, M.F.; CRUZ, O.d.C.; FRAISSAT, R.A.; PESSOTO, U.C.; JUNQUEIRA, V. A descentralização do sistema de saúde no Brasil - uma proposta de investigação sobre o impacto de políticas. São Paulo: Instituto de Saúde - Secretaria de Estado da Saúde, 1988.

JIMENEZ, E.J.; SHIMAZAKI, M.E. Planejamento familiar eficiente e criterioso em Curitiba auxilia casais na escolha do melhor método anticoncepcional. Experiências Inovadoras //. Brasília: Ministério da Saúde. Secretaria de Assistência à Saúde, 2002. p. 28-30.

KESSNER, M.; KALK, C.E.; SINGER, J. Evaluación de la calidad de la salud por el método de los procesos trazadores. In: OPAS, (White, K.L., editor principal). Investigaciones sobre servicios de salud: una antología. - Washington, D.C.: OPS (Publicacion Científica n. 534), p. 555-563, 1992.

MARTÍN, Teresa Quiroz. Descentralización, políticas públicas e iniciativas hacia la igualdad de género. In: Los procesos de reforma del Estado a la luz de las teorías de género. Cuaderno del Centro Latinoamericano de Capacitación y Desarrollo de los Gobiernos Locales, IULA/CELCADEL. Quito, n. 26, p. 69-82, octubre/1997.

MATUS, C. La descentralizacion: una Nueva Panacea para impulsar el desarrolo local? Cuadernos del CLAEH, Montividéo n. 51, p. 57-75, 1989.

MATUS ,C. Política, planejamento e governo. 2a ed. Brasília: IPEA, Tomo I, 1997. p. 1-28 e p. 297-334.

MULLER NETO, Júlio S. Políticas de Saúde no Brasil: a descentralização e seus atores. Cadernos da Nona Conferência Nacional de Saúde. Brasília, p.43-59, 1992.

PAIM, J.S. A reforma sanitária e os modelos assistenciais. Epidemiologia e saúde. ALMEIDA-FILHO, R. Rio de Janeiro: MEDSI, 1999, p. 473-488.

PAIM, J.S. Saúde: política e reforma sanitária. Salvador: ISC/CEPS, 2002.

SOLLA, J.; SANTOS, F.P.; MALTA, D.C.; REIS, A.T. Avaliação da implantação das ações de controle, avaliação e auditoria na gestão plena do Sistema Municipal de Saúde de Vitória da Conquista. Experiências Inovadoras, v. 2, p. 83-85, 2002. 
VIANA, A.L.d.A.; HEIMANN, L.S.; LIMA, L.D.d.; OLIVEIRA, R.G.d.; RODRIGUES, S.d.H. "Mudanças significativas no processo de descentralização do sistema de saúde no Brasil." Cadernos de Saúde Pública, v. 18 (Suplemento), p. 139-151, 2002. VIEIRA-DA-SILVA, L.M.; PAIM, J.S. e outros. Desigualdades na mortalidade, espaço e estratos sociais em uma capital da região nordeste. Revista de Saúde Pública de São Paulo, v. 33, n. 2, p. 187-97, 1999.

VIEIRA-DA-SILVA, L.M. Avaliação do processo de descentralização das ações de saúde. Ciência e Saúde Coletiva, v. 4, n. 2, p. 331-339, 1999.

VIEIRA-DA-SILVA, L. M.; HARTZ, Z.; CHAVES, S.C.L.; PACHECO, F.; SILVA, G.A.P.d.; MACHADO, R.L.; COSTA, M.C.N.; PAIM, J.S. Avaliação da descentralização da saúde na Bahia. Relatório de pesquisa. Salvador: Instituto de Saúde Coletiva /UFBA/ Ministério da Saúde, 2002.

YIN, R.K. Case study designs for evaluating high-risk youth programs: the program dictates the design. In: Applications of case study research. Newbury Park, CA: SAGE Publications, p. 77-93, 1993.

VIENONEN, O. Towards evidence-based health care reform. Bulletin of the World Health Organization, v. 77, n. 1, p. 10-15, 1999. 


\section{Anexos}

\section{Figura 1}

Modelo Lógico

\section{Contexto nacional}

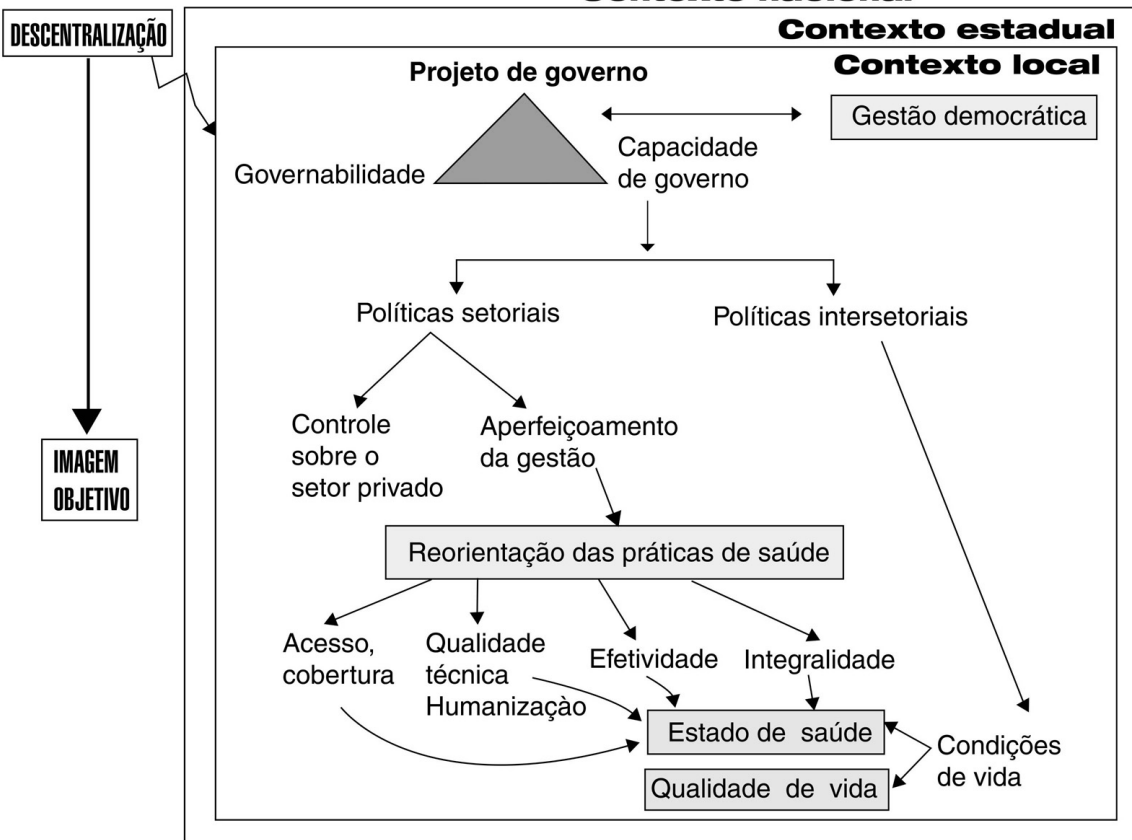




\section{Figura 2}

Grau de implantação da descentralização na atenção à saúde no município A segundo pontuação máxima e atingida a partir das dimensões das características de governo, gestão da saúde, práticas assistenciais e efetividade das práticas. Bahia, 2001

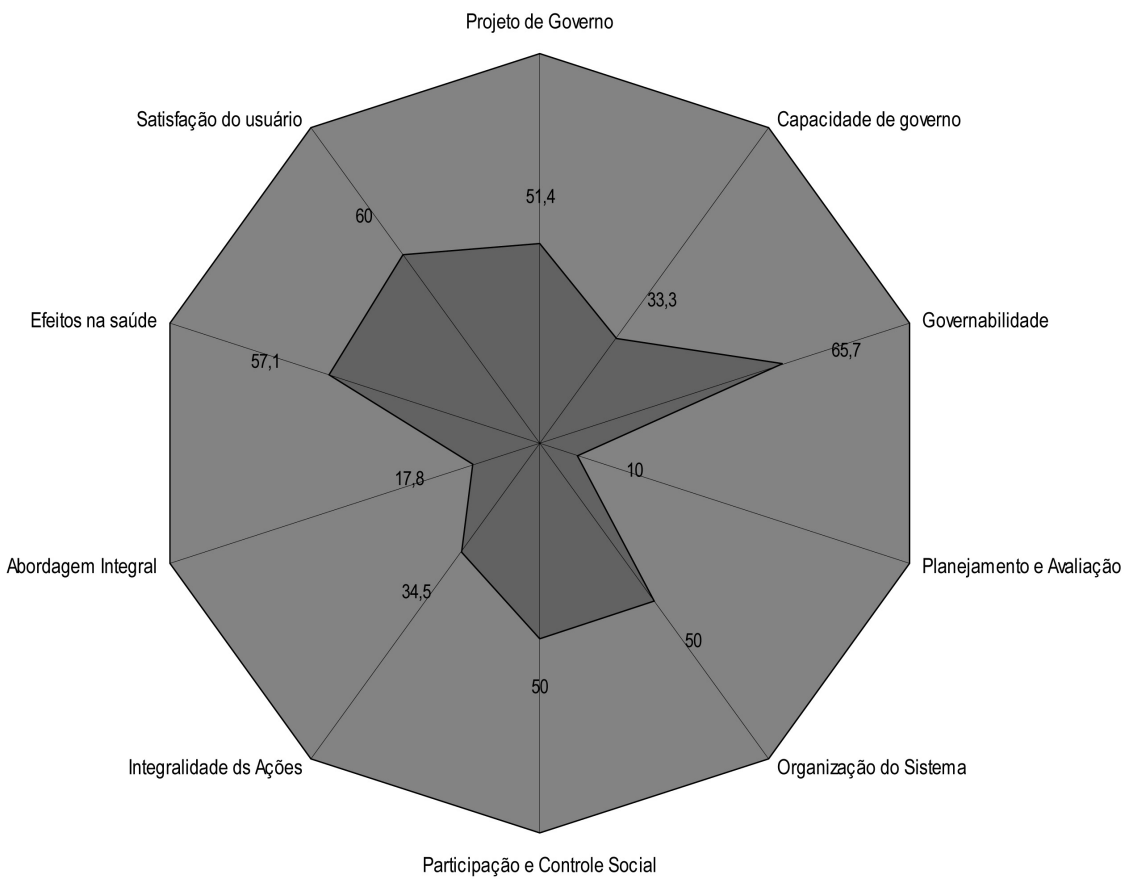

$\square$ Pontos máximos $\quad \square$ Pontos atingidos 
Figura 2

Grau de implantação da descentralização na atenção à saúde no município A segundo percentual atingido a partir das dimensões componentes de governo, gestão da saúde, práticas assistenciais e efeitos observados. Bahia, 2001

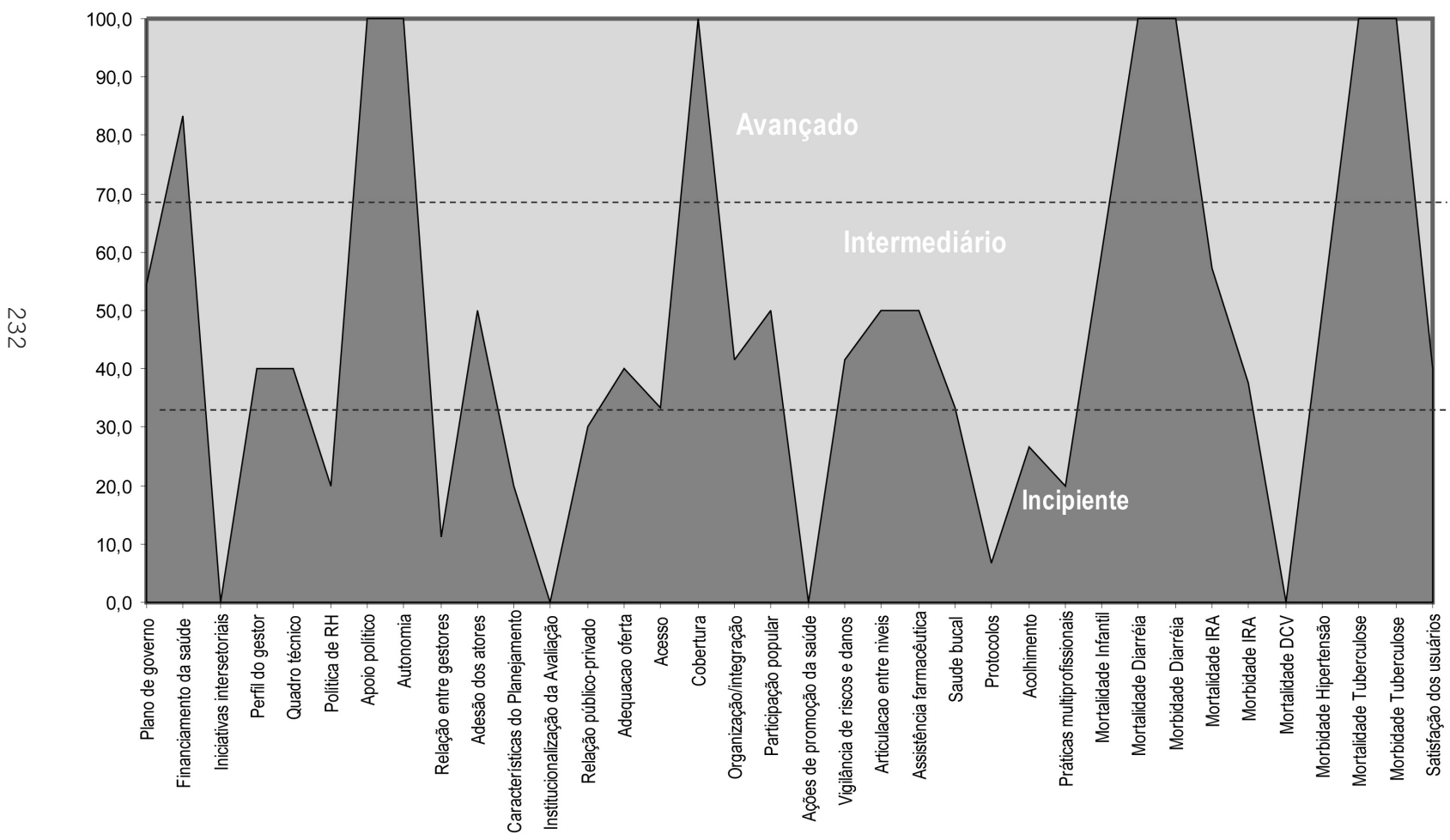




\section{Quadro 1}

Avaliação da Gestão Descentralizada do SUS em municípios selecionados da Bahia. Matriz de dimensões e critérios

\section{NÍVEL 1- CONTEXTO POLÍTICO (100 pontos) ${ }^{1}$}

\begin{tabular}{|c|c|c|c|c|}
\hline Dimensões & Subdimensões & Critérios & Graduação & Base de evidências \\
\hline $\begin{array}{l}1.1 \text { - } \\
\text { Projeto } \\
\text { de Governo } \\
\text { Max. } 35 \\
\text { pts. }\end{array}$ & $\begin{array}{l}\text { Plano de } \\
\text { governo. } \\
\text { Max.11 pts. } \\
\text { Obs.: } \\
(\%)\end{array}$ & $\begin{array}{l}\text { a)A saúde é explicitada como prioridade no plano de } \\
\text { governo e no discurso dos entrevistados; ( } 6 \text { pts.) } \\
\text { b) no plano de saúde há coerência entre problemas } \\
\text { priorizados e ações propostas. ( } 5 \text { pts.) }\end{array}$ & $\begin{array}{l}\text { ( ) Avançado (a } \\
+ \text { b) } \\
\text { ( ) Intermediário } \\
\text { (a ou b) }\end{array}$ & $\begin{array}{l}\text { - Entrevistas com técnicos, representante } \\
\text { - } \quad \text { Análise de coerência do plano de saúde }\end{array}$ \\
\hline Obs.: & $\begin{array}{l}\text { Financiamento } \\
\text { para a saúde. } \\
\text { Max. } 12 \text { pts. } \\
\text { Obs.: } \\
\left(\begin{array}{l}\%\end{array}\right)\end{array}$ & $\begin{array}{l}\text { a) O percentual do orçamento executado (gastos com } \\
\text { saúde) do Tesouro Municipal previsto na EC } 29 \text {. (6 pts.) } \\
\text { Se EC 29: gasto é acima de } 8 \% 6 \text { pts. } \\
\text { EC 29: } 10 \text { pts. (entre } 7 \text { e } 8 \% \text { ) } 4 \text { pts. } \\
\text { EC 29: } 5 \text { pts. (abaixo de } 7 \% \text { ) } 2 \text { pts. }\end{array}$ & $\begin{array}{l}(\quad) \\
\text { Avançado: } \\
\text { a ( >EC 29) ou } \\
\text { b ( > = } 150 \\
\text { U\$ per capita) } \\
\quad \quad \text { ) } \\
\text { Intermediário: } \\
\text { a (=EC29) ou } \\
\text { b (<U } \$ 150 \text { e } \\
>=80)\end{array}$ & $\begin{array}{l}\text { - Entrevistas com gestor, técnicos do nível } \\
\text { central e trabalhadores da saúde } \\
\text { - Relatório de gestão } 1999 \text { e } 2000 . \\
\text { - Repasses federais do SUS para os } \\
\text { municípios entre } 1997 \text { e } 2001 \text {. }\end{array}$ \\
\hline
\end{tabular}

${ }^{1}$ Cada nível de análise, correspondente a 100 pontos. Este deve ser equivalente ao somatório de pontos de suas dimensões, totalizadas pelas respectivas sub-dimensões e critérios. A classificação "Incipiente" será sempre atribuída por exclusão. Simulações com diferentes escalas e/ou técnicas estatísticas serão usadas para construção de escores agregados. A graduação e os pontos de corte dos escores agregados podem ser redefinidos depois do consenso nacional e/ou incorporação dos critérios utilizados pelos traçadores. 


\begin{tabular}{|c|c|c|c|c|}
\hline Dimensões & Subdimensões & Critérios & Graduação & Base de evidências \\
\hline & & $\begin{array}{l}\text { b) Gastos per capita em Real e U\$ (6 pts.) } \\
\text { Se }>150 \cup \$ \text { per capita) } 6 \text { pts. } \\
<\cup \$ 150 \text { e } 80 \cup \$: 4 \text { pts. } \\
\quad<80: 2 \text { pts. }\end{array}$ & 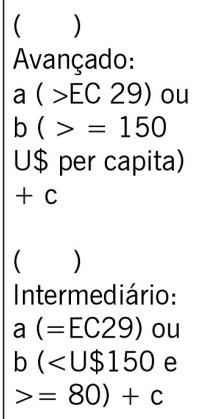 & $\begin{array}{l}\text { - Relatório de gestão } 1999 \text { e } 2000 . \\
\text { Gastos municipais /população total no ano } \\
\text { Gastos federais / pop. Total no ano } \\
\text { Gastos totais/ pop. No ano } \\
\text { Gasto per capita em R\$ e U\$. } \\
\text { - Repasses federais do SUS para o } \\
\text { município A entre } 1997 \text { e } 2001 .\end{array}$ \\
\hline & $\begin{array}{l}\text { Iniciativas } \\
\text { intersetoriais } \\
\text { Max. } 12 \text { pts } \\
\text { Obs.: } \\
(\quad \%)\end{array}$ & $\begin{array}{l}\text { a) Planejamento integrado/comitê gestor misto; ( } 4 \text { pts.) } \\
\text { b) Orçamento próprio para os projetos; (4 pts.) } \\
\text { c) Existência de, pelo menos, um projeto implantado. } \\
\text { (4 pts.) }\end{array}$ & $\begin{array}{l}(\quad) \text { Avançado: } \\
a+b+c \\
(\quad) \\
\text { Intermediário: } \\
a+ \\
(b \text { ou } c)\end{array}$ & $\begin{array}{l}\text { - Entrevistas com gestor e técnicos do } \\
\text { nível central. } \\
\text { - Relatório de gestão } 1999 \text { e } 2000 . \\
\text { - Plano Municipal de Saúde 1998-2001. }\end{array}$ \\
\hline
\end{tabular}


NÍVEL 1- CONTEXTO POLíTICO (100 pontos)

\begin{tabular}{|c|c|c|c|c|}
\hline Dimensões & Subdimensões & Critérios & Graduação & Base de evidências \\
\hline $\begin{array}{l}1.2- \\
\text { Capacidade } \\
\text { de Governo } \\
\text { Max. } 30 \\
\text { pts. } \\
\text { Obs.: } \\
\left(\begin{array}{c}\%\end{array}\right)\end{array}$ & $\begin{array}{l}\text { Perfil da direção } \\
\text { Max. } 10 \text { pts } \\
\text { Obs.: } \\
(\quad \%)\end{array}$ & $\begin{array}{l}\text { a) Existência de liderança ou quadro político na direção } \\
\text { do setor saúde; (04 pts.) } \\
\text { b) Formação na área de saúde coletiva do dirigente; (03 } \\
\text { pts.) } \\
\text { c) Concepção de um sistema de saúde local universal e } \\
\text { de qualidade. (03 pts.) }\end{array}$ & $\begin{array}{l}\text { ( ) Avançado: } \\
a+b+c \\
(\quad) \\
\text { Intermediário: } \\
a+\text { (b ou c) }\end{array}$ & $\begin{array}{l}\text { - Entrevistas com gestor. } \\
\text { - Entrevista com técnicos do nível central. } \\
\text { - Entrevista com trabalhadores da saúde. }\end{array}$ \\
\hline
\end{tabular}




\begin{tabular}{|c|c|c|c|c|}
\hline Dimensões & Subdimensões & Critérios & Graduação & Base de evidências \\
\hline & $\begin{array}{l}\text { Adequação do } \\
\text { Quadro técnico } \\
\text { às necessidades } \\
\text { do sistema } \\
\text { municipal de } \\
\text { saúde. } \\
\text { Max. } 10 \text { pts. } \\
\text { Obs.: } \\
(\%)\end{array}$ & $\begin{array}{l}\text { a)Quadros técnicos qualificados por instituições de } \\
\text { saúde coletiva; ( } 04 \text { pts.) } \\
\text { b)Número adequado de profissionais por área de } \\
\text { atuação; ( } 03 \text { pts.) } \\
\text { c)Quadros técnicos qualificados em sua área de atuação. } \\
\text { (03 pts.) }\end{array}$ & $\begin{array}{l}(\quad) \text { Avançado: } \\
a+(b+c) \\
(\quad) \\
\text { Intermediário: a } \\
+(b \text { ou } c)\end{array}$ & $\begin{array}{l}\text { - Plano Municipal de Saúde. } \\
\text { - Relatório de Gestão } 1999-2000 . \\
\text { - Entrevista com gestor, trabalhadores de } \\
\text { saúde e técnicos nível central. }\end{array}$ \\
\hline & $\begin{array}{l}\text { Política de RH } \\
\text { Max. } 10 \text { pts. } \\
\text { Obs.: } \\
\left(\begin{array}{c}\%)\end{array}\right.\end{array}$ & $\begin{array}{l}\text { a) Plano de cargos e salários; ( } 3 \text { pts.) } \\
\text { b) Servidores contratados através de concurso público; } \\
\text { ( } 3 \text { pts.) } \\
\text { c) Servidores contratados através de seleção pública; } \\
\text { ( } 1 \text { pt.) } \\
\text { d) Incentivo à capacitação ligado à remuneração; } \\
\text { ( } 2 \text { pts.) } \\
\text { e) Iniciativas de capacitação sem vínculo com } \\
\text { remuneração. ( } 1 \text { pt.) }\end{array}$ & $\begin{array}{l}\text { ( )Avançado: } \\
\text { todos } \\
(\quad) \\
\text { Intermediário: } \\
\text { pelo menos três }\end{array}$ & $\begin{array}{l}\text { - Plano Municipal de Saúde. } \\
\text { - Relatório de Gestão } 1999 \text {-2000. } \\
\text { - Entrevistas com gestor, trabalhadores de } \\
\text { saúde e técnicos nível central. }\end{array}$ \\
\hline
\end{tabular}


NÍVEL 1- CONTEXTO POLÍTICO (100 pontos)

(continuação)

\begin{tabular}{|c|c|c|c|c|}
\hline Dimensões & Subdimensões & Critérios & Graduação & Base de evidências \\
\hline $\begin{array}{l}1.3- \\
\text { Governabi- } \\
\text { lidade. } \\
\text { Max. } 35 \\
\text { pts. } \\
\text { Obs.: } \\
(\quad \%)\end{array}$ & $\begin{array}{l}\text { Base de apoio } \\
\text { político. } \\
\text { Max. } 9 \text { pts. } \\
\text { Obs.: } \\
(\quad \%)\end{array}$ & $\begin{array}{l}\text { a) Maioria na câmara de vereadores; (04 pts.) } \\
\text { b) Apoio da sociedade civil organizada; ( } 05 \text { pts.) }\end{array}$ & $\begin{array}{l}\text { ( ) Avançado: } \\
a+b \\
(\quad) \\
\text { Intermediário: a } \\
\text { ou b }\end{array}$ & $\begin{array}{l}\text { - Entrevista com gestor. } \\
\text { - Entrevista com representante dos } \\
\text { usuários ou representante dos } \\
\text { prestadores de serviço no Conselho } \\
\text { Municipal de Saúde. }\end{array}$ \\
\hline
\end{tabular}


NÍVEL 1- CONTEXTO POLÍTICO (100 pontos) (continuação)

\begin{tabular}{|c|c|c|c|c|}
\hline Dimensões & Subdimensões & Critérios & Graduação & Base de evidências \\
\hline & $\begin{array}{l}\text { Autonomia } \\
\text { financeira } \\
\text { Max. } 9 \text { pts. } \\
\text { Obs.: } \\
(\%)\end{array}$ & $\begin{array}{l}\text { a) Secretário com autonomia para utilização dos } \\
\text { recursos municipais; ( } 05 \text { pts.) } \\
\text { b) Comissão da SMS para realizar os processos } \\
\text { licitatórios; (02 pts.) } \\
\text { c) Existência de um profissional responsável pela parte } \\
\text { financeira do FMS. (02 pts.) }\end{array}$ & $\begin{array}{l}\text { ( ) Avançado: } \\
a+b+c \\
(\quad) \\
\text { Intermediário: a } \\
+ \text { (b ou c) }\end{array}$ & $\begin{array}{l}\text { - Entrevistas com gestor e técnicos nível } \\
\text { central. }\end{array}$ \\
\hline & $\begin{array}{l}\text { Relacionamento } \\
\text { entre gestores } \\
\text { para definição e } \\
\text { implementação } \\
\text { de políticas. } \\
\text { Max. } 9 \text { pts. } \\
\text { Obs.: } \\
(\quad \%)\end{array}$ & $\begin{array}{l}\text { a) Realização de propostas inovadoras; (05 pts.) } \\
\text { b) Município propositivo, nos espaços de negociação; (03 } \\
\text { pts.) } \\
\text { c) Participação nos órgãos colegiados do SUS. (01 pt.) }\end{array}$ & $\begin{array}{l}\text { ( ) Avançado: } \\
a+b+c \\
(\text { ) } \\
\text { Intermediário: a } \\
+ \text { (b ou c) }\end{array}$ & $\begin{array}{l}\text { - Entrevistas com gestor e técnicos nível } \\
\text { central de áreas específicas como a } \\
\text { vigilância epidemiológica. }\end{array}$ \\
\hline & $\begin{array}{l}\text { Adesão dos } \\
\text { agentes das } \\
\text { práticas. } \\
\text { Max. } 08 \text { pts. } \\
\text { Obs.: } \\
\text { ( \%) }\end{array}$ & $\begin{array}{l}\text { a)Profissionais sentem-se participantes do processo de } \\
\text { gestão; ( } 04 \text { pts.) } \\
\text { b)Profissionais sentem-se satisfeitos com o seu trabalho e } \\
\text { prazer em desenvolvê-lo. ( } 04 \text { pts.) }\end{array}$ & $\begin{array}{l}\text { ( ) Avançado: } \\
a+b \\
(\quad) \\
\text { Intermediário: } b\end{array}$ & $\begin{array}{l}\text { - Entrevista com trabalhadores de saúde. } \\
\text { - Entrevista com técnicos nível central. }\end{array}$ \\
\hline
\end{tabular}


NÍVEL 2 - GESTÃO DO SISTEMA (100 pontos)

\begin{tabular}{|c|c|c|c|c|}
\hline Dimensões & Subdimensões & Critérios & Graduação & Evidências \\
\hline $\begin{array}{l}2.1- \\
\text { Planeja- } \\
\text { mento e } \\
\text { Avaliação } \\
\text { Max. } 20 \\
\text { pts. }\end{array}$ & $\begin{array}{l}\text { Características do } \\
\text { planejamento. } \\
\text { Max. } 10 \text { pts. } \\
\text { Obs.: } \\
(\%)\end{array}$ & $\begin{array}{l}\text { a) Práticas de planejamento situacional } \\
\text { local em saúde; ( } 05 \text { pts.) } \\
\text { b) O planejamento é regular e usado } \\
\text { como instrumento de gestão; (04 pts.) } \\
\text { c) O planejamento é normativo. (01 pt.) }\end{array}$ & $\begin{array}{l}\text { ( ) Avançado: } \\
\text { a }+ \text { b } \\
\text { ( ) Intermediário: b }\end{array}$ & $\begin{array}{l}\text { - Entrevistas com gestor. } \\
\text { - Entrevistas com técnicos nível central. } \\
\text { - Entrevistas com trabalhadores de saúde. }\end{array}$ \\
\hline $\begin{array}{l}\text { Obs.: } \\
\text { (\%) }\end{array}$ & $\begin{array}{l}\text { Institucionaliza- } \\
\text { ção da Avaliação } \\
\text { Max. } 10 \text { pts. } \\
\text { Obs: pts. } \\
(\quad \%)\end{array}$ & $\begin{array}{l}\text { a) Existem responsáveis que realizam } \\
\text { regularmente a avaliação e o produto é } \\
\text { usado na tomada de decisões; (05 pts.) } \\
\text { b) Os gestores e técnicos utilizam dados } \\
\text { dos sistemas de informação oficiais na } \\
\text { monitorização e outras avaliações } \\
\text { pontuais. } \\
\text { (05 pts.) }\end{array}$ & $\begin{array}{l}\text { ( ) Avançado: } \\
a+b \\
\text { ( ) Intermediário: b }\end{array}$ & $\begin{array}{l}\text { - } \quad \text { Plano Municipal de Saúde 1998-2001. } \\
\text { - Entrios de campo. } \\
\text { central. }\end{array}$ \\
\hline $\begin{array}{l}2.2 \\
\text { Organiza- } \\
\text { ção do } \\
\text { Sistema } \\
\text { Max. } 56 \\
\text { pts. } \\
\text { Obs.: } \\
\text { (\%) }\end{array}$ & $\begin{array}{l}\text { Relação público- } \\
\text { privado. } \\
\text { Max. } 10 \text { pts. } \\
\text { Obs.: } \\
\text { ( \%) }\end{array}$ & $\begin{array}{l}\text { a) Ações de média e alta complexidade } \\
\text { geridas pelo setor público; (04 pts.) } \\
\text { b) Existência de serviços públicos de } \\
\text { referência para regulação da oferta; (03 } \\
\text { pts.) } \\
\text { c) Ações de média e alta complexidade } \\
\text { referenciada para o setor privado } \\
\text { contratado e conveniado. (03 pts.) }\end{array}$ & $\begin{array}{l}\text { ( ) Avançado: } \\
a+b+c \\
(\quad) \text { Intermediário: } \\
a+\text { (b ou c) }\end{array}$ & $\begin{array}{l}\text { - } \quad \text { Relatório de Gestão } 1999 \text { e } 2000 . \\
\text { - } \quad \text { Entrevista com usuários. } \\
\text { - Entrevistas com trabalhadores de saúde. } \\
\text { - Entrevistas com gestor. }\end{array}$ \\
\hline
\end{tabular}




\begin{tabular}{|c|c|c|c|c|}
\hline \multirow[t]{2}{*}{ Dimensões } & Subdimensões & Critérios & Graduação & Evidências \\
\hline & $\begin{array}{l}\text { Adequação da } \\
\text { oferta às } \\
\text { necessidades da } \\
\text { população. } \\
\text { Max. } 10 \text { pts. } \\
\text { Obs.: } \\
\text { ( \%) }\end{array}$ & $\begin{array}{l}\text { a)Incorporação de ações programáticas } \\
\text { de saúde e oferta de serviços adequada } \\
\text { ao perfil epidemiológico e social; (6 pts.) } \\
\text { b)Incorporação de ações programáticas } \\
\text { exclusivamente dos programas definidos } \\
\text { pelo nível federal e oferta de serviços } \\
\text { sem relação com o perfil epidemiológico } \\
\text { (atendimento prioritário da demanda } \\
\text { espontânea). (4 pts.) }\end{array}$ & $\begin{array}{l}\text { ( ) Avançado: a } \\
\text { ( ) Intermediário: b }\end{array}$ & $\begin{array}{l}\text { - Entrevista com trabalhadores de saúde. } \\
\text { - Entrevista com usuários. } \\
\text { - } \quad \text { Trajetória dos traçadores. } \\
\text { - Entrotório de Gestão } 1999 \text { e } 2000 .\end{array}$ \\
\hline & $\begin{array}{l}\text { Acesso. } \\
\text { Max. } 12 \text { pts. } \\
\text { Obs.: } \\
(\%)\end{array}$ & $\begin{array}{l}\text { a) Melhoria da acessibilidade com } \\
\text { sistema de marcação de consultas, } \\
\text { incluindo serviços de diferente } \\
\text { complexidade e internação, com } \\
\text { sistema de referência e central de } \\
\text { vagas; (6 pts.) } \\
\text { b) Proporção de população adscrita na } \\
\text { rede básica; (3 pts.) } \\
\text { c) Acessibilidade geográfica } \\
\text { (localização de unidades + sistemas } \\
\text { de comunicação e transporte). } \\
\text { (3 pts.) }\end{array}$ & $\begin{array}{l}\text { ( ) Avançado: } \\
a+b+c \\
(\text { ) Intermediário: } \\
a+(\text { b ou } c)\end{array}$ & $\begin{array}{l}\text { - Entrevistas com Gestor, Trabalhadores de } \\
\text { saúde e usuários. } \\
\text { - Relatório de gestão } 2000 \text { (ver mapa de } \\
\text { localização das unidades básicas). } \\
\text { - Dados secundários de cobertura do PACS e } \\
\text { PSF } 1998 \text { e } 2000 \text { e alguns indicadores } \\
\text { selecionados como cobertura do pré-natal e } \\
\text { vacinação. }\end{array}$ \\
\hline
\end{tabular}


NÍVEL 2 - GESTÃO DO SISTEMA (100 pontos)

(continuação)

\begin{tabular}{|c|c|c|c|c|}
\hline Dimensões & Subdimensões & Critérios & Graduação & Evidências \\
\hline & $\begin{array}{l}\text { Cobertura } \\
\text { assistencial. } \\
\text { Max. } 12 \text { pts. } \\
\text { Obs.: } \\
(\quad \%)\end{array}$ & $\begin{array}{l}\text { a)Ampliação da cobertura assistencial } \\
\text { real (utilização de serviços); (6 pts.) } \\
\text { b)Ampliação da cobertura assistencial } \\
\text { potencial (oferta de serviços). (6 pts.) }\end{array}$ & $\begin{array}{l}\text { ( ) Avançado: } \\
a+b \\
\text { ( ) Intermediário: b }\end{array}$ & $\begin{array}{l}\text { - } \quad \text { Relatório de gestão } 1999 \text { e } 2000 . \\
\text { Dados secundários de Produção } \\
\text { ambulatorial (quantidade aprovada e } \\
\text { solicitada) da atenção básica por tipo de } \\
\text { prestador no sistema de Informação } \\
\text { ambulatorial (SIA-SUS). }\end{array}$ \\
\hline & $\begin{array}{l}\text { Organização e } \\
\text { integração da } \\
\text { rede de serviços } \\
\text { em uma lógica } \\
\text { hierarquizada e } \\
\text { regionalizada. } \\
\text { Max. } 12 \text { pts. } \\
\text { Obs.: } \\
(\%)\end{array}$ & $\begin{array}{l}\text { a)Município corresponde à qualificação } \\
\text { dada pelo nível federal (NOAS 2001) } \\
\text { como sede de um módulo assistencial } \\
\text { ou pólo de uma microrregião; (5 pts.) } \\
\text { b)Presença de referência-contra } \\
\text { referência com fluxo formalizado e } \\
\text { registro de atendimento e controle de } \\
\text { pacientes. ( } 7 \text { pts.) }\end{array}$ & $\begin{array}{l}\text { ( ) Avançado: } \\
\mathrm{a}+\mathrm{b} \\
\text { ( ) Intermediário: b }\end{array}$ & $\begin{array}{l}\text { - } \quad \text { Mapa da micro-região. } \\
\text { - } \quad \text { Entrevista com gestor. } \\
\text { - } \quad \text { Diário de campo. }\end{array}$ \\
\hline
\end{tabular}


NÍVEL 2 - GESTÃO DO SISTEMA (100 pontos)

(continuação)

\begin{tabular}{|c|c|c|c|c|}
\hline Dimensões & Subdimensões & Critérios & Graduação & Evidências \\
\hline $\begin{array}{l}2.3- \\
\text { Participaçã } \\
\text { o popular e } \\
\text { controle } \\
\text { social. } \\
\text { Max. } 24 \\
\text { pts. } \\
\text { Obs.: } \\
(\%)\end{array}$ & $\begin{array}{l}\text { Participação da } \\
\text { sociedade nas } \\
\text { decisões sobre a } \\
\text { política de saúde. } \\
\text { Max. } 24 \text { pts. } \\
\text { Obs.: } \\
\text { ( } \%)\end{array}$ & $\begin{array}{l}\text { a)Presença de Conselho Municipal } \\
\text { representativo, propositivo e atuante } \\
\text { (controle da aplicação de recurso e } \\
\text { funcionamento regular); ( } 8 \text { pts.) } \\
\text { b)Convocação de Conferências } \\
\text { Municipais sobre a política de saúde; } \\
\text { (4 pts.) } \\
\text { c)Componentes dos Conselhos } \\
\text { Municipal e Locais de saúde foram } \\
\text { capacitados adequadamente para o } \\
\text { exercício da função; ( } 8 \text { pts.) } \\
\text { d)Existência de conselhos locais de } \\
\text { saúde atuantes e com funcionamento } \\
\text { regular. (4 pts.) }\end{array}$ & $\begin{array}{l}\text { ( ) Avançado: } \\
\mathbf{a}+\mathbf{b}+\mathbf{c}+\mathbf{d} \\
\left(\begin{array}{l}\text { ) Intermediário: } \\
a+(b \text { ou c ou } d)\end{array}\right.\end{array}$ & $\begin{array}{l}\text { - } \quad \text { Relatório de Gestão } 1999 \text { e } 2000 . \\
\text { - } \text { no CMS.revista com representante dos usuários } \\
\text { - Entrevistas com trabalhadores de saúde. } \\
\text { - Entrevista com gestor. }\end{array}$ \\
\hline
\end{tabular}


NÍVEL 3 - PRÁTICAS ASSISTENCIAIS²

\begin{tabular}{|c|c|c|c|c|}
\hline Dimensões & Sub-dimensões & Critérios & Graduação & Evidências \\
\hline \multirow[t]{2}{*}{$\begin{array}{l}3.1- \\
\text { Integralida- } \\
\text { de das } \\
\text { ações } \\
\text { Max. } 55 \\
\text { pts. } \\
\text { Obs.: } \\
(\%)\end{array}$} & $\begin{array}{l}\text { Ações de } \\
\text { promoção da } \\
\text { saúde. } \\
\text { Max. } 13 \text { pts. } \\
\text { Obs.: } \\
(\%)\end{array}$ & $\begin{array}{l}\text { a) Existência de ações intersetoriais } \\
\text { voltadas para os problemas priorizados } \\
\text { no território; ( } 7 \text { pts.) } \\
\text { b)Incorporação de tecnologias de } \\
\text { comunicação social. (6 pts.) }\end{array}$ & $\begin{array}{l}\text { ( ) Avançado: } \\
a+b \\
(\quad) \text { Intermediário: } \\
\text { a ou b }\end{array}$ & $\begin{array}{l}\text { - Entrevistas com gestor, trabalhadores de } \\
\text { saúde e usuários. } \\
\text { - Trajetória dos traçadores. }\end{array}$ \\
\hline & $\begin{array}{l}\text { Ações de } \\
\text { Vigilância de } \\
\text { riscos e danos à } \\
\text { saúde } \\
\text { Max. } 12 \text { pts } \\
\text { Obs: } \\
\text { ( \%) }\end{array}$ & $\begin{array}{l}\text { a)Utilização dos dados dos sistemas de } \\
\text { informação para monitoramento da } \\
\text { situação de saúde e tomada de decisões } \\
\text { no nível local; ( } 6 \text { pts.) } \\
\text { b)Estruturação de um sistema de } \\
\text { vigilância da saúde com } \\
\text { integração/articulação entre as ações de } \\
\text { VE e VISA. (6 } 6 \text { pts.) }\end{array}$ & $\begin{array}{l}\text { ( ) Avançado: } \\
a+b \\
(\quad) \text { Intermediário: } \\
\text { a ou b }\end{array}$ & $\begin{array}{l}\text { - Entrevistas com gestor e técnicos nível } \\
\text { central das áreas específicas. } \\
\text { - Entrevistas com trabalhadores de saúde. }\end{array}$ \\
\hline
\end{tabular}

${ }^{2} \mathrm{~A}$ análise dos níveis de 3 e 4 serão complementados com patologias traçadoras - tuberculose, hipertensão e MI em menores de 5 anos- associando ainda itinerários terapêuticos ou trajetória de cuidados: "conjunto de contatos do paciente com o sistema assistencial situados no tempo (datas) , caracterizados pelos profissionais envolvido nas diversas estruturas e pelo conjuntos de bens e serviços prestados (natureza e volume)". CREDES (Centre de Recherche d'Etude e de Documentation em Economie de la Santé), Bulletin n $37,2001$. 
NÍVEL 3 - PRÁTICAS ASSISTENCIAIS

(continuação)

\begin{tabular}{|c|c|c|c|c|}
\hline Dimensões & Subdimensões & Critérios & Graduação & Evidências \\
\hline & $\begin{array}{l}\text { Articulação dos } \\
\text { níveis de } \\
\text { prevenção, } \\
\text { recuperação e } \\
\text { reabilitação da } \\
\text { saúde e de } \\
\text { controle dos } \\
\text { problemas de } \\
\text { saúde locais. } \\
\text { Max. } 12 \text { pts. } \\
\text { Obs.: } \\
(\quad \%)\end{array}$ & $\begin{array}{l}\text { a)Existência de estratégias do } \\
\text { diagnóstico precoce e prevenção pelo } \\
\text { menos para grupos de risco da } \\
\text { hipertensão arterial; (4 pts.) } \\
\text { b)Integração dos níveis de prevenção, } \\
\text { recuperação e reabilitação para os } \\
\text { agravos/problemas priorizados em cada } \\
\text { município; (4 pts.) } \\
\text { c)Coerência entre as ações de prevenção } \\
\text { e controle (ações sobre os riscos) } \\
\text { realizadas e os problemas priorizados. } \\
\text { (4 pts.) }\end{array}$ & $\begin{array}{l}\text { ( ) Avançado: } \\
a+b+c \\
(\quad) \text { Intermediário: } \\
a+(\text { b ou } c)\end{array}$ & $\begin{array}{l}\text { - Entrevistas com usuários de ambas as } \\
\text { - ENIDADES de observação. } \\
\text { - } \quad \text { Trajetrevista com profissionais de saúde. } \\
\text { Arterial, DCV, Diarréia e IRA. }\end{array}$ \\
\hline
\end{tabular}


NÍVEL 3 - PRÁTICAS ASSISTENCIAIS

(continuação)

\begin{tabular}{|c|c|c|c|c|}
\hline Dimensões & Subdimensões & Critérios & Graduação & Evidências \\
\hline & $\begin{array}{l}\text { Assistência } \\
\text { Farmacêutica. } \\
\text { Max. } 12 \text { pts. } \\
\text { Obs.: } \\
(\text { \%) }\end{array}$ & $\begin{array}{l}\text { a)Disponibilidade de medicamentos para } \\
\text { doenças de maior prevalência e/ou } \\
\text { gravidade/custo; ( } 6 \text { pts.) } \\
\text { b)Desenvolvimento de ações de } \\
\text { promoção do uso racional de } \\
\text { medicamentos. ( } 6 \text { pts.) }\end{array}$ & $\begin{array}{l}\text { ( ) Avançado: } \\
a+b \\
\text { ( ) Intermediário: } \\
\text { a ou b }\end{array}$ & $\begin{array}{l}\text { - Entrevistas com usuários e trabalhadores de } \\
\text { saúde. } \\
\text { - Diário de campo. }\end{array}$ \\
\hline & $\begin{array}{l}\text { Atenção à saúde } \\
\text { bucal. } \\
\text { Max. } 6 \text { pts. } \\
\text { Obs.: } \\
\left(\begin{array}{l}\%)\end{array}\right.\end{array}$ & $\begin{array}{l}\text { a)Programação e intervenção sobre os } \\
\text { problemas relacionados com a saúde } \\
\text { bucal a partir do perfil epidemiológico; } \\
\text { ( } 3 \text { pts.) } \\
\text { b)Ênfase nas ações preventivas e } \\
\text { coletivas; ( } 2 \text { pts.) } \\
\text { c)Disponibilidade de atendimento } \\
\text { restaurador. ( } 1 \text { pt.) }\end{array}$ & $\begin{array}{l}\text { ( ) Avançado: } \\
a+b+c \\
(\quad) \\
\text { Intermediário: } \\
b+c\end{array}$ & $\begin{array}{l}\text { - Entrevista com técnico nível central. } \\
\text { - } \quad \text { Dadrevista com cirurgião-dentista. } \\
\text { odontológica no município entre 1994- } \\
2001 \text { no SAI-SUS. } \\
\text { - Diário de Campo. }\end{array}$ \\
\hline
\end{tabular}




\begin{tabular}{|c|c|c|c|c|}
\hline & Cubdimñ̃ & (continuaçaoo) & & \\
\hline Dimensões & Subdimensōes & Critérios & Graduação & Evidências \\
\hline \multirow[t]{2}{*}{$\begin{array}{l}\text { 3.2- } \\
\text { Abordagem } \\
\text { integral } \\
\text { (cuidado } \\
\text { completo e } \\
\text { contínuo) } \\
\text { Max. } 45 \\
\text { pts. } \\
\begin{array}{l}\text { Obs.: } \\
(\quad \%)\end{array}\end{array}$} & $\begin{array}{l}\text { Protocolos de } \\
\text { atenção para } \\
\text { agravos } \\
\text { específicos } \\
\text { priorizados. } \\
\text { Max. } 15 \text { pts. } \\
\text { Obs.: } \\
\text { ( \%) }\end{array}$ & $\begin{array}{l}\text { a)Elaboração de protocolos específicos de } \\
\text { nível local; (8 pts.) } \\
\text { b)Utilização sistemática dos protocolos de } \\
\text { atenção para agravos de prioridade } \\
\text { estadual/nacional. (7 pts.) }\end{array}$ & $\begin{array}{l}(\quad) \text { Avançado: } \\
a+b \\
(\quad) \text { Intermediário: } \\
\text { a ou b }\end{array}$ & $\begin{array}{l}\text { - Entrevista com técnico nível central e } \\
\text { trabalhadores de saúde. } \\
\text { - Trajetória dos traçadores. }\end{array}$ \\
\hline & $\begin{array}{l}\text { Estratégias de } \\
\text { acolhimento. } \\
\text { Max. } 15 \text { pts. } \\
\text { Obs.: } \\
\text { ( } \%)\end{array}$ & $\begin{array}{l}\text { a)Instalações físicas com } \\
\text { conforto mínimo (bancos e cadeiras } \\
\text { suficientes, área coberta com acesso a } \\
\text { banheiros e água potável e garantia a } \\
\text { privacidade do atendimento); ( } 7 \text { pts.) } \\
\text { b)Utilização de diálogo e flexibilidade na } \\
\text { rotina da rede de serviços; (4 pts.) } \\
\text { c)Triagem realizada por profissional de } \\
\text { saúde. (4 pts.) }\end{array}$ & $\begin{array}{l}\text { ( ) Avançado: } \\
a+b+c \\
(\quad) \text { Intermediário: } \\
a+(b \text { ou } c)\end{array}$ & $\begin{array}{l}\text { - Entrevistas com trabalhadores de saúde e } \\
\text { usuários de ambas as UNIDADES DE } \\
\text { OBSERVAÇÃO. } \\
\text { - Observação da UNIDADE. }\end{array}$ \\
\hline
\end{tabular}


NÍVEL 3 - PRÁTICAS ASSISTENCIAIS

(continuação)

\begin{tabular}{|c|c|c|c|c|}
\hline Dimensões & Subdimensões & Critérios & Graduação & Evidências \\
\hline & $\begin{array}{l}\text { Práticas com } \\
\text { equipes multi- } \\
\text { disciplinares. } \\
\text { Max. } 15 \text { pts. } \\
\text { Obs.: } \\
\text { ( \%) }\end{array}$ & $\begin{array}{l}\text { a)Atividades de grupo (terapêuticos, } \\
\text { preventivos, e educativos); (5 pts.) } \\
\text { b)Projetos terapêuticos integrados e } \\
\text { centrados no usuário; (5 pts.) } \\
\text { c) Utilização de protocolos nas atividades } \\
\text { realizadas pela equipe. (5 pts.) }\end{array}$ & $\begin{array}{l}\text { ( ) Avançado: } \\
a+b+c \\
(\quad) \text { Intermediário: } \\
a+(b \text { ou } c)\end{array}$ & $\begin{array}{l}\text { - Entrevista com trabalhador de saúde. } \\
\text { - Entrevista com usuário. } \\
\text { - Diário de campo. }\end{array}$ \\
\hline
\end{tabular}


NÍVEL 4- EFETIVIDADE DAS PRÁTICAS

\begin{tabular}{|c|c|c|c|c|}
\hline Dimensões & Subdimensões & Critérios & Graduação & Evidências \\
\hline $\begin{array}{l}4.1 \text {-Efeitos } \\
\text { relacionados à } \\
\text { saúde. } \\
\text { Max. } 70 \text { pts. } \\
\text { Obs.: } \\
\text { ( \%) }\end{array}$ & $\begin{array}{l}\begin{array}{l}\text { Evolução da } \\
\text { mortalidade } \\
\text { infantil. }\end{array} \\
10 \text { pts. } \\
\text { Obs.: } \\
(\%)\end{array}$ & $\begin{array}{l}\text { a)Redução na mortalidade infantil e de } \\
\text { proporção de óbitos evitáveis na série } \\
\text { histórica analisada; ( } 6 \text { pts). } \\
3 \text { pts. - redução na mortalidade infantil } \\
3 \text { pts. - redução de óbitos evitáveis } \\
\text { b)Revisão de óbitos evitáveis pelo } \\
\text { comitê de M. Infantil; ( } 2 \text { pts.) } \\
\text { c)Busca ativa e investigação de óbitos } \\
\text { infantis. ( } 2 \text { pts.) }\end{array}$ & $\begin{array}{l}\text { ( ) Avançado: } \\
a+b+c \\
(\quad) \text { Intermediário: } \\
a+(b \text { ou } c)\end{array}$ & $\begin{array}{l}\text { - Série histórica da TMI e da proporção } \\
\text { de óbitos evitáveis no período de } \\
\text { 1980-1999. } \\
\text { - Entrevista com gestor. } \\
\text { - Entrevista com técnicos nível central. }\end{array}$ \\
\hline
\end{tabular}


NÍVEL 4- EFETIVIDADE DAS PRÁTICAS

(continuação)

\begin{tabular}{|c|c|c|c|c|}
\hline Dimensões & Subdimensões & Critérios & Graduação & Evidências \\
\hline & $\begin{array}{l}\text { Evolução dos } \\
\text { agravos } \\
\text { traçadores }\end{array}$ & $\begin{array}{l}\text { a)Redução na mortalidade }{ }^{4} \text { (em } \\
\text { percentagem) maior que a redução } \\
\text { do estrato na série histórica } \\
\text { analisada para a diarréia; (7 pts.) } \\
\text { b)Redução na morbidade (em } \\
\text { percentagem) maior que a redução } \\
\text { do estrato na série histórica } \\
\text { analisada para a diarréia; ( } 8 \text { pts.) } \\
\text { c)Redução na mortalidade (em } \\
\text { percentagem) maior que a redução } \\
\text { do estrato na série histórica } \\
\text { analisada para a IRA; ( } 7 \text { pts.) } \\
\text { d)Redução na morbidade(em } \\
\text { percentagem) maior que a redução } \\
\text { do estrato na série histórica } \\
\text { analisada para a IRA (8 pts.) }\end{array}$ & $\begin{array}{l}\text { ( ) Avançado: } \\
\text { a + b } \\
\text { ( ) Intermediário: } \\
\text { a ou b } \\
\text { ( ) Avançado: } \\
\text { c+ d } \\
\text { ( ) Intermediário: } \\
\text { c ou d }\end{array}$ & $\begin{array}{l}\text { - Série histórica do coeficiente de } \\
\text { mortalidade por diarréia em menores } \\
\text { de um ano entre } 1980 \text { e } 1999 . \\
\\
\text { - Série histórica de internação } \\
\text { hospitalar por diarréia em menores de } \\
\text { um ano entre } 1995 \text { e } 2002 \text {. } \\
\text { - Série histórica do coeficiente de } \\
\text { mortalidade por IRA entre } 1980 \text { e } \\
1999 . \\
\text { - Série histórica de internação } \\
\text { hospitalar por IRA em menores de um } \\
\text { ano entre } 1995 \text { e } 2002 \text {. }\end{array}$ \\
\hline
\end{tabular}

${ }^{3}$ Para morbidade e mortalidade, critérios de pontuação: Na redução:

Acima do estrato: 7 ou 8 pontos,

No aumento:

Acima de $66,6 \%$ do estrato: 4 ou 5 pontos,

Entre 33,3\% e 66,6 do estrato: 3 ou 4 pontos,

Abaixo de $33,3 \%$ do estrato: 2 ou 3 pontos,

cima do estrato: 0 pontos,

Acima de $66,6 \%$ do estrato: 1 ou 2 pontos,

Entre $33,3 \%$ e 66,6 do estrato: 2 ou 3 pontos,

Abaixo de $33,3 \%$ do estrato: 3 ou 4 pontos,

Nenhuma redução: zero ponto

Redução no município e aumento no estrato: 7 ou 8 pontos

${ }^{4}$ Morbidade (internação hospitalar) - Há pontuação progressiva se a redução na internação hospitalar no município for maior que a redução do estrato na série histórica analisada ou aumento menor que no estrato.

${ }^{5}$ Pontuação progressiva se a mortalidade por agravo for maior que a redução do estrato na série histórica analisada ou aumento menor que no estrato. A análise é feita pela variação das médias por quinquênios. 
NÍVEL 4- EFETIVIDADE DAS PRÁTICAS

(continuação)

\begin{tabular}{|c|c|c|c|c|}
\hline Dimensões & Subdimensões & Critérios & Graduação & Evidências \\
\hline & & $\begin{array}{l}\text { e)Redução na mortalidade (em } \\
\text { percentagem) maior que a redução do } \\
\text { estrato na série histórica analisada } \\
\text { para a DCV; (7 pts.) } \\
\text { f) Redução na morbidade (em } \\
\text { percentagem) maior que a redução do } \\
\text { estrato na série histórica analisada } \\
\text { para a Hipertensão Arterial; (8 pts.) } \\
\text { g)Redução na mortalidade (em } \\
\text { percentagem)maior que a redução do } \\
\text { estrato na série histórica analisada } \\
\text { para a tuberculose; (7 pts.) } \\
\text { h)Redução na morbidade (em } \\
\text { percentagem)maior que a redução do } \\
\text { estrato na série histórica analisada } \\
\text { para a tuberculose. (8 pts.) }\end{array}$ & $\begin{array}{l}\text { ( ) Avançado: } \\
\text { e }+f \\
\text { ( ) Intermediário: } \\
\text { e ou } f \\
\text { ( ) Avançado: } \\
g+h \\
\text { ( ) Intermediário: } \\
g \text { ou h }\end{array}$ & $\begin{array}{l}\text { - Série histórica do coeficiente de } \\
\text { mortalidade por doença cérebro } \\
\text { vascular entre } 1980 \text { e } 1999 . \\
\text { - Série histórica de internação } \\
\text { hospitalar por hipertensão arterial entre } \\
1995 \text { e } 2002 . \\
\text { - Série histórica do coeficiente de } \\
\text { mortalidade por tuberculose entre } \\
1980 \text { e } 1999 . \\
\text { - Série histórica de internação } \\
\text { hospitalar por tuberculose entre } 1995 \\
\text { e } 2002 \text {. }\end{array}$ \\
\hline
\end{tabular}


NÍVEL 4- EFETIVIDADE DAS PRÁTICAS

(continuação)

\begin{tabular}{|c|c|c|c|c|}
\hline Dimensões & Subdimensões & Critérios & Graduação & Evidências \\
\hline $\begin{array}{l}\text { 4.2-Satisfação } \\
\text { dos usuários. } \\
\text { Max. } 30 \text { pts. } \\
\text { Obs.: } \\
\left(\begin{array}{l}\%)\end{array}\right.\end{array}$ & $\begin{array}{l}\text { Percepção da } \\
\text { população. } \\
\text { Max. } 30 \text { pts. } \\
\text { Obs.: } \\
\left(\begin{array}{l}\%\end{array}\right)\end{array}$ & $\begin{array}{l}\text { a)Em relação às estratégias de } \\
\text { acolhimento aos usuários pela rede } \\
\text { de serviços (instalações físicas, } \\
\text { constituição de espaços de diálogo, } \\
\text { mecanismos de triagem); (6 pts.) } \\
\text { b)Em relação à resolução das } \\
\text { queixas na atenção básica; (6 pts.) } \\
\text { c)Em relação ao atendimento nas } \\
\text { especialidades; (6 pts.) } \\
\text { d)Em relação às ações preventivas } \\
\text { dos Agentes Comunitários de } \\
\text { Saúde; (6 pts.) } \\
\text { e) Em relação ao vínculo com a } \\
\text { equipe e profissionais das unidades } \\
\text { de saúde. (6 pts.) }\end{array}$ & $\begin{array}{l}\text { ( ) Avançado: } \\
\mathbf{a}+\mathbf{b}+\mathbf{c}+\mathbf{d}+\mathbf{e} \\
(\quad) \text { Intermediário: } 3 \\
\text { ou } 4 \text { critérios positivos }\end{array}$ & $\begin{array}{l}\text { - } \quad \text { entrevista com usuários das } \\
\text { unidades de observação. } \\
\text { - } \quad \text { entrevista com trabalhadores de } \\
\text { saúde. } \\
\text { - } \quad \text { trajetória dos traçadores. }\end{array}$ \\
\hline
\end{tabular}


Tabela 2

Escores obtidos (n e \%) no MUNICÍPIO A em relação aos valores da Matriz de Implantação para avaliação da gestão descentralizada do SUS

\begin{tabular}{|c|c|c|c|c|c|c|c|}
\hline Dimensões & Pontos máximos & Pontos obtidos & $\%$ & Sub-dimensões & Pontos máximos & Pontos obtidos & $\%$ \\
\hline & & & & Plano de governo & 11 & 6 & 54,5 \\
\hline \multirow[t]{3}{*}{ Projeto de Governo } & 35 & 16 & 45,7 & Financiamento da saúde & 12 & 10 & 83,3 \\
\hline & & & & Iniciativas intersetoriais & 12 & 0 & 0,0 \\
\hline & & & & Perfil do gestor & 10 & 4 & 40,0 \\
\hline \multirow[t]{3}{*}{ Capacidade de governo } & 30 & 10 & 33,3 & Quadro técnico & 10 & 4 & 40,0 \\
\hline & & & & Política de RH & 10 & 2 & 20,0 \\
\hline & & & & Apoio político & 9 & 9 & 100,0 \\
\hline \multirow[t]{3}{*}{ Governabilidade } & 35 & 23 & 65,7 & Autonomia & 9 & 9 & 100,0 \\
\hline & & & & Relação entre gestores & 9 & 1 & 11,1 \\
\hline & & & & Adesão dos atores & 8 & 4 & 50,0 \\
\hline \multirow[t]{2}{*}{ Nível - Componentes de governo } & 100 & & & & 100 & 49 & 499,0 \\
\hline & & & & Características do Planejamento & 10 & 2 & 20,0 \\
\hline \multirow[t]{3}{*}{ Planejamento e Avaliação } & 20 & 2 & 10,0 & Institucionalização da Avaliação & 10 & 0 & 0,0 \\
\hline & & & & Relação público-privado & 10 & 3 & 30,0 \\
\hline & & & & Adequacao oferta & 10 & 4 & 40,0 \\
\hline \multirow[t]{3}{*}{ Organização do Sistema } & 56 & 28 & 50,0 & Acesso & 12 & 4 & 33,3 \\
\hline & & & & Cobertura & 12 & 12 & 100,0 \\
\hline & & & & Organização/integração & 12 & 5 & 41,7 \\
\hline Participação e Controle Social & 24 & 12 & 50,0 & Participação popular & 24 & 12 & 50,0 \\
\hline \multirow[t]{3}{*}{ Nível - Gestão da Saúde } & 100 & & & & 100 & 42 & $\overline{42,0}$ \\
\hline & & & & Ações de promoção da saúde & 13 & 0 & $\overline{0,0}$ \\
\hline & & & & Vigilância de riscos e danos & 12 & 5 & 41,7 \\
\hline \multirow[t]{4}{*}{ Integralidade ds Ações } & 55 & 19 & 34,5 & Articulacao entre niveis & 12 & 6 & 50,0 \\
\hline & & & & Assistência farmacêutica & 12 & 6 & 50,0 \\
\hline & & & & Saude bucal & 6 & 2 & 33,3 \\
\hline & & & & Protocolos & 15 & 1 & 6,7 \\
\hline \multirow[t]{2}{*}{ Abordagem Integral } & 45 & 8 & 17,8 & Acolhimento & 15 & 4 & 26,7 \\
\hline & & & & Práticas multiprofissionais & 15 & 3 & 20,0 \\
\hline
\end{tabular}




\begin{tabular}{|c|c|c|c|c|c|c|c|}
\hline Dimensões & Pontos máximos & Pontos obtidos & $\%$ & Șub-dimensões & Pontos máximos & Pontos obtidos & $\%$ \\
\hline Nível-Práticas Assistenciais & 100 & & & & 100 & 27 & 27,0 \\
\hline \multirow{9}{*}{ Efeitos na saúde } & \multirow{9}{*}{70} & \multirow{9}{*}{47} & \multirow{9}{*}{67,1} & Mortalidade Infantil & 10 & 6 & 60,0 \\
\hline & & & & Mortalidade Diarréia & 7 & 7 & 100,0 \\
\hline & & & & Morbidade Diarréia & 8 & 8 & 100,0 \\
\hline & & & & Mortalidade IRA & 7 & 4 & 57,1 \\
\hline & & & & Morbidade IRA & 8 & 3 & 37,5 \\
\hline & & & & Mortalidade DCV & 7 & 0 & 0,0 \\
\hline & & & & Morbidade Hipertensão & 8 & 4 & 50,0 \\
\hline & & & & Mortalidade Tuberculose & 7 & 7 & 100,0 \\
\hline & & & & Morbidade Tuberculose & 8 & 8 & 100,0 \\
\hline Satisfação do usuário & 30 & 12 & 40,0 & Percepção dos usuários & 30 & 12 & 40,0 \\
\hline Nível-Efetividade das práticas & 100 & & & & 100 & 59 & 59,0 \\
\hline TOTAL GERAL & 400 & & & & 400 & 177 & 44,3 \\
\hline
\end{tabular}

400

400

44,3 


\title{
UMA EXPERIÊNCIA DE INTEGRAÇÃO DOS ATENDIMENTOS MÉDICOS EM UMA ZONA RURAL: OS DESAFIOS DA IMPLANTAÇÃO'
}

\author{
Nassera Touati \\ André-Pierre Contandriopoulos \\ Jean Louis Denis \\ Rosario Rodriguez \\ Claude Sicotte \\ Hung Nguyen
}

\section{INTRODUÇÃO}

Há alguns anos, a integração dos serviços é um conceito que age como um mito racional (HATCHUEL, 1996) nos meios da saúde. Esperase, sobretudo, que esta integração melhore a eficiência (PROVAN; MILWARD, 1995) e a eficácia da prestação de serviço (ACKERMAN, 1992; SHORTELL e outros, 1993). Isto posto, uma grande confusão envolve esta noção de «integração» (DAVIES, 1999) e os desempenhos de tais sistemas suscitam numerosas questões (WALSTON e outros, 1996).

Quanto a nós, ficamos com a definição de Shortell e outros, de um sistema integrado, ou seja,

Um sistema de serviços de saúde e de serviços sociais integrados é uma rede de organizações interdependentes e coordenadas nos planos funcional, clínico e financeiro responsável pela saúde de uma população dada, à qual ele fornece um continum de serviços adaptados às necessidades desta população.

Definida sumariamente, a integração clínica corresponde aos meios empregados para melhorar a coordenação dos serviços clínicos. Estes meios 
podem ser de natureza organizacional (ex.: constituição de equipes multidisciplinares, de comitês clínicos), ou instrumental (ex.: divisão de protocolos clínicos). Quanto à integração funcional, ela tem a ver com o sistema de gerência e visa particularmente a coordenar as funções administrativas (gestão dos recursos humanos, gestão da qualidade, planejamento estratégico, articulação dos sistemas de informação para a tomada de decisão prioritariamente administrativa) e com o alinhamento de incentivos entre os diferentes níveis de atendimento (gestão financeira), inclusive as que estão relacionadas com o papel dos médicos.

O sistema de saúde do Quebec submetido, a exemplo de outros países, às pressões exercidas pela ação simultânea do desenvolvimento dos conhecimentos e das técnicas, do envelhecimento da população e da mundialização dos mercados financeiros (CONTANDRIOPOULOS, 2000), não escapa à onda de racionalização. Atualmente no Quebec, inúmeros projetos experimentais de integração dos serviços de saúde estão sendo instalados para que se possa justamente apreender os desafios da implantação desses sistemas e avaliar seus impactos em termos de melhoria da qualidade e da eficiência dos atendimentos.

Entre os projetos experimentais financiados pelos Fundos de Adaptação dos Serviços de Saúde (FASS), figura um projeto de integração dos serviços de saúde em zona rural. Este projeto parece-nos particularmente interessante pois, como veremos, ele visa uma integração dos atendimentos sobre uma base populacional, diferentemente de outros projetos, cujo alvo eram clientelas específicas. No âmbito deste artigo, nos propomos a resumir os principais ensinamentos dessa experiência. Esses ensinamentos, tirados essencialmente da análise das entrevistas com os atores chave deste projeto (27 entrevis$\operatorname{tas}^{2}$ ), da observação participante e não participante de reuniões de trabalho e da análise dos artefatos de mudança, ilustram perfeitamente a complexidade da instalação de um sistema integrado de atendimento.

Mais precisamente, este artigo que trata da avaliação da implantação ${ }^{3}$ (CHAMPAGNE; DENIS, 1992) está estruturado da maneira seguinte:

- em um primeiro momento, faremos a descrição do contexto da experimentação;

- em seguida, apresentaremos o modelo de intervenção, tal como planejado; 
- na etapa posterior, resumiremos os resultados obtidos, isto é, o modelo realizado;

- em um quarto momento, interpretaremos, colocando em evidência os fatores de sucesso e os obstáculos para a implantação, os progressos realizados, bem como as lacunas que ainda persistem;

- finalmente, como conclusão, iniciaremos uma discussão sobre a aplicação dessas transformações ao conjunto da rede de saúde.

\section{O CONTEXTO DA EXPERIMENTAÇÃO: AS FORÇAS E AS DIFICULDADES DO SISTEMA LOCAL DE ATENDIMENTO}

A experimentação em questão concerne uma região rural com 25000 habitantes, constituída por duas comunidades culturais relativamente separadas, de francófonos e de anglófonos. O sistema local de atendimento compreende:

- um hospital de curta permanência, com 49 leitos oferecendo principalmente serviços de medicina, de cirurgia geral, de geriatria e alguns serviços de diagnóstico, bem como serviços ambulatoriais.

- um Centro Local de Serviços Comunitários (CLSC) com um equivalente a 62,24 empregados com tempo integral e prestando serviços paramédicos, psico-sociais e alguns serviços médicos, sobretudo no âmbito do programa de saúde mental;

- um centro de atendimento de longa permanência (CHSLD) com 60 leitos divididos entre 53 leitos de ocupação permanente e 7 leitos de ocupação temporária;

- 15 médicos generalistas repartidos entre três clínicas médicas.

Embora a área seja relativamente "bem dotada» em recursos institucionais, inúmeros atores consideram que ela sofre de uma deficiência grave em serviços especializados (entre outros, em serviços de readaptação); o que, segundo eles, acaba prejudicando a continuidade do tratamento. A ausência de meios de transporte agrava o problema do acesso aos serviços de saúde, particularmente para a população mais idosa e para as pessoas de baixa renda. 
Por outro lado, cabe lembrar que a comunidade anglófona, ao contrário da comunidade francófona mais próxima do CLSC e do CHSLD, se identifica bastante, por razões históricas, com o hospital e contribui financeiramente para a oferta de serviços. Por este motivo, o hospital ocupa um lugar importante na organização dos serviços ; o que, para alguns atores, representa uma lacuna do sistema, pois este hospitalocentrismo penaliza a prevenção. Estes mesmos atores reconhecem uma capacidade ociosa do potencial dos serviços do CLSC na medida que o hospital poderia justamente servir melhor como referência e remeter-se a seu parceiro para os serviços ambulatoriais.

No que concerne mais especificamente à prática médica, devemos sublinhar que todos os médicos da região participam do Conselho dos Médicos, Dentistas e Farmacêuticos do hospital; o que, evidentemente, favorece a coordenação desses serviços. Além dos esforços de coordenação, os médicos da região têm uma prática médica polivalente, de tipo medicina familiar. Trabalhando simultaneamente em suas clínicas, no hospital e na emergência, eles assumem naturalmente o acompanhamento de sua clientela entre os diferentes atos. Os médicos se organizam igualmente para assegurar uma acessibilidade aos serviços médicos e isto durante as horas regulares (em certos casos, inclusive no início da noite e durante os fins de semana). Uma sondagem efetuada (CROP, 2000) no âmbito desta avaliação revelou que entre 70 e $75 \%$ da população se beneficia de um médico de família. Conforme podemos constatar, a área é relativamente bem aquinhoada por força de sua primeira linha de atendimento. Se a oferta de serviços médicos parece a priori satisfatória em seu conjunto, ela é julgada unanimemente como frágil. A impossibilidade de substitutos, a falta de recursos e a idade relativamente avançada dos médicos explicam este sentimento de fragilidade.

Resumindo, estamos diante de um contexto de experimentação que reúne as forças e as fragilidades seguintes: uma prática de medicina familiar, relações de trabalho cordiais entre os prestadores de atendimento, segundo as entrevistas (o que se traduz, por exemplo, por uma facilidade na comunicação), um engajamento da população com relação ao seu sistema de saúde mas, a contrario, uma falta de serviços de saúde de referência, problemas de recrutamento médico no funcionamento organizacional e profissional do Sistema Local de Saúde (apesar das relações amigáveis entre 
aqueles que prestam atendimento). Embora todos os atores tenham tido sempre a consciência destas forças e fragilidades, como a análise das entrevistas confirma, foi preciso esperar a ocorrência de circunstâncias excepcionais, que ameaçavam o status quo, para que o processo de mudança pudesse se iniciar.

As primeiras etapas do projeto datam de 1997-1998. Durante estes anos, o sistema de saúde quebequense teve que absorver compressões orçamentárias consideráveis para permitir à província equilibrar seu orçamento. Uma reestruturação da oferta de atendimento surgiu como a melhor maneira de rentabilizar estes recursos. Na municipalidade, o temor do fechamento do hospital deu origem a um projeto, iniciado pelo hospital, de fusão administrativa dos três estabelecimentos (o hospital, o CHSLD e o CLSC). Entretanto, a Regional não aceitou esta opção por causa da oposição feita pelo CLSC, que temia que os serviços hospitalares tomassem a dianteira no que diz respeito à primeira linha. Dentro das discussões sobre a reunião dos estabelecimentos, o CLSC havia, sobretudo, pensado em abrir um ponto de serviços nas dependências do hospital, com o objetivo de ser mais amplamente conhecido, de aumentar o número de referências e assegurar um continum de atendimentos mais completo em meio comunitário. No entanto, esses projetos não vingaram. Em situação de impasse, a implantação de um projeto experimental de integração dos serviços de saúde, financiado pelo Fundo para a adaptação dos serviços de saúde (FASS), que deveria escalonar-se de abril de 1999 a março de 2001, surgiu então como uma possibilidade de melhoria da oferta de serviços. Tanto mais que, nessa região, a primeira linha sempre ocupou um lugar de destaque e isto constituía um exemplo interessante para experimentar um novo modelo de integração de atendimentos (PRINGLE e outros, 2000; DEVERS e outros, 1994; DENIS e outros, 1999). Por força de seu interesse, vários atores foram mobilizados em torno deste projeto, tais como: o Regional, os conseIhos de administração dos estabelecimentos, os médicos da região, os gestores, os profissionais e uma equipe de pesquisadores do Gris, encarregada da avaliação. Convém mencionar que alguns membros da equipe de avaliação também tinham sido envolvidos no momento da elaboração do modelo de intervenção e, em certa medida, na pilotagem deste projeto.

A seção seguinte fornecerá mais detalhes sobre o modelo de intervenção planejado. 


\section{A INTERVENÇÃO: O MODELO PLANEJADO}

Conforme mencionamos anteriormente, a intervenção se afigurava como uma tentativa de integrar os serviços de saúde para o conjunto da população, baseando-se amplamente no papel da primeira linha. É graças, entre outros fatores, ao reforço do papel do médico de família, através do trabalho de colaboração com uma enfermeira como elemento de integração, que o tratamento global, contínuo e coordenado do usuário que enfrentava problemas de saúde diversos, tornou-se possível.

Conforme foi submetido ao FASS, o projeto de integração dos serviços previa duas fases de experimentação. A primeira fase consistia essencialmente na implantação dos componentes clínicos e administrativos do modelo. Um financiamento através de captação (per capita) deveria ser introduzido posteriormente a fim de criar um estímulo suplementar para a integração. Durante a primeira fase da experimentação, apesar do financiamento não ter sido ainda implantado enquanto tal, uma alocação financeira foi gradativamente introduzida a fim de vincular a utilização do orçamento do FASS à colaboração entre os estabelecimentos da Municipalidade e à criação de projetos comuns.

A partir de agora, descreveremos as duas vertentes do modelo de intervenção que constituem a primeira fase da experimentação, ou seja, os modelos clínico e administrativo.

Submodelo clínico:

1) O médico de família é o gestor dos atendimentos, a «porta de entrada» do sistema e o coordenador do conjunto dos serviços;

2) Os atendimentos e os serviços solicitados pelas pessoas que perderam a autonomia são coordenados por um gestor de caso;

3) Os serviços de primeira linha são privilegiados, assim como o trabalho em equipes multidisciplinares. Principalmente, está previsto que os médicos de família disponham de pessoal de enfermagem em sua clínica. A enfermeira deve desempenhar um papel no ensino, no acompanhamento sistemático da clientela que sofre de problemas de saúde crônicos, e na coordenação dos serviços. Isto representa uma inovação importante; 
4) As informações clínicas de base tornam-se acessíveis em todos os pontos de serviços;

5) A prática interdisciplinar é estimulada;

6) A prevenção e o acompanhamento sistemático de algumas clientelas devem possibilitar que se evite recorrer a recursos de serviços terciários ou de alta complexidade.

Em um primeiro momento, os esforços de integração visavam quatro tipos de clientela: as pessoas idosas com perda de autonomia, as pessoas com problemas de saúde mental, as pessoas com problemas cardiovasculares e finalmente, a clientela ambulatorial. É preciso lembrar que, por um lado, essas clientelas já totalizam $80 \%$ do consumo de atendimentos e serviços na região e que, por outro lado, são elas que deveriam se beneficiar mais com a integração dos atendimentos.

Submodelo administrativo

1) As decisões são tomadas, para o conjunto da rede, por uma única entidade decisória, resultante da fusão dos três estabelecimentos da região;

2) Os médicos participam da organização dos serviços. Esta contribuição é remunerada mediante um valor estipulado;

3) Um sistema de informação integrado orienta os gestores em suas decisões. Este sistema reúne os dados a respeito da clientela, os procedimentos de atendimentos, os serviços prescritos e recebidos, assim como seus custos, os agentes envolvidos etc;

4) A entidade decisória assina os entendimentos com os estabelecimentos fora do território;

5) A Direção delega à entidade decisória a responsabilidade de organizar os serviços no território. A Direção se reserva um papel no controle da gestão e dos resultados (qualidade dos atendimentos e dos serviços, efeitos sobre a saúde da população do território).

O que aconteceu com o modelo planejado? 


\section{RESULTADOS: O MODELO REALIZADO}

\section{EM QUE MEDIDA O MODELO ADMINISTRATIVO FOI IMPLANTADO?}

O projeto de fusão dos estabelecimentos fracassou pelas razões que explicitaremos posteriormente. Para contornar este problema, um comitê diretor, que reúne representantes da Direção Regional, os diretores de estabelecimentos, o chefe do projeto e representantes da equipe de avaliação foi constituído. Este comitê devia controlar a correta utilização do envelope financeiro do FASS, selecionando corretamente os projetos que contemplam uma integração dos serviços. Por outro lado, para assegurar um impulso aos projetos aprovados, os estabelecimentos deviam contribuir com o financiamento do projeto.

Apesar do projeto de fusão administrativa não ter se concretizado, cabe sublinhar que a integração funcional entre os atores do sistema (GILLIES e outros, 1993) foi objeto de esforços consideráveis. Além de coordenar a utilização do orçamento FASS e de selecionar os programas clínicos a serem desenvolvidos, os gestores dos estabelecimentos decidiram entrar em acordo para planejar as formações associadas ao projeto de integração dos serviços. Eles também decidiram organizar os serviços de saúde durante o período de verão, quando há falta de pessoal e quando é preciso então otimizar a utilização dos recursos. Uma certa mobilidade dos profissionais foi igualmente estimulada. Em suma, a função de gestão dos recursos humanos (formação, organização do trabalho etc.) se beneficiou amplamente com o desenvolvimento de uma visão comum.

\section{EM QUE MEDIDA O MODELO CLÍNICO FOI IMPLANTADO?}

Levando em conta o fracasso da integração administrativa, os atores em campo se concentraram na colaboração dos recursos clínicos para implantar um sistema de atendimento integrado. Nesta perspectiva, os profissionais dos estabelecimentos da rede local e os médicos na prática privada trabalharam em comitês multidisciplinares para identificar as necessidades prioritárias da população em termos de atendimento e elaboraram a partir de então, diferentes projetos clínicos interestabelecimentos. Esses projetos clínicos oferecem um triplo interesse: 
- todos os estabelecimentos estão envolvidos na gestão dos casos, o que permite a continuidade do tratamento durante o percurso do usuário (no hospital, nas unidades ambulatoriais, a domicílio);

- eles harmonizam as práticas clínicas na medida que os estabelecimentos devem praticar os mesmos protocolos;

- eles são um remédio contra a deficiência de certos serviços especializados na região, melhorando assim a continuidade do tratamento. Evitar o apelo a recursos pesados constitui o aspecto mais vantajoso do desenvolvimento desses serviços. Isto ocorre, por exemplo, para os serviços de readaptação ao seu meio de vida para as pessoas com problemas de saúde mental ou serviços especializados em oftalmologia para a clientela diabética, entre outros casos.

Foi implantado um total de vinte programas clínicos. Esses programas, por si mesmos, contribuem para a integração dos serviços. Por exemplo, a implantação de serviços ininterruptos para a clientela idosa com problemas cognitivos (serviços assistidos pelos recursos do CHSLD da região) permitiu estabelecer mais vínculos entre o CHSLD e o CLSC: os usuários remetem-se prioritariamente ao neuro-psicólogo do CHSLD, as discussões de caso são animadas pelos participantes dos dois estabelecimentos.

Isto significa, segundo opinião de vários atores, que a experimentação do trabalho multidisciplinar em clínica médica reúne certamente o maior potencial em matéria de integração dos atendimentos, pois é a enfermeira que é responsável por estabelecer as ligações entre os programas e por tecer as relações entre todos os prestadores de atendimento. O sistema de informação clínica implantado vincula as clínicas médicas aos outros estabelecimentos do sistema, permitindo assim o acesso rápido e fácil (sem ter necessidade de passar por uma pilha de dossiês) aos resultados de laboratório, bem como aos relatórios dos serviços de emergência. Este constitui seguramente um instrumento essencial de coordenação.

Do ponto de vista global, as enfermeiras e os médicos julgam satisfatório o balanço do trabalho multidisciplinar na clínica. Alguns médicos atribuem ao recrutamento da enfermeira na clínica a possibilidade de poder passar mais tempo com os casos complicados e menos tempo com os mais sim- 
ples, pois a enfermeira ajuda na avaliação destes últimos. A evolução da prática médica não se deu de um dia para o outro. No início, os médicos tinham a tendência de refazer o histórico dos casos, mesmo quando a enfermeira já tinha se dado ao trabalho de redigi-lo. A confiança entre os dois profissionais se constrói progressivamente. Mesmo que a avaliação da enfermeira conclua que o paciente não tem necessidade de um exame médico, este exame não será por isso anulado. Apesar dessas lacunas, o recrutamento de uma enfermeira na clínica médica contribuiu efetivamente, segundo opinião das enfermeiras e outros profissionais, para reforçar os vínculos entre as clínicas médicas e os outros estabelecimentos. A título de ilustração, para a clientela diabética, existe, no território, um continum de serviços integrados na medida que subsistem relações permanentes entre o médico clínico e a clínica especializada. Esse funcionamento permitiu iniciar certos tratamentos fora do hospital; o que representa, é claro, um aumento da eficiência.

Deixando de lado a melhoria da coordenação entre os prestadores de atendimento no interior da região, o projeto também ambicionava a formalização dos vínculos com os estabelecimentos fora do território. Somente o programa «saúde mental» do CLSC pareceu desenvolver esforços notáveis para atingir este objetivo. Procedimentos, por exemplo, junto a um hospital psiquiátrico situado em uma área vizinha, foram empreendidos a fim de que este comunique imediatamente, caso ocorra a internação de usuários, com o intuito de retorná-los rapidamente para dentro da comunidade. Estes procedimentos de busca ativa de casos demonstram o domínio de um princípio fundamental do modelo de intervenção, a saber, a responsabilidade populacional.

Em suma, segundo a voz de numerosos atores do sistema local de atendimento, os progressos realizados durante esta primeira fase de experimentação mostram-se significativos. Mais precisamente, eles reconhecem a melhoria da coordenação, um reforço da prevenção e um acompanhamento rigoroso da clientela atingida por problemas de saúde crônicos.

No entanto, vários entrevistados sublinham que ainda faltam esforços a serem realizados para melhorar a integração do sistema de atendimento. Em particular, eles admitem que certos serviços foram desenvolvidos de modo paralelo, não existindo complementaridade entre eles. É o caso dos serviços de televigilância desenvolvidos pelo hospital para as pessoas com 
perda de autonomia, e, de ambas as partes, dos serviços de plantão 24/7 implantados pelo CLSC. Alguns, dentre os quais, profissionais não médicos, se questionam igualmente sobre a validade de argumentos apresentados por alguns médicos da comunidade anglófona, que não concordam com que todos os leitos de atendimento paliativo estejam localizados no CHSLD (como foi sugerido pelo grupo de trabalho), embora isto represente um ganho de eficiência; eles se perguntam se a pouca pressa desses médicos em encaminhar seus pacientes para o CHSLD em questão, assegurando-Ihes a continuidade do acompanhamento médico, não está no fundo ligada à clivagem existente entre as duas comunidades ${ }^{4}$ ou às rivalidades para se aquinhoar mais recursos.

Para outros também, enquanto o papel de gestor de caso $^{5}$ não for institucionalizado, o objetivo visado com a integração, sobretudo se quisermos sistematizar o acompanhamento junto a pessoas idosas com perda de autonomia ou junto a pessoas com problemas de saúde mental, não será atingido. É preciso saber que alguns médicos não aceitam completamente a noção de gestão de caso e isto se explica por duas razões: seja porque eles duvidam que o gestor de caso possa ajudá-los a assumir seu papel de gestor de atendimento ${ }^{6}$, seja porque consideram que cabe ao médico desempenhar o papel de gestor de caso. Até o momento, apenas o setor de «saúde mental» se esforça no sentido de implantar a gestão de caso.

Como conclusão a esta parte, podemos afirmar que todos os atores do sistema de atendimento local estimam que o balanço desta experimentação é globalmente positivo. Podemos perceber, entretanto, um empenho menor por parte de alguns atores no sentido de ir mais longe na integração dos atendimentos, "reação" que, como veremos na próxima seção, pode ser facilmente compreendida.

Do nosso ponto de vista de equipe de avaliação do projeto, cabe-nos assinalar primeiramente que os impactos da experiência ainda não foram avaliados, quanto à utilização dos serviços de saúde particularmente, e isto por falta de disponibilidade de bases de dados administrativos ${ }^{7}$. Podemos, contudo, estimar que as mudanças introduzidas na região são positivas. Certos índices sustentam esta afirmação: por um lado, as observações dos atores que, embora reconhecendo que estas podem ser "artificiais», nem por isso deixam de ter um certo valor. Por outro lado, alguns dos exemplos citados neste texto nos levam a crer que progressos efetivos estão ocorren- 
do. Embora prudentes em nossas conclusões, podemos a priori considerar que o modelo de intervenção experimentado se anuncia como promissor. Sem uma busca de mudanças notadamente no plano financeiro, a perenidade dos progressos observados nos parece ameaçada. Mais adiante, teremos a ocasião de retomar esta crítica.

\section{OS FATORES DE SUCESSO E OS OBSTÁCULOS DESSE PROCESSO DE MUDANÇA: O EFEITO DETERMINANTE DO CONTEXTO, DO MODELO DE INTERVENÇÃO E DAS MODALIDADES DE PILOTAGEM DA MUDANÇA}

O desenvolvimento desta experimentação nos leva a tirar vários ensinamentos quanto aos fatores de sucesso e aos obstáculos encontrados durante este tipo de mudança. Estes fatores nos remetem na verdade ao contexto distintivo do projeto, à natureza do modelo de intervenção e às modalidades de pilotagem da mudança.

Como o contexto do projeto pode sustentar a mudança ou, ao contrário, prejudicá-lo?

Ocorre que diversas características do contexto do projeto, a saber o clima de trabalho harmonioso, a preexistência de boas relações de trabalho (RING; VAN DE VEN, 1994) entre alguns atores da rede, a pouca extensão do território, que favorece o estabelecimento de laços, o engajamento da população com relação ao sistema de saúde, um capital social coletivo importante (PUTNAM, 1993; PEPPER, 1995; LERNER e outros, 1995), útil, entre outras coisas, para viabilizar o financiamento de programas clínicos valorizados pela comunidade mostraram-se fatores de sucesso dessa experimentação. É claro que a força da primeira linha constitui a chave do processo de mudança. Isto significa dizer que, em certos momentos, a natureza da prática médica na região, ou seja, uma medicina familiar «muito próxima» da clientela, motivou provavelmente a resistência de alguns médicos a mudanças de prática. As barreiras encontradas para a implantação da gestão de caso ilustram este estado de coisas. Do quadro geral que apresentamos, nós destacamos o engajamento dos médicos da região, particularmente de três deles, com respeito ao processo de mudança, considerado por vários, sobretudo os administradores e os quadros da Direção Regional, como admirável; isso figura entre os fatores de sucesso determinantes desta experimentação. 
No entanto, as dificuldades de recrutamento de algumas categorias de profissionais (médicos, fonoaudiólogos) particularmente presentes nas zonas rurais explicam, em parte, o sucesso parcial da implantação de alguns programas clínicos. A incerteza quanto ao final do projeto não permitiu manter o entusiasmo do pessoal.

Além do problema da fusão dos postos de trabalho, as rivalidades entre as duas comunidades culturais distintas constituíram, sem sombra de dúvida, um obstáculo à integração dos serviços. Com efeito, o apego das comunidades ao seu estabelecimento e as desavenças quanto à composição do conselho de administração impediram a concretização do projeto de fusão administrativa dos estabelecimentos, apesar da insistência da Direção sobre a necessidade desta junção. A Direção regional, obrigada a legitimar suas decisões pelas vias democráticas, não dispunha de poder para impor sua autoridade neste processo, tanto mais que este não possuía todos os dados comprobatórios necessários para convencer os membros dos conseIhos de administração da importância desta integração administrativa. Para inúmeros entrevistados, o fracasso era por sinal previsível, pois os membros dos conselhos de administração não captavam o interesse da integração e consideravam a fusão mais como uma medida burocrática, que ameaçava a autonomia dos estabelecimentos. Fora a perda de tempo ocasionada pelas negociações em torno da fusão, vários atores sustentam que o aborto do projeto de fusão, durante esta primeira fase, não se revelou prejudicial à experimentação na medida que não impediu de forma significativa a progressão no sentido da integração clínica. Com o desaparecimento do financiamento do FASS, a necessidade de desenvolver uma direção unificada não mais se impunha, com toda certeza. De fato, a questão do financiamento dos programas interestabelecimentos só se colocaria neste momento específico.

Como o modelo de intervenção pode favorecer ou, ao contrário, entravar a mudança?

Esta experimentação mostra o interesse em atribuir um papel preponderante ao médico de família, ator indispensável do sistema de atendimento, e de implantar medidas organizacionais, bem como estímulos para uma cooperação maior deste médico na integração dos atendimentos. Isto responde a orientação atual das reformas dos sistemas de saúde que privilegia uma revalorização dos serviços primários (DEPARTMENT OF HEALTH, 
1997; HEALTH SERVICES RESTRUCTURING COMMISSION, 1999; COMISSÃO DE ESTUDOS SOBRE OS SERVIÇOS DE SAÚDE E SERVIÇOS SOCIAIS, 2000; COMMISSION ON MEDICARE, 2001). Neste sentido, a introdução de medidas de incentivo, sob a forma de uma remuneração dos médicos para participarem da organização dos serviços, parece ter sido, no âmbito deste projeto, um fator determinante de sucesso. Infelizmente, os mecanismos de incentivo aos médicos não tentaram melhorar, no âmbito da experimentação, a eficiência da prestação de serviços médicos; conseqüentemente, bloqueios nas práticas (como algumas redundâncias entre enfermeira e médico) foram constatados. Cabe mencionar, contudo, que durante os últimos meses da experimentação, uma evolução dos modos de remuneração dos médicos foi aventada e negociações foram agendadas neste sentido ${ }^{8}$. Podemos então esperar que essas mudanças repercutam nas práticas profissionais, confirmando «0 sucesso» conseguido pela introdução, durante a primeira fase do projeto, de incentivos econômicos com vistas a uma integração real dos médicos.

Do mesmo modo, o recurso a incentivos para favorecer uma maior colaboração dos estabelecimentos (regras de utilização dos novos recursos aportados pelo FASS) desempenhou um papel essencial neste projeto. Infelizmente, esses incentivos guardam um alcance limitado e efêmero na medida que o essencial dos financiamentos dos estabelecimentos provém de fontes independentes; isso explicaria a estagnação nos progressos realizados. Com efeito, o não-alinhamento dos incentivos contribui para que os estabelecimentos não reconheçam verdadeiramente sua independência e não invistam muito nesta independência para desenvolver mais efetivamente a cooperação; logo, o status quo nas relações interorganizacionais (GRAY, 1989; LEVINE; WHITE, 1961; OUCHI, 1980). É preciso, neste caso, «impor» uma fusão administrativa dos estabelecimentos, mesmo que se tenha que forçar uma integração funcional? Esta experimentação traz à luz o fato de que a passagem crítica entre integração funcional - integração dos médicos não constitui necessariamente a única maneira de se chegar a uma integração dos atendimentos, conforme foi sugerida pelo modelo teórico de Shortell e outros (1993). Como já explicamos anteriormente, em certas circunstâncias, a fusão parece ameaçadora para as organizações constituídas, pois ela questiona os poderes adquiridos, sem esquecer que os atores, como revelam as entrevistas analisadas, não vislumbram necessariamente 
a importância da integração administrativa. De fato, do modelo de intervenção, eles apreendem essencialmente as dimensões clínicas (harmonização dos procedimentos, acompanhamento sistemático etc.). Através destes exemplos, podemos levantar a hipótese de que, no início, pode parecer mais coerente fazer com que os atores trabalhem em cima de projetos clínicos, que fazem mais sentido para eles, e fazê-los progressivamente evoluir para uma maior integração funcional. Esta experimentação sugere que trajetórias de mudança, diferentes do encaminhamento linear, integração funcional (integração dos médicos) - integração dos atendimentos, podem ser consideradas.

Enfim, uma outra lição capital desta experimentação diz respeito ao interesse pelo princípio da responsabilidade populacional, no sentido pleno do termo. Isto se verifica em campo, onde os atores não medem esforços para, de um lado, estabelecer vínculos entre os diferentes programas clínicos e, de outro, buscar ativamente os usuários que necessitam de serviços de saúde, prática pouco difundida no resto da rede no Quebec.

Em que as modalidades de pilotagem de mudança podem favorecer ou desfavorecer esta mudança?

As modalidades de condução da mudança constituem seguramente fatores que determinam o sucesso do processo. Esta experimentação levanta mais uma vez a questão da importância da liderança exercida na pilotagem do projeto (HOSKING, 1988). Na verdade, segundo numerosos entrevistados, a presença de uma visão estratégica mobilizadora constitui um fator que, na opinião de várias pessoas, mostrou-se deficiente, durante a experimentação. Vários atores teriam preferido uma liderança administrativa mais forte. Aparentemente, o dispositivo de gestão deste projeto, composto por um chefe de projeto e por uma diretoria (já apresentado), não foi plenamente satisfatório, na medida que não conseguiu desenvolver uma visão estratégica que reunisse o conjunto dos atores envolvidos. Outros gostariam que a Direção regional desempenhasse esse papel de liderança. A Direção se limitou a uma atitude benevolente com relação ao projeto. Este contentou-se em encorajar os atores da região a se organizarem, em função de suas próprias necessidades, apostando na «descentralização» da tomada de decisão. A este respeito, os representantes do Consórcio trabalharam especialmente no sentido de trazer um suporte para os procedimentos empreendidos pelos atores em campo. Este papel técnico (anima- 
ção de reuniões, redação de atas etc.) foi efetivamente apreciado pelos membros dos comitês; entretanto, resta saber se não deveria ter tido também um papel mais estratégico. Embora tenha desempenhado um papel de animador do processo de aprendizado, o consórcio não teria ousado ir ao encontro de uma descentralização da tomada de decisão.

À estas lacunas constatadas na liderança administrativa, soma-se uma certa fragilidade da liderança médica. É claro, sublinhamos várias vezes, a participação dos médicos em grupos de trabalho e nos comitês, como contribuição bastante apreciável. Sem pretender que este papel de liderança caiba apenas aos médicos, devemos constatar que nenhum deles assumiu verdadeiramente a liderança do processo de reorganização dos serviços. Além do problema de disponibilidade de tempo, vários consideram seu modo de prática habitual como adequado e eficiente; diante da ampla satisfação presumida dos pacientes, torna-se então difícil identificar as mudanças necessárias, as transformações a serem introduzidas, bem como compreender as exigências e a necessidade de uma integração maior dos atendimentos na região. Para alguns médicos, o projeto permite sobretudo diminuir certos fatores inconvenientes de sua condição de trabalho do que defender uma nova visão integrada dos atendimentos.

Isto quer dizer que se a falta de liderança prejudicou uma implantação mais bem sustentada de mudança no quadro desta experimentação, esta reuniu, contudo, inúmeros outros fatores de sucesso, explicando assim o balanço globalmente positivo do projeto. Dentre esses fatores figura o caráter democrático (TOURAINE, 1994) e participativo do processo (VROOM; JAGO, 1988) de pilotagem da mudança. Embora um modelo de intervenção tenha sido proposto desde o início do projeto, este ficou em segundo plano ao longo do processo. De qualquer maneira, este modelo de intervenção amplamente «lacunar» como qualquer modelo (no sentido em que ele indicava apenas as linhas mestras) necessitava bastante ser completado e contextualizado. Na verdade, todos os detalhes do modelo clínico (quais os serviços que deveriam ser desenvolvidos? Quem faz o que? Quais são os protocolos clínicos a serem adotados? etc.) foram definidos pelos comitês constituídos pelos participantes provenientes dos diferentes estabelecimentos. Isso foi determinante no processo de apropriação da mudança.

Por outro lado, a criação dos comitês interestabelecimentos, que desempenhavam sobretudo o papel de estruturas de mediação (BRYSON; 
CROSBY, 1992), contribuiu bastante para o desenvolvimento de uma visão comum que favorecia automaticamente uma melhor integração dos serviços na região. É o caso dos comitês clínicos, entre outros, que se compõem de representantes dos diferentes estabelecimentos. Esses comitês tornaram possível a confrontação de várias visões a respeito do modelo de intervenção (exemplo: qual é o perfil adequado de uma enfermeira para uma clínica privada? Qual deverá ser o seu papel? Quais são os mecanismos de coordenação que devem ser previstos?) que levam progressivamente a soluções aceitáveis para os diferentes protagonistas e trazem mudanças positivas às práticas.

Dentre os fatores de sucesso desta experimentação, não podemos nos esquecer de assinalar também o papel da equipe de avaliação, embora esta, tendo em vista seus limites (falta de dados comprobatórios para construir um consenso, papel da intervenção não inteiramente legitimado etc.), não tenha tido a amplitude esperada. Muitos entrevistados se disseram tranqüilizados pelo papel de «muro de proteção» assumido pela equipe de avaliação. Eles também apreciaram a formação oferecida por esta equipe. Os comentários emitidos em certas ocasiões pelos membros da equipe de avaliação suscitaram igualmente alguns questionamentos e foram sugeridas algumas vias possíveis para a melhoria da organização dos serviços. Em suma, mais uma vez, a aproximação dos atores egressos da esfera acadêmica e dos gestores parece ter se revelado benéfica para a instalação do processo de mudança, especialmente quando estes se mostram complexos.

\section{CONCLUSÃO}

\section{A QUESTÃO DA TRANSFERIBILIDADE DESSE MODELO DE INTERVENÇÃO}

A questão que pode ser levantada por qualquer um pode ser enunciada assim: em que medida este modelo de intervenção, baseado na responsabilidade populacional, pode ser generalizado dentro do resto da rede de saúde no Quebec?

À primeira vista, tudo nos leva a crer que a implantação de uma abordagem populacional, similar à descrita neste artigo, não deveria trazer problemas em outras regiões rurais do Quebec. Poderíamos até esperar que a aplicação do modelo em outras regiões se efetuasse relativamente de modo 
mais fácil, tendo em vista (comparativamente à experiência relatada aqui), que escapariam à dificuldade de ter que conciliar duas comunidades culturais distintas: além das raras exceções, dentre as quais a região aqui considerada, as regiões rurais do Quebec são geralmente habitadas unicamente por francófonos. A integração dos serviços de saúde nas zonas rurais, por causa de seu potencial de melhoria da eficiência e eficácia, permanece uma via interessante para facilitar o acesso aos serviços, problema considerado mais sério nesse tipo de zona. Essa via merece ser explorada, considerando-se o fracasso experimentado das medidas de incentivo aplicadas pelo governo para estimular o estabelecimento dos médicos na região (FOURNIER, 2001).

Com relação à questão da generalização do modelo nas zonas urbanas, sem que isso seja impossível, poderíamos a priori afirmar que estaria confrontada a desafios específicos que tornam mais complexo o processo de mudança. Com efeito, nesse meio, a prática médica não é semelhante à da medicina familiar, no sentido em que a prática de consultas sem marcação e dos serviços de emergência são preponderantes (DEMERS; BRUNELLE, 2000). Nas cidades, não existe a tradição de um acompanhamento médico contínuo.

- a rede de serviços parece muito mais complexa: entre outros, há relativamente muito mais cobertura para os papéis desempenhados pelos diferentes produtores de atendimento (por exemplo, entre os CLSC, as clínicas médicas privadas, as clínicas médicas nos hospitais). Por outro lado, os recursos são mais numerosos. Se isso representa, por um lado, uma vantagem na medida que a mobilização de alguns desses recursos (recursos comunitários, programas de readaptação etc.) permite evitar que se recorra a recursos mais pesados, constituindo assim um atrativo para a melhoria da eficiência, por outro lado, a coordenação de todos esses recursos torna-se uma tarefa necessariamente mais delicada.

- enfim, o contexto, associado ao perfil da clientela, mostra-se igualmente mais complexo: de um lado, os hábitos de consumo dos usuários são mais difíceis de serem acompanhados (em outras palavras, não é possível estar perto da população); por outro, existe, nas zonas urbanas, uma variedade cultural maior, repercutindo diretamente na demanda de serviços. 
Concluindo: estes são desafios que devemos enfrentar para a implantação de uma abordagem populacional integrada nas zonas urbanas.

\section{NOTAS}

${ }^{1}$ Traduzido de Une expérience d'integration des soins dans une zone rurale: les enjeux de la mise em oeuvre. Ruptures, v. 8 n. 2, p. 93-108, 2001.

${ }^{2}$ Divididos da maneira seguinte: 5 profissionais não médicos, trabalhando em estabelecimento, 5 médicos, diretor do projeto, diretores de estabelecimentos, responsáveis pelos atendimentos de enfermagem nos estabelecimentos, 3 enfermeiras das clínicas, 4 quadros da Direção.

${ }^{3}$ Definida sumariamente, a avaliação da implantação busca compreender como o contexto (profissional, organizacional etc.) interage com a intervenção e como essa interação afeta os desempenhos obtidos.

${ }^{4}$ Outros, ao contrário, estão conscientes que a concentração de leitos seria prejudicial para 0 acesso aos atendimentos.

${ }^{5}$ Na região, vários atores consideram que a enfermeira na clínica privada não pode assumir o papel de gestora de caso, pois ela não está a par do cotidiano nem da vivência do usuário.

${ }^{6} \mathrm{Na}$ verdade, eles temem que a tarefa de comunicação com o gestor de caso venha aumentar sua carga de trabalho.

${ }^{7}$ Os dados posteriores à data da implantação dos projetos ainda não foram fornecidos pelas instâncias envolvidas. A equipe de avaliação poderia eventualmente organizar-se para negociar junto a essas instâncias a recepção em tempo real dos dados administrativos. Isso exigiria recursos humanos que a equipe não dispunha. Considerando a duração da experimentação, a equipe concentrou seus esforços na avaliação dos processos.

${ }^{8}$ A questão é saber se as mudanças de modos de remuneração adotados fazem com que os médicos de primeira linha contribuam efetivamente com a implantação de um sistema integrado de atendimentos.

\section{REFERÊNCIAS}

ACKERMAN III, F.K. The movement toward vertically integrated regional health systems. Health Care Management Review, v. 17, n. 3, p. 81-88. 1992.

BRYSON, J.M.; CROSBY, B.C. Leadership for the common good: tacking problems in a shared power world. San Francisco, CA: Jossey-Bass Publishers, 1992.

CHAMPAGNE, F.; DENIS, J.L. Para uma avaliação sensível ao meio ambiente das intervenções: a análise da implantação. Serviço Social: L'avenir des Services ou Services d'Avenir, v. 41, n. 1, p. 143-163, 1992.

COMISSÃO DE ESTUDOS SOBRE OS SERVIÇOS DE SAÚDE E SERVIÇOS SOCIAIS. Les solutions émergentes. Governo do Quebec, Canadá, 2000. 
COMMISSION ON MEDICARE. Caring for medicare. Sustaining a quality system. Saskatchewan, Canadá, 2001.

CONTANDRIOPOULOS, A.P.; POUVOURVILLE, G.; POULLIER, J.P.; CONTANDRIOPOULOS, D. Em busca de uma terceira via: os sistemas de saúde no século XXI. In: POMEY, M.P.; POULLIER, J.P.; LEJEUNE, B. (eds.). Santé publique: états des lieux, enjeux et perspectives. Paris: Ellipses Éditions Marketing, 2000. p. 637-667.

CROP. Enquête sur les services de santé. MRC Haut Saint-Laurent, 2000.

CROZIER, M.; FRIEDBERG, E. L'acteur et le sistema. Paris: Editions du Seuil, 1997.

DAVIES, P. Making sense of integrated care in New Zealand. Australian Health Review, v. 22, n. 4, p. 25-44, 1999.

DEMERS, M.; BRUNELLE, Y. Organisation de l'omnipratique au Québec entre 19941999. Québec: Ministério da Saúde e Serviços Sociais, 2000.

DENIS, J.L.; LAMOTHE, L.; LANGLEY, A.; VALETTE, A. The struggle to redefine boundaries in health care systems. In: BROCK, D.M.; POWELL, M.J.; HININGS, C.R. (eds.). Restructuring the professional organization. New York, NY: Routledge, 1999. p. 105-130.

DEVERS, K.J.; SHORTELL, S.M.; GILLIES, R.R.; ANDERSON, D.A.; MITCHELL, J.B.; ERICKSON, K.L.M. Implementing organized delivery systems: an integration scorecard. Health Care Management Review, v. 19, n. 3, p. 7-20, 1994.

FOURNIER, M.A. Políticas de mão-de-obra médica no Quebec: balanço 19702000. Ruptures, v. 7, n. 2, p. 79-98, 2001.

GILLIES, R.R.; SHORTELL, S.M.; ANDERSON, D.A.; MITCHELL, J.B.; MORGAN, K.L. Conceptualizing and measuring integration: findings from the health systems integration study. Hospital and Health Services Administration, v. 38, n. 4, p. 467489, 1993.

GRAY, B. Collaborating: finding common ground for multiparty problems. San Francisco, CA: Jossey-Bass Publishers, 1989.

HATCHUEL, A. Comment penser l'action collective? Théorie des mythes rationnels. In: Annales littéraires de Besançon, série AGON, obra coletiva coordenada por André Tosel e Robert Damien. Laboratório de pesquisas em filosofias do Agir, 1996.

HEALTH SERVICES RESTRUCTURING COMMISSION. Primary health care strategy: advice and recommendations to the honourable Elizabeth Witmer, Minister of Health. Ontario, Canadá, 1999.

HOSKING, E. Organizing, leadership and skillful process. Journal of Management Studies, v. 25, n. 2, p. 147-166, 1988.

LERNER, W.M. e outros. Governance in integrated delivery systems: serving the public's interest. Frontiers of Health Services Management, v. 11, n. 3, p. 44-46, 1995.

LEVINE, S.; WHITE, P.E. Exchange as a conceptual framework for the study of interorganizational relationships. Administrative Science Quaterly, v. 5, p. 583$601,1961$. 
OUCHI, W.G. Markets, bureaucraties and clans. Administrative Science Quaterly, v. 25, p. 557-582, 1980.

PEPPER, H.L.P. Addressing social and economic responsibilities through governance. Frontiers of Health Services Management, v. 11, n. 3, p. 40-43, 1995.

PRINGLE, D.; LEVITT, C.; HORSBURGH, M.E.; WILSON, R.; WHITTAKER, M.K. A colaboração interdisciplinar e a reforma dos atendimentos de saúde primários. Canadian Journal of Public Health, v. 91, p. 2, p. 87-88, 2000.

PROVAN, K.G.; MILWARD, H.B. A Preliminary theory of interorganizational network effectiveness: a comparative study of four community mental health systems. Administrative Science Quarterly, v. 40, p. 1-33, 1995.

PUTNAM, R.D. The prosperous community. Social capital and public life. The American Prospect, v. 13, p. 35-42, 1993.

RING, P.S.; VAN DE VEN, A. Developmental cooperative relations between organizations. Academy of Management Review, v. 19, p. 841-856, 1994.

SHORTELL, S.M.; GILLIES, R.R.; ANDERSON, D.A.; MITCHELL, J.B; MORGAN, K.L. Creating organized delivery systems: the barriers and facilitators. Hospital and Health Services Administration, v. 38, n. 4, p. 447-466, 1993.

SHORTELL, S.M. e outros. Remaking health care in America. Building organized delivery systems. San Francisco: Jossey-Bass Publishers, 1996.

TOURAINE, A. Qu'est ce que la démocratie? Paris: Fayard, 1994.

VROOM, V.H.; JAGO, A.G. The new leadership: managing participation in organizations. Englewood Cliffs, N.J., Toronto, Prentice Hall, 1988.

WALSTON, S.L.; KIMBERLY, J.R.; BURNS, L.R. Owned vertical integration and health care: promise and performance. Health Care Management Review v. 21, n. 1, p. 83-92, 1996. 
Este livro foi composto no formato $160 \times 230 \mathrm{~mm}$.

Miolo papel Pólen Bold $70 \mathrm{~g} / \mathrm{m}^{2}$.

Tiragem de 1000 exemplares.

Reimpressão, CTP e acabamento: Imprinta Express Gráfica e Editora Ltda. 